\title{
TMI-2 - A Case Study for PWR Instrumentation Performance During a Severe Accident
}

\author{
Joy L. Rempe
}

Darrell L. Knudson

March 2013

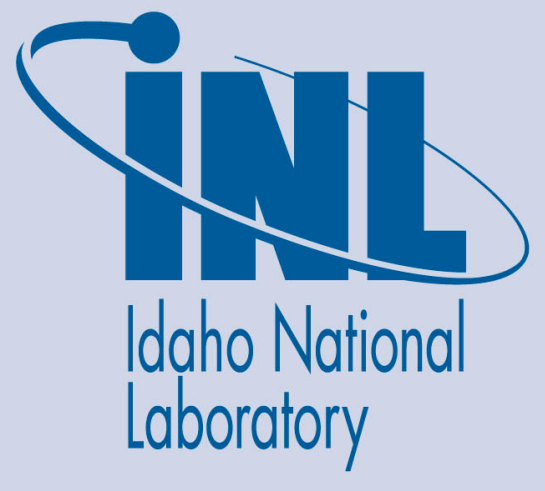

The INL is a U.S. Department of Energy National Laboratory operated by Battelle Energy Alliance 
INL/EXT-13-28043

\title{
TMI-2 - A Case Study for PWR Instrumentation Performance During a Severe Accident
}

\author{
Joy L. Rempe \\ Darrell L. Knudson
}

March 2013

\begin{abstract}
Idaho National Laboratory
Idaho Falls, Idaho 83415
\end{abstract}

http://www.inl.gov

\author{
Prepared for the \\ U.S. Department of Energy \\ Office of Nuclear Energy \\ Under DOE Idaho Operations Office \\ Contract DE-AC07-05ID14517
}




\section{DISCLAIMER}

This information was prepared as an account of work sponsored by an agency of the U.S. Government. Neither the U.S. Government nor any agency thereof, nor any of their employees, makes any warranty, express or implied, or assumes any legal liability or responsibility for the accuracy, completeness, or usefulness of any information, apparatus, product, or process disclosed, or represents that its use would not infringe privately owned rights. References herein to any specific commercial product, process, or service by trade name, trademark, manufacturer, or otherwise, does not necessarily constitute or imply its endorsement, recommendation, or favoring by the U.S. Government or any agency thereof. The views and opinions of authors expressed herein do not necessarily state or reflect those of the U.S. Government or any agency thereof. 



\section{ABSTRACT}

The accident at the Three Mile Island Unit 2 (TMI-2) reactor provided a unique opportunity to evaluate sensors exposed to severe accident conditions. Conditions associated with the release of coolant and the hydrogen burn that occurred during this accident exposed instrumentation to harsh conditions, including direct radiation, radioactive contamination, and high humidity with elevated temperatures and pressures. As part of a program initiated in 2012 by the Department of Energy Office of Nuclear Energy (DOE-NE), a review was completed to gain insights from prior TMI-2 sensor survivability and data qualification efforts. This new effort focussed upon a set of sensors that provided critical data to TMI-2 operators for assessing the condition of the plant and the effects of mitigating actions taken by these operators. In addition, the effort considered sensors providing data required for subsequent accident simulations.

Over 100 references related to instrumentation performance and post-accident evaluations of TMI-2 sensors and measurements were reviewed. Insights gained from this review are summarized within this report. For each sensor, a description is provided with the measured data, conclusions related to the sensor's survivability, and the basis for conclusions about its survivability. As noted within this document, several techniques were invoked in the TMI-2 post-accident evaluation program to assess sensor status, including comparisons with data from other sensors, analytical calculations, laboratory testing, and comparisons with sensors subjected to similar conditions in large-scale integral tests and with sensors that were similar in design but more easily removed from the TMI-2 plant for evaluations. Conclusions from this

review provide important insights related to sensor survivability and enhancement options for improving sensor performance. In addition, this document provides recommendations related to the sensor survivability and data evaluation process that could be implemented in upcoming Fukushima Daiichi recovery efforts. 
INL/EXT-13-28043 


\section{CONTENTS}

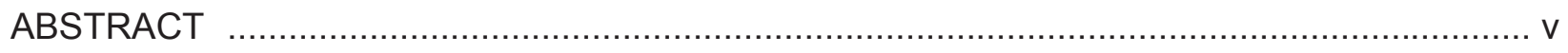

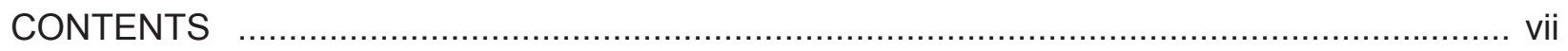

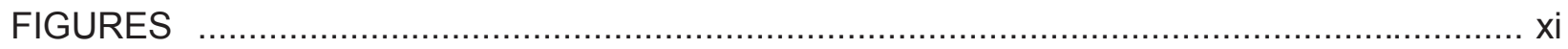

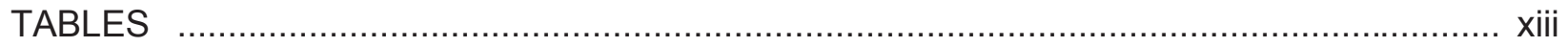

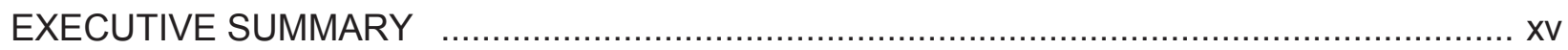

ACRONYMS AND ABBREVIATIONS ............................................................... xxvii

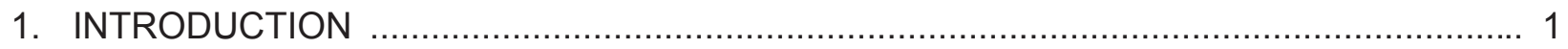

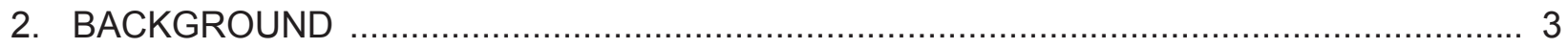

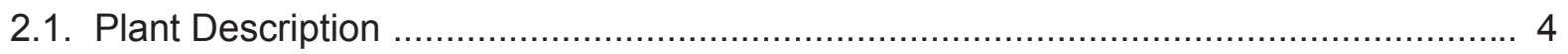

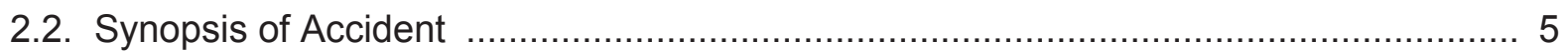

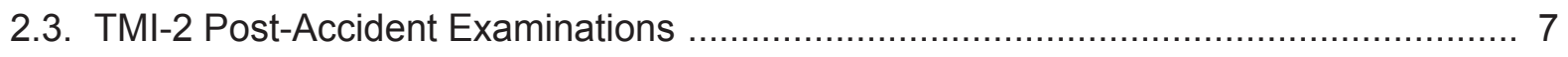

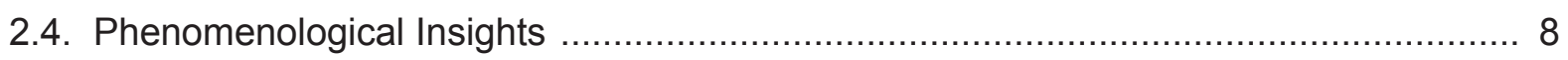

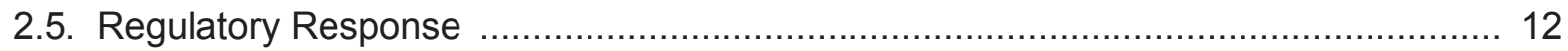

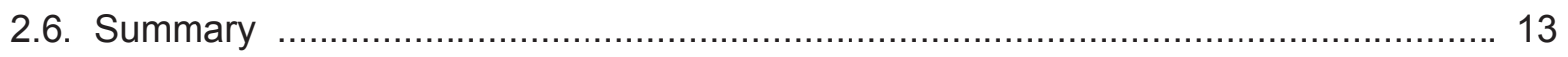

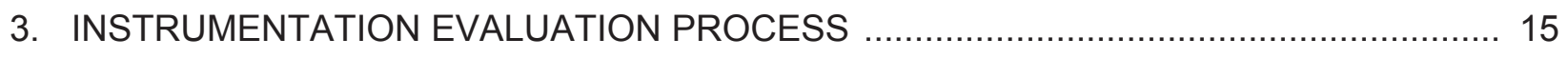

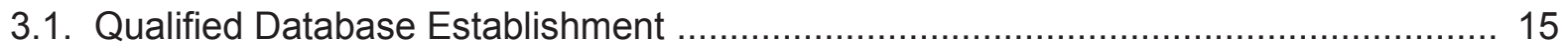

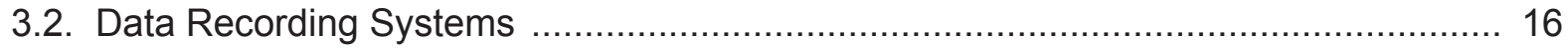

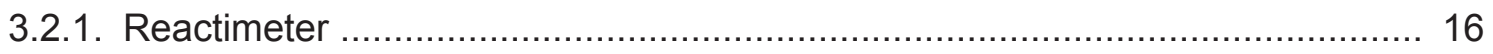

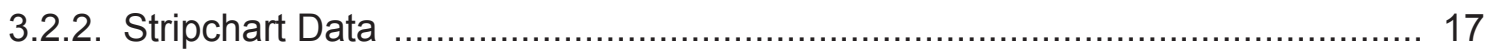

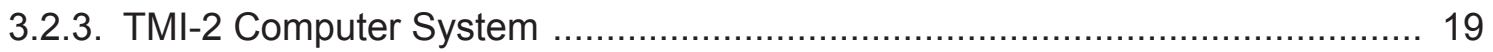

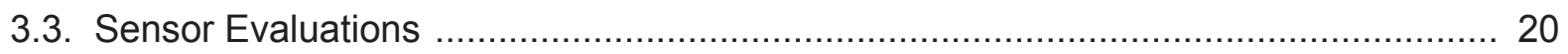

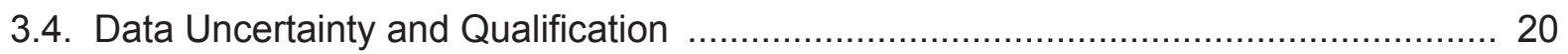

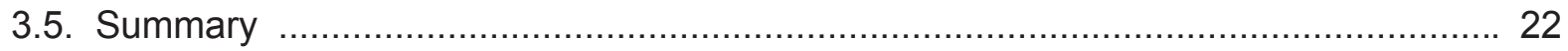

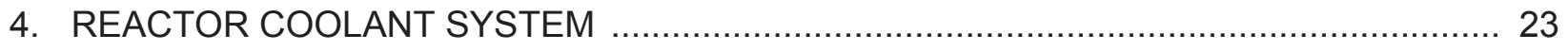

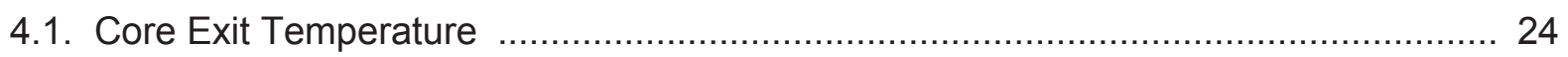

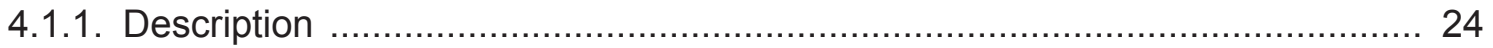

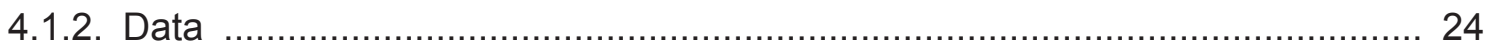

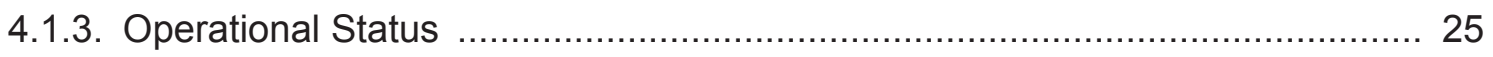

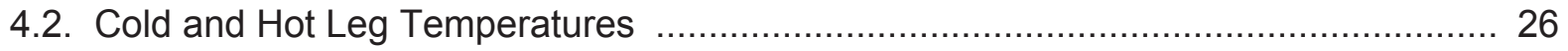

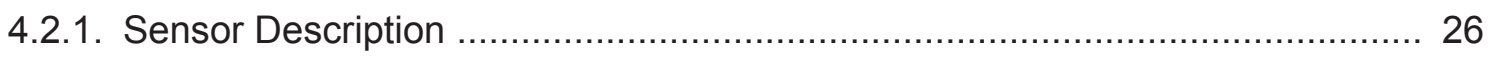

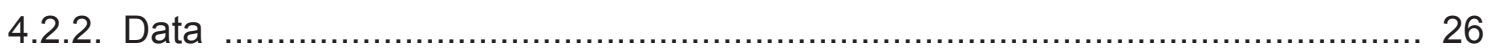

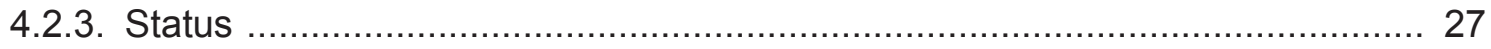

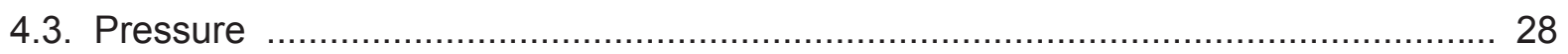




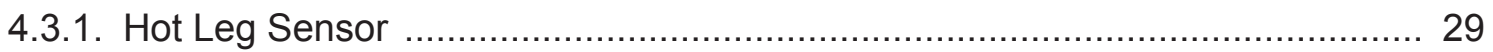

4.3.2. Data …

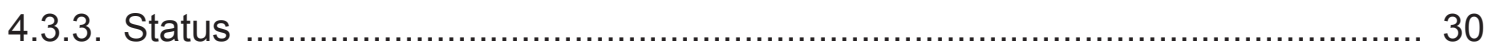

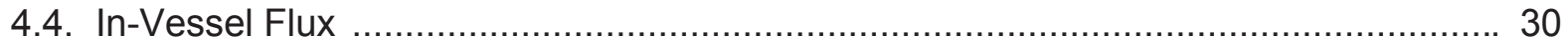

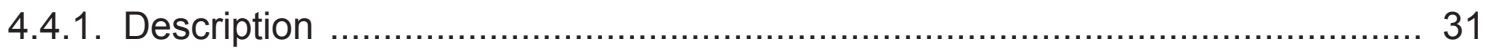

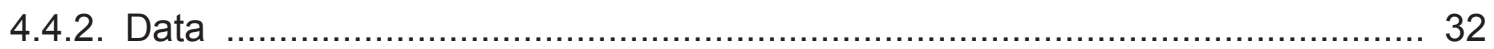

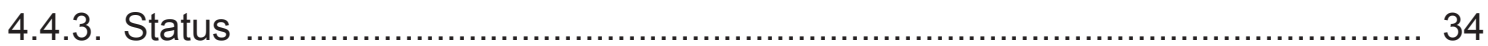

4.5. Ex-Vessel Flux …………… 35

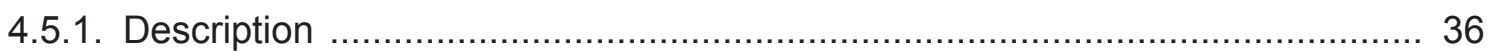

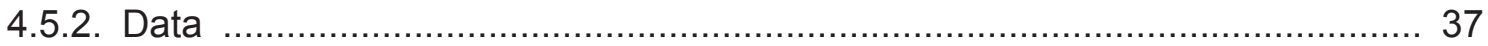

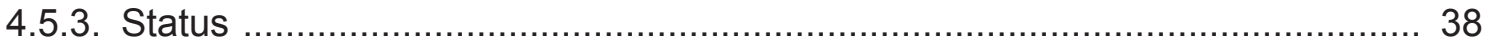

4.6. Pressurizer Water Level ............................................................................ 40

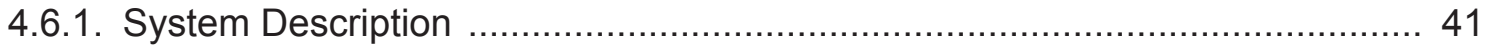

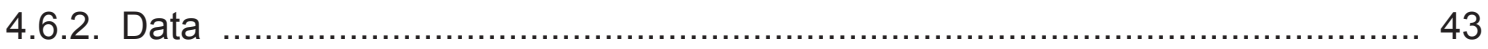

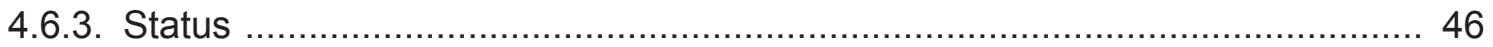

4.7. Steam Generator Secondary Water Level .................................................... 46

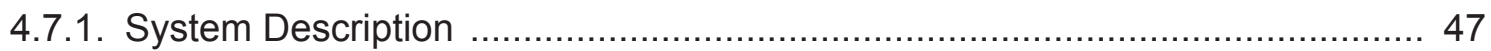

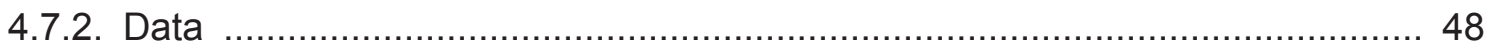

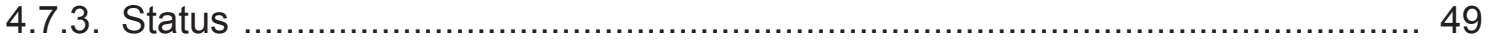

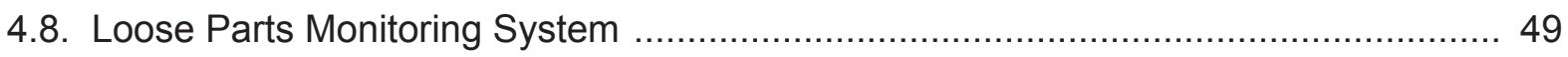

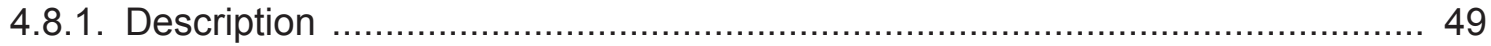

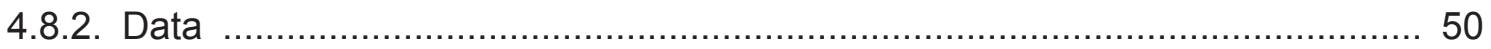

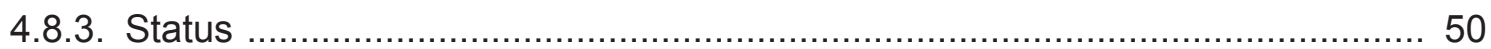

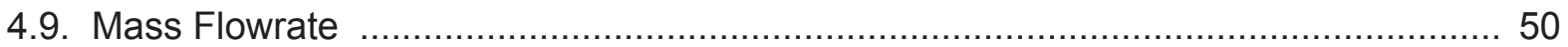

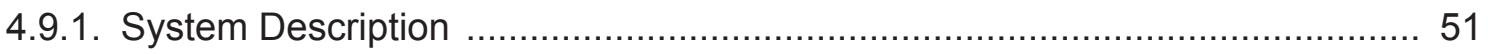

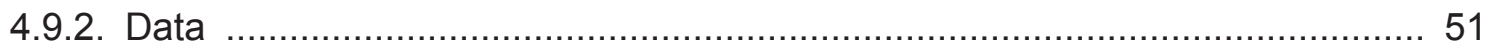

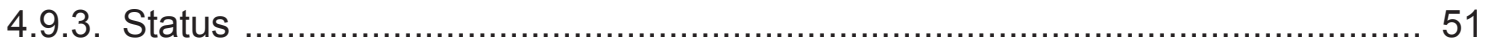

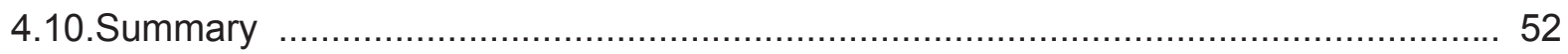

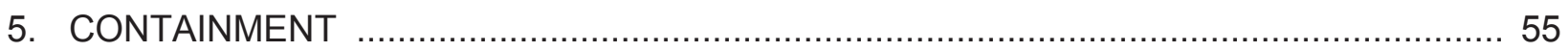

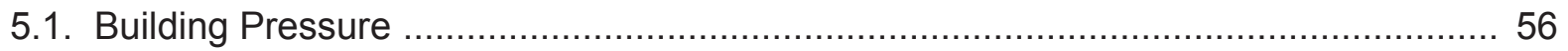

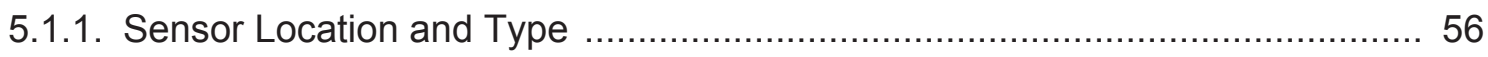

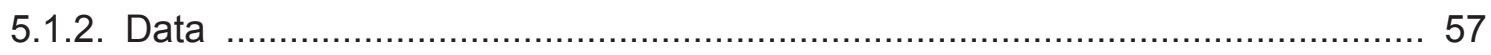

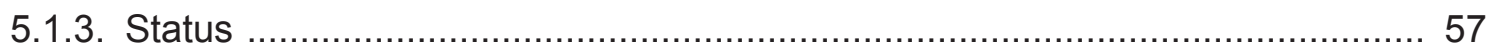

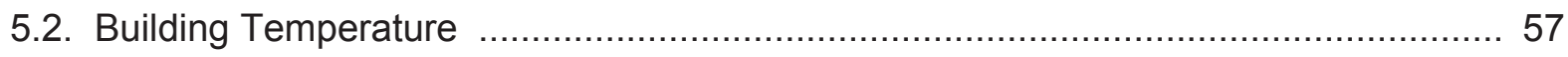

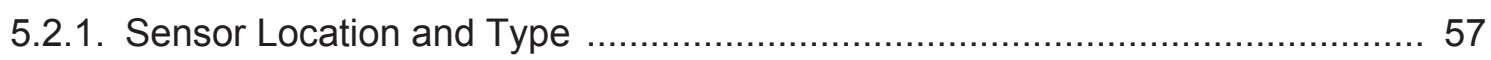

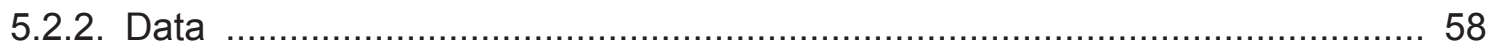

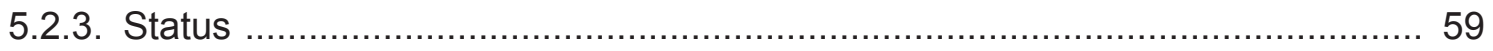

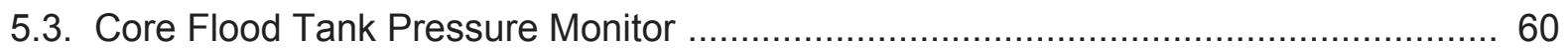

5.3.1. Sensor Location and Type ................................................................ 60 


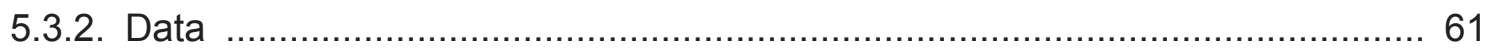

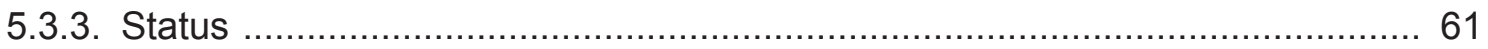

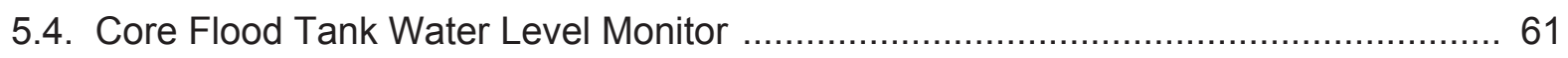

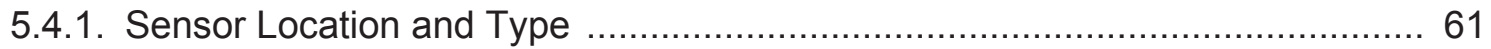

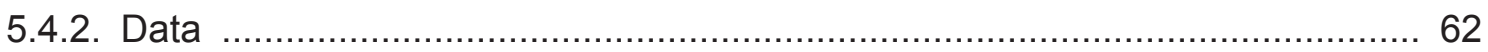

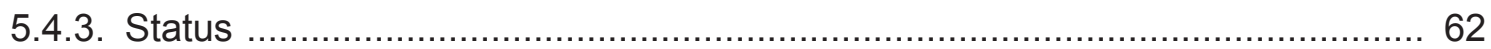

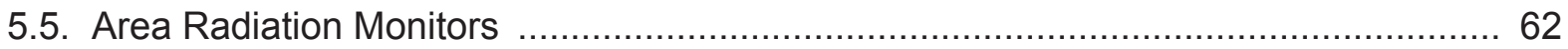

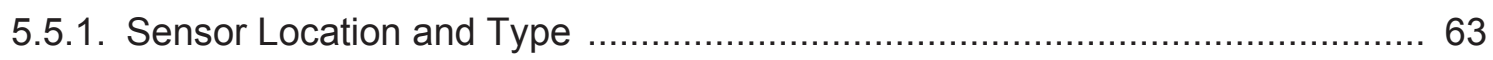

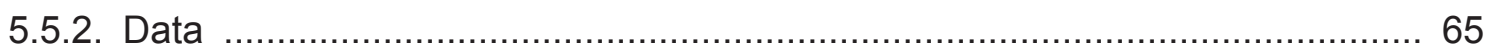

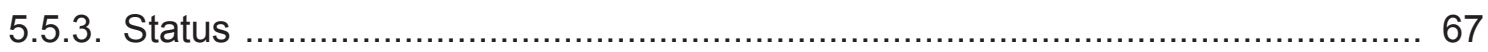

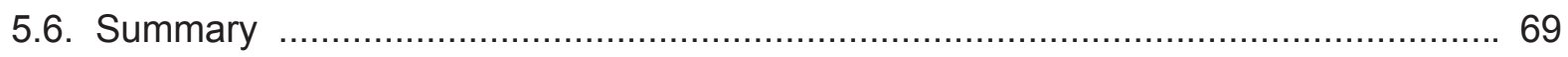

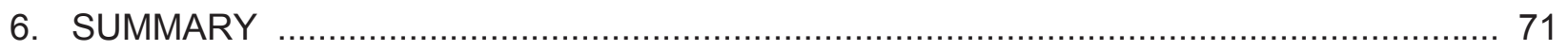

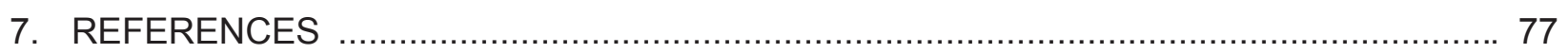

APPENDIX A. IN-CORE SYSTEMS …................................................................. A

A.1. In-core Instrumentation System …............................................. A-1

A.2. Moveable In-core Detector System ........................................... A-3

A.3. Axial Power Shaping Rods .................................................. A-4 


\section{FIGURES}

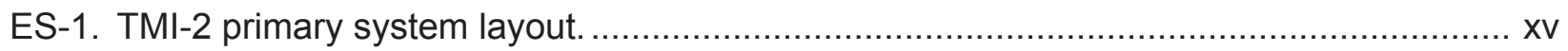

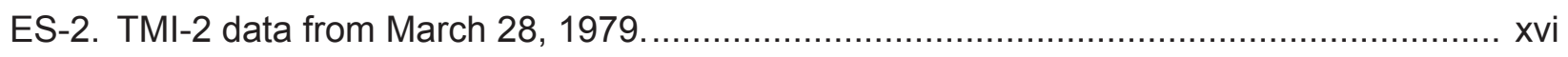

ES-3. Integrated process used to develop TMl-2 accident insights. ................................ xviii

ES-4. Postulated final state of materials within the TMI-2 vessel................................... xviii

ES-6. End-state of nozzles on the TMl-2 vessel lower head........................................... xix

ES-5. Location of TMI-2 lower head vessel boat samples and 'hot spot.' ............................. xix

ES-7. Overlay of SRM count rate, RCS pressure measurements, and cold leg

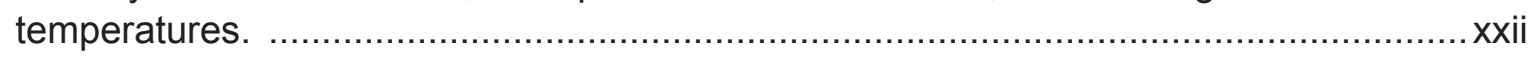

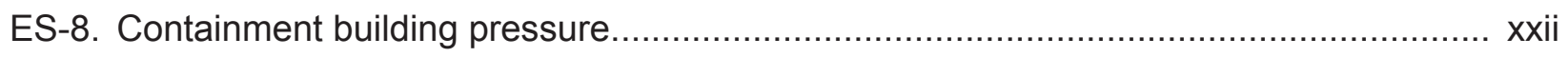

ES-9. Reactor building temperatures at selected locations........................................... xxii

ES-10.Comparison of A-loop wide range pressure recorded on the strip chart and

B-loop narrow range pressure on the reactimeter (Note: narrow range

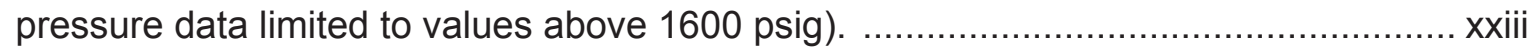

ES-11.TMI-2 SRM response during the first 4 hours of the accident................................. xxiv

ES-12.Containment radiation monitor response (Two curves are provided for HP-R-214 to reflect upper and lower bounds associated with uncertainties in

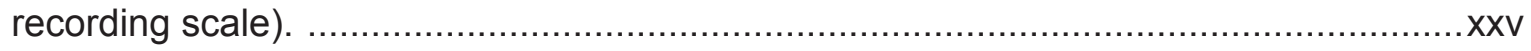

2-1. Integrated process used to develop TMI-2 accident insights. .............................. 3

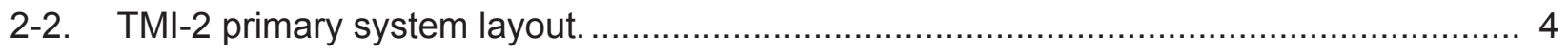

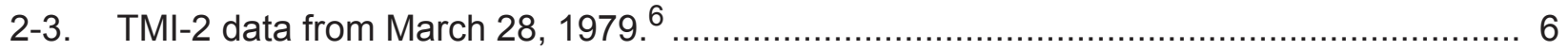

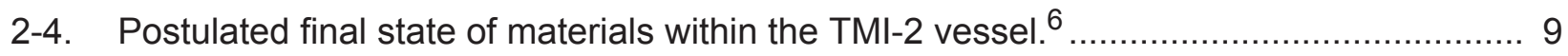

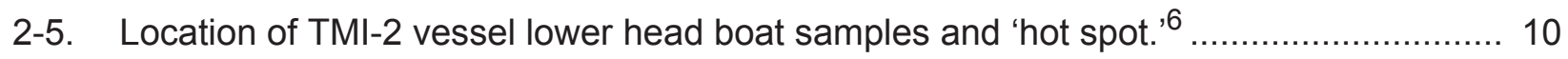

2-6. Video exams of the $\mathrm{H} 8$ instrumentation nozzle with crack on vessel......................... 11

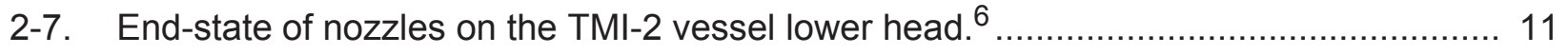

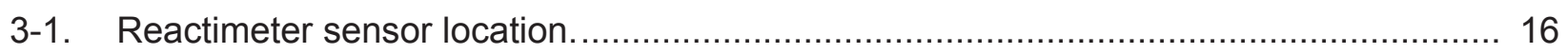

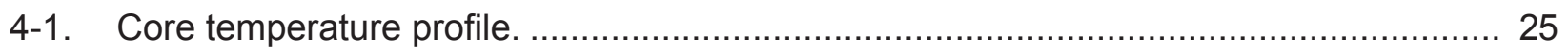

4-2. $\quad$ Rosemount Model 177HW RTD: (a) photograph and x-ray (b) thermowell and PRT from Rosemount Model 177HW PRT S/N 3670 removed from TMI-2 (the PRT appeared undamaged but radioactive deposits were found on the

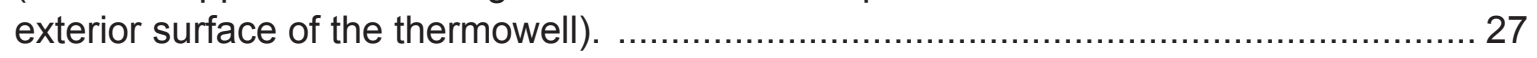

4-3. TMI-2 A-loop temperatures $(-10$ to 100 minutes) ........................................... 28

4-4. Comparison of A-loop wide range pressure recorded on the strip chart and the $\mathrm{B}-$-loop narrow range pressure on the reactimeter. .......................................... 30

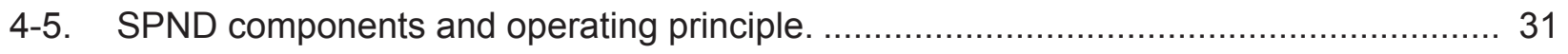

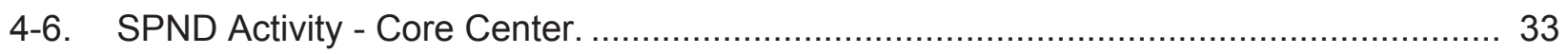

4-7. Signals from the $\mathrm{H}-8 \mathrm{SPNDs}$ at the 24 , and 6 levels...................................... 34

4-8. TMI-2 source, intermediate, and power range monitor configuration........................ 36

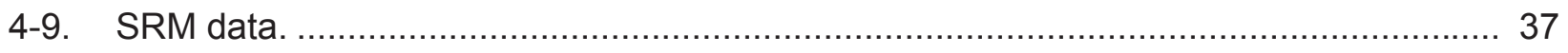


4-10. IRM data

4-11. Observed response (in green), and "normal" following reactor shutdown that occurred at TMI-2 on March 7, 1979 and calculated (in blue). ${ }^{54}$

4-12. Core water level estimate sensitivity to boron concentration model assumptions. $^{54}$ 39

4-13. Recorded, "normal", and predicted with $2 \% / \mathrm{hr}$ I-135 leaching SRM response. 40

4-14. TMI-2 SRM response during the first 4 hours of the accident. 41

4-15. Pressurizer water level measurement system. 42

4-16. TMI-2 pressurizer liquid level and primary system pressure (0 to 10 minutes) 43

4-17. TMI-2 pressurizer liquid level and primary system pressure (0 to 100 minutes).

4-18. TMI-2 pressurizer liquid level and primary system pressure (50 to 300 minutes).

4-19. OTSG flow and water level indication.

4-20. Water level in each TMI-2 steam generator.

4-21. Recorded hot leg mass flow rate. 52

4-22. Qualified hot leg mass flow rates and uncertainties.

4-23. Overlay of SRM count rate, RCS pressure measurements, and cold leg temperatures.

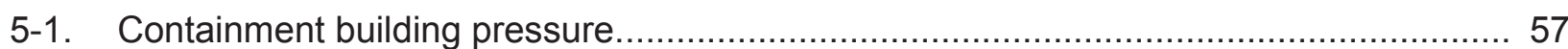

5-2. Reactor building temperatures at selected locations.......................................... 59

5-3. President Jimmy Carter observes radiation monitors in TMI-2 control room on April 1, 1979, accompanied by Pennsylvania Governor Richard Thornburgh and Harold Denton, NRC, (front to back). ${ }^{25}$

5-4. Containment radiation area monitor location.

5-5. Photo and schematic of TMI-2 HP-R-214 dome monitor in stainless steel container.

5-6. Containment radiation monitor response (Two curves are provided for HP-R-214 to reflect upper and lower bounds associated with uncertainties in recording scale).

A-1. Grid locations for TMI-2 core instrumentation. .............................................. A-1

A-2. Block diagram of in-core instrument assembly and associated cabling..................... A-2

A-3. Axial configuration of the TMI-2 in-core instruments. ........................................ A-2

A-4. Standard in-core detector assembly ......................................................... A

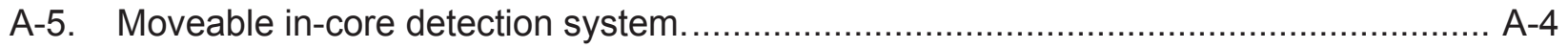

A-6. TMl-2 axial power shaping rod assembly ..................................................... A-5

A-7. Cross section of TMl-2 reactor vessel, showing typical axial power shaping rod assembly. 


\section{TABLES}

ES-1. TMI-2 sensors reviewed in this report. ........................................................

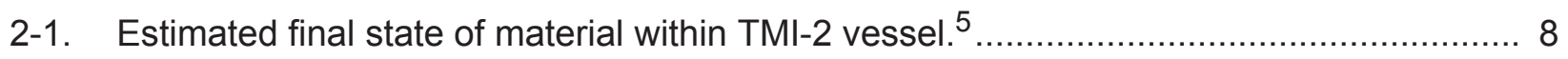

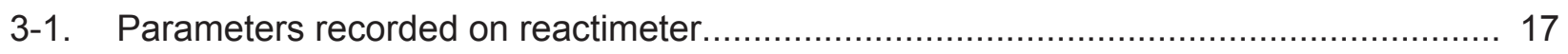

3-2. Parameters recorded on strip charts............................................................ 18

3-3. TMI-2 sensors reviewed in this report. ....................................................... 21

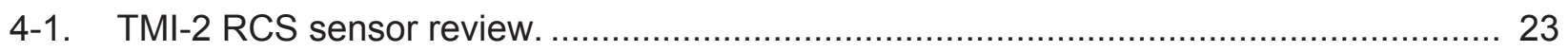

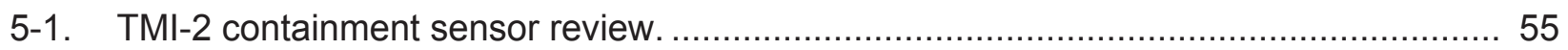

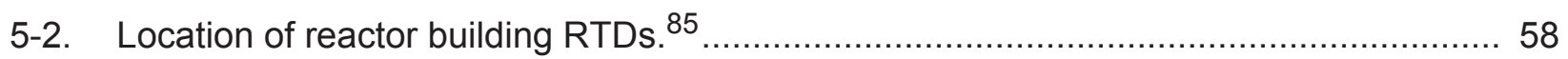

6-1. TMI-2 Sensors Reviewed in this Report......................................................... 72 


\section{EXECUTIVE SUMMARY}

The accidents at the Three Mile Island Unit 2 (TMI-2) and Fukushima Daiichi Units 1, 2, and 3 nuclear power plants demonstrate the critical importance of accurate, relevant, and timely information on the status of reactor systems during a severe accident. Conditions associated with the loss of coolant and the hydrogen burn that occurred during the TMI-2 accident exposed Pressurized Water Reactor (PWR) instrumentation to harsh conditions, including direct radiation, radioactive contamination, and high humidity with elevated temperatures and pressures. The TMI-2 accident also highlighted the importance of understanding and focusing on the key elements of system status information in an environment where operators may be overwhelmed with superfluous and sometimes conflicting data but have to make urgent decisions. While progress in these areas has been made since the TMI-2 accident, the events at Fukushima suggest that there is still a need for additional improvement, in particular with respect to gaining insights related to sensors exposed to Boiling Water Reactor (BWR) severe accident conditions.

In preparation for addressing this need, a review was completed to gain insights from TMI-2 sensor survivability and data qualification efforts. Over 100 references related to instrumentation performance and post-accident evaluations of TMI-2 sensors and measurements were reviewed. As documented in this report, post-accident evaluations of instrumentation components and data provided significant insights related to what types of conditions (e.g., temperatures, pressures, dose levels, etc.) were experienced by TMI-2 sensors, what failures occurred, and what types of enhancements were needed to ensure that operators have better access in the future to the data required to diagnose and mitigate unanticipated events.

\section{Background Information}

As discussed in Section 2, the TMI-2 power plant contained a Babcock \& Wilcox, Inc. (B\&W) PWR with a Reactor Coolant System (RCS) that consisted of the reactor vessel, two vertical once-through steam generators, four shaft-sealed reactor coolant pumps, an electrically heated pressurizer, and interconnecting piping. As shown in Figure ES-1, the RCS was arranged into two heat transport loops, each with two pumps and a steam generator (often designated as the A and B loops).

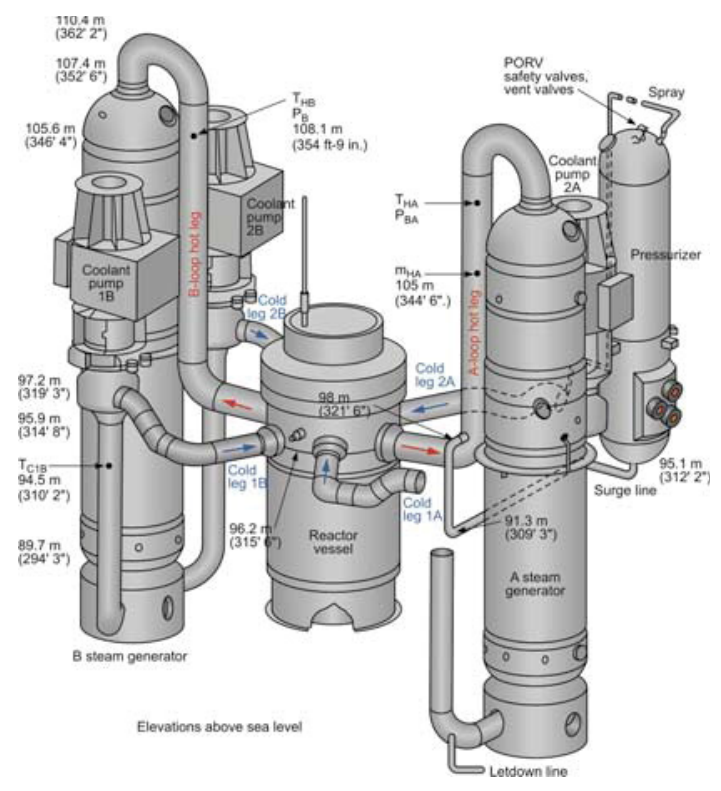

Figure ES-1. TMI-2 primary system layout. 
The TMI-2 accident was initiated on March 28, 1979, by a shutdown of secondary feedwater flow due to condensate booster pump and feedwater pump trips that occurred when the plant staff was trying to unclog a pipe leading from the condenser demineralizers. Best estimates for plant data and events during the accident, as obtained from various post-accident evaluation programs, are depicted in Figure ES-2. As described in Section 2, significant events occurring during the initial stages of the accident included turbine isolation (defined as time zero in Figure ES-2), reactor trip (when reactor pressure reached 16.3 MPa at 10 seconds after turbine trip), RCS heat up and pressurization. The Pilot Operated Relief Valve (PORV) opened to relieve RCS pressure, but failed to close when RCS pressure decreased. This was incorrectly interpreted by the reactor operators, as indicating that the RCS was nearly full of water; when in fact, the RCS was continually losing its water inventory. Emergency core cooling was reduced by operators, and the coolant void fraction increased due to coolant loss through the PORV and decay heat generation in the fuel. The steam fraction in the primary system piping increased to such an extent that RCS pumps were tripped by the operators to prevent permanent damage from pump cavitation after 100 minutes.
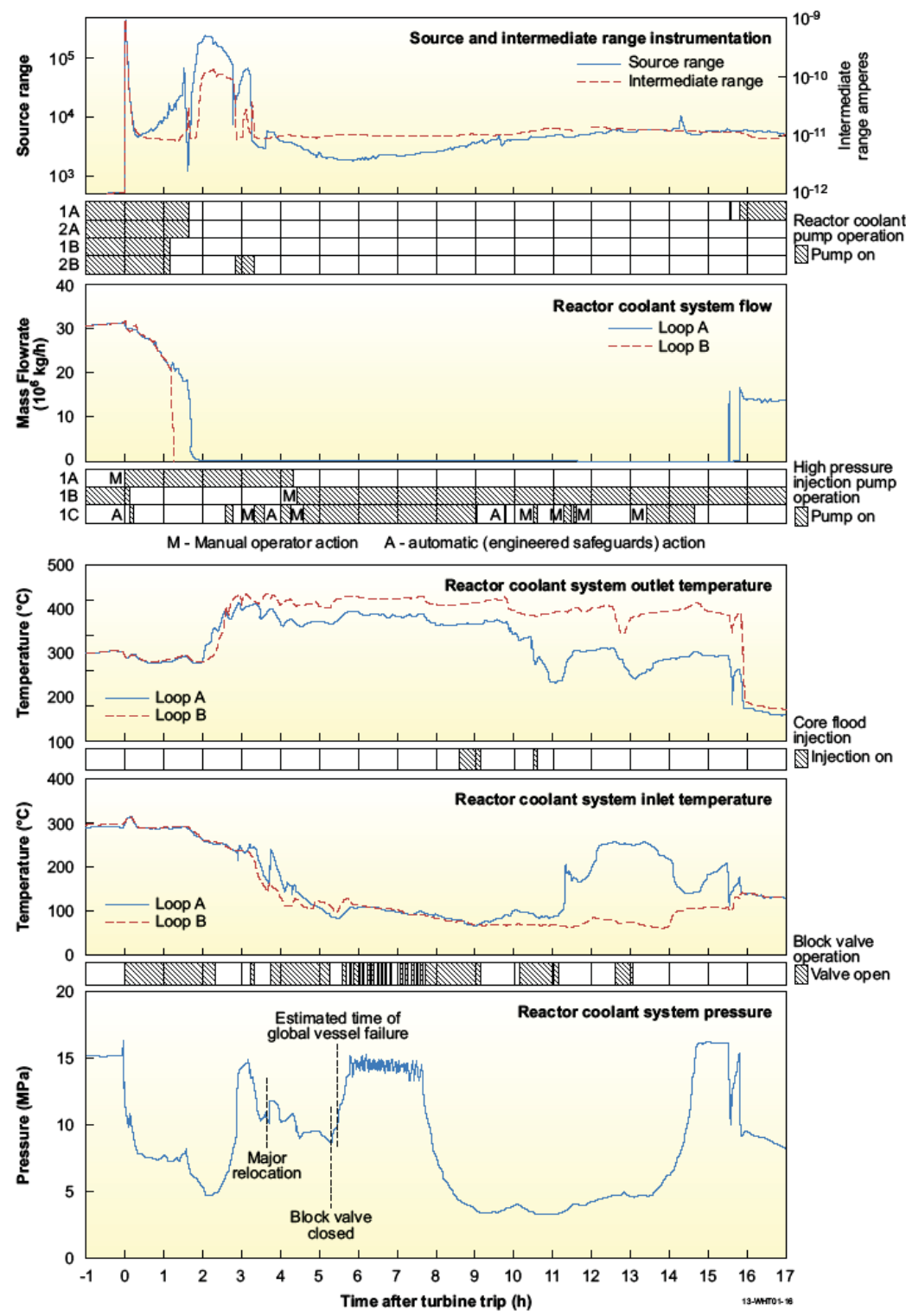

Figure ES-2. TMI-2 data from March 28, 1979. 
As described within this document, instrumentation response suggests that core uncovery began between 114 and 120 minutes and that the vessel liquid level had dropped to the core midplane by approximately 140 minutes. Insufficient decay heat removal associated with core uncovery is estimated to have led to upper regions of the core heating to temperatures that caused the cladding to overheat, balloon, and rupture. When operators finally realized that the PORV was failed in the open position, they closed the pressurizer block valve upstream of the PORV. In-core self powered neutron detector (SPND) output and RCS pressure data (see Figure ES-2) indicate that core temperatures continued to increase between 150 and 165 minutes. Zircaloy-steam exothermic reactions were initiated, producing large amounts of hydrogen and dramatically increasing the core heatup rate. When Zircaloy melting temperatures were exceeded, molten Zircaloy and some liquefied fuel relocated to lower core regions, solidifying near the coolant interface. This continued until 174 minutes, when a dense agglomeration of degraded core material formed in the lower regions of the core, which blocked core flow.

At 174 minutes, one of the reactor coolant pumps in the B-loop was turned on for approximately 19 minutes. This coolant injection into the vessel rapidly repressurized the RCS. At 200 minutes, the high pressure injection system was operated for 17 minutes, and the reactor vessel was refilled with water by approximately 207 minutes. Although the core was estimated to have been covered with coolant, analyses suggest that little coolant was able to penetrate into core regions with agglomerated debris and that these materials continued to heat up. Between 224 and 226 minutes after reactor scram, plant instrumentation (RCS pressure increases, Source Range Monitors (SRMs) count rate increases, cold leg temperature increases, and in-core SPND signal increases) indicated that the outer crust (resolidified molten material) surrounding the relocated core material failed; and molten core material relocated to the lower plenum. Increases in SRM count rates (see Figure ES-2) suggest that small quantities of molten debris may have continued to relocate to the lower head between 230 and 930 minutes, although peak count rates are considerably lower than values during the 224 to 226 minute relocation time period. At 930 minutes, one of the A-loop primary coolant pumps was restarted, re-establishing heat removal from the vessel.

As reported in Section 2, post-accident insights related to what occurred at TMI-2 event were not available until at least a decade after the event and required an integrated process that included post-accident videos, examinations of samples of core debris and vessel structures, instrumentation data, calculations with 'best-estimate' severe accident analysis tools, separate effects laboratory tests, and in some cases, data from large integral tests. This process is schematically shown in Figure ES-3. Analyses to interpret and integrate these information sources was crucial, since insufficient data were available from any single source to uniquely define a consistent understanding about the TMI-2 accident scenario. Example insights highlighted in Section 2 include:

- All TMI-2 fuel assemblies were damaged. Large regions of the core exceeded the melting temperature of the cladding $\left(\sim 1900^{\circ} \mathrm{C}\right)$. Significant fuel liquefaction by melted Zircaloy and some fuel melting occurred (corresponding to peak temperatures of at least $2800^{\circ} \mathrm{C}$ ).

- Approximately $20 \%$ of the core materials escaped from the core as a liquid phase and solidified in lava-like formations in the core bypass region, the Core Support Assembly (CSA) region, and the reactor vessel lower head region.

- Based on the end-state core and CSA configuration and supporting analysis of core heatup, it is believed that the crust (or resolidified molten material) surrounding the relocated core material failed near the top of the molten core region in the southeast quadrant of the reactor vessel. Limited damage to the CSA occurred as the core material flowed to the lower plenum. Figure ES-4 illustrates the final state of materials within the TMI-2 vessel. 


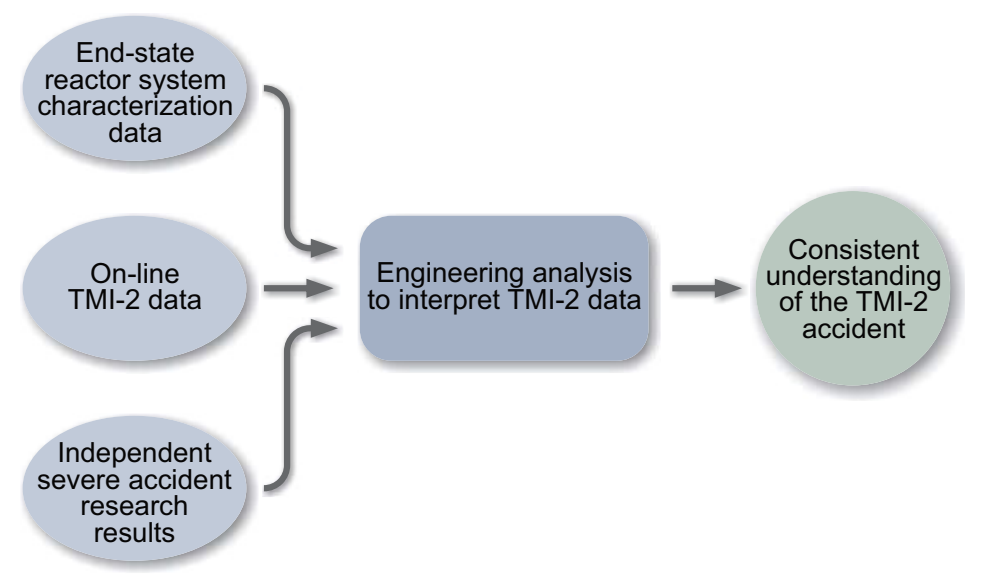

Figure ES-3. Integrated process used to develop TMI-2 accident insights.

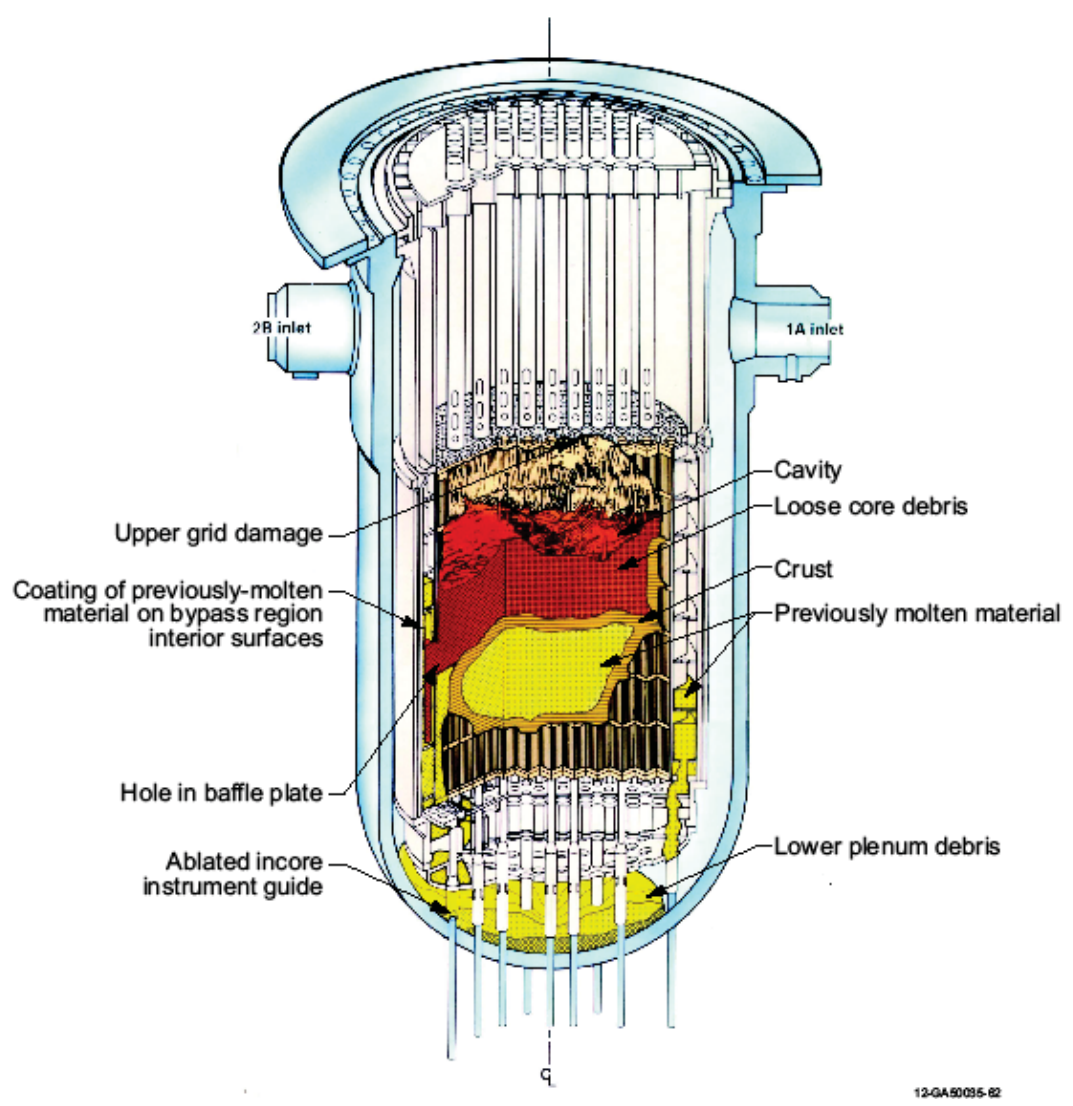

Figure ES-4. Postulated final state of materials within the TMI-2 vessel.

- Metallurgical examinations of the vessel lower head steel samples in conjunction with visual observations suggest that an elliptical region of the vessel, approximately $0.8 \mathrm{~m}$ by $1.0 \mathrm{~m}$, reached peak temperatures of $1100{ }^{\circ} \mathrm{C}$ during the accident (see Figure ES-5). At locations away from the hot spot, there is no evidence to indicate that vessel steel temperatures exceeded $727^{\circ} \mathrm{C}$. 


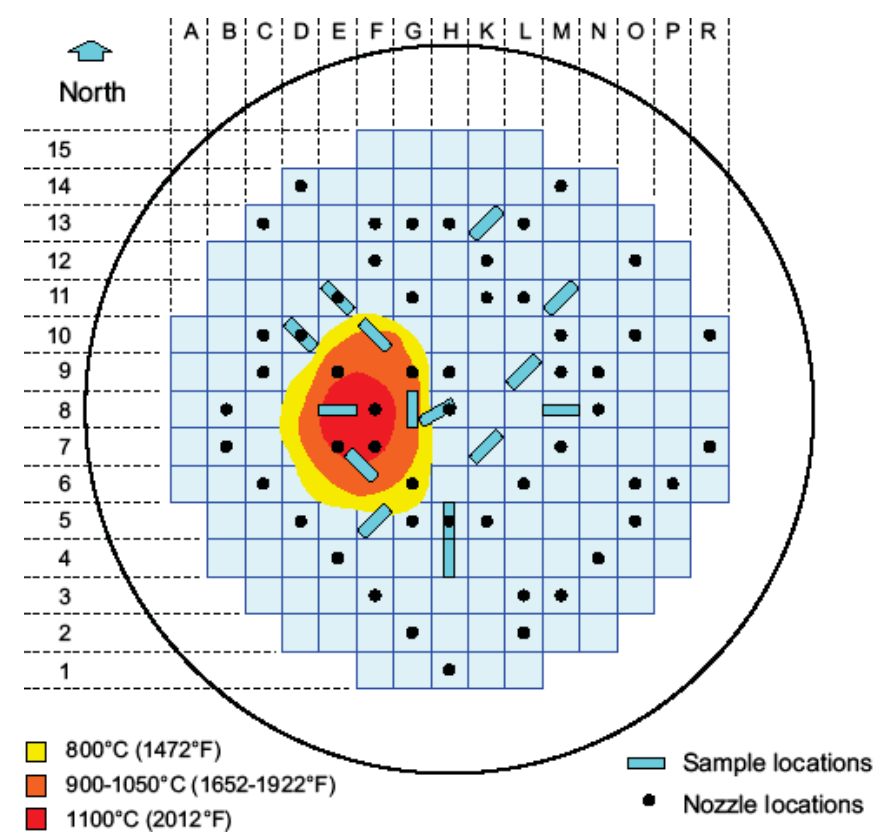

Figure ES-5. Location of TMI-2 lower head vessel boat samples and 'hot spot.'

- Instrumentation nozzle damage (see Figure ES-6) was caused by molten core material relocating to the lower head. The most severe damage was observed in nozzles located within the "hot spot" region of the vessel and not related to the embedded debris height (e.g., nozzle L6 was submerged in debris, but remained undamaged).

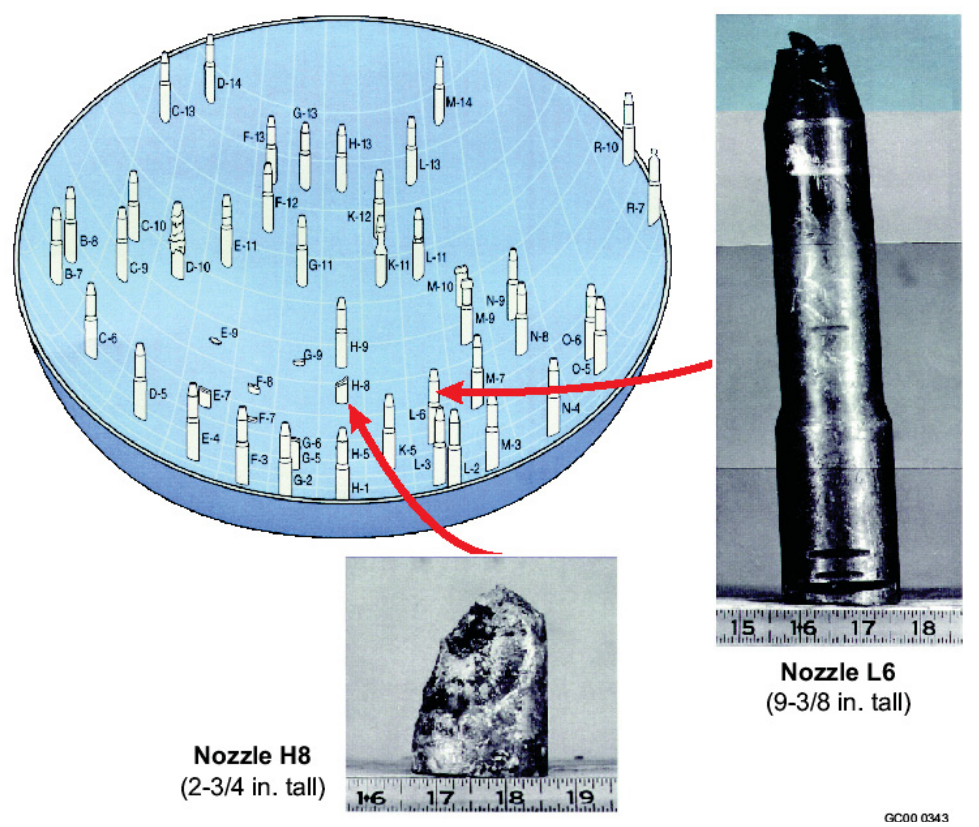

Figure ES-6. End-state of nozzles on the TMI-2 vessel lower head. 


\section{TMI-2 Sensor Evaluations}

As reported in Section 2, post-accident insights related to the TMI-2 sensor survivability were not available until at least a decade after the event and required an integrated process that included evaluation of instrumentation data. Detailed TMI-2 sensor evaluations were conducted to gain confidence about instrumentation data which provided a basis for assessing and improving severe accident simulation models and to assess the ability of sensors to provide operators much needed information to assess the status of the plant and the effect of mitigating actions.

An important aspect of the TMI-2 Accident Evaluation Program (AEP) was to provide a qualified data base for an analysis of the TMI-2 Accident, known as the "TMI-2 Analysis Exercise." This analysis exercise was completed to assess the accuracy of available data and modeling tools, which were developed using small-scale experiments, when they were applied to a full scale PWR. A qualified database and a data qualification process were established for this analysis exercise. Prior to being entered into the database, the data and estimated uncertainties were reviewed by a Data Integrity Review Committee (DIRC). Understanding gained from the TMI-2 Accident Exercise was ultimately applied toward improving phenomenological models related to the chemical and materials interactions that occurred in the TMI-2 core and resolving applicable severe accident and source term issues. Hence, the analysis exercise contributed toward establishing a sound technical basis for post-TMI-2 regulatory actions.

Sensors allowed approximately 3000 measurements to be made at TMI-2. However, earlier programs focused on data required by TMI- 2 operators to assess the condition of the reactor and containment and the effects of mitigating actions taken by these operators. In addition, these prior efforts focused upon sensors providing data required for subsequent accident simulations. Prior efforts to evaluate data from TMI-2 sensors included careful integration of instrumentation data, analysis relying on basic engineering principals, operator information, laboratory evaluations, comparisons with accident simulation results and large integral test data, and post-accident inspection.

The current review focused upon the set of sensors deemed most important by post-TMI-2 DIRC and instrumentation evaluation programs. Table ES-1 lists the RCS and containment sensors evaluated in this effort and summarizes their status. More detailed information related to the design and location of instrumentation, such as the position of temperature and flux detectors, is found within Sections 4 and 5 and Appendix A of this document. As discussed within this document, sensor failures were primarily associated with the combination of moisture, high temperatures, high pressure, and radiation exposure. Specific insights gained from the TMI-2 sensor and data evaluations include:

- The simultaneous increase in SRM count rate, RCS pressure, and cold leg temperatures, provided confidence about the timing of a major relocation of materials from the reactor core to the lower head (see Figure ES-7).

- Peak values for containment building temperature would not have been obtained without considering data from other sensors such as the containment building pressure transmitters. Calculations assuming peak containment pressures (see Figure ES-8) yielded peak containment temperatures of $650{ }^{\circ} \mathrm{C}$, which are much higher than the measured $93{ }^{\circ} \mathrm{C}$ peak temperature data (Figure ES-9). Recognizing that the TMI-2 containment temperature data had a limited sampling rate, experts qualified the containment pressure and a modified set of containment temperature data.

- Data unavailability was often due to computational limits, such as storage memory, inadequate paper or ink, insufficient sampling rates, and 'preset' limits associated with anticipated operating ranges (rather than sensor operating limits as illustrated by the pressure data shown in Figure ES-10). A wider 
Table ES-1. TMI-2 sensors reviewed in this report.

\begin{tabular}{|c|c|c|c|}
\hline Parameter & Sensor & Function & Post-Accident Status \\
\hline \multicolumn{4}{|c|}{ RCS } \\
\hline $\begin{array}{l}\text { Core Exit } \\
\text { Temperature }\end{array}$ & Type K Thermocouple (TC) & $\begin{array}{l}\text { Primary: core exit } \\
\text { temperature; } \\
\text { Secondary: Insights on liquid } \\
\text { level }\end{array}$ & $\begin{array}{l}\text { Failed due to high temperatures, steam, and } \\
\text { moisture ingress following sheath degradation; } \\
\text { Virtual junction formation occurred in many of } \\
\text { these thermocouples. }\end{array}$ \\
\hline $\begin{array}{l}\text { Cold Leg } \\
\text { Temperature }\end{array}$ & $\begin{array}{l}\text { Platinum Resistance Temperature } \\
\text { Detectors (RTDs) }\end{array}$ & Primary: Inlet temperature & $\begin{array}{l}\text { Operating; some cabling and connector } \\
\text { damage may have allowed moisture to degrade } \\
\text { insulation; extension cable shorting may have } \\
\text { occurred }\end{array}$ \\
\hline $\begin{array}{l}\text { Hot Leg } \\
\text { Temperature }\end{array}$ & Platinum RTDs & $\begin{array}{l}\text { Primary: Outlet temperature } \\
\text { Secondary: Insights on } \\
\text { Reactor Coolant System } \\
\text { (RCS) pressure }\end{array}$ & $\begin{array}{l}\text { Operating; some cabling and connector } \\
\text { damage may have allowed moisture to degrade } \\
\text { insulation; extension cable shorting may have } \\
\text { occurred }\end{array}$ \\
\hline $\begin{array}{l}\text { Reactor Coolant } \\
\text { Pressure }\end{array}$ & Pressure transmitters & Primary: RCS pressure & $\begin{array}{l}\text { Operational, but RCS pressure primarily below } \\
11.7 \mathrm{MPa} \text {-gauge. }\end{array}$ \\
\hline $\begin{array}{l}\text { Flux - In-Core } \\
\text { Measurements }\end{array}$ & $\begin{array}{l}\text { Self-Powered Neutron Detectors } \\
\text { (SPNDs) on In-Core } \\
\text { Instrumentation Assemblies and } \\
\text { Moveable In-Core Detection } \\
\text { System }\end{array}$ & $\begin{array}{l}\text { Primary: Neutron flux } \\
\text { Secondary: Insights on } \\
\text { temperature and liquid level }\end{array}$ & $\begin{array}{l}\text { Most damaged due to high temperatures, } \\
\text { steam, and moisture ingress causing sheath } \\
\text { degradation. }\end{array}$ \\
\hline \multirow{3}{*}{$\begin{array}{l}\text { Flux - Ex-Core } \\
\text { Measurements }\end{array}$} & Source Range Monitors (SRMs) & \multirow{3}{*}{$\begin{array}{l}\text { Primary: Neutron flux } \\
\text { Secondary: Qualitative } \\
\text { insights on core liquid level }\end{array}$} & Operational \\
\hline & $\begin{array}{l}\text { Intermediate Range Monitors } \\
\text { (IRMs) }\end{array}$ & & $\begin{array}{l}\text { Operational, but large uncertainty. Power } \\
\text { levels at lower end of operating range. }\end{array}$ \\
\hline & Power Range Monitors (PRM) & & Power levels at lower end of operating range. \\
\hline $\begin{array}{c}\text { Pressurizer Liquid } \\
\text { Level }\end{array}$ & Differential Pressure Transmitter & $\begin{array}{l}\text { Primary: Pressurizer liquid } \\
\text { level }\end{array}$ & Operational \\
\hline $\begin{array}{l}\text { Steam Generator } \\
\text { Water Level }\end{array}$ & Differential Pressure Transmitters & Primary: SG water level & $\begin{array}{l}\text { Operational, but full range transmitter installed } \\
\text { incorrectly. }\end{array}$ \\
\hline $\begin{array}{l}\text { Loose Parts } \\
\text { Monitoring }\end{array}$ & $\begin{array}{l}\text { Accelerometer and charge } \\
\text { converters }\end{array}$ & $\begin{array}{l}\text { Primary: Presence of loose } \\
\text { parts }\end{array}$ & $\begin{array}{l}\text { Charge converter degraded due to gamma } \\
\text { radiation }\end{array}$ \\
\hline $\begin{array}{l}\text { Hot Leg Mass } \\
\text { Flowrate }\end{array}$ & Mass flowmeter & Primary: Mass flowrate & $\begin{array}{l}\text { Operational; required corrections for } \\
\text { depressurization and voiding }\end{array}$ \\
\hline \multicolumn{4}{|c|}{ Containment } \\
\hline Building Pressure & Pressure transmitter & $\begin{array}{l}\text { Primary: Pressure; } \\
\text { Secondary: timing of hydrogen } \\
\text { burn }\end{array}$ & Operational \\
\hline $\begin{array}{l}\text { Building } \\
\text { Temperature }\end{array}$ & Platinum RTDs & Primary: Temperature & $\begin{array}{l}\text { Operational, although possible degradation } \\
\text { due to moisture; Data points too far apart to be } \\
\text { useful during hydrogen burn. }\end{array}$ \\
\hline $\begin{array}{l}\text { Core Flood Tank } \\
\text { Pressure Monitor }\end{array}$ & $\begin{array}{l}\text { Pressure transmitter sealed in } \\
\text { stainless steel casing }\end{array}$ & $\begin{array}{l}\text { Primary: Core Flood Tank } \\
\text { Pressure }\end{array}$ & Operational \\
\hline $\begin{array}{l}\text { Core Flood Tank } \\
\text { Water Level } \\
\text { Monitor }\end{array}$ & $\begin{array}{l}\text { Transmitter with linear variable } \\
\text { differential transformer (LVDT) } \\
\text { and bellows }\end{array}$ & Primary: Water Level & $\begin{array}{l}\text { Three of the four units experienced seal } \\
\text { failures allowing severe corrosion }\end{array}$ \\
\hline $\begin{array}{l}\text { Building Radiation } \\
\text { Levels }\end{array}$ & $\begin{array}{l}\text { Area Radiation Monitors } \\
\text { Most: Geiger-Muller (G-M) tube } \\
\text { gamma detectors } \\
\text { Dome Monitor: Ion chamber }\end{array}$ & $\begin{array}{l}\text { Primary: radiation monitor; } \\
\text { Secondary: Timing of fuel } \\
\text { failure and fission product } \\
\text { release }\end{array}$ & $\begin{array}{l}\text { Failed due to high temperatures, pressure wave } \\
\text { associated with hydrogen burn, high radiation } \\
\text { levels, and moisture. }\end{array}$ \\
\hline
\end{tabular}




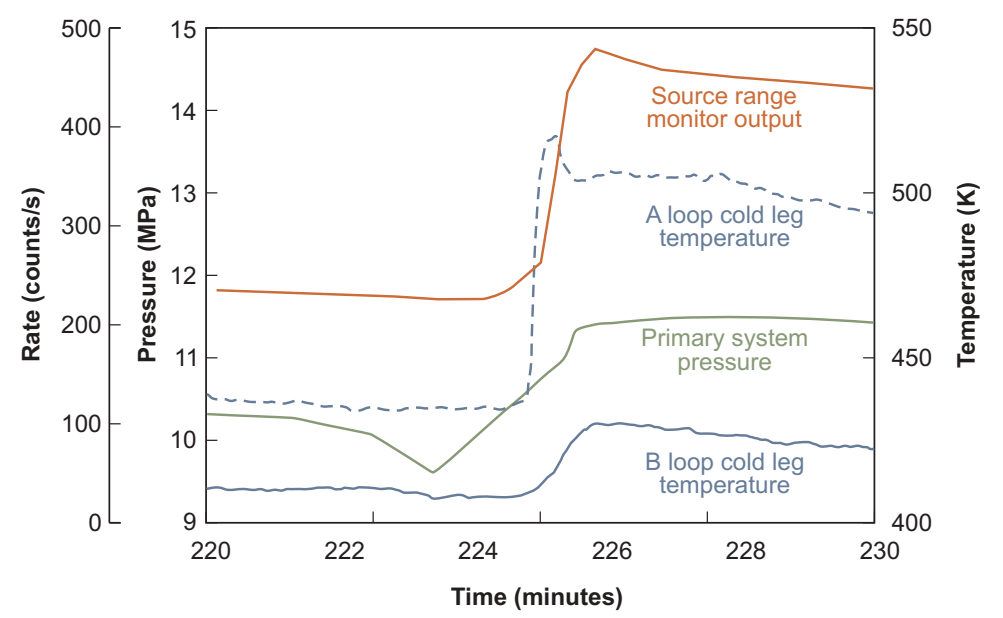

Figure ES-7. Overlay of SRM count rate, RCS pressure measurements, and cold leg temperatures.

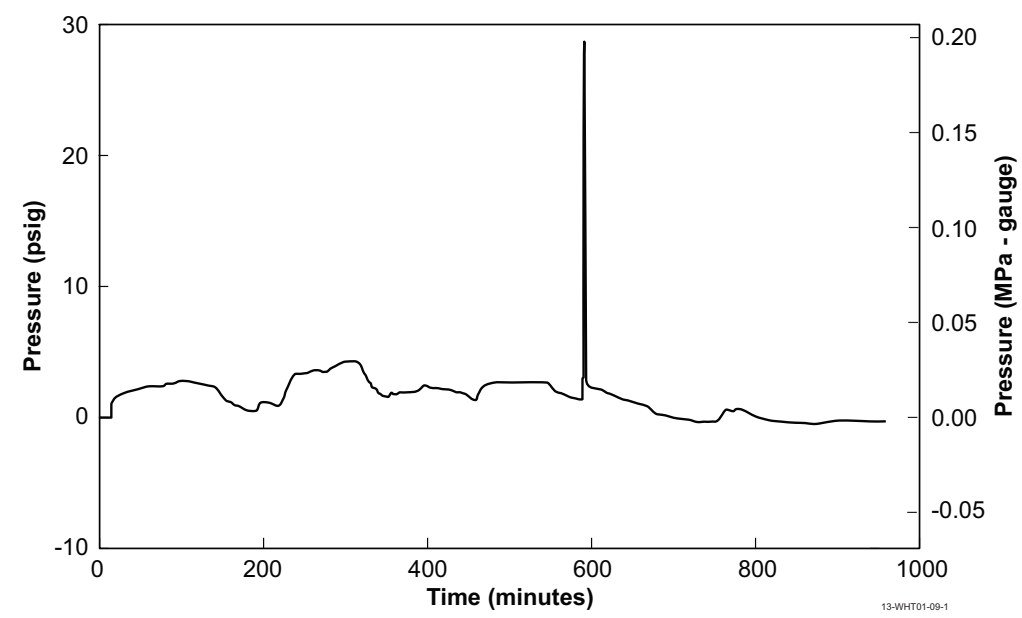

Figure ES-8. Containment building pressure.

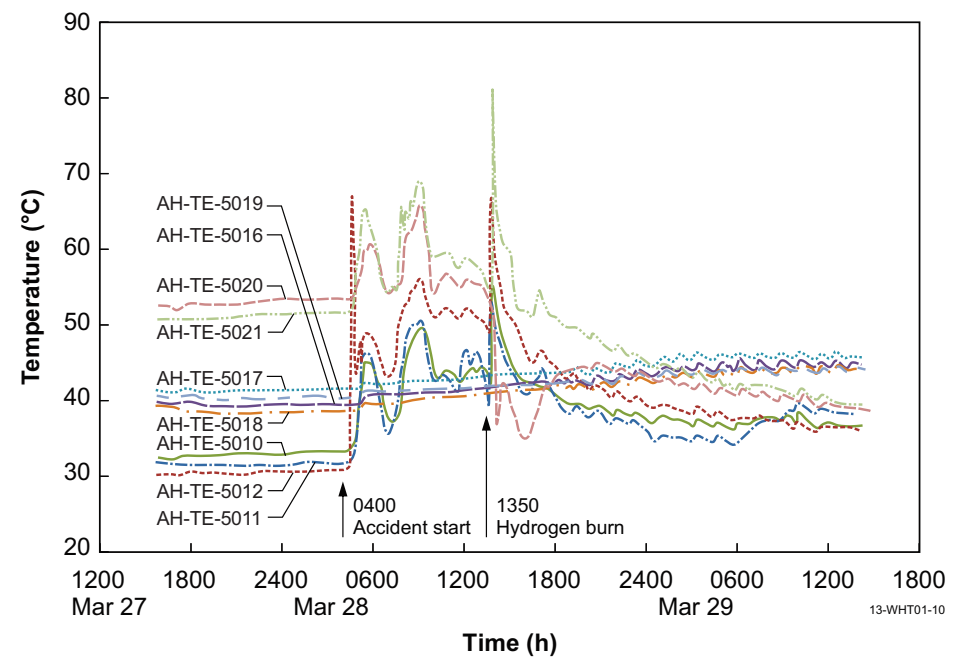

Figure ES-9. Reactor building temperatures at selected locations. 
range of limits and enhanced computational capabilities, with easy-to-read graphical displays, could alleviate such issues, as occurred with TMI-2 building resistance temperature detector (RTD) temperature and steam generator reference pressure transmitter sampling.

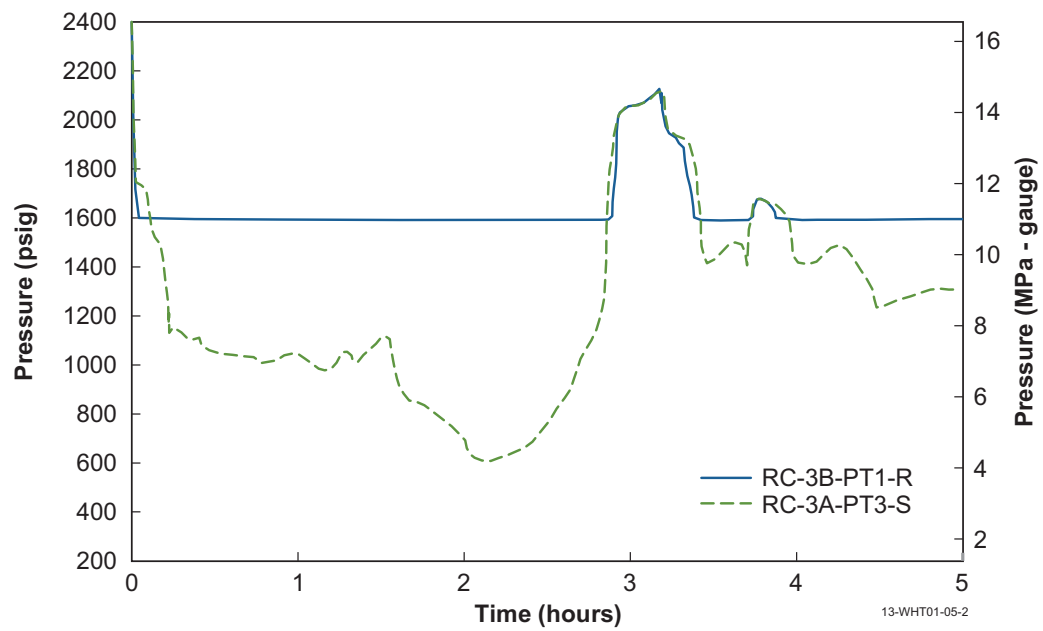

Figure ES-10. Comparison of A-loop wide range pressure recorded on the strip chart and B-loop narrow range pressure on the reactimeter (Note: narrow range pressure data limited to values above $1600 \mathrm{psig}$ ).

- Data unavailability was often due to sensor range limitations that were focused on assumed normal operating conditions. For example, sensors with ranges that encompassed unanticipated accident conditions (e.g., at saturated conditions with steam voids present in a PWR) could have provided operators much needed information.

- Data unavailability was also attributed to inadequate status indicators. For example, the inability of the operators to detect that the PORV failed to close could have been rectified by the use of additional indicators and sensors. In this case, indicators were only available to show that the solenoid coil was energized (nothing about the status of the valve position). Since the TMI-2 accident, the US Nuclear Regulatory Commission (NRC) required that licensees make design changes so that positive indication of valve position is available in the control room. However, sensors could also have been included to measure the drain tank water level, which would have provided the operators information that the drain tank relief valve was open. A thorough investigation of other such situations could help alleviate similar occurrences in the future.

- Failures in sensors located within the vessel were often due to a combination of high temperatures and moisture ingress following sheath failure. In some cases, vibrations, moisture, and/or radiation exposure led to failures of sensors. Clearly, it is important to have sensors with operating envelopes that are extended to consider more likely accident conditions.

- Failures were often related to transmission component exposure, rather than sensor exposure. For example, cabling and connectors located outside the RCS were subjected to higher than anticipated temperatures, moisture levels, and radiation levels. It was speculated that most of the moisture intrusion problems would have occurred eventually in the plant without the accident. However, better positioning and enhanced components and/or shielding could alleviate such limitations.

- Qualitative insights can be obtained by considering sensor response for alternate applications, e.g., ex-core source-range detector signals provide insights about real-time RCS water levels, in-core 
SPNDs provide insights about RCS temperature and water levels. However, such interpretations often require detailed analyses and assumptions related to the status of the core, the RCS and containment (as evidenced from efforts to interpret SRM data in Figure ES-11).

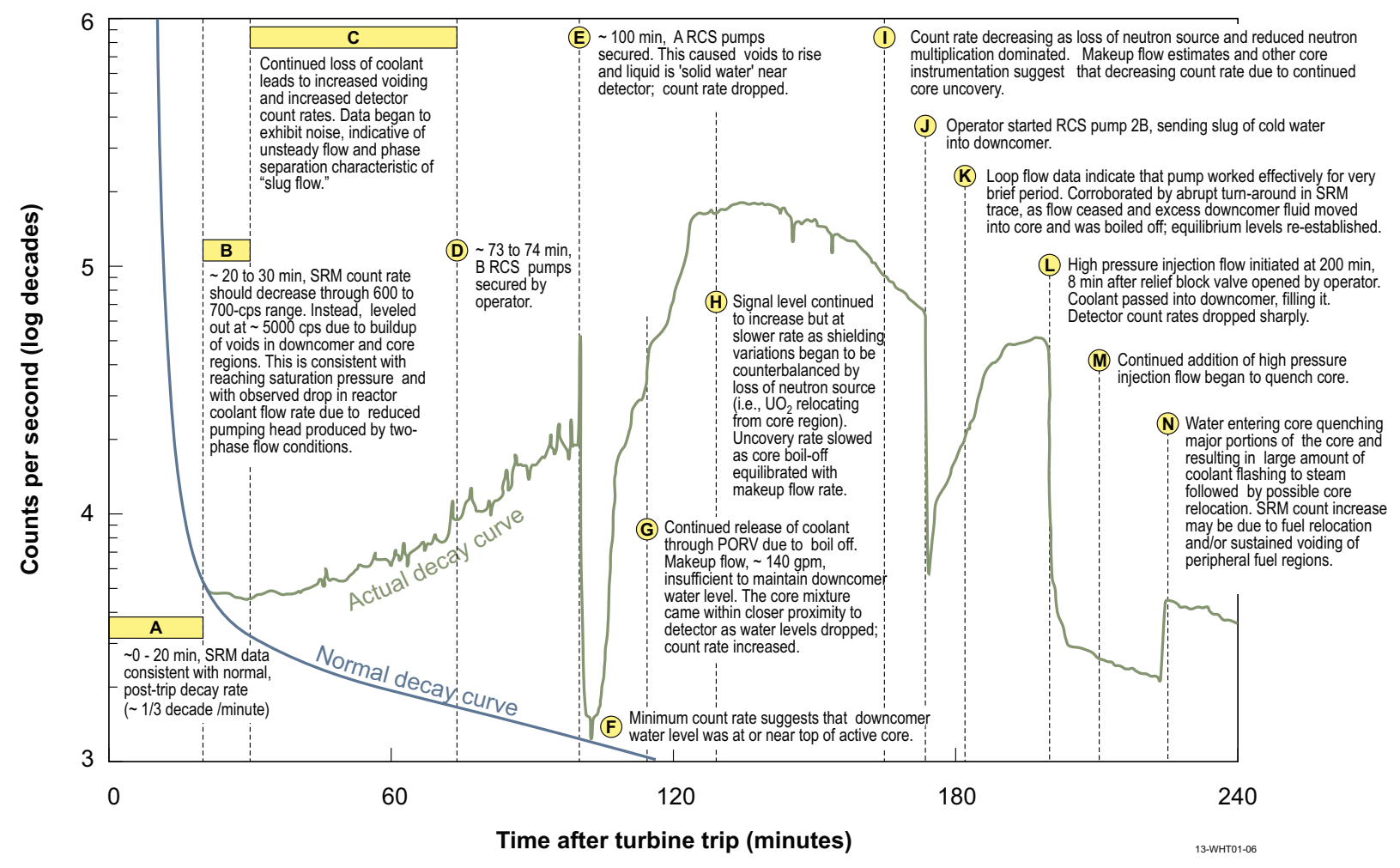

Figure ES-11. TMI-2 SRM response during the first 4 hours of the accident.

- No functional damage to the nuclear plant instrumentation or electrical components from thermal effects of the hydrogen burn could be identified. One Geiger-Mueller tube was determined to have failed at the time of the hydrogen burn, but its failure was deemed to be shock-related, possibly caused by the pressure wave associated with the hydrogen burn.

- Evaluations emphasized the need to consider anticipated applications and more extensive inspection and maintenance programs for instrumentation and related systems. For example, data unavailability or high uncertainties could have been alleviated by the use of better installation and testing procedures with increased calibration checks. Such actions could have alleviated issues observed in dome monitor and RTD components.

- Post-accident evaluations emphasized the need for more accurate containment radiation measurements. Identified Dome Monitor failures and data uncertainties (see Figure ES-12) led to several recommendations for design improvements, such as better seals that are periodically leak tested, the use of moisture and radiation resistant components and cabling, and relocating electronics outside the containment so that the lead shield could be removed.

- Post-accident extraction and examinations are needed to confirm insights from some evaluations. For example, inspections of components from the loose parts monitor system found that they had degraded due to radiation exposure; whereas, data suggested that sensors were still operational.

- Careful evaluations of sensor data led to unexpected detection of instrumentation errors. For example, comparison of steam generator (SG) water level data led to the conclusion that the full range transmit- 


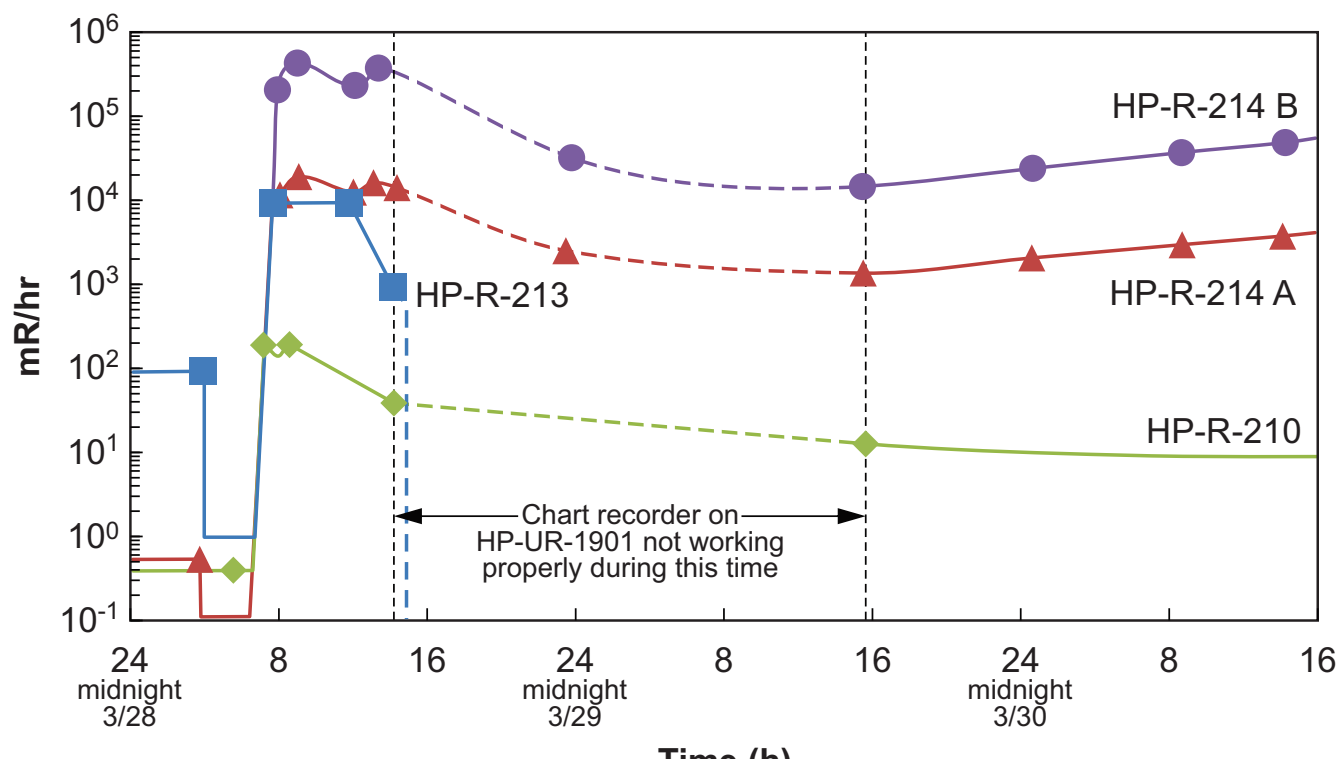

Time (h)

Figure ES-12. Containment radiation monitor response (Two curves are provided for HP-R-214 to reflect upper and lower bounds associated with uncertainties in recording scale).

ter was incorrectly installed because readings were observed to be erroneously low when the SG was steaming.

- Surrogate testing of similar sensors and components that were more easily accessible and not required for plant safety monitoring, such as core drain tank water level and pressure measuring system components, allow insights related to instrumentation degradation to be obtained without adversely impacting systems essential to maintaining the TMI-2 plant in a safe condition.

Evaluations emphasized the need for 'applications analyses' to determine possible environments during which the devices must function (or not fail). These "environments" are not limited to just temperature, pressure, humidity (or steam), submersion (flooding), radiation, and vibration (both operational and seismic). They should also include the availability of power sources and the characteristics of supporting services such as instrument air, cooling water, lubrication (allowable contamination levels, moisture), calibration, and preventive maintenance. Such factors are often overlooked details of applications engineering that affect both equipment reliability and the interpretation of information received, as demonstrated at TMI-2.

Evaluations found that TMI-2 instrument and electrical equipment degradation was often due to moisture ingress and corrosion. Water and vapor intrusion into the equipment housings caused erratic readings and ultimate failure. The TMI-2 post-accident environment was more moist than normal plant conditions, but the number of paths for moisture intrusion, the number of instrument failures, and the extent of corrosion found have generic implications for long-term equipment operability and maintenance practices at operating plants. These findings are reinforced by the fact that TMI-2 had just begun power operation. Seals had not undergone any significant aging, and there was limited human activity regarding disassembly of connectors or potential damage to conduit, connectors, or housing seals. In operating plants, routine maintenance activities will repeatedly disturb and challenge these seals. 
It is also worth noting how the US regulatory response was informed by TMI- 2 instrumentation evaluations. As noted above, the US NRC initially required that licensees make design changes so that positive indication of valve position is available in the control room. In addition, prescriptive requirements for more robust instrumentation and computational and power sources to support this instrumentation were implemented. As more insights related to sensor performance became available, additional requirements related to anticipated accident environments were implemented. Although current requirements are less prescriptive, they still require that licensees be aware of what data are needed and the conditions that sensors must withstand. Nevertheless, current regulatory guidance for instrumentation has not included a comprehensive evaluation of the instrumentation required for severe accident conditions. It is possible that this situation may change as the US NRC addresses the Near Term Task Force Actions that they identified be taken after the events at Fukushima.

In summary, a comprehensive set of instrumentation evaluations, that included careful integration of available data, analysis relying on basic engineering principals, operator information, laboratory evaluations, comparisons with accident simulation results and large integral tests, and post-accident inspection, was required for researchers to qualify sensor data for TMI-2 accident simulations. Knowledge gained from these evaluations offered important lessons for the industry with respect to sensor survivability, the need for additional and/or enhanced sensors and indicators, and the identification of unanticipated failure modes for sensors when exposed to extreme accident conditions. The events at Fukushima Daiichi Units 1, 2 , and 3 offer the nuclear industry the opportunity to reap BWR-specific benefits. 


\section{ACRONYMS AND ABBREVIATIONS}

ACRS Advisory Committee on Reactor Safeguards

AEP Accident Evaluation Program

APSR Axial Power Shaping Rod

BWR Boiling Water Reactor

B\&W Babcock \& Wilcox, Inc.

CSA Core Support Assembly

DIRC Data Integrity Review Committee

DOE-NE Department of Energy Office of Nuclear Energy

GPU General Public Utilities

G-M Geiger-Muller

HPIS High Pressure Injection System

ID Inner Diameter

IEEE Institute of Electrical and Electronics Engineers

IRM Intermediate Range Monitors

KPPH Thousand Pounds Per Hour

LOCA Loss of Coolant Accident

LOFT Loss of Fluid Test

LPM Loose Parts Monitoring system

LVDT Linear Variable Differential Transformer

LWRS Light Water Reactor Sustainability

Met Ed Metropolitan Edison

MIDS Movable In-core Detector System

MILS One Thousandth of an Inch

MPPH Million Pounds Per Hour

NEET Nuclear Energy Enabling Technology

NRC Nuclear Regulatory Commission

NSAC Nuclear Science Advisory Committee

OD Outer Diameter 


\begin{tabular}{ll} 
OECD & Organization for Economic Development \\
OTSG & Once-Through Steam Generator \\
PORV & Pilot Operated Relief Valve \\
PRM & Power Range Monitor \\
PRT & Platinum Resistance Thermocouple \\
PWR & Pressurized Water Reactor \\
QA & Quality Assurance \\
REC & Rosemount Engineering Company \\
RCS & Reactor Coolant System \\
RTD & Resistance Temperature Detector \\
SG & Steam Generator \\
SPND & Self Powered Neutron Detector \\
SRM & Source Range Monitor \\
TC & Thermocouple \\
TDR & Time Domain Reflectometry \\
TMI-2 & Three Mile Island Unit 2 \\
US & United States \\
VIP & Vessel Investigation Project \\
\hline
\end{tabular}




\section{INTRODUCTION}

The accidents at the Three Mile Island Unit 2 (TMI-2) and Fukushima Daiichi Units 1, 2, and 3 nuclear power plants demonstrate the critical importance of accurate, relevant, and timely information on the status of reactor systems during a severe accident. Conditions associated with the loss of coolant and the hydrogen burn that occurred during the TMI-2 accident exposed instrumentation to harsh conditions, including direct radiation, radioactive contamination, and high humidity with elevated temperatures and pressures. The TMI-2 accident also highlighted the critical importance of understanding and focusing on the key elements of system status information in an environment where operators may be overwhelmed with superfluous and sometimes conflicting data and yet have to make urgent decisions. While progress in these areas has been made since TMI-2, the accident at Fukushima suggests that there may still be some potential for further improvement. Recognizing the significant technical and economic challenges associated with modification of plant instrumentation, it is important to focus on the most essential data needs.

The TMI-2 accident provided a unique opportunity to evaluate sensors exposed to severe accident conditions. As part of a program initiated by the Light Water Reactor Sustainability (LWRS) and Nuclear Energy Enabling Technology (NEET) Programs within the Department of Energy Office of Nuclear Energy (DOE-NE), a review was completed to gain insights about the process used to evaluate sensor survivability and qualify data obtained from TMI-2 instrumentation. This effort was undertaken to provide insights related to sensor and data evaluations that could be implemented in upcoming Fukushima Daiichi recovery efforts. This new effort is focussed upon sensors providing critical data to the TMI-2 operators to assess the condition of the reactor and containment and the effects of mitigating actions taken by those operators. In addition, the effort considered sensors providing data required for accident simulations.

Over 100 references related to instrumentation performance and post-accident evaluations of TMI-2 sensors and measurements were reviewed. Results from this review are documented in this report, which is organized into seven sections. Section 2 of this report provides background information related to the TMI-2 reactor and containment design, accident progression, and post-accident recovery efforts, which included evaluations of the instrumentation data, post-accident examinations, and accident simulations. Section 3 describes the process used to develop a TMI-2 qualified data base, the various sensors from which data were available, the various computer systems on which data were displayed and stored, and the types of activities completed to assess sensor survivability and qualify sensor data. Sections 4 and 5 provide additional details related to selected sensors within the Reactor Coolant System (RCS) and the containment, respectively. Sensor designs and locations are described; available data are presented with its qualification status; and an assessment of the survivability of the sensor or system is provided. As noted within this report, several techniques were invoked in the TMI-2 Accident Evaluation Program (AEP) to assess sensor status, including comparisons with data from other sensors, analytical calculations, laboratory testing, and comparisons with sensors subjected to similar conditions in large-scale integral tests and with sensors that were similar in design to instruments easily removed from the TMI-2 plant for evaluations. For selected components or systems, additional information is provided related to missing sensors that could have assisted operators in mitigating the accident. In addition, alternate applications of sensor data, for example using flux detector data to infer water height, are documented in these sections. Appendix A of this document provides additional design information about TMI-2 instrumentation systems containing multiple sensors. Insights gained from this review are summarized in Section 6. As documented in this report, this review provides insights related to enhancement options for improving sensor performance

and suggestions for a process for evaluating data and sensor survivability that could be implemented in Fukushima Daiichi recovery efforts. References reviewed in this document are listed in Section 7. 


\section{BACKGROUND}

Numerous insights were gained from the TMI-2 post-accident evaluations. Although there is still some debate about certain aspects of the TMI-2 accident, ${ }^{1,2}$ the information obtained from post-accident evaluations and enhanced models provided a basis for improving plant design features, operator training, and accident mitigation strategies. At the time, the TMI-2 reactor was the only source of full-scale severe-accident data for addressing outstanding technical issues related to severe accident phenomena. Insights from TMI-2 proved invaluable to the nuclear industry and led to significant post-accident safety improvements.

As noted in Reference 4, such insights were not available until at least a decade after the event and required an integrated process that included several activities. This integration process, which is schematically shown in Figure 2-1, included information from plant instrumentation, post-accident evaluations and inspections to characterize the reactor endstate, severe accident research results from accident simulations, separate effects laboratory tests, and in some cases, data from large integral tests. Analyses to interpret and integrate these information sources was crucial, because insufficient data were available from any single source to uniquely define a consistent understanding of the TMI-2 accident scenario.

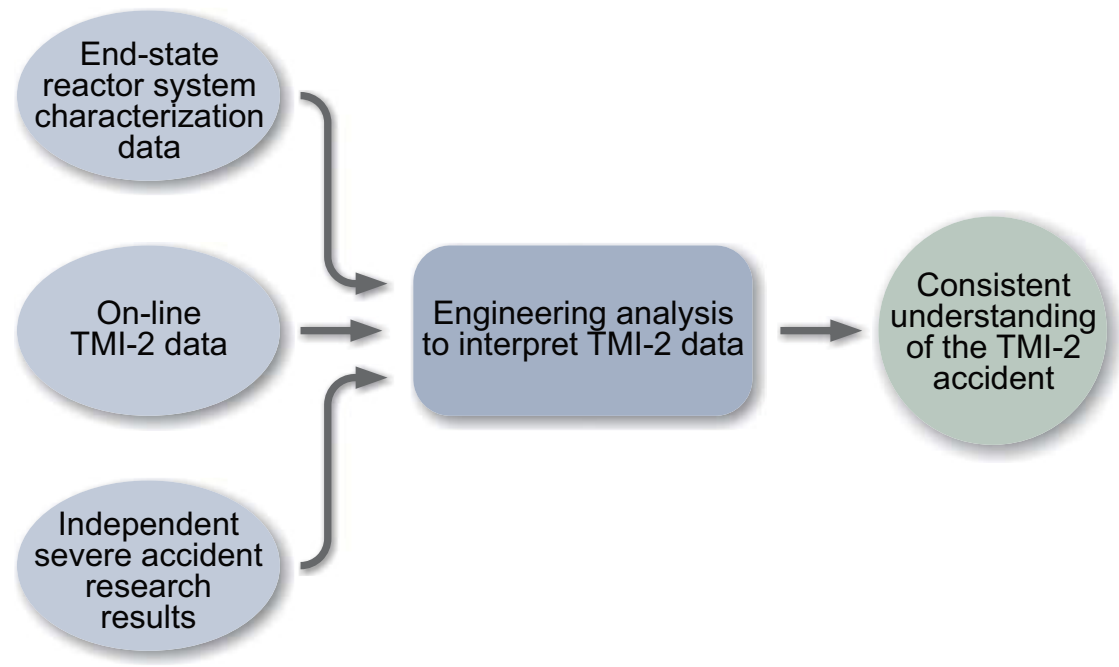

Figure 2-1. Integrated process used to develop TMI-2 accident insights.

In the area of instrumentation, the accident at TMI-2 provided a unique opportunity to evaluate sensors exposed to unusual conditions, i.e., direct radiation, radioactive contamination, moisture, high humidity with elevated temperatures and pressures, and pressure shock waves associated with hydrogen burns. Initially, various evaluation techniques were used to assess the accuracy of available plant instrumentation and improve accident simulations. As additional data from post-accident evaluations became available, accident descriptions were clarified; and accident simulation models were improved.

The remainder of this section provides relevant TMI-2 background information. Plant design features are summarized, and significant accident events with representative plant parameters are presented. Important insights from post-accident sample examination data and significant phenomenological insights gained from TMI-2 post-accident evaluation activities are highlighted. In addition, regulatory actions taken to address instrumentation needs identified by the TMI-2 accident are reviewed. 


\subsection{Plant Description}

The TMI-2 power plant, which was owned and operated by General Public Utilities (GPU) and Metropolitan Edison (Met Ed), contained a pressurized water reactor (PWR) designed and manufactured by Babcock \& Wilcox, Inc. (B\&W). The core housed 177 fuel assemblies, corresponding to 93.1 metric tonnes of fuel. The fuel was designed for a maximum local burnup of 55,000 MWd/MTU. At the time of the accident, the burnup ranged from 900 to $6,000 \mathrm{MWd} / \mathrm{MTU} .^{3}$ Core reactivity was controlled with control rod assemblies containing silver-indium-cadmium alloy and boron dissolved in the coolant. Reactivity was also controlled with burnable poison rod assemblies during the first fuel cycle. As shown in Figure 2-2, the RCS consisted of the reactor vessel, two vertical once-through steam generators, four shaft-sealed reactor coolant pumps, an electrically heated pressurizer, and interconnecting piping. The system was arranged into two heat transport loops, each with two pumps and a steam generator (often designated as the A and B loops).

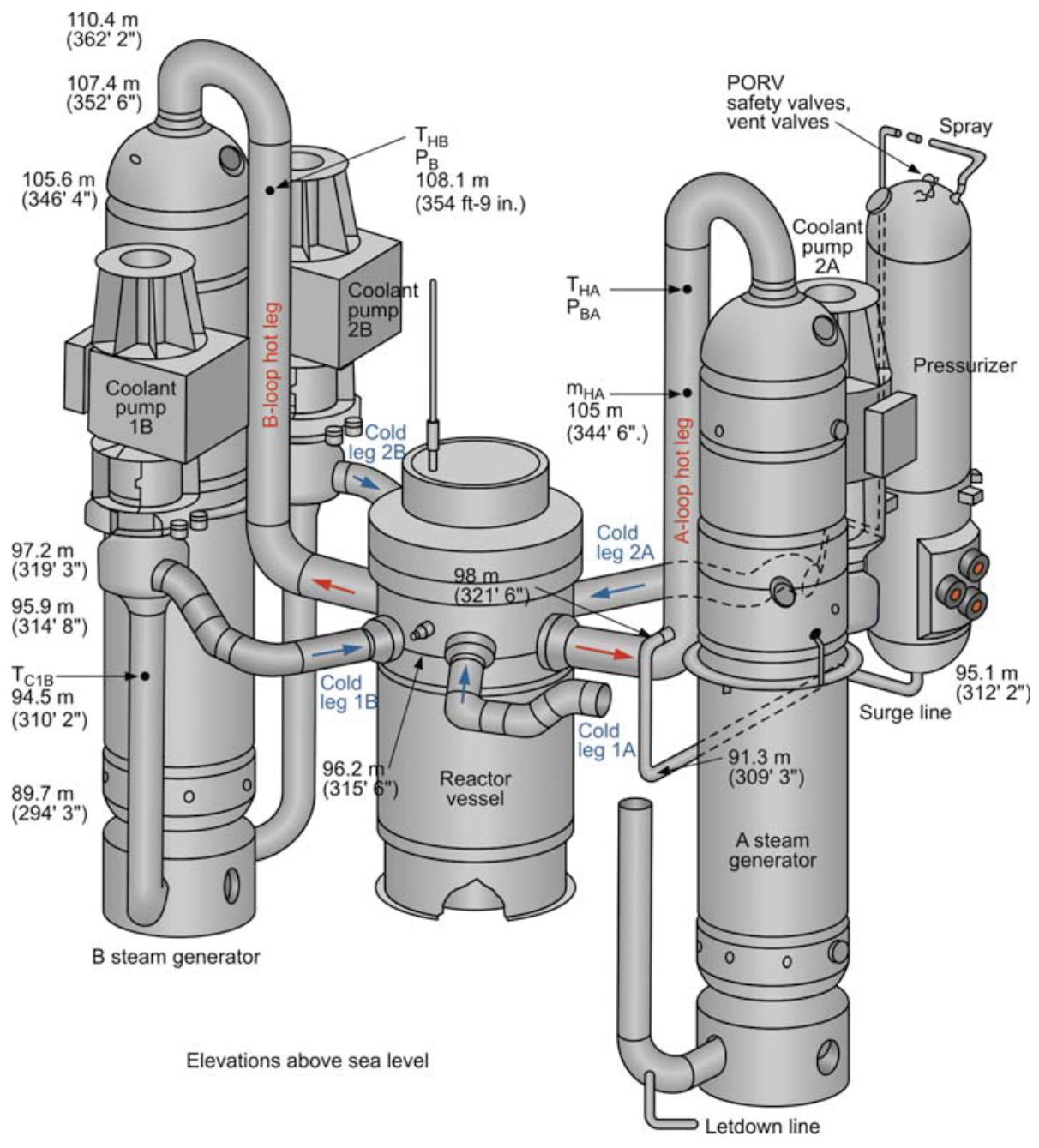

Figure 2-2. TMI-2 primary system layout.

The TMI-2 operating license was issued on February 8, 1978. It began commercial operation on December 30, 1978. 


\subsection{Synopsis of Accident}

Numerous references provide descriptions of the TMI- 2 accident sequence. ${ }^{4}$ through 10 Such descriptions were informed and updated as TMI-2 AEP results became available. The scenario defined at the end of the TMI-2 post-accident examinations and selected 'recommended' data characterizing plant response are presented in this section. As noted within this and subsequent sections, many details pertaining to the core heatup and relocation scenario could only be obtained from post-accident examinations and testing. Likewise, as discussed in Section 3, instrumentation data to characterize the plant response could only be qualified after detailed evaluations were completed.

The TMI-2 accident started at about 4 a.m. on March 28, 1979. During attempts to unclog a pipe leading from the full-flow demineralizers downstream of the condenser, the accident was initiated by a shutdown of secondary feedwater flow due to a trip of the condensate booster pumps followed by a trip of the feedwater pumps. Best estimates for plant data and events during the accident, as obtained from various post-accident evaluation programs ${ }^{6}$ are depicted in Figure 2-3. Following turbine isolation (defined as time zero in Figure 2-3) and reactor trip (when reactor pressure reached 16.3 MPa at 10 seconds after turbine trip), the steam generator boiled dry; and the resultant reduction of primary-to-secondary heat exchange caused the primary coolant to heat up, surge into the pressurizer, and increase the primary system pressure. The Pilot Operated Relief Valve (PORV) opened to relieve pressure when the RCS pressure reached 15.7 MPa. ${ }^{4}$ However, the PORV failed to close when RCS pressure decreased. The first $100 \mathrm{~min}-$ utes of the accident can therefore be characterized as a small break loss-of-coolant accident (LOCA) (through the PORV) with a corresponding decrease in RCS inventory and pressure. The event differed from a typical small break LOCA in that the pressurizer liquid level remained high. This was incorrectly interpreted by the reactor operators ${ }^{4,6}$ as indicating that the RCS was nearly full of water, when in fact, the RCS was continually losing its water inventory. Emergency core cooling was reduced by operators to address their concerns about a full RCS. However, the coolant void fraction increased due to coolant loss through the PORV and decay heat generation in the fuel. The steam inventory in the primary system piping increased to such an extent that RCS pumps were tripped by the operators to prevent permanent damage from pump cavitation after 100 minutes. ${ }^{4,6}$

At the time that pump operation ceased (see Figure 2-3), increases in Source Range Monitor (SRM) count rate and coolant system temperature and pressure, suggest that the reactor vessel liquid level had decreased. Studies correlating the response of the SRMs with the core liquid level suggest that core uncovery began between 114 and 120 minutes and that the liquid level had dropped to the core midplane by approximately 140 minutes. ${ }^{6,7}$ Insufficient decay heat removal associated with core uncovery is estimated to have led to upper regions of the core heating to temperatures that caused the cladding to overheat, balloon, and rupture. ${ }^{7,11}$ Such cladding failure, which results in the release of gaseous fission products, was substantiated by significant increases in containment radiation levels at 140 minutes. When operators finally realized that the PORV was failed in the open position, they closed the pressurizer block valve upstream of the PORV, terminating coolant loss and the release of fission products to the containment.

In-core self powered neutron detector (SPND) output and RCS pressure data (see Figure 2-3) indicate that core temperatures continued to increase between 150 and 165 minutes. Subsequent analysis of the SPND output indicated that temperatures probably reached $1077^{\circ} \mathrm{C}^{12}$ Insights gained from materials interaction and severe accident testing (e.g., see References 13 and 14) suggest that Zircaloy-steam exothermic reaction initiated, producing large amounts of hydrogen and dramatically increasing the core heatup rate. Zircaloy melting temperatures were exceeded, resulting in relocation of the molten Zircaloy and 

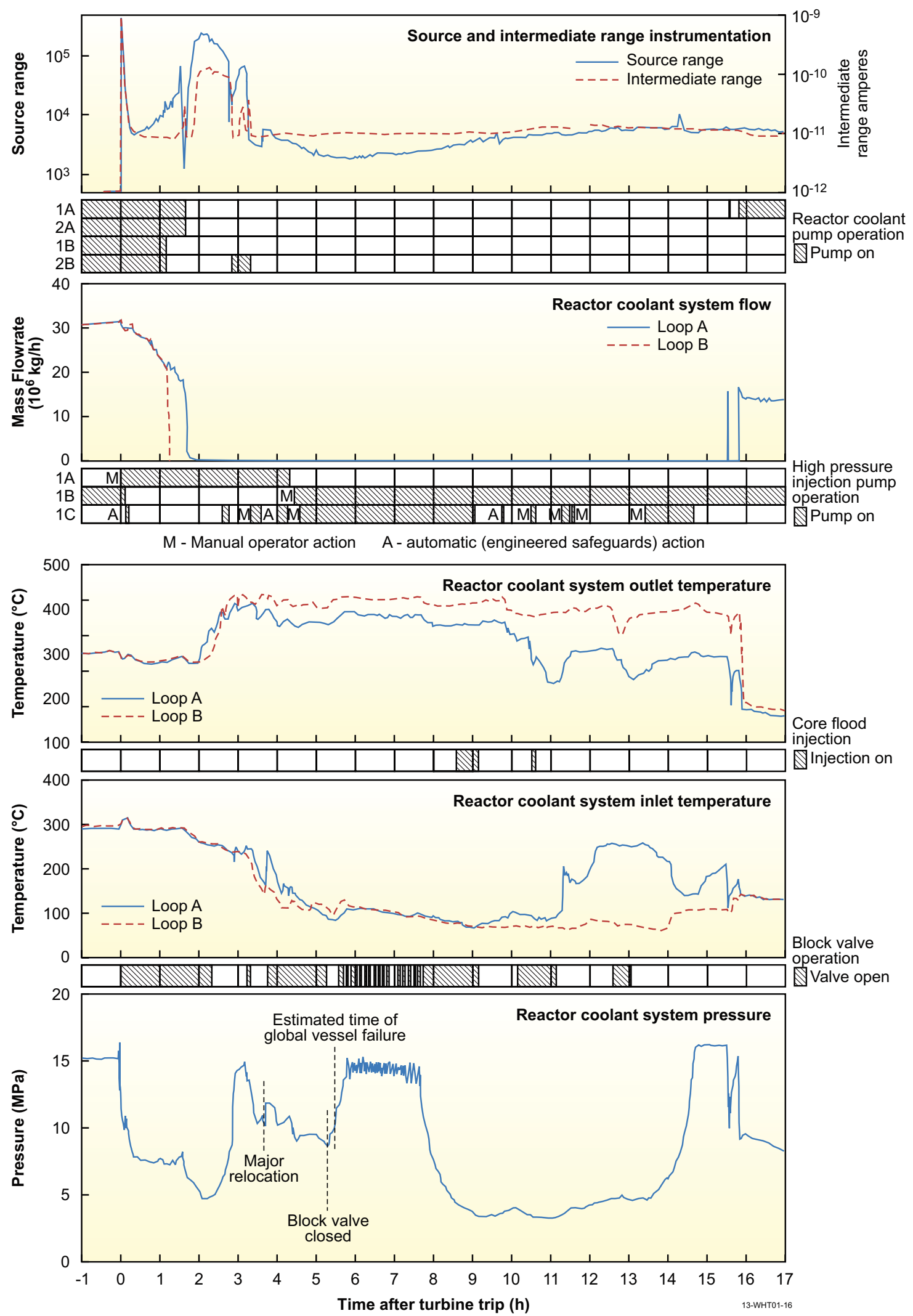

Figure 2-3. TMI-2 data from March 28, $1979 .^{6}$ 
some liquefied fuel to the lower core regions, solidifying near the coolant interface. This continued until 174 minutes, when a dense agglomeration of degraded core material formed in the lower regions of the core and blocked core flow.

At 174 minutes, one of the reactor coolant pumps in the B-loop was turned on for approximately 19 minutes, and coolant was pumped into the reactor vessel. This coolant injection rapidly repressurized the RCS. Core exit thermocouples above peripheral fuel assemblies indicate cooling occurred, and SRM count rate decreased at the time of this injection (see Figure 2-3). Several references ${ }^{4,7,15}$ indicate that the thermal-mechanical forces resulting from this injection and follow-on rapid steam formation may have shattered the oxidized fuel rod remnants in the upper regions of the core, forming a rubble bed on top of the consolidated core materials. At 200 minutes, the high pressure injection system was operated for 17 minutes. The reactor vessel was refilled with water by approximately 207 minutes.

Although the core was estimated to have been covered with coolant, analyses suggest that little coolant was able to penetrate the consolidated core region and that these materials continued to heat up. ${ }^{11}$ Between 224 and 226 minutes after reactor scram, plant instrumentation (RCS pressure increases, SRM count rate increases, cold leg temperatures increase, and in-core SPND signals increase) indicated that the outer crust (resolidified molten material) surrounding the relocated core material failed; and molten core material relocated to the lower plenum. ${ }^{4,6,7}$ Increases in SRM count rates (see Figure 2-3) suggest that small quantities of molten debris may have continued to relocate to the lower head between 230 minutes and 930 minutes (15.5 hours), although peak count rates are considerably lower than values during the 224 to 226 minute relocation time period. At 15.5 hours, one of the A-loop primary coolant pumps was restarted, re-establishing heat removal from the vessel.

\subsection{TMI-2 Post-Accident Examinations}

Once video examinations showed that a significant amount of core damage had occurred, ${ }^{6,16}$ the TMI-2 post-accident examination effort was expanded to included several activities to extract and evaluate samples from the reactor vessel. Samples included debris grab samples from the core rubble bed, fuel rod segments, core stratification samples, distinct fuel assembly and control rod cluster components (e.g., cladding, control rods, spiders, spacer grids, end fittings, hold-down springs), in-core instrumentation, and debris from the lower vessel. Fuel removal was initiated on November 12, 1985. A total of 23,000 $\mathrm{kg}$ of the $140,000 \mathrm{~kg}$ of the core material was removed, including upper end fittings from the fuel, control rod, and burnable poison rod assemblies, partial fuel assemblies, and loose debris. In addition, samples were extracted from the reactor vessel upper and lower plenums, the primary RCS piping and vessels, and the TMI-2 equipment and buildings external to the primary RCS. Sample examinations applied a variety of metallurgical, chemical, and radiochemistry methods.

As part of the TMI-2 Vessel Investigation Project (VIP), ${ }^{6}$ examinations were performed on samples from the cohesive layer of debris next to the vessel, often referred to as the 'companion' debris samples. In addition, the TMI-2 VIP included removal and examination of vessel steel, nozzle and guide tube samples. In removing the companion debris samples, it was observed that this dense layer of debris was extremely hard and that it had to be broken into pieces for removal. However, there was virtually no adherence of the material to the lower head. ${ }^{17,18}$ Electrical discharge machining methods were used to cut 15 prism-shaped metallurgical "boat samples" of steel from the vessel lower head; ${ }^{19}$ and examinations ${ }^{20}$ were performed at United States (US) and Organization for Economic Development (OECD) partner laboratories to deter- 
mine the peak temperatures experienced by the steel, the duration of these peak temperatures, and the subsequent cooling rate for the steel. Optical metallographic and hardness tests ${ }^{21}$ were also performed on vessel steel to estimate the maximum temperature various portions of the lower head reached during the accident. Creep and tensile tests ${ }^{20}$ provided insights about changes in material properties after this steel experienced elevated temperatures. Metallurgical examinations ${ }^{22}$ were also performed on vessel steel samples with cracked cladding overlayer material. Nozzle and guide tube examinations ${ }^{23}$ included micro and macro photography, optical metallography, scanning electron microscope measurements, gamma scanning, melt penetration measurements, and micro-hardness measurements.

Several other TMI-2 components were also examined as part of the TMI-2 AEP. ${ }^{24}$ For example, one major activity was to characterize surface deposits and peak temperatures experienced at locations other than the core region, such as RCS components and structures, control rod leadscrews, leadscrew support tubes, plenum cover debris, resistance thermal detector thermowells, steam generator manway cover backing plates, and makeup and letdown system filters. In addition, samples were obtained from the reactor building, such as basement sediment and reactor coolant drain tank contents.

\subsection{Phenomenological Insights}

Post-accident video and sample examinations, combined with instrumentation data and calculations with 'best-estimate' severe accident analysis tools, led to significant insights related to phenomena occurring during the TMI-2 accident. Examples highlighted in Reference 2 include:

- All TMI-2 fuel assemblies were damaged. Large regions of the core exceeded the melting temperature of the cladding $\left(\sim 1900^{\circ} \mathrm{C}\right)$. Significant fuel liquefaction by melted Zircaloy and some fuel melting occurred (corresponding to peak temperatures of at least $2800{ }^{\circ} \mathrm{C}$ ).

- Approximately $20 \%$ of the core materials escaped from the core as a liquid phase and solidified in lava-like formations in the core bypass region, the Core Support Assembly (CSA), and the reactor vessel lower head region. The estimated damage and core end-state configuration is summarized in Table 2-1.

Table 2-1. Estimated final state of material within TMI-2 vessel. ${ }^{5}$

\begin{tabular}{|c|c|}
\hline Region & Percent Core Material $^{\text {Cavity in Upper Core Region }}$ \\
\hline $\begin{array}{c}\text { Standing but damaged fuel assemblies or fuel assembly stubs } \\
\text { Loose (unmelted and previously molten core material mixture) } \\
\text { debris below the cavity in the upper core region }\end{array}$ & $33 \%$ \\
\hline Previously molten core material: & $20 \%$ \\
\hline Retained in Core Boundary & $47 \%$ \\
\hline Escaped from Core Boundary & $25 \%$ \\
\hline Core Bypass Region $^{\mathrm{a}}$ & $22 \%$ \\
\hline Core Support Assembly $^{\mathrm{b}}$ & $3 \%$ \\
\hline Lower Plenum $^{\mathrm{b}}$ & $4 \%$ \\
\hline
\end{tabular}

a. Not included in core material total.

b. Between reactor vessel lower head and CSA.

- Based on the end-state core and CSA configuration and supporting analysis of core heatup, it is believed that the crust (or resolidified molten material) surrounding the relocated core material 
(see Section 2.2) failed near the top of the molten core region in the southeast quadrant of the reactor vessel. Limited damage to the CSA occurred as the core material flowed to the lower plenum. Figure 2-4 illustrates the final state of materials within the TMI-2 vessel based on available instrumentation, analyses, and post-accident examinations. ${ }^{7}$

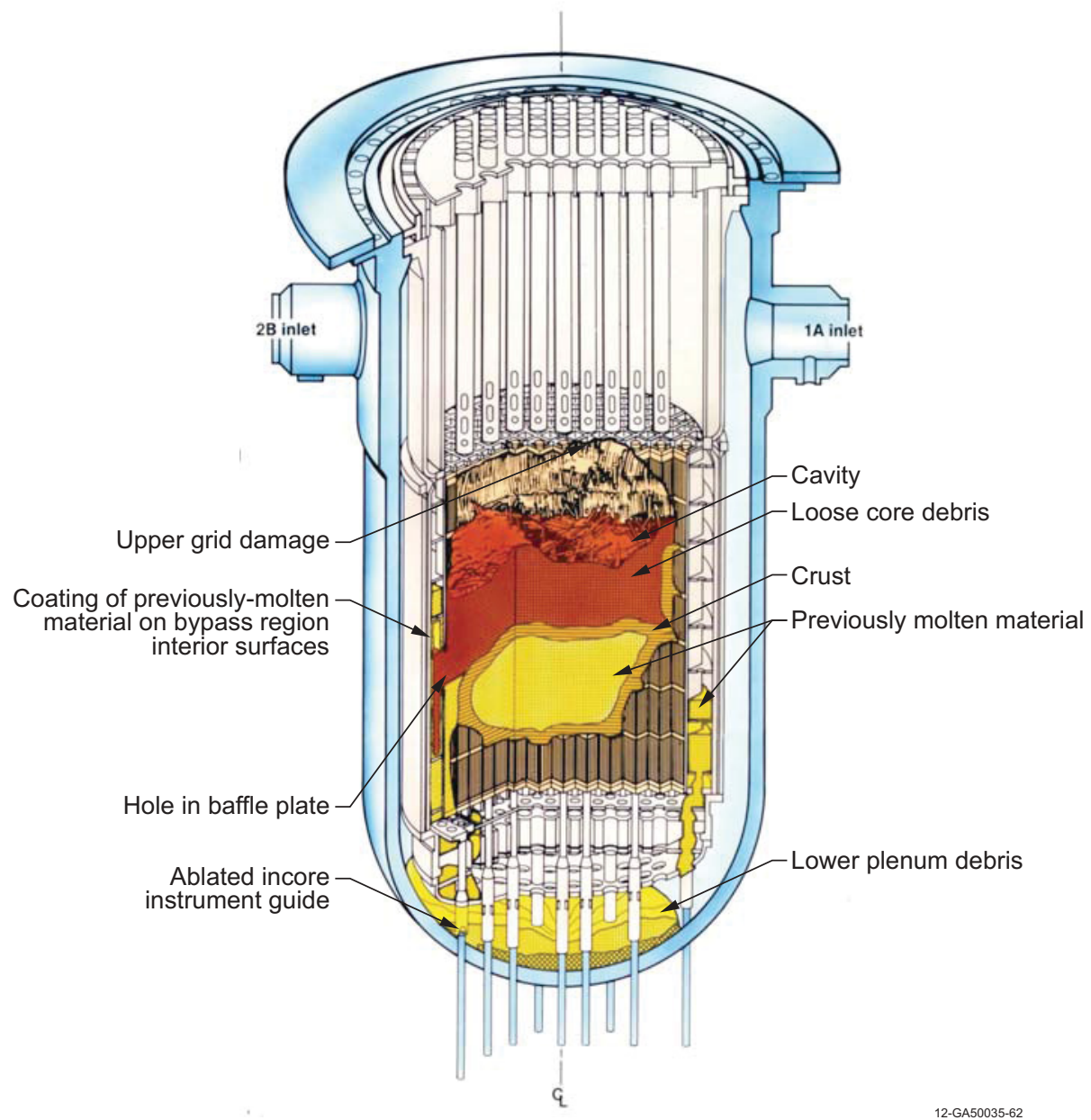

Figure 2-4. Postulated final state of materials within the TMI-2 vessel. ${ }^{6}$

- Metallurgical examinations of the vessel lower head 'boat samples' in conjunction with visual observations suggest that an elliptical region of the vessel, approximately $0.8 \mathrm{~m}$ by $1.0 \mathrm{~m}$, reached peak temperatures of $1100^{\circ} \mathrm{C}$ during the accident (see Figure 2-5). This peak temperature was well above the steel's transition temperature of $727^{\circ} \mathrm{C}$, where ultimate strength is significantly reduced (due to the transition from ferritic to austenitic steel). At $5 \mathrm{~cm}$ below the inner surface of the vessel, peak temperatures were at least $100 \pm 50^{\circ} \mathrm{C}$ lower. ${ }^{20,21}$ Examinations ${ }^{21}$ indicate that the steel may have remained at peak temperatures for as long as 30 minutes before cooling occurred. Cooling rates of 10 to $100{ }^{\circ} \mathrm{C} / \mathrm{min}$ were inferred, ${ }^{20,21}$ from examinations. At locations away from the hot spot, there is no evidence to indicate that vessel steel temperatures exceeded $727^{\circ} \mathrm{C}^{20,21}$

- Metallurgical examinations of cracks or 'tears' in the reactor vessel cladding (see Figure 2-6) in samples taken near the hot spot (positions E-6 and G-8) indicate that the damage extended down to, but not into, the carbon steel vessel. ${ }^{22}$ Cracks were typically found near nozzles. 


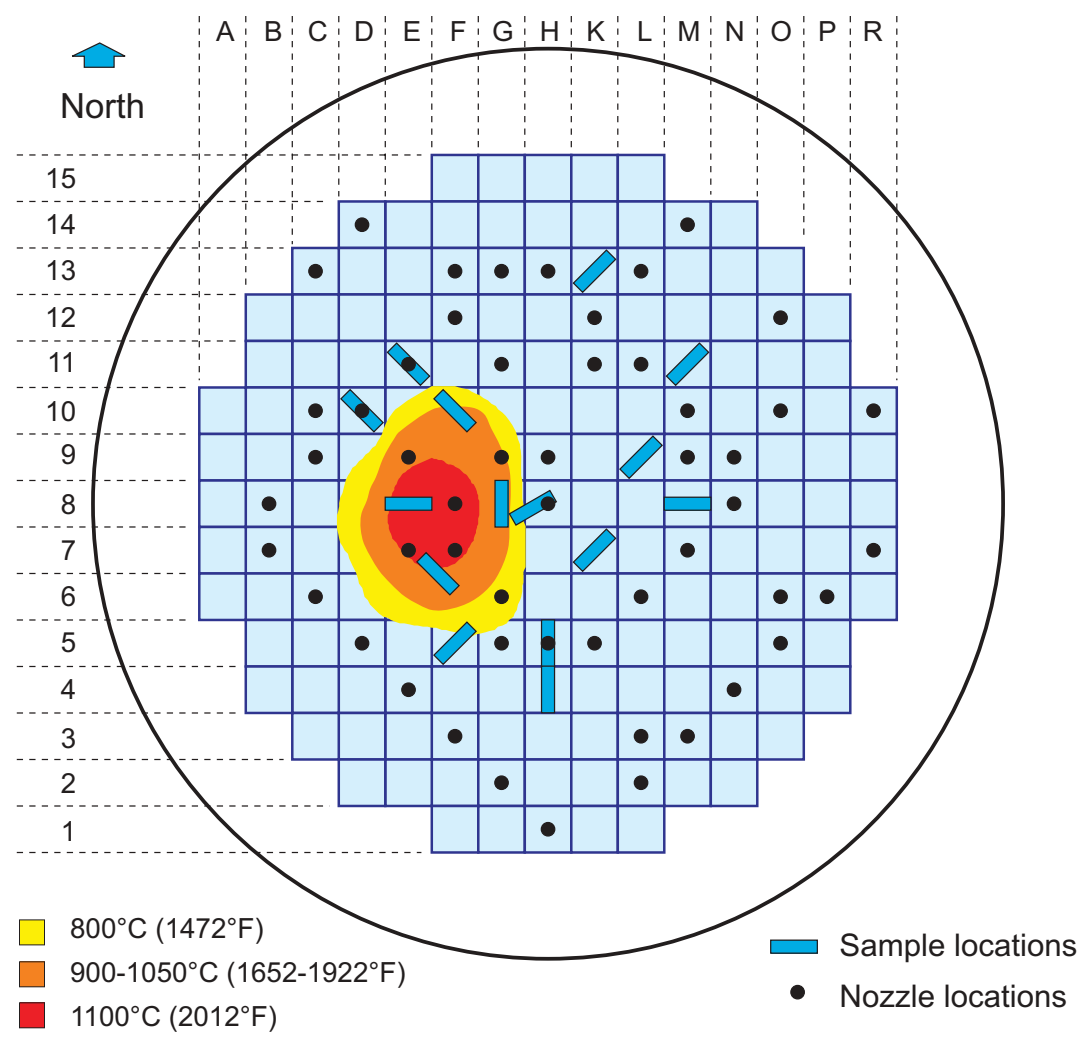

Figure 2-5. Location of TMI-2 vessel lower head boat samples and 'hot spot.'6

Examinations $^{22}$ indicated that these cracks were due to differential thermal expansion between the stainless steel cladding and the carbon steel vessel. Metallurgical examinations ${ }^{22}$ supported the conclusion that the tearing was due to differential thermal expansion between the stainless steel cladding and the carbon steel vessel when these materials were subjected to rapid cooling (at rates from 10 to $100^{\circ} \mathrm{C} / \mathrm{min}$ ). Furthermore, the presence of control material within the cladding tears indicates that control material relocated to the lower head prior to the time when the primary relocation of reactor fuel occurred.

- Instrumentation nozzle damage (see Figure 2-7) was caused by molten core material relocating to the lower head. ${ }^{23}$ The most severe damage was observed in nozzles located within the "hot spot" region of the vessel. Examinations indicate that the observed damage was not related to the embedded debris height (e.g., nozzle L6 was submerged in debris, but remained undamaged). Partially melted nozzle stubs indicate that peak temperatures were as high as $1415^{\circ} \mathrm{C}$, the liquidus temperature for Inconel 600. Surface scale found on the nozzles below their melt-off points suggest that molten material flowed on top of a crust of pre-existing solidified fuel debris. In fact, lower portions of the nozzles appear to have been protected by crusts that rapidly formed near vessel surfaces. Maximum fuel penetration depths observed in gaps within the nozzles indicate that melt solidified before it could relocate to depths below the lower head thickness. Examinations also indicated that $\mathrm{Ag}$ and $\mathrm{Cd}$ were present on nozzle surfaces, suggesting that control material relocated prior to the primary fuel relocation.

- Approximately $7 \mathrm{~kg}$ of the $19,000 \mathrm{~kg}$ of debris that relocated to the lower head were examined to develop estimates of debris decay heat in relocated material. It should be noted that only the quad- 


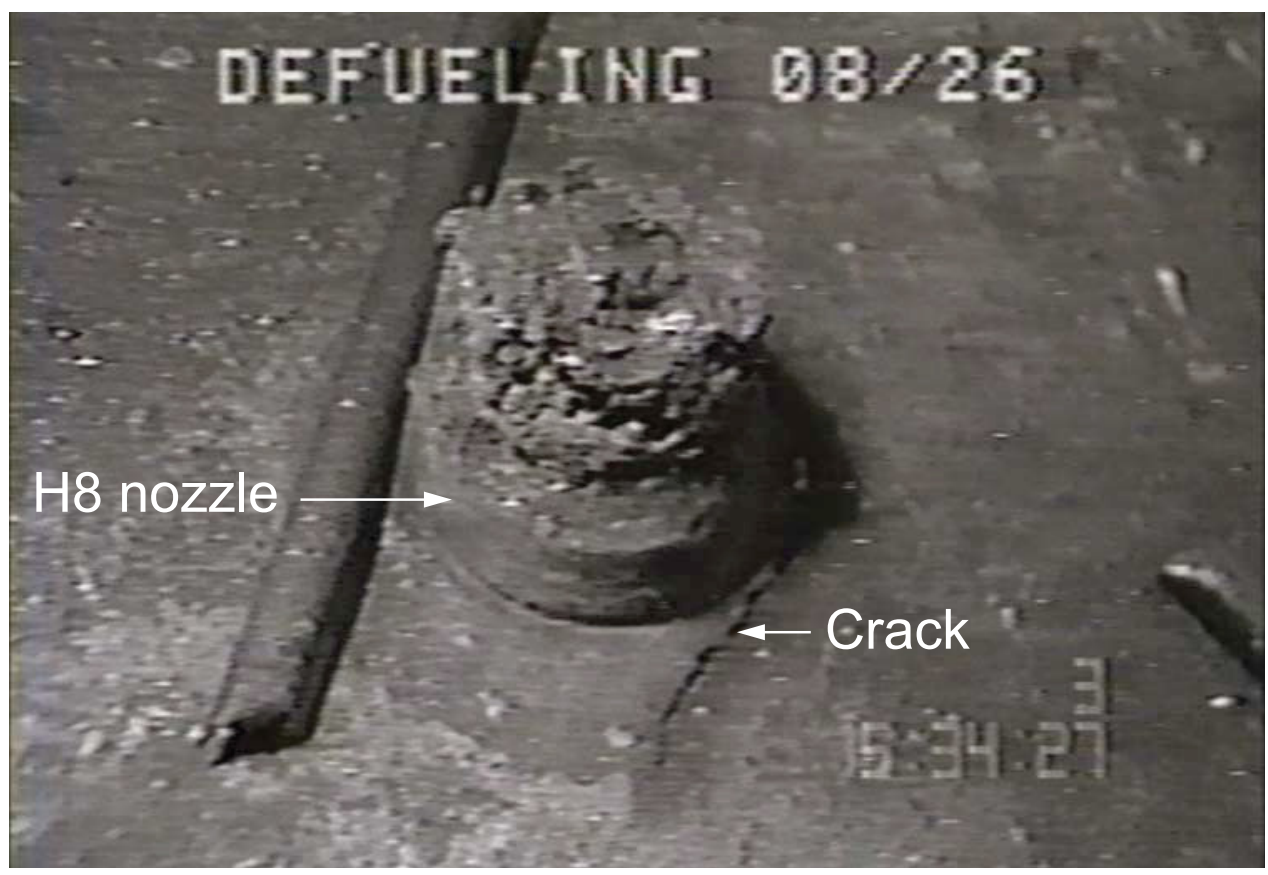

Figure 2-6. Video exams of the H8 instrumentation nozzle with crack on vessel.

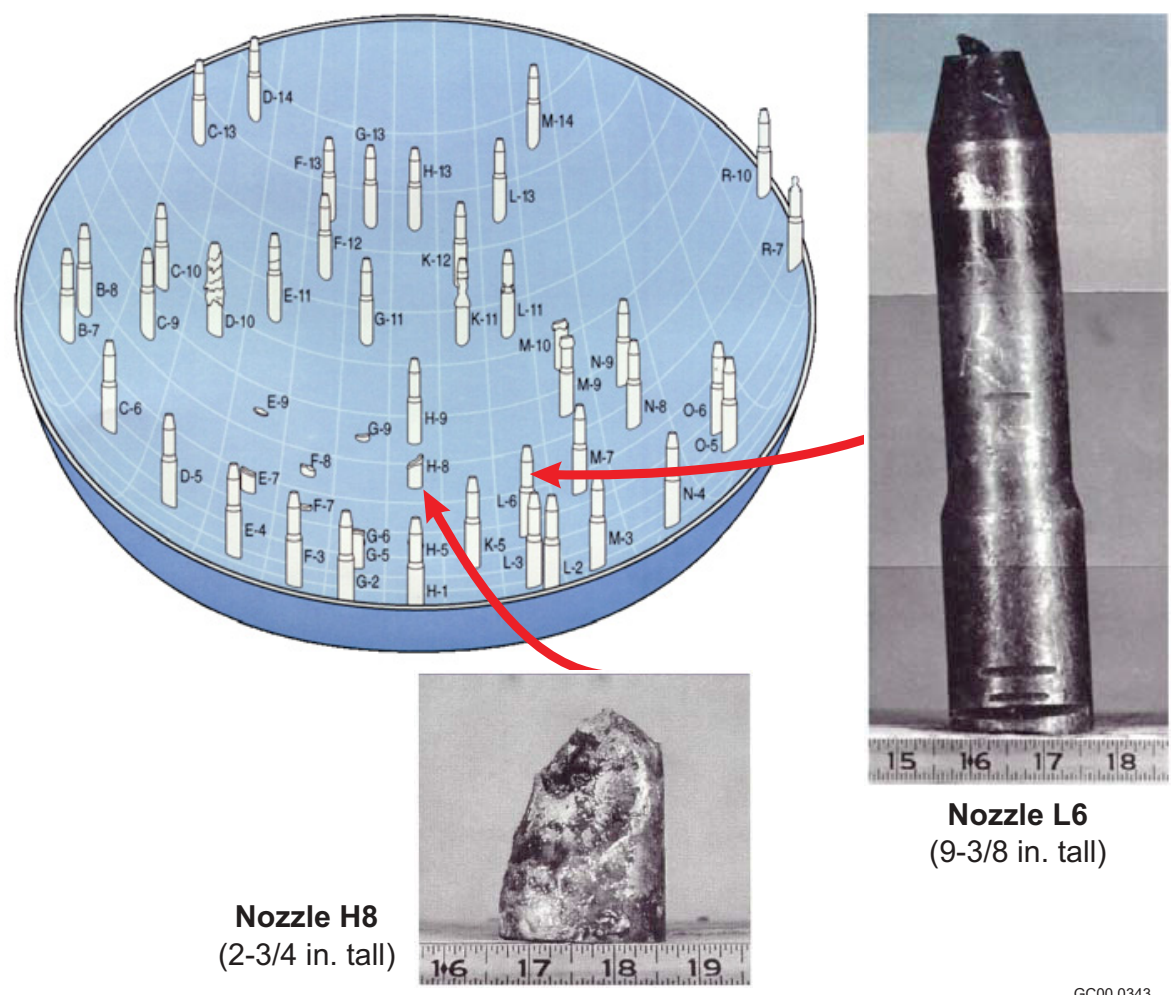

Figure 2-7. End-state of nozzles on the TMI-2 vessel lower head. ${ }^{6}$ 
rant from where the samples were taken was known and that the hard layer had to be broken into pieces as part of the acquisition process. Nevertheless, examination results yielded consistent values for all of the samples examined.

\subsection{Regulatory Response}

The US Nuclear Regulatory Commission (NRC) implemented a number of regulatory actions in response to investigations and lessons learned reviews following the accident. ${ }^{25}$ The first wave of actions that the NRC approved in the initial days and months following the accident were orders to individual licensees and generic communications, such as bulletins and generic letters. For example, within 30 days of the accident, the NRC's Office of Inspection and Enforcement issued a series of bulletins ${ }^{26-31}$ instructing all operating power plant licensees to take a number of immediate actions to avoid repeating events that occurred during the accident that contributed significantly to its severity. Bulletins 79-05 and 79-05A specifically required licensees of PWR facilities to review procedures to ensure that operators would be cognizant of the potential for safety relief valves to not reseat and procedures to ensure that operators would take actions to minimize the associated potential for void formation and compromised core cooling in the primary system. Although it was recognized that there were still many aspects of the accident that weren't known, Bulletin 79-08 instructed licensees of BWR facilities to also implement relevant lessons from the TMI-2 accident. $^{32}$

Then, various investigative groups, such as the Congress, ${ }^{33}$ the General Accounting Office, ${ }^{34-35}$ the President's Commission on the Accident at Three Mile Island, ${ }^{9}$ the NRC Special Inquiry Group, ${ }^{10}$ the NRC Advisory Committee on Reactor Safeguards (ACRS), ${ }^{36}$ the Lessons-Learned Task Force and the Bulletins and Orders Task Force of the NRC Office of Nuclear Reactor Regulation, ${ }^{37-38}$ the Special Review Group of the NRC Office of Inspection and Enforcement, ${ }^{39-40}$ the NRC Staff Siting Task Force and Emergency Preparedness Task Force, the NRC Office of Standards Development, and the NRC Office of Nuclear Regulatory Research, reviewed the events that occurred at TMI-2 and documented their recommendations. The staff developed the TMI-2 Action plan (NUREG-0660), ${ }^{41}$ in which various recommendations and possible actions of all the principal investigations were assessed and either rejected, adopted or modified. In NUREG-0660, the staff compiled their recommended actions, studies, and criteria development activities into broad subject categories: operational safety; siting and design; emergency preparedness and radiation effects; practices and procedures; and NRC policy, organization, and management. Implemented actions, which were judged to be immediately necessary to improve the safety of operating nuclear power plants were included in the NUREG-0660 action plan. In finalizing this plan, various drafts were reviewed and revised based on comments from the ACRS, the Commissioners, and the Office of the NRC Executive Director of Operations.

NUREG-0660 recommendations approved by the Commission were consolidated in NUREG-0737, "TMI Action Plan"42 and "Clarification of TMI Action Plan Requirements." 43 These documents identified approximately 371 individual requirements. ${ }^{25}$ Of these, the NRC found that 13,863 action plan items were applicable when reviewed against each specific licensed nuclear power plant. Some of these requirements involved changes to the NRC organization, processes, and practices. A few requirements caused the Commission to issue policy statements and specific changes to the NRC regulations through the rulemaking process. Both of these long-term regulatory tools required extensive internal and external stakeholder involvement. NUREG-0933, 44 "Resolution of Generic Safety Issues, Section 1 TMI Action Plan Items" documented the prioritization and closeout of the TMI Action Plan requirements. Typically, activities were 
prioritized based on the ratio of their estimated impact (by estimating possible risk reductions associated with activities, considering the frequency and consequences of events that could occur if such activities weren't implemented) to their estimated cost to implement. Note that NUREG-0933 identified certain risk or risk-related thresholds related to public dose and core melt frequency that would cause an activity to always be ranked high. Of particular interest to TMI-2 instrumentation evaluations were the disposition of the following three issues:

- Task Quality Assurance (QA) - Because enhanced QA offered the potential of safer operation, the staff initially ranked this issue high and initiated efforts to implement an improved QA program for systems and components important to safety. As efforts progressed, the staff concluded that enhanced QA programs depended primarily on management acceptance and implementation rather than criteria. The staff concluded that the existing regulation provided adequate guidance and requirements for QA programs, and this issue was dropped.

- Task II.D: Reactor Coolant System Relief and Safety Valves - The staff issued testing and maintenance requirements to qualify RCS relief and safety valves, block valves, and associated piping for operating and accident conditions. In addition, the staff required licensees to make design changes so that positive indication of valve position was available in the control room. Design changes implemented included acoustic monitoring devices, stem-position indicators, and flow indicators in the valve discharge pipe.

- Task II.F: Instrumentation and Control - The objective of this task was to provide instrumentation to monitor plant variables and systems during and following an accident. This objective was addressed by requiring the staff to update Regulatory Guide $1.97^{45,46}$ to provide detailed specifications for operating plants.

With respect to the last issue, several updates were performed to Regulatory Guide 1.97. Currently, Revision 3 of Regulatory Guide $1.97,{ }^{45}$ which contains a prescriptive list of parameters to monitor in BWR and PWR plants with a list of design and qualification criteria, remains in effect for licensees of operating reactors that continue to adhere to its guidance. Revision 4 of Regulatory Guide $1.97^{46}$ was issued for licensees of new reactor plants. This revision accommodates the increased use of microprocessor-based instrumentation systems in the existing and next generation of advanced design nuclear power plants. Rather than providing a list of instrument variables to monitor, Regulatory Guide 1.97 Revision 4 provides criteria for how the variables should be selected. Revision 4 also endorses (with some clarifying regulatory positions) a standard issued by the Institute of Electrical and Electronics Engineers (IEEE) Standard 497-2002, "IEEE Standard Criteria for Accident Monitoring Instrumentation for Nuclear Power Generating Stations." 47 However, current regulatory guidance has not included a comprehensive evaluation of the instrumentation required for severe accident conditions.

\subsection{Summary}

Clearly, the accident at TMI-2 provided a unique opportunity in several areas. New insights were gained related to accident progression and improved models were developed for simulating accident progression. In the area of instrumentation, TMI-2 provided an opportunity to evaluate instrumentation exposed to unusual conditions, i.e., direct radiation, radioactive contamination, moisture, and high humidity with elevated temperatures and pressures. 
Insights gained from these instrumentation evaluations are summarized in the remaining sections of this document. As noted above, the curves presented in Figure 2-3 were only obtained after extensive studies were completed. Furthermore, as discussed in this document, initial actions proposed by the regulators related to enhanced instrumentation were informed by examinations of sensors removed from TMI-2. Section 3 describes the process used to evaluate the performance of and data obtained from TMI- 2 sensors used to monitor critical TMI-2 reactor and containment parameters, either directly or indirectly, during and after the accident. 


\section{INSTRUMENTATION EVALUATION PROCESS}

Many post-accident investigations noted that the manner in which the plant was operated contributed to the TMI-2 accident. The operators' ability to mitigate the accident was also impacted by their limited access to accurate plant data. Hence, an evaluation program was initiated to determine what data were available to the operators and the status of sensors from which such data were obtained. In addition, it was recognized that the ability to improve severe accident analysis codes was dependent upon the quality of data used in accident simulations. This section summarizes the process used to develop a TMI-2 qualified data base, the various sensors from which data were available, the various computer systems on which data were displayed and stored, and the types of activities completed to assess sensor survivability and qualify sensor data. Sections 4 and 5 provide additional information about selected sensors, their measured data, their assessed status after the accident, and specific methods used to assess their survivability.

\subsection{Qualified Database Establishment}

An important aspect of the TMI-2 AEP was to provide a qualified data base for an analysis based on the TMI-2 accident, known as the "TMI-2 Analysis Exercise." This analysis exercise was completed to assess the accuracy of available data and modeling tools, which were obtained from small-scale experiments, when they were applied to a full scale PWR. ${ }^{48}$ Understanding gained from this analysis exercise was ultimately applied toward improving phenomenological models related to the chemical and materials interactions that occurred in the TMI-2 core and resolving applicable severe accident and source term issues. By resolving such technical issues, the analysis exercise contributed toward establishing a sound technical basis for post-TMI-2 regulatory actions.

A TMI-2 Initial and Boundary Conditions Data Base was established to provide a qualified database for this analysis exercise. A data qualification process was developed that included: collecting the TMI-2 measurement data and support information; establishing priorities and designing a formal approach for systematically performing the uncertainty analyses; and establishing quality categories of the data. Prior to being entered into the database, the data and uncertainties were reviewed by a Data Integrity Review Committee (DIRC), which was composed of a panel of experienced persons knowledgeable in TMI-2 data analysis. The DIRC reviewed available information, including analyses, evaluations, and comparisons, to ensure that the data met the following criteria:

- Consistency with respect to single channel analysis criteria (range, noise limits, time response, and correlation with the significant plant events and prior history);

- Agreement with other redundant information; and

- Agreement with thermal-hydraulic theory.

The DIRC also reviewed any underlying assumptions required to obtain the data. Prior to inclusion into the TMI-2 Initial and Boundary Conditions Data Base, the DIRC also approved qualification levels and uncertainty assigned to each set of data.

Basic information on the instrument systems was generally available, i.e., items such as system diagrams and manufacturer instruction sheets. Hence, analysts contributing to the data base usually knew and understood how the measurement systems worked. The major information lacking was calibration information on the measurement systems and components, especially near the accident date. 


\subsection{Data Recording Systems}

Data at TMI-2 were recorded on computer print outs, magnetic tapes, and analog stripcharts. After the accident, all such records were impounded, and access was only allowed for copying or study. Sources of data included microfilm, photographs, and microfiche of the hard copy data and copies of magnetic tapes. Enlarged color photographs of selected multipoint recorder data and support documentation to be used in the uncertainty analyses (instrument calibrations, circuit diagrams, operating manuals, etc.) were also obtained. Computational systems where data were displayed and stored are highlighted in this section.

\subsubsection{Reactimeter}

Much of the available plant data recorded during the accident were stored on the plant "reactimeter," a 24 channel data acquisition system. Its name derives from its capability to record core reactivity data, which were normally used during reactor start-up testing. However, the reactimeter also recorded other data, such as pressurizer pressure, hot and cold leg temperatures, loop A and B coolant flow, etc. The 24 channels of data were recorded on magnetic tape in the form of voltage readings. These voltages were directly proportional to the parameters being monitored, e.g., pressure, temperature, and flow. Table 3-1 lists the 24 parameters recorded by the reactimeter at the time of the accident. Positions for sensors monitored by the reactimeter are shown in Figure 3-1.

The reactimeter could sample each channel on any time interval from 0.2 second to 12.6 seconds. During the accident, the reactimeter was set to sample each channel on a 3 second interval, that is, it sampled all 24 channels in two $1.6 \mathrm{~ms}$ intervals once every three seconds. Hence, all 24 channels were sampled in $1.6 \mathrm{~ms}$, or essentially simultaneously. The availability of data from the reactimeter, which could be displayed in tables and graphs, made it a valuable resource for analyzing the TMI-2 accident.

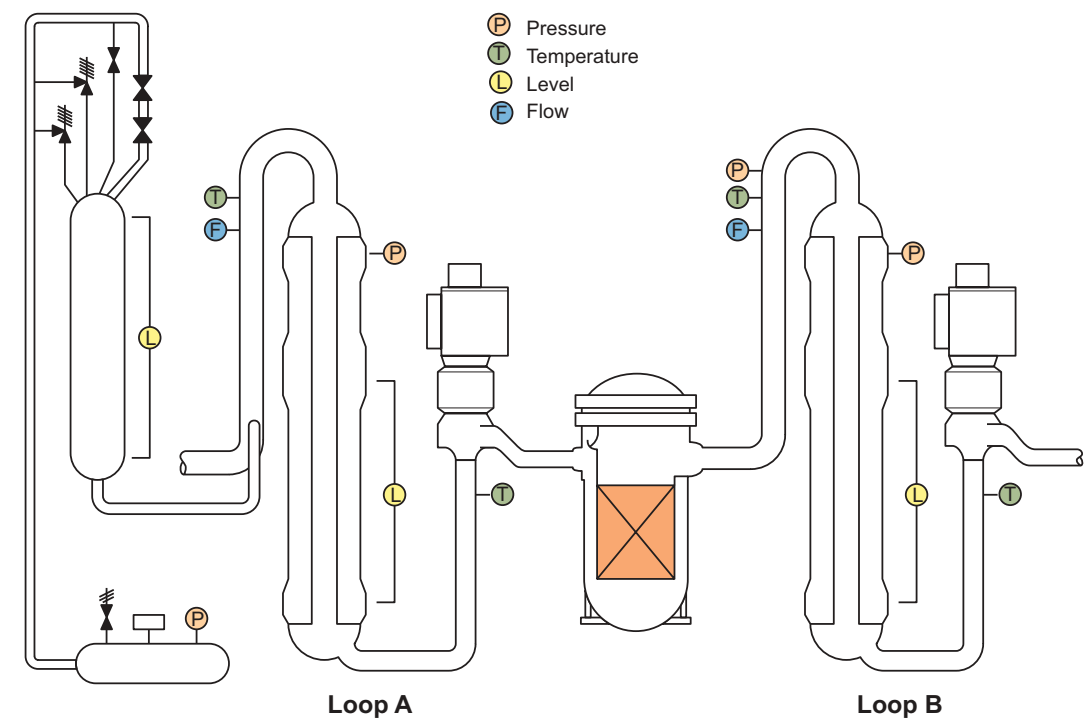

Figure 3-1. Reactimeter sensor location. 
Table 3-1. Parameters recorded on reactimeter.

\begin{tabular}{|c|c|}
\hline Channel & Parameter (Range) \\
\hline 1 & Power range level--nuclear instrument-5 (0-125\%) \\
\hline 2 & Loop A hot leg temperature--narrow range $\left(520-620^{\circ} \mathrm{F}\right)$ \\
\hline 3 & Loop B hot leg temperature--narrow range $\left(520-620^{\circ} \mathrm{F}\right)$ \\
\hline 4 & Loop A cold leg temperature--wide range $\left(50-620^{\circ} \mathrm{F}\right)$ \\
\hline 5 & Loop B cold leg temperature--wide range $\left(50-620^{\circ} \mathrm{F}\right)$ \\
\hline 6 & Loop A reactor coolant flow--temperature compensated; [0-90 million pounds per hour (MPPH)] \\
\hline 7 & Pressurizer level--temperature compensated (0-400 in.) \\
\hline 8 & Makeup tank level (0-100 inches) \\
\hline 9 & Pressurizer spray valve position (open-closed) \\
\hline 10 & Drain tank pressure $(0-250$ psig) \\
\hline 11 & Loop B reactor coolant pressure--narrow range (1700-2500 psig) \\
\hline 12 & Reactor trip (run-trip) \\
\hline 13 & Loop B reactor coolant flow--temperature compensated [0-90 MPPH] \\
\hline 14 & Feedwater temperature $\left(0-500^{\circ} \mathrm{F}\right)$ \\
\hline 15 & Turbine header pressure--Loop A (600-1200 psig) \\
\hline 16 & Steam generator A operate level $(0-100 \%)$ \\
\hline 17 & Steam generator A start-up level (0-250 in.) \\
\hline 18 & Feedwater flow--Loop A[0-6500 thousand pounds per hour (KPPH)] \\
\hline 19 & Feedwater flow--Loop B [0-6500 KPPH] \\
\hline 20 & Turbine trip (run-trip) \\
\hline 21 & Steam generator A steam pressure (0-1200 psig) \\
\hline 22 & Steam generator B steam pressure (0-1200 psig) \\
\hline 23 & Steam generator B operate level $(0-100 \%)$ \\
\hline 24 & Steam generator B start-up level (0-250 in.) \\
\hline
\end{tabular}

\subsubsection{Stripchart Data}

Data were also available on stripcharts at TMI-2. Unlike data stored on computers and magnetic tapes that could easily be extracted, stripchart data had to be digitized. Such digitalization was generally done on an apparatus which transferred the plot coordinates directly into the computer.

Some important parameters, such as the wide-range primary system pressure, containment pressure, and source and intermediate range neutron detector signals, were not available from the reactimeter. However, values for these and other primary and secondary plant parameters (see Table 3-2), were continuously recorded on stripchart recorders located in the control room. These recorders allowed the operators to observe and create historical records of trends in monitored parameters. There were basically two types of recorders used in the control room: pen recorders, which employed an ink pen to produce a continuous line plot of a parameter's value, and a multipoint recorder, which monitored several parameters and printed a code number identifying each parameter at a location on a strip chart representing the parameter's value.

Legibility was the biggest problem encountered in trying to extract information from the strip charts. This was especially true for the multipoint recorders when several parameter values were printed on top of each other and were difficult to read. The problem of legibility was compounded by the slow speed at 
Table 3-2. Parameters recorded on strip charts.

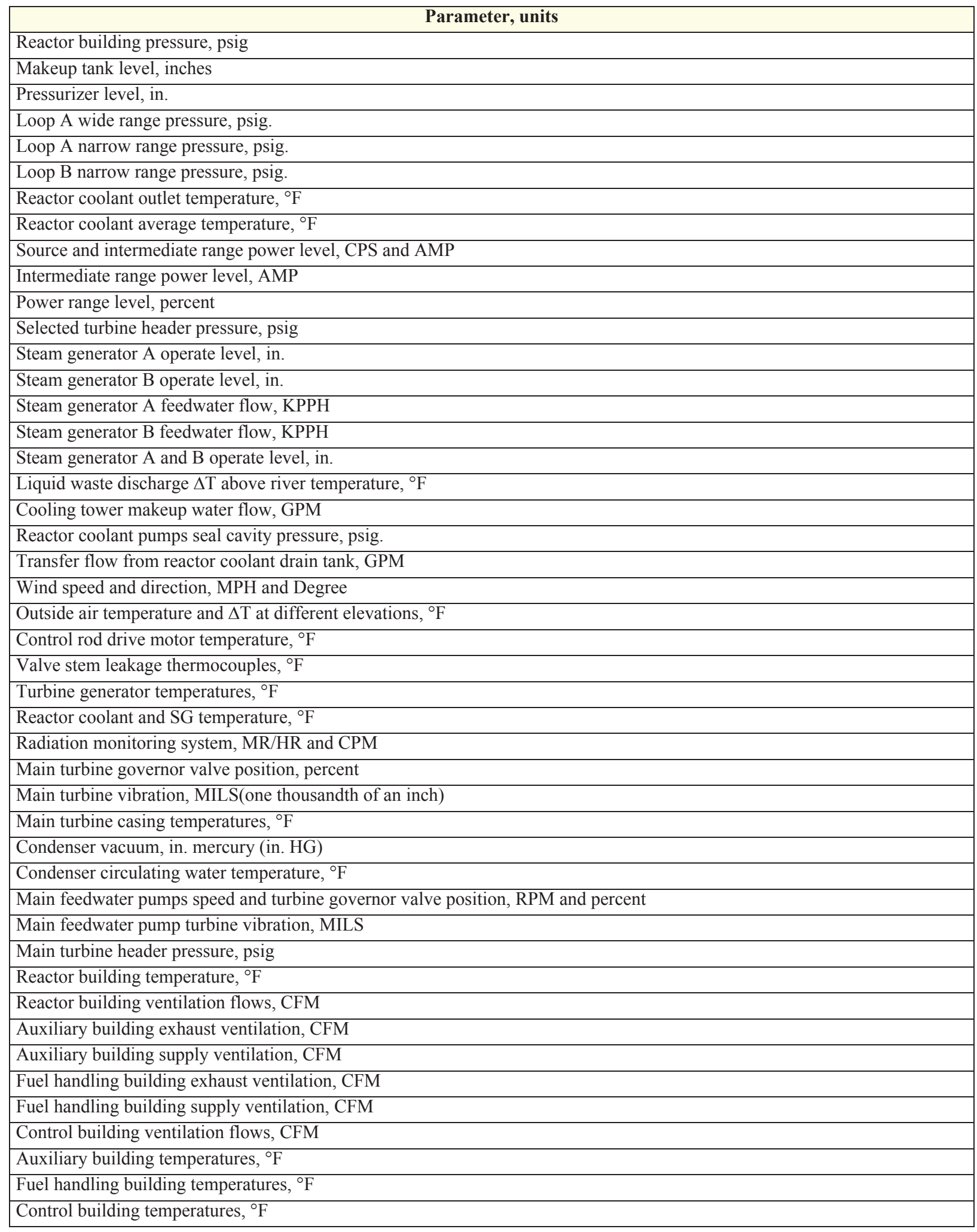

which the strip chart traveled (e.g., typically $1 \mathrm{inch} /$ hour for the pen plotters) and the large amount of data compressed onto them. In several cases, stripchart recorders had paper jams which were not corrected for 
several hours. In other instances, the measurement systems were over ranged by abnormally large input signals which caused the electrical systems to saturate. In addition, errors with respect to timing were introduced if the strip charts were not properly annotated when removed from the recorder.

Comparisons between stripchart and reactimeter values indicated that strip chart data were generally less accurate. However, stripchart data were found to be a good source of trend information. In addition, the stripcharts were calibrated periodically and had acceptable accuracy for most purposes--especially as a source of trend information.

\subsubsection{TMI-2 Computer System}

The TMI-2 plant computer system was an additional source of information. The principal function of the computer system was to monitor plant parameters (approximately 3000) and to display them along with any related calculations. ${ }^{49,4}$ The only permanent computer system record of instrumentation data was "hard-copy" from the utility printer (which only writes data if requested), the alarm printer (which writes data when an unusual occurrence happens such as a parameter exceeding an alarm setpoint or changing state), and the periodic log data (which were automatically printed out every hour and annotated to the minute).

The alarm inputs were stored by the computer in an alarm-backup-buffer until they were printed. This buffer could store up to 1365 alarm inputs. The alarm printer could only print one alarm every 4.2 seconds. If alarms were occurring at a faster rate, the printer got behind. At one point during the TMI- 2 accident, the alarm printer was at least 161 minutes behind. After the buffer was filled (i.e., 1365 alarms were waiting to be printed), the computer program was designed to print the message "Alarm Monitor Holdup" indicating that future alarms would not be stored until some of the 1365 backlogged alarms were printed. The operators had the option of suppressing the alarm sequence. This erased all prior alarms from the computer memory and caused it to start printing new alarms which originated after the suppression. At 167 minutes into the accident, the operators exercised this option in order to obtain current information (at this time, there was a data queue that would have taken 93 minutes to print). Because the operators needed timely information, they erased the memory buffer (destroying all alarm data between 74 and 167 minutes). This time period unfortunately corresponded to the time when the initial core heatup and uncovery occurred. The decision to exercise this option eliminated the possibility of printing backlogged and unstored alarms.

The utility printer provided output on request. The value or condition of any monitored parameter could be requested. The computer was also programmed to record automatically all changes in state of a predesignated group of parameters called "Sequence of Events" inputs. These event inputs were stored in the computer and could be printed on request. This particular computer function did not use the scan process described above, but used a continuous monitoring process which enabled it to print the exact time that the "Sequence of Events" inputs occurred. Another feature programmed into the computer was the "Memory Trip Review." Triggered by a reactor or turbine trip, this routine recorded a set of predesignated parameter inputs for 15 minutes before and 15 minutes after the trip. This information was stored until the operator requested that it be printed.

The plant computer provided the operator with an efficient means of keeping logs and showing trends on a large number of plant parameters under normal operating conditions. The computer was not designed to accommodate the data needs of the operator in an accident situation. Using the computer in an accident situation required that the operator leave his control panels in order to request computer output. It took the 
computer several seconds to supply the requested output; and the automatic alarm printout was often several minutes behind real time. All of these tended to limit the computer's usefulness in an accident situation.

\subsection{Sensor Evaluations}

Sensors allowed approximately 3000 measurements to be made at TMI-2. As documented in Reference 49, the DIRC identified 300 measurements of interest and developed a list of 170 measurements that were prioritized based on their ability to provide data required for subsequent accident simulations. As documented in Reference 49, only about half of these measurements were actually evaluated and included in the database at the completion of the TMI-2 data evaluation effort. Table 3-3 lists the sensors evaluated in this report. These sensors are a subset of the 170 measurements deemed of higher priority by the DIRC, The current effort selected sensors based on the availability of information in the literature. Table 3-3 also identifies report subsections that describe the design of the sensor or system, its measured data and qualification status, and conclusions related to its survivability. As noted within the referenced subsections, several techniques were invoked to assess sensor status, including comparisons with data from other sensors, analytical calculations, laboratory testing, and comparisons with sensors subjected to similar conditions in large-scale integral tests and with sensors that were similar in design and easily removed from the TMI-2 plant for evaluations. For selected components or systems, additional information is provided related to missing sensors that could have assisted operators in mitigating the accident.

Table 3-3 also lists secondary functions for which sensors measurements were used. As part of the TMI-2 post-accident evaluations, plant sensor data were evaluated in alternate ways to gain insights about the final state of materials within the TMI- 2 vessel. ${ }^{5}$ For example, estimates for core materials in the lower head were informed by results from ion chamber scans of in-core instrumentation calibration tubes; ${ }^{50}$ electrical resistance measurements of thermocouples were used to determine their remaining lengths; ${ }^{51}$ and neutron dosimeter measurements were used to detect uranium distribution. ${ }^{52}$ Mechanical probes were also used to determine the depth of loose debris and elevations of resolidified molten material or crust at locations below the core cavity and in the core bypass region, and the location of plugs in the in-core instrumentation calibration tubes. 53

\subsection{Data Uncertainty and Qualification}

Where possible, data uncertainty analyses were completed as part of the TMI-2 AEP. In some cases, it was deemed that problems with the data precluded any reasonable evaluation of measurement uncertainties. For example, analysts attempting to perform uncertainty analyses often found that it was impossible to obtain any statistical error information on instrumentation. ${ }^{49}$ In addition, there were cases where assumptions were invoked that allowed uncertainties to be expressed as a function of time due to the nature of the data and increasing uncertainties in other parameters (for example, the uncertainties in mass flowrate due to increased voiding in the coolant). ${ }^{49}$

As part of the TMI-2 AEP, the quality of the data were evaluated. Data were deemed "Qualified' for cases where the data had reasonably sized uncertainty and were well-behaved. Data were deemed "Trend" for cases where uncertainties were unreasonably large and where data only approximated the phenomenon being measured. "Failed" data contained no useful information and were not retained in the database. 
Table 3-3. TMI-2 sensors reviewed in this report.

\begin{tabular}{|c|c|c|c|}
\hline Parameter & Sensor & Report Section & Function \\
\hline \multicolumn{4}{|c|}{ RCS } \\
\hline $\begin{array}{c}\text { Core Exit } \\
\text { Temperature }\end{array}$ & Type K TC & Sections 4.1 & $\begin{array}{l}\text { Primary: core exit temperature; } \\
\text { Secondary: Insights on liquid level }\end{array}$ \\
\hline $\begin{array}{l}\text { Cold Leg } \\
\text { Temperature }\end{array}$ & $\begin{array}{l}\text { Platinum Resistance } \\
\text { Thermometers (PRTs) }\end{array}$ & Section 4.2 & Primary: Inlet temperature \\
\hline $\begin{array}{c}\text { Hot Leg } \\
\text { Temperature }\end{array}$ & PRTs & Section 4.2 & $\begin{array}{l}\text { Primary: Outlet temperature } \\
\text { Secondary: Insights on RCS pressure }\end{array}$ \\
\hline $\begin{array}{l}\text { Reactor Coolant } \\
\text { Pressure }\end{array}$ & Pressure transmitters & Section 4.3 & Primary: RCS pressure \\
\hline $\begin{array}{l}\text { Flux - In-Core } \\
\text { Measurements }\end{array}$ & $\begin{array}{l}\text { Self-Powered Neutron Detectors } \\
\text { (SPNDs) on In-Core } \\
\text { Instrumentation Assemblies and } \\
\text { Moveable In-Core Detection } \\
\text { System }\end{array}$ & $\begin{array}{l}\text { Sections A.1, } \\
\text { A. } 2 \text {, and } 4.4\end{array}$ & $\begin{array}{l}\text { Primary: Neutron flux } \\
\text { Secondary: Insights on temperature and liquid level }\end{array}$ \\
\hline \multirow{3}{*}{$\begin{array}{l}\text { Flux - Ex-Core } \\
\text { Measurements }\end{array}$} & Source Range Monitors (SRMs) & Section 4.5 & \multirow{3}{*}{$\begin{array}{l}\text { Primary: Neutron flux } \\
\text { Secondary: Qualitative insights on core liquid level }\end{array}$} \\
\hline & $\begin{array}{l}\text { Intermediate Range Monitors } \\
\text { (IRMs) }\end{array}$ & Section 4.5 & \\
\hline & Power Range Monitors (PRM) & Section 4.5 & \\
\hline $\begin{array}{l}\text { Pressurizer Liquid } \\
\text { Level }\end{array}$ & Differential Pressure Transmitter & Section 4.6 & Primary: Pressurizer liquid level. \\
\hline $\begin{array}{l}\text { Steam Generator } \\
\text { Water Level }\end{array}$ & Differential Pressure Transmitters & Section 4.7 & Primary: SG water level \\
\hline $\begin{array}{l}\text { Loose Parts } \\
\text { Monitoring }\end{array}$ & $\begin{array}{l}\text { Accelerometer and charge } \\
\text { converters }\end{array}$ & Section 4.8 & Primary: Presence of loose parts \\
\hline $\begin{array}{l}\text { Hot Leg Mass } \\
\text { Flowrate }\end{array}$ & Mass flowmeter & Section 4.9 & Primary: Mass flowrate \\
\hline \multicolumn{4}{|c|}{ Containment } \\
\hline Building Pressure & Pressure transmitter & Section 5.1 & $\begin{array}{l}\text { Primary: Pressure } \\
\text { Secondary: Timing of hydrogen burn }\end{array}$ \\
\hline $\begin{array}{l}\text { Building } \\
\text { Temperature }\end{array}$ & Platinum RTDs & Section 5.2 & Primary: Temperature \\
\hline $\begin{array}{l}\text { Core Flood Tank } \\
\text { Pressure Monitor }\end{array}$ & $\begin{array}{l}\text { Pressure transmitter sealed in } \\
\text { stainless steel casing }\end{array}$ & Section 5.3 & Primary: Core Flood Tank Pressure \\
\hline $\begin{array}{l}\text { Core Flood Tank } \\
\text { Water Level } \\
\text { Monitor }\end{array}$ & $\begin{array}{l}\text { Transmitter with linear variable } \\
\text { differential transformer (LVDT) } \\
\text { and bellows }\end{array}$ & Section 5.4 & Primary: Water Level \\
\hline $\begin{array}{c}\text { Building } \\
\text { Radiation Levels }\end{array}$ & $\begin{array}{l}\text { Area Radiation Monitors } \\
\text { Most: Geiger-Muller (G-M) tube } \\
\text { gamma detectors } \\
\text { Dome Monitor: Ion chamber }\end{array}$ & Section 5.5 & $\begin{array}{l}\text { Primary: radiation monitor } \\
\text { Secondary: Timing of fuel failure and fission } \\
\text { product release }\end{array}$ \\
\hline
\end{tabular}




\subsection{Summary}

Clearly, plant instrumentation data was essential in understanding the TMI-2 accident scenario. In addition, the accident at TMI-2 provided a unique opportunity to evaluate instrumentation exposed to unusual conditions, i.e., direct radiation, radioactive contamination, moisture, and high humidity with elevated temperatures and pressures. Insights gained from sensor evaluations are summarized in remaining sections of this document. Specifically, the report summarizes available information obtained for sensors that were used during or after the accident to monitor, either directly or indirectly, TMI-2 reactor (Section 4) and containment parameters (Section 5). 


\section{REACTOR COOLANT SYSTEM}

This section provides details about sensors within the RCS and current views related to their survivability. Table 4-1 lists the sensors discussed in this section, highlights aspects about their design, and identifies the report section providing additional details related to each sensor.

Table 4-1. TMI-2 RCS sensor review.

\begin{tabular}{|c|c|c|c|c|c|}
\hline Parameter & Sensor & $\begin{array}{c}\text { Report } \\
\text { Section(s) }\end{array}$ & Function & Range & Post-Accident Status \\
\hline $\begin{array}{l}\text { Core Exit } \\
\text { Temperature }\end{array}$ & Type K Thermocouple (TC) & Sections 4.1 & $\begin{array}{l}\text { Primary: core exit } \\
\text { temperature; } \\
\text { Secondary: Insights on } \\
\text { liquid level }\end{array}$ & 0 to $1100{ }^{\circ} \mathrm{C}$ & $\begin{array}{l}\text { Failed due to high temperatures, } \\
\text { steam, and moisture ingress } \\
\text { following sheath degradation; } \\
\text { Virtual junction formation occurred } \\
\text { in many of these thermocouples. }\end{array}$ \\
\hline $\begin{array}{l}\text { Cold Leg } \\
\text { Temperature }\end{array}$ & $\begin{array}{l}\text { Platinum Resistance } \\
\text { Temperature Detectors } \\
\text { (RTDs) }\end{array}$ & Section 4.2 & $\begin{array}{l}\text { Primary: Inlet } \\
\text { temperature }\end{array}$ & 10 to $343{ }^{\circ} \mathrm{C}$ & $\begin{array}{l}\text { Operating; some cabling and } \\
\text { connector damage may have } \\
\text { allowed moisture to degrade } \\
\text { insulation; extension cable shorting } \\
\text { may have occurred }\end{array}$ \\
\hline $\begin{array}{l}\text { Hot Leg } \\
\text { Temperature }\end{array}$ & Platinum RTDs & Section 4.2 & $\begin{array}{l}\text { Primary: Outlet } \\
\text { temperature } \\
\text { Secondary: Insights on } \\
\text { RCS pressure }\end{array}$ & 271 to $327^{\circ} \mathrm{C}^{\mathrm{a}}$ & $\begin{array}{l}\text { Operating; some cabling and } \\
\text { connector damage may have } \\
\text { allowed moisture to degrade } \\
\text { insulation; extension cable shorting } \\
\text { may have occurred }\end{array}$ \\
\hline $\begin{array}{l}\text { Reactor Coolant } \\
\text { Pressure }\end{array}$ & Pressure transmitters & Section 4.3 & Primary: RCS pressure & $\begin{array}{l}\text { narrow range: } 11.7 \\
\text { to } 17.2 \mathrm{MPa} \text {-gauge } \\
\text { wide range: } 0-17.2 \\
\text { MPa-gauge }\end{array}$ & $\begin{array}{l}\text { Operational, but RCS pressure } \\
\text { primarily below } 11.7 \text { MPa-gauge }\end{array}$ \\
\hline $\begin{array}{l}\text { Flux - In-Core } \\
\text { Measurements }\end{array}$ & $\begin{array}{l}\text { SPNDs on In-Core } \\
\text { Instrumentation Assemblies } \\
\text { and Moveable In-Core } \\
\text { Detection System }\end{array}$ & $\begin{array}{l}\text { Sections A.1, } \\
\text { A.2, and } 4.4\end{array}$ & $\begin{array}{l}\text { Primary: Neutron flux } \\
\text { Secondary: Insights on } \\
\text { temperature and liquid } \\
\text { level }\end{array}$ & 0 to $100 \%$ power & $\begin{array}{l}\text { Most damaged due to high } \\
\text { temperatures, steam, and moisture } \\
\text { ingress causing sheath degradation. }\end{array}$ \\
\hline \multirow{3}{*}{$\begin{array}{l}\text { Flux - Ex-Core } \\
\text { Measurements }\end{array}$} & $\begin{array}{l}\mathrm{SRMs}_{\left(\mathrm{BF}_{3} \text { proportional }\right.} \\
\text { counters) }\end{array}$ & Section 4.5 & \multirow{3}{*}{$\begin{array}{l}\text { Primary: Neutron flux } \\
\text { Secondary: Qualitative } \\
\text { insights on core liquid } \\
\text { level }\end{array}$} & $<10^{6} \mathrm{n} / \mathrm{cm}^{2}-\mathrm{s}$ & Operational \\
\hline & $\begin{array}{l}\text { IRMs (compensated ion } \\
\text { chambers) }\end{array}$ & Section 4.5 & & Up to $100 \%$ power & $\begin{array}{l}\text { Operational, but large uncertainty. } \\
\text { Power levels at lower end of } \\
\text { operating range. }\end{array}$ \\
\hline & PRMs & Section 4.5 & & 0 to $125 \%$ power & $\begin{array}{l}\text { Power levels at lower end of } \\
\text { operating range. }\end{array}$ \\
\hline $\begin{array}{l}\text { Pressurizer } \\
\text { Liquid Level }\end{array}$ & $\begin{array}{l}\text { Differential Pressure } \\
\text { Transmitter }\end{array}$ & Section 4.6 & $\begin{array}{l}\text { Primary: Pressurizer } \\
\text { liquid level. }\end{array}$ & 0 to $1016 \mathrm{~cm}$ & Operational \\
\hline \begin{tabular}{|c} 
Steam \\
Generator (SG) \\
Water Level
\end{tabular} & $\begin{array}{l}\text { Differential Pressure } \\
\text { Transmitters }\end{array}$ & Section 4.7 & Primary: SG water level & $\begin{array}{l}\text { Full Range: } \\
15-1539 \mathrm{~cm} \\
\text { Start-Up Range: } \\
15-650 \mathrm{~cm} \\
\text { Operating Level: } \\
0-100 \%\end{array}$ & $\begin{array}{l}\text { Operational, but full range } \\
\text { transmitter installed incorrectly. }\end{array}$ \\
\hline $\begin{array}{l}\text { Loose Parts } \\
\text { Monitoring }\end{array}$ & $\begin{array}{l}\text { Accelerometer and charge } \\
\text { converters }\end{array}$ & Section 4.8 & $\begin{array}{l}\text { Primary: Presence of } \\
\text { loose parts }\end{array}$ & NA & $\begin{array}{l}\text { Charge converter degraded due to } \\
\text { gamma radiation }\end{array}$ \\
\hline $\begin{array}{l}\text { Hot Leg Mass } \\
\text { Flowrate }\end{array}$ & Mass flowmeter & Section 4.9 & Primary: Mass flowrate & 0 to $4.5 \times 10^{6} \mathrm{~kg} / \mathrm{hr}$ & $\begin{array}{l}\text { Operational; required corrections } \\
\text { for depressurization and voiding }\end{array}$ \\
\hline
\end{tabular}

a. PRT sensor could measure from 10 to $343^{\circ} \mathrm{C}$, but reactimeter limits for the hot leg PRT were set at 271 to $327^{\circ} \mathrm{C}$. 


\subsection{Core Exit Temperature}

Temperatures within the TMI-2 reactor vessel were measured using resistance temperature devices (RTDs) and Type K thermocouples. As discussed in this section, the primary coolant RTDs (Rosemount Model 177) on the TMI-2 cold and hot legs were tested after the accident and found to have maintained their calibration, dynamic response, and integrity. In contrast, as discussed in this section, the 52 Type K core exit thermocouples at TMI-2, which were part of the In-core Instrumentation System (see Appendix A.1), had largely failed due to high temperatures, steam, and moisture ingress following sheath degradation. Additional details related to their design, available data, and status are discussed below.

\subsubsection{Description}

As noted above, the core exit thermocouples are part of the In-core Instrumentation System. Because this system contains several different types of sensors, its description is included in Appendix A.1. Each in-core instrumentation system assembly houses a $2.3 \mathrm{~mm}$ diameter, Inconel 600 sheathed, alumina insulated Type K (chromel versus alumel) thermocouple. The thermocouple passes through the active fuel region and terminates $15 \mathrm{~cm}$ above the top of the active fuel bundle. As noted in Appendix A of Reference 54, the thermoelement wires of these thermocouples are not exposed to coolant unless the oversheath of the in-core assembly and the thermocouple sheath fails. However, the thermocouple can be exposed to high temperatures within the core. During normal operation, this gradient is small, nominally 25 to $35^{\circ} \mathrm{C}$. During the TMI-2 accident, the fuel uncovered and experienced a very high temperature gradient, at least several thousands of degrees Celsius.

Numerous references (e.g., see Reference 55) indicate that the accuracy of Type K thermocouples is questionable once they are exposed to temperatures greater than $1100{ }^{\circ} \mathrm{C}$. Prior tests at high temperature show that significant drift will occur due to contaminants from the sheath migrating through the insulation into the thermoelements.

\subsubsection{Data}

As noted in Reference 56, TMI-2 core exit thermocouple data were limited for several reasons. First, the alarm printer and/or the process computer failed to retain records during a crucial phase of the accident (see Section 3.2.3). Second, the scale limits were set at temperatures less than $371^{\circ} \mathrm{C}$ for time periods less than 330 minutes after turbine trip (with "one notable exception"). The "one notable exception" occurred on March 28, 1979 (between 8:00 a.m. and 9:00 a.m.), when a Met Ed instrument engineer, using a digital voltmeter, obtained readings from the thermocouples. There were no direct supporting data immediately prior to or after this hand-taken data. Only after substantial cooldown was thermocouple temperature again recorded by the plant computer. Figure 4-1 compares the core temperature profile obtained by this engineer on March 28, 1979 with data obtained on March 31, 1979 and April 6, 1979.

Several factors should be considered in evaluating the data in Figure 4-1. As noted in Appendix A of Reference 54, the process of taking data by hand is laborious and susceptible to inaccuracies, partly due to the time required to obtain such data. Several minutes may have elapsed between individual data points, so the sequence of data taking influenced the core map since a core cooldown was in progress. From interviews and the raw data sheets, Reference 54 concluded that the data were taken in sequence from the inner core region to the outer core region. Hence, the core cooldown and sequence of data impacted the recorded 


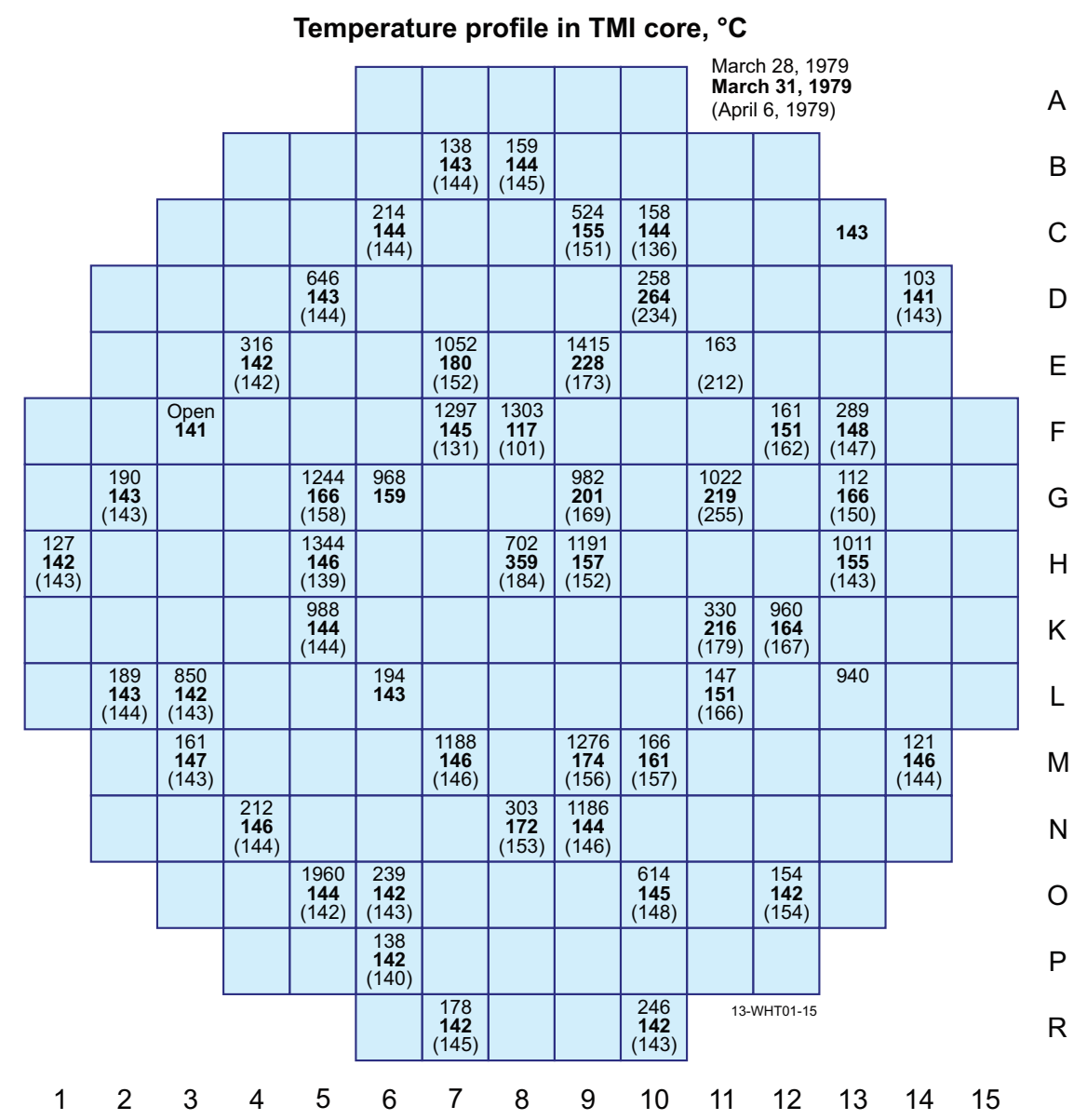

Figure 4-1. Core temperature profile.

temperature differentials between inner and outer core regions. Furthermore, the data shown for locations $\mathrm{E} 9, \mathrm{~F} 7, \mathrm{~F} 8, \mathrm{G} 5, \mathrm{H} 5, \mathrm{M} 9$, and $\mathrm{O} 5$, indicate temperatures above $1200{ }^{\circ} \mathrm{C}$, which is well-above the value where temperature-induced drift will significantly degrade the accuracy of these thermocouples. In addition, there are significant differences in adjacent thermocouple readings at several locations, such as at O5 and $\mathrm{O} 6$ and at M9 and M10.

\subsubsection{Operational Status}

Post accident in situ testing ${ }^{57}$ indicated that all of the thermocouples in the instrumentation assembly had failed, with 24 of the 52 thermocouples appearing to have formed virtual junctions at new locations. In general, it is believed that data from these thermocouples are accurate if such data were obtained prior to the time when temperatures causing the virtual junctions to form occurred. Independent laboratory tests performed on Type K designs similar to those deployed at TMI-2 observed that open-circuit failures of Type $\mathrm{K}$ thermocouples occurred at temperatures in excess of $1400^{\circ} \mathrm{C}$. In general, Type $\mathrm{K}$ thermocouple evaluations indicate that significant decalibration may occur at temperatures greater than $1100{ }^{\circ} \mathrm{C} .{ }^{55} \mathrm{After}$ cooldown, tests found that open circuit thermocouples can reform physical junctions, but data from such junctions are questionable due to their unknown location, changes in the metallurgical properties, changes in the chemical composition of thermoelement wires, and insulation degradation. Thermocouple loop 
resistance measurements were made to infer the location of core damage by the location where virtual junctions formed in the thermocouples. However, there is considerable uncertainty associated with such measurements.

\subsection{Cold and Hot Leg Temperatures}

TMI-2 primary coolant temperatures were monitored using four hot leg and two cold leg Rosemount Engineering Company (REC) platinum RTDs. RTDs with nuclear safety-related qualifications are often used in the primary coolant system of PWR plants. If the RTD's sensing element is made of platinum wire, the RTD is often referred to as a platinum-resistance thermometer (PRT) or platinum RTD (PRT is used throughout the remainder of this subsection). In addition to excellent reliability and accident survivability, nuclear safety-related PRTs are expected to have good calibration and fast dynamic response time. These characteristics are important to plant safety and economy because the PRTs provide the coolant temperatures used to estimate the reactor power. For that reason, the primary coolant PRTs in PWR plants are typically calibrated to an accuracy of $0.3{ }^{\circ} \mathrm{C}$ or better before installation. In addition, there are stringent requirements for the response time of primary coolant PRTs in PWR plants to provide operators timely information to trigger a mitigating action, such as a reactor scram.

\subsubsection{Sensor Description}

Figure 4-2a shows photographs and x-rays of two direct immersion Rosemount Model 177 HW PRTs, the model of PRTs installed in the primary coolant pipes of the TMI- 2 reactor. ${ }^{58}$ Figure $4-2$ also shows the thermowell-mounted counterpart of this PRT. The Model $177 \mathrm{HWs}$ are dual-element, 4-wire PRTs with a threaded silver bushing on the sheath surrounding the sensor. The calibrations above $0{ }^{\circ} \mathrm{C}$ are made in oil baths, and an uncertainty of $\pm 0.036^{\circ} \mathrm{C}$ at $316^{\circ} \mathrm{C}$ is asserted. Repeatability specifications require that agreement at $316^{\circ} \mathrm{C}$ be obtained with no more than $\pm 0.17^{\circ} \mathrm{C}$ deviation from a REC factory calibration. Reference 49 notes that the TMI-2 PRTs installed in the RCS cold legs have measuring ranges from 10 to $343{ }^{\circ} \mathrm{C}$. Uncertainties in RCS cold leg temperatures, which considered contributions from the sensor element, calibration, and reactimeter system, were estimated to be less than $\pm 2.1^{\circ} \mathrm{C}$.

The threaded silver bushing on the PRT sheath is intended to improve heat transfer between the PRT sheath and the matched thermowell, thus decreasing the installed response time. The bushing diameter and the mating thermowell are sized so that the bushing threads scrub against the inner surface of the thermowell when the PRT is inserted into the thermowell. It is important to note that the soft silver threads are distorted once the PRT is inserted; therefore, if the PRT is removed and reinserted (or even rotated in the thermowell). The metal-to-metal contact will not be as good as on initial insertion.

\subsubsection{Data}

Hot leg temperatures began indicating superheated steam conditions approximately two minutes after pump shutdown, and temperatures began increasing rapidly approximately 10 minutes after pump shutdown. At later times, the hot leg regions of both loops contained a stratified steam/gas mixture. The hot leg temperature was estimated by considering reactimeter and stripchart data. The reactimeter channels had a temperature range from 520 to $620^{\circ} \mathrm{F}\left(271\right.$ to $\left.327^{\circ} \mathrm{C}\right)$. During the time that the hot leg temperatures exceeded these limits, temperature data were taken from the stripchart. 


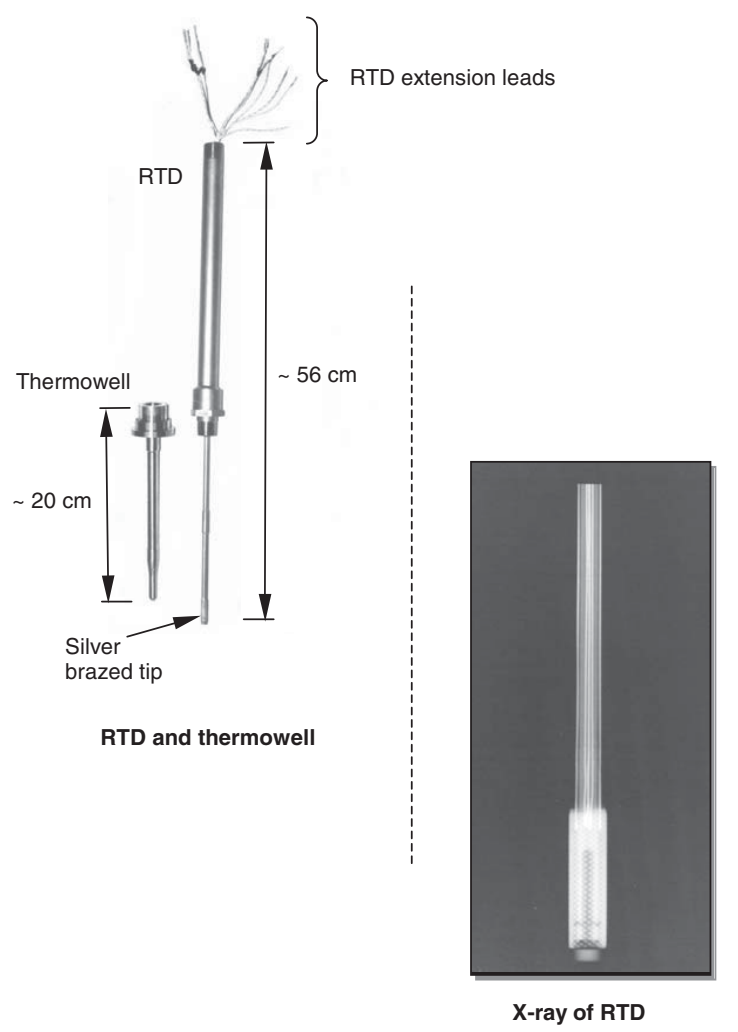

(a)
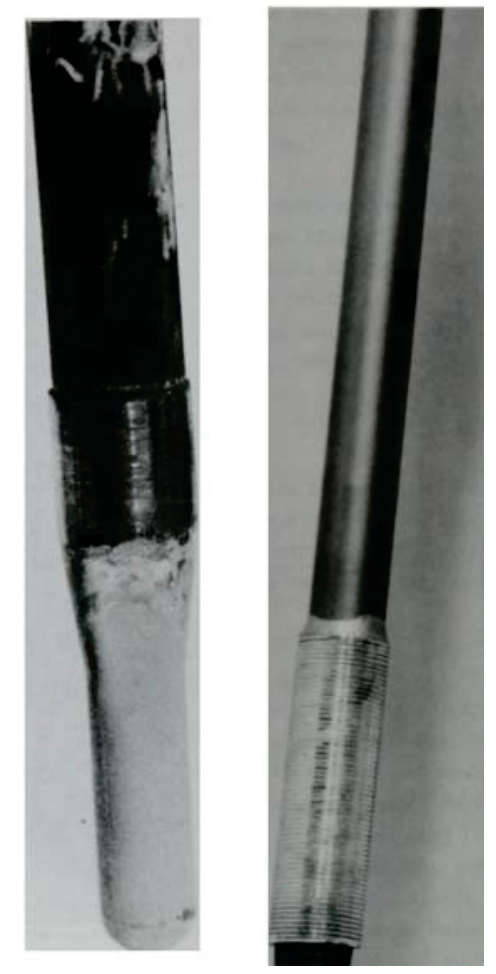

(b)

Figure 4-2. Rosemount Model 177HW RTD: (a) photograph and x-ray (b) thermowell and PRT from Rosemount Model 177HW PRT S/N 3670 removed from TMI-2 (the PRT appeared undamaged but radioactive deposits were found on the exterior surface of the thermowell).

Figure 4-3 compares A-loop hot and cold leg temperatures with A-loop saturation temperatures in the primary and secondary system. ${ }^{4}$ Between 20 and 80 minutes, the fluid temperatures remained relatively constant, ranging from approximately 280 to $290^{\circ} \mathrm{C}$. Between 20 and 80 minutes, A-loop primary temperatures closely followed the secondary saturation temperature. During this time period, a two-phase condition existed throughout the primary system. As mass continued to be lost from the RCS through the PORV, the void fraction of the two phase flow increased. At about 85 minutes, feedwater injection into the A-loop steam generator apparently terminated. By 92 minutes, the A-loop steam generator secondary had boiled dry, which resulted in a significant decrease in primary-to-secondary heat transfer. As shown in Figure 4-3, the primary temperatures were significantly above the secondary saturation temperature. At 95 minutes, the auxiliary feedwater flow was increased to the A-steam generator, increasing primary-to-secondary heat transfer and enhancing cooling of the RCS.

\subsubsection{Status}

During the accident, the TMI-2 PRTs were subjected to excessive temperatures, vibration, and radiation. After the reactor was shut down, the PRTs continued to be subjected to gamma radiation from the fission products deposited in the coolant loops. Reference 59 reports results from evaluations to assess the 


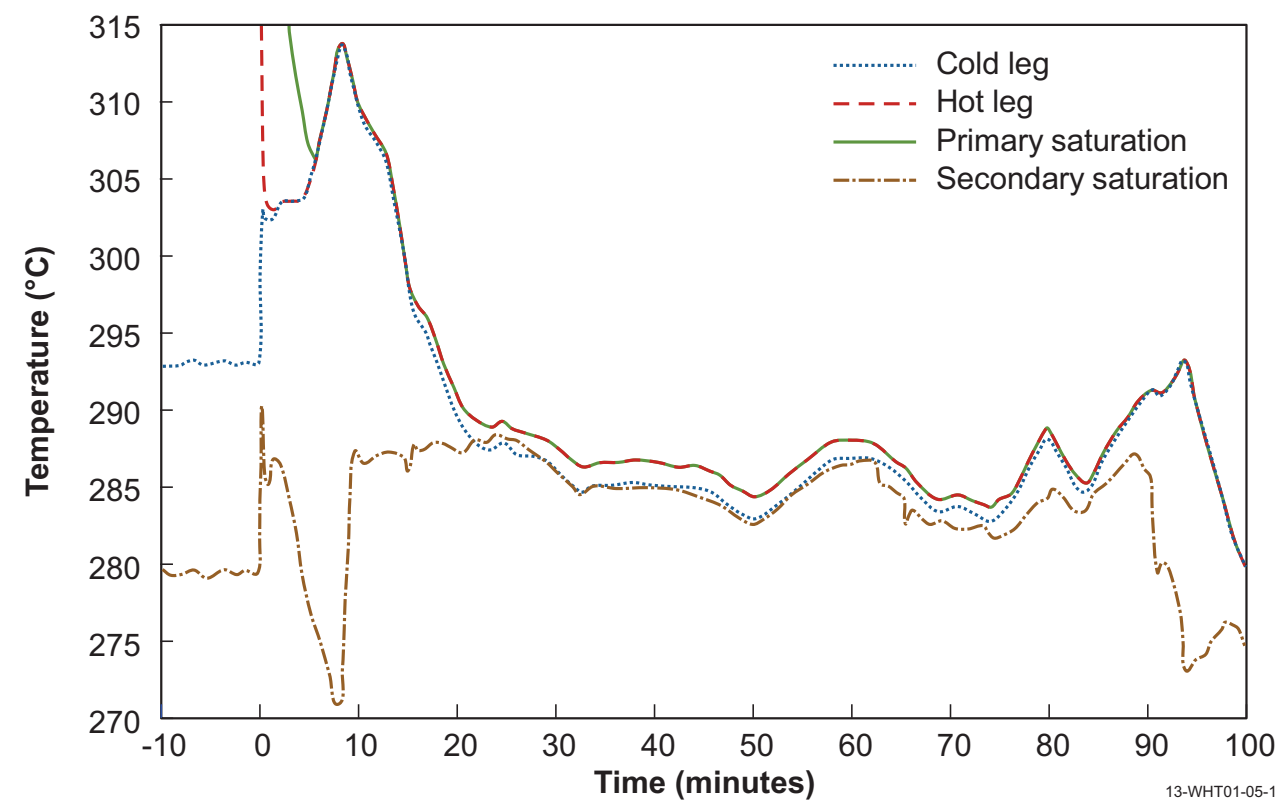

Figure 4-3. TMI-2 A-loop temperatures (-10 to 100 minutes).

condition of PRTs installed in the TMI-2 reactor vessel. A "worst-case" PRT (S/N 3670) was removed from the hot leg of loop A of the TMI-2 RCS four years after the March 1979 accident. Testing reported in Reference 59 found that this PRT conformed to the original purchase specifications for calibration, response time, and electrical properties. The unit met the bench mark response time in $75{ }^{\circ} \mathrm{C}$ water flowing at $0.9 \mathrm{~m} / \mathrm{s}$. In addition, it was confirmed that the PRT response time at full power conditions $\left(290{ }^{\circ} \mathrm{C}\right.$ and $15 \mathrm{~m} / \mathrm{s}$ ) met the plant technical specifications.

The removed PRT was selected because testing had shown that it had the lowest insulation resistance and heat transfer coefficient of seven PRTs tested while installed in the hot and cold legs of loops A and B. Examination determined that the low insulation resistance was a result of cable degradation, and further, that this was probably caused by a damaged conduit connection that allowed water and steam to enter. Since testing indicated that this PRT was the worst case PRT and since it met plant specifications, it was concluded that all PRTs survived the accident environment without functional damage.

However, shorting of PRT extension cables during the accident may have caused erroneous temperature readings. The protective conduit connection to the thermometer head was found to be broken on the worst-case PRT, allowing steam to enter the connecting terminal housing and the cable during the accident. All but two of the PRTs tested showed evidence of moisture in the measuring circuit.

\subsection{Pressure}

One of the essential parameters required for thermal-hydraulic analysis of the TMI- 2 accident is the primary system pressure. The pressure is required for comparison to computer code predictions of the accident and to obtain the phase properties of the fluid in any analysis effort. Unfortunately, no single data source was available for estimating the pressure during the entire TMI-2 accident sequence. Hence, as documented in Appendix E of Reference 49, a composite of various data sources was used to obtain the primary system pressure. 


\subsubsection{Hot Leg Sensor}

In each hot leg of the TMI-2 reactor are two penetrations for measuring the system pressure. These penetrations are at an elevation of approximately 108 meters (separated by 90 degrees) and the locations are shown in an isometric of the TMI-2 system in Figure 2-2. Connected to each of these penetrations, through $1.3 \mathrm{~cm}$ sensing lines, are two pressure transmitters mounted in the reactor building basement at an elevation of approximately 88 meters. The narrow range pressure transmitter was a Rosemount model 1152GP variable capacitance pressure transmitter (output 4-20 mADC) and was setup for a 11.7 to 17.2 MPa-gauge measurement range. ${ }^{*}$ The two narrow range transmitters in each loop were identified as RC-3B-PT1 and PT2 and RC-3A-PT1 and PT2. The other transmitter type connected to each sense line was a Foxboro model E11GH bourdon tube/electronic force balance pressure transmitter (output of 10-50 mADC) with a measurement range of 0 to $17.2 \mathrm{MPa}$-gauge, and referred to as the wide range measurement. The two wide range transmitters in each loop were identified as RC-3A-PT3 and PT4 and RC-3B-PT3 and PT4.

\subsubsection{Data}

The system pressure prior to the accident initiation (initial condition) was $14.8 \mathrm{MPa}$-gauge. Output from one of the narrow range pressure transmitters in the B-loop (RC-3B-PT1-R) ${ }^{\dagger}$ was recorded on the reactimeter at a sample rate of one sample every 3 seconds. These data (see Figure 4-4) were considered to be the best available TMI-2 RCS pressure data. ${ }^{49}$ Following the reactor trip, the primary system pressure quickly dropped below the minimum range for this measurement (by 2.2 minutes). With the exception of certain periods in which the system pressure increased to within the range of this transmitter (approximately 2.8 hours), other data sources were required for obtaining the primary system pressure.

Output from one of the wide range pressure transmitters installed in the A-loop (RC-3A-PT3) was recorded on the utility printer for two significant time periods. The first period was from -15 minutes to +15 minutes of the turbine trip, which was recorded on the utility printer as the Memory Trip Review. The second time period started at 570 minutes and continued throughout the remainder of the first day of the accident. The data were recorded on the utility printer as operator group trend C, recorded once every 2 minutes. Output from RC-3A-PT3 was also recorded on a strip chart mounted on one of the operators control panels (strip chart \# 59). As discussed in Section 3.2.2, strip chart data were considered to be the least accurate data available and only used when no other data were available. Adjustment of this data was required to match the initial pressure and event timing in comparison to the reactimeter data.

Knowledge of the thermal-hydraulic conditions in the reactor system, during the first 100 minutes, also allows the possibility of obtaining the system pressure from the measured hot leg temperature. By 6 minutes into the accident, the system had depressurized to the point where a two-phase mixture was exiting the core and flowing through the entire primary system (both steam generators had boiled dry by this time).

* Although the narrow range measurement was set-up for a range of 11.7 to 17.2 MPa-gauge, the measurement continued to produce readings slightly below 11.0 MPa-gauge. Therefore, the reactimeter data down to $11.0 \mathrm{MPa}$-gauge was used in the composite pressure.

$\dagger$ The TMI-2 AEP uses the basic measurement identifications originally assigned by GPU. However, a suffix is typically added which identifies the recording device. For example; - $\mathrm{R}$ is added for measurements recorded on the Reactimeter; -s is added for measurements recorded on Strip charts; and -P is added for measurements recorded on either the utility or alarm printers. 


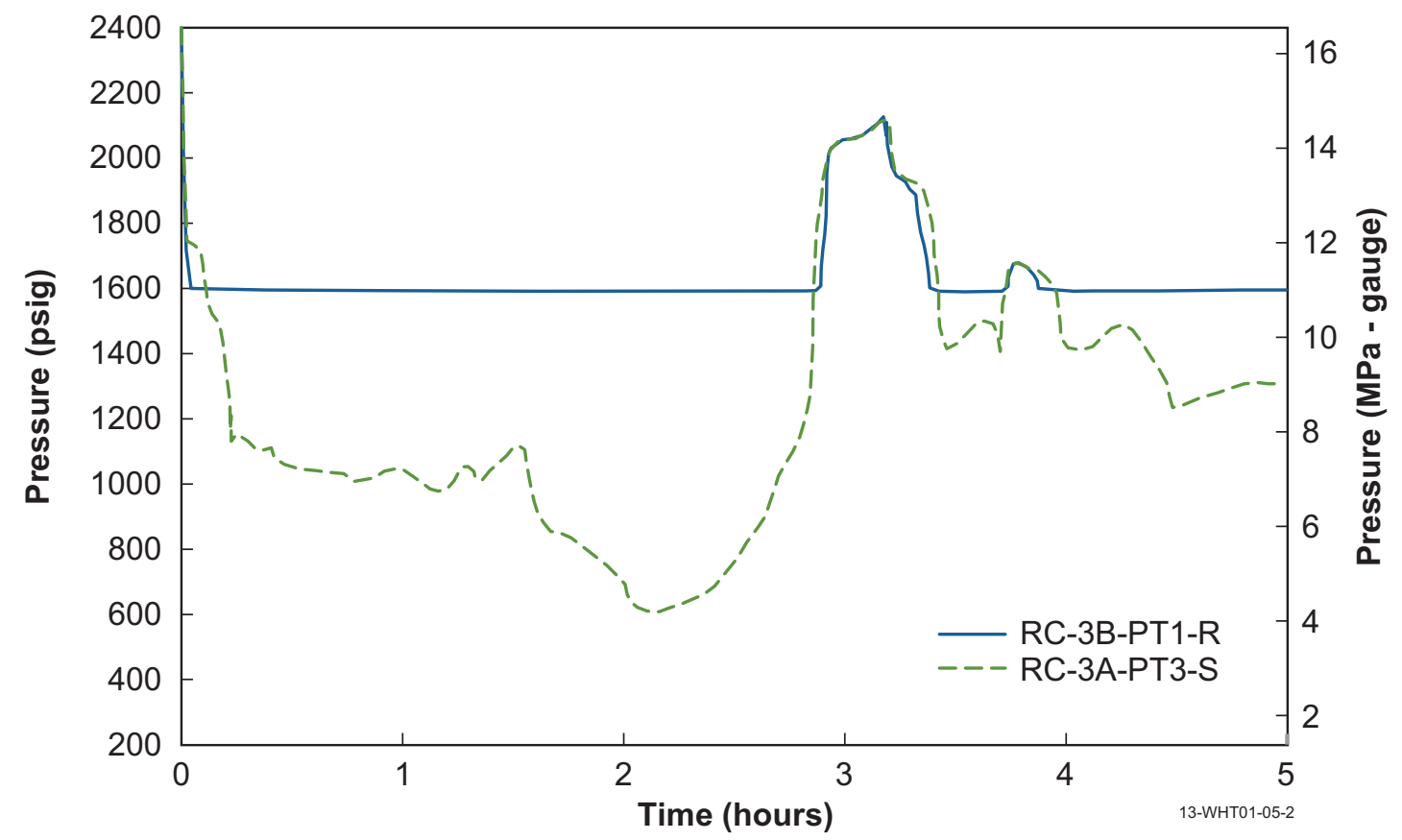

Figure 4-4. Comparison of A-loop wide range pressure recorded on the strip chart and the B-loop narrow range pressure on the reactimeter.

This observation is supported by the increasing output from the source range neutron detectors. During the period in which a two-phase mixture was flowing through the system, the system pressure had to have been at saturation pressure. The saturation pressure was obtained from the steam tables using the measured hot leg temperature which was recorded on the reactimeter (RC-4A-TE1-R).

The aforementioned data sources were used to create a best estimate composite of the primary system pressure. This composite pressure is found in Figure 2-3.

\subsubsection{Status}

As noted within this section, the time-dependent primary system pressure was estimated by considering several data sources (reactimeter, printer, and strip chart). Uncertainties for the composite pressure were estimated by considering the uncertainties associated with each source. The composite system pressure was assigned a classification of "Qualified" with a maximum calculated uncertainty of $+2.8 \mathrm{kPa}$-gauge by the DIRC during the July 14, 1986 meeting.

\subsection{In-Vessel Flux}

In-vessel flux measurements were made using SPNDs in two types of instrumentation assemblies - the In-Core Instrumentation System, which is described in Appendix A.1, and the movable in-core detector system (MIDS), which is described in Appendix A.2. 
Under normal operating conditions, the nuclear power distribution is monitored at 364 locations in the core using SPNDs that are part of the in-core instrumentation system. There are 52 of these assemblies, with each assembly consisting of seven SPNDs, one background sensor, and one thermocouple.

The TMI-2 MIDS contained seven SPND strings, one reference detector, and one Type K core exit thermocouple. The MIDS was used to identify fuel densification and calibrate the in-core SPNDs. Hence, it is capable of insertion into any instrumented assembly in the core. However, the repositioning process required entering the containment; hence, the MIDS location was limited to position N8 during the TMI-2 accident.

\subsubsection{Description}

An individual SPND (see Figure 4-5) consists of: a rhodium emitter, $0.46 \mathrm{~mm}$ diameter by $0.12 \mathrm{~m}$ long; alumina insulation (99.75\% pure); a Zircaloy-2 center conductor lead wire, $0.28 \mathrm{~mm}$ in diameter by $39.0 \mathrm{~m}$ long; and an Inconel 600 oversheath (1.6 mm OD / $1.1 \mathrm{~mm}$ ID and $39.0 \mathrm{~m} \mathrm{long}$ ). The background sensor is identical to an SPND except it contains no emitter. The emitter has a reasonably high thermal-neutron-activation cross section; upon activation by neutrons, the emitter becomes a high energy beta emitter. Under normal operating conditions and temperatures $\left(<371^{\circ} \mathrm{C}\right)$, the current produced is proportional to the net beta escape from the emitter. Hence, under equilibrium beta emission, the current measured to ground is proportional to neutron flux.

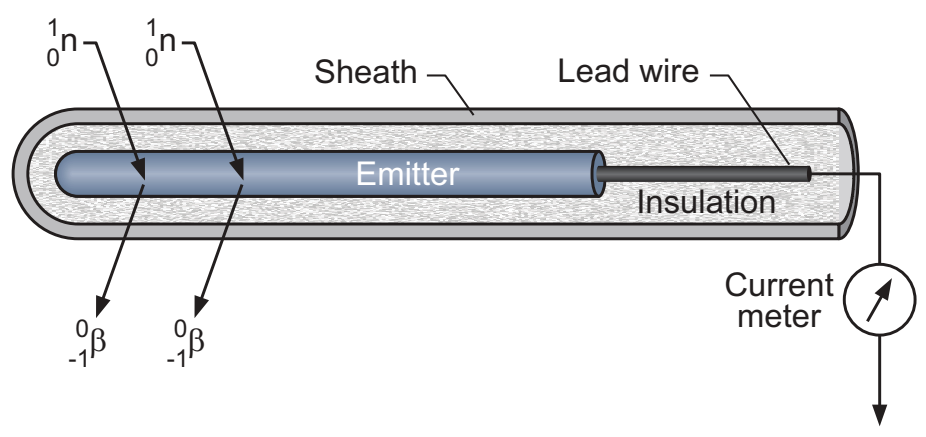

Figure 4-5. SPND components and operating principle.

The SPND is designed to be a neutron detector; however, it also has an electrical output that is a function of temperature. At the normal operating temperature of approximately $316^{\circ} \mathrm{C}$, this temperature-induced output can be assumed as negligible compared to the neutron-induced output. During the TMI-2 accident, neutron flux levels decreased after the initial few minutes. As the water level lowered, the SPND environment reached the 649 to $982{ }^{\circ} \mathrm{C}$ region. The resulting output can then only be considered a function of temperature. Post accident laboratory investigations concluded that it was possible to infer temperature, water level, and flux levels from SPND signals. ${ }^{12}$ However, as discussed in this section, the extreme conditions to which the SPNDs were exposed and data acquisition difficulties reduced the usefulness of SPND data for quantitative measuring conditions during the TMI-2 event. 


\subsubsection{Data}

After the event, researchers found the following sources of SPND data:

- Plant computer output during the first day of the accident (March 28, 1979)

- $\quad$ Plant computer output for March 30, 1979

- Two backup multipoint recorders that monitored 36 selected SPNDs

- SPND and background detector resistance measurements by Warren ${ }^{60}$ in April 1979

- SPND, background detector, and thermocouple resistance measurements by Yancey ${ }^{57}$ in 1981

Computational limitations reduced the availability of data, as described below.

\section{Plant Computer Data Sources}

The principal function of the plant computer system at TMI-2 was to monitor plant parameters (approximately 3000) and to display them with any related calculations. ${ }^{4}$ The only permanent computer record of the in-core instrumentation was "hard-copy" from two plant printers, the utility (which only writes data if requested) and the alarm (which writes data when an unusual occurrence happens such as a parameter exceeding an alarm setpoint or changing state). For the SPNDs, this computer only printed a status report when the signal changed from on-scale to off-scale or when it returned to on-scale. The normal full power output current from the SPNDs was approximately 1000 nanoamperes. Signal setpoint limits for being off-scale were currents less than -20 nA and greater than $2000 \mathrm{nA}$ (and -20 and +200 nanoamperes for the background detector). The computer would interrogate each of the 364 SPNDs once each minute, and only print an alarm if the instrument changed status. The magnitude and polarity of the signal were printed when the SPND alarmed on-scale, and a series of four question marks printed when it alarmed off-scale.

When the reactor tripped at TMI-2 (at about 4 a.m. on March 28, 1979), all SPND responses dropped to a few nanoamps, as expected when they are operating as neutron detectors under normal temperature conditions. For the first 74 minutes into the accident, there were no alarms from the in-core instruments except for one thermocouple reading which was thought to be spurious. After that time, the data queue waiting to be printed on the alarm hard copy unit became very large. As discussed in Section 3.2.3, at 167 minutes, the operators erased the memory buffer and deleted all alarm data between 74 and 167 minutes. This time period unfortunately corresponded to the time when the initial core heatup and uncovery occurred.

At 226 minutes into the accident, the Nuclear Science Advisory Committee (NSAC) report indicated that 51 SPNDs went offscale (see Figure 4-6). At this time, all or nearly all of the seven levels of SPNDs in locations G9, F7, F8, E7, G6, G5, H5, and M9 went off scale. This behavior suggests that something was happening along the full length of the fuel element. Since the SPNDs were individually sheathed and sealed, it is unlikely that a fault would propagate from one to another. Thus, the effect must have been external to the instrument tube. Subsequent furnace evaluations suggest that such behavior is consistent with a rapid temperature increase.

On March 30, 1979, the computer program was modified so that the sign and magnitude of each of the generated signals from the 364 SPNDs and 52 background detectors could be recorded. Results were: 


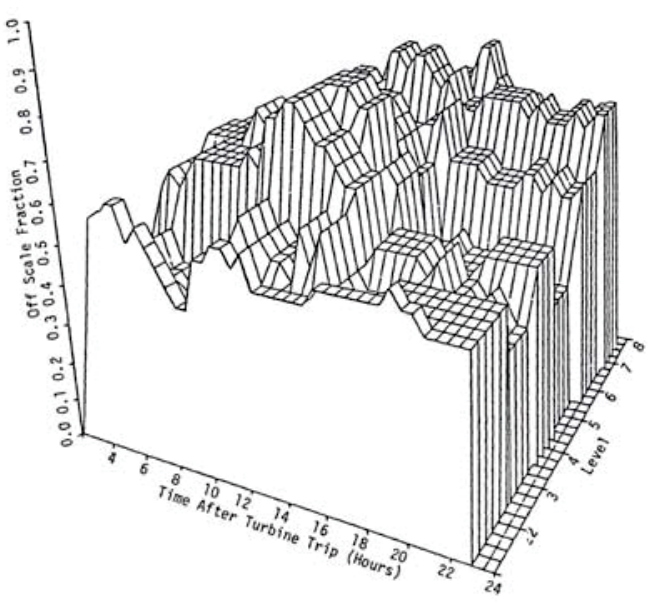

View 1

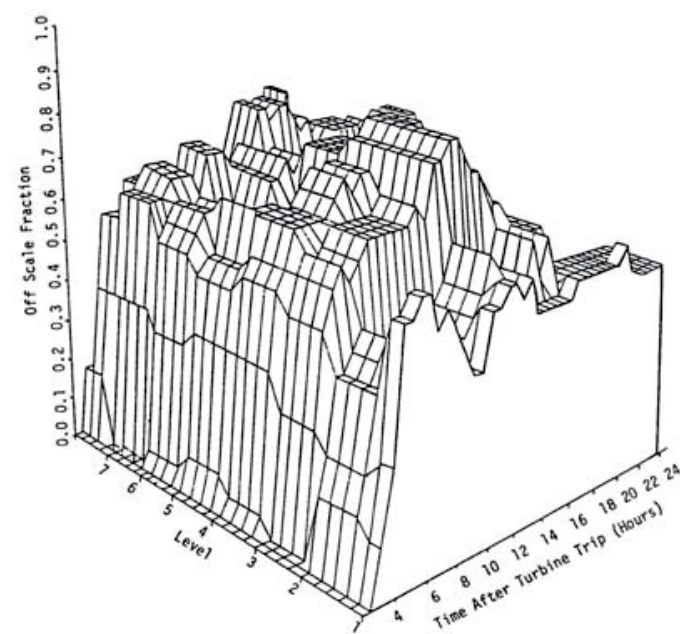

View 2

Figure 4-6. SPND Activity - Core Center.

- 305 SPNDs (83.8\%) were generating negative currents in the range of 0 to $-2000 \mathrm{nA}$

- 30 SPNDs $(8.2 \%)$ were not producing any current

- 29 SPNDs (8\%) were producing positive signals in the range of 0 to $2000 \mathrm{nA}$

\section{Backup Multipoint Recorders}

Thirty-six SPNDs (at the 2, 4, and 6 levels; see Figure A-3 in Appendix A.1) were monitored and recorded on two backup multipoint recorders (18 channels on each recorder). A data point for each channel was printed every 2.5 minutes with a channel identification number. Later, it was discovered that Backup Recorder 2 data could not be used due to inadequate pen ink. The data on Backup Recorder 1 had to be decoded and tabulated before it could be placed in a database (so it was not readily accessible during the accident). The data indicate that just prior to the accident, with the reactor at $97 \%$ power, the SPND signals ranged from +500 to $+850 \mathrm{nA}$. When the reactor scrammed during the initial stages of the accident, the SPNDs responded with their signals dropping to a few nanoamperes within 5 minutes. The first anomalous signals were produced 135 minutes into the accident when at least two SPND channels became negative (e.g., currents less than -20 nA). However, at 155 minutes, most of the SPND signal channels became positive, some in excess of $1000 \mathrm{nA}$. Figure 4-7 illustrates this behavior by providing data from the H-8 SPNDs at the 2, 4, and 6 levels.

\section{Post-accident examinations}

Both Warren ${ }^{60}$ and Yancey ${ }^{57}$ measured the resistance of the in-core instruments as a method to diagnose the survivability of the SPNDs. A high resistance (e.g., $\mathrm{R}>10^{8} \mathrm{ohms}$ ) indicated an intact or operating SPND, whereas a low resistance (e.g., $\mathrm{R}<10^{5} \mathrm{ohms}$ ) indicated a failed SPND. Evaluations in 1982 by Yancey indicated that all of the thermocouples and the majority of the SPNDs (all but 22) were damaged to some extent. ${ }^{57}$ Evaluations indicate that major damage occurred to the entire core above the first and second SPND level locations and throughout the central area of the core. This estimate of damage was based on the location of operational SPNDs as determined by the 1982 in situ testing. Later video examinations and probing confirmed that such extensive core damage had occurred. 


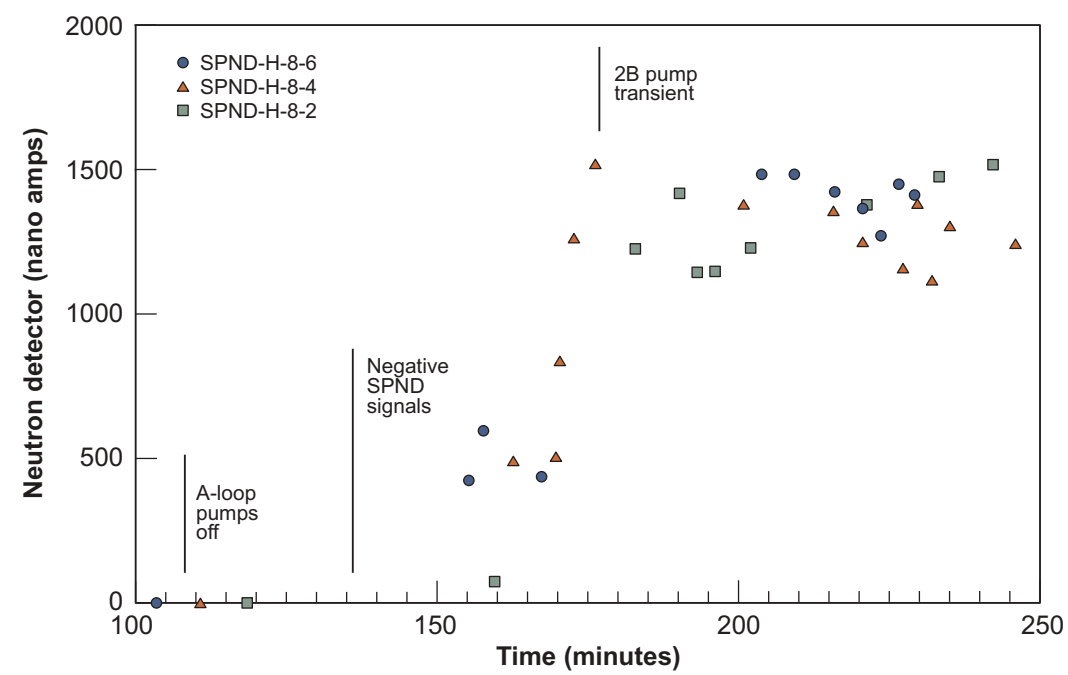

Figure 4-7. Signals from the H-8 SPNDs at the 24 , and 6 levels.

\subsubsection{Status}

SPND damage ranged from none (for those that were still considered operational) to severe (for the SPNDs that failed by shorting). SPNDs indicating a reduced insulation resistance, but not shorted, could have experienced a more moderate form of damage consisting of moisture ingress due to sheath failure. ${ }^{61}$ Sheath failure could have resulted from temperatures above $1350{ }^{\circ} \mathrm{C}$ or at a lower temperature of approximately $900{ }^{\circ} \mathrm{C}$ during a rapid quench. The shorting which occurred could also indicate that temperatures may have reached the melting point of SPND materials, such as Inconel $600\left(1390\right.$ to $\left.1425^{\circ} \mathrm{C}\right)$ and Zircaloy $\left(\sim 1845^{\circ} \mathrm{C}\right)$, or that there was a shift in some of the mechanical structure resulting a pinch point/ shorting condition.

Although it is known that SPND response can be correlated to temperature, initial investigations ${ }^{62}$ found that there was too much uncertainty with respect to the heat transfer between the fuels and SPNDs and in the integrity of the SPNDs to obtain quantitative core temperature data during the accident. In Reference 51, it was observed that SPND alarms and thermocouples with reformed 'virtual' junctions appear to be collocated. Hence, Reference 51 concluded that mechanical deformation caused contact between various materials within the in-core instrument assembly. References 12 and 54 describe additional evaluations completed to infer information about the reactor water level and temperatures from SPND data, including separate effects tests and data from the integral Loss of Fluid Test FP-2 (LOFT LP-FP-2) an integral test that simulated a LOCA with delayed emergency core cooling.

As discussed in References 12 and 54, tests considering the effects of temperature and gamma exposure were conducted by Warren, ${ }^{60}$ Baldwin and Warren, ${ }^{63}$ Warren and Shah, ${ }^{64}$ and by Rock and Rantanen. ${ }^{65}$ To try to reproduce the negative and positive signals observed in the TMI-2 SPNDs, the sensors were heated up to the melting temperature for their Inconel sheaths. Results indicate that prototypic SPNDs, built to TMI-2 SPND specifications, will generate small positive signals (less than 100 nanoamperes) when exposed to temperatures up to $537^{\circ} \mathrm{C}$. At higher temperatures, the generated currents change to negative polarity; and the magnitude increases. The temperature at which this polarity reversal occurred appeared to be related to the length of the SPND emitter being heated; the shorter the length, the higher the temperature at which reversal occurred. However, tests with temperature and gamma fields by Baldwin 
and Warren, ${ }^{63}$ did not see the high readings observed in SPNDs at the TMI-2 reactor. In furnace tests with steam environments, Cannon ${ }^{66}$ observed that SPNDs generated larger positive output currents at temperatures greater than approximately $900{ }^{\circ} \mathrm{C}$ (with output currents increasing with temperature and the length of the rhodium emitter heated). Steam appeared to responsible for the large positive output signals. When steam was removed, the output signal dropped to below $50 \mathrm{nA}$. In Reference 12, Taylor notes that he repeated the tests performed by Warren and by Collins and observed results similar to the results reported in References 60 and 66.

Signals from two rhodium SPNDs (one positioned at 11 inches above the core and one positioned at 27 inches above the top of the core) were monitored in LOFT LP-FP-2. Similar to the events in the TMI-2 core, the simulated LOCA in this integral LOFT test caused the center fuel bundle to overheat, oxidize, melt, and relocate. Both of the SPNDs started producing negative polarity signals at $1140 \mathrm{~s}$, when the temperature near the top SPND was near $850 \mathrm{~K}$. Later, when the temperature of the 27 inch SPND was near $1350 \mathrm{~K}$, it started producing large positive signals and saturated the signal conditioning system. The temperature near the 11 inch SPND did not exceed $1250 \mathrm{~K}$ during the test, and it never changed polarity. Reference 12 postulates that the negative signals could have been due to oxidation of the center Zircaloy-2 lead wire. This reference further asserts that the high temperatures experienced by the 27 inch SPND caused it to generate large positive signals because junctions had formed between the Zircaloy-2 lead wire and the Inconel 600 sheath, possibly due to degradation of the alumina insulation from moisture in the SPND or due to metallic bonding at high temperatures.

In summary, laboratory and large integral system testing suggests that the observed SPND signals can be used to infer the presence of steam in conjunction with surrounding temperatures in excess of $850 \mathrm{~K}$ and $1350 \mathrm{~K}$. Other general conclusions inferred from SPND signals include:

- Sensor response correlated with the sequence of events that occurred during the course of the accident; i.e., signals decreased sharply at times when there were safety injections and increased during times when other instrumentation indicated significant core voiding (see Section 4.5).

- Sensor response corresponded to transients occurring over the course of the accident, the most dramatic of which occurred at approximately 3.50 hours (7:30 a.m. clock time). At this time, the signal response increased about 40 percent, suggesting that significant core voiding and uncovering occurred at this time. The transient was characterized by a rapid increase in off-scale activity for detectors located around the core edge followed by a rapid increase for those located near the core center. The off-scale trend at the core edge is attributed to an upswing in temperature driven by metal-water reaction of cladding in this region. The center of the core already had experienced significant oxidation However, off-scale SPND signals at the core center is attributed to mechanical failure of these sensors in conjunction with fuel dislocation and coolant path blockage.

- The percentage of failed SPNDs after forced cooling was re-established was used as a measure of local core damage. Using this methodology, it was found that core damage was greatest near the core top and toward the core center.

\subsection{Ex-Vessel Flux}

TMI-2 ex-vessel nuclear instrumentation consisted of three ranges of detectors (source, intermediate, and power) to monitor neutron flux levels overlapping twelve decades of power change. The SRM system is used to monitor reactor neutron flux from startup to a very low value of reactor power, while the inter- 
mediate range monitors (IRMs) overlap with the SRMs and continue to about $100 \%$ reactor power. The power range monitors (PRMs) operate up to $125 \%$ power. The source range detectors are the most sensitive of these instruments and were found to yield the most useful information. SRM response data are important since they provided insights related to the core and downcomer liquid levels and the configuration of the core.

\subsubsection{Description}

As shown in Figure 4-8, the low-level startup neutron flux was measured using two SRMs (N1-1 and N1-2) located azimuthally 180 degrees apart. The SRMs were a cluster of four boron trifluoride $\left(\mathrm{BF}_{3}\right)$-filled proportional counters connected to operate as a single unit. The detector had an overall length of about $75 \mathrm{~cm}$ long with a sensitive length of $66 \mathrm{~cm}$. It was mounted between the reactor vessel and the biological shield at the reactor mid-plane, as shown in Figure A-3. ${ }^{67}$ In the IRM measurement channel, detectors NI-3 and NI-4 were electronically compensated ion chambers about $75 \mathrm{~cm}$ long and mounted at the midplane of the reactor similarly to the SRM detectors. Figure 4-8 also shows the location of the IRM detectors. A discriminator circuit effectively eliminated any pulses caused by gamma radiation striking the neutron detectors.

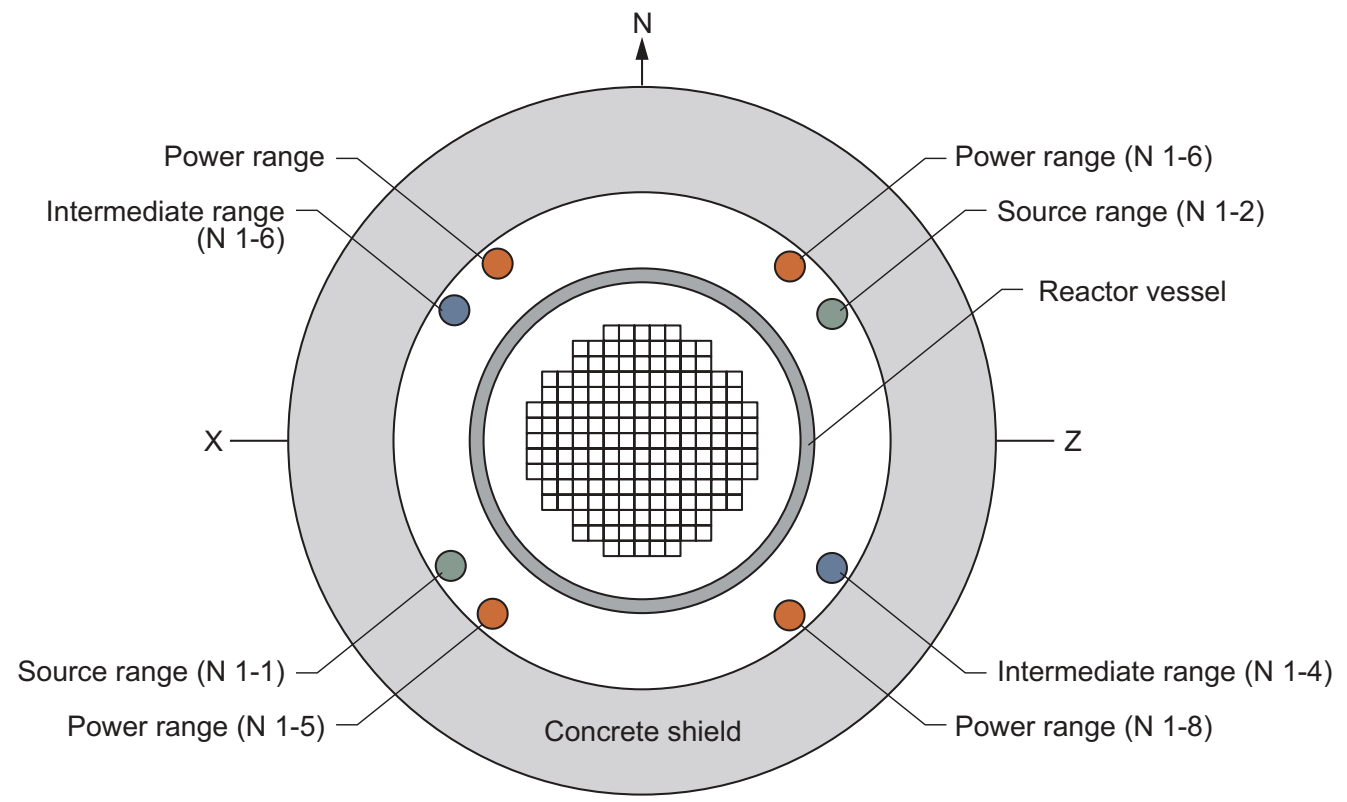

Figure 4-8. TMI-2 source, intermediate, and power range monitor configuration.

The SRM detector high voltage was interlocked with the reactor control rod system so that the high voltage was disconnected before the neutron flux exceeded the operating specifications for the detector $\left(10^{6} \mathrm{n} / \mathrm{cm}^{2}-\mathrm{s}\right)$. This resulted in a greatly increased lifetime for the $\mathrm{BF}_{3}$ detectors, but meant that the SRM detectors were not active at the time of the reactor scram. The SRMs did not begin to operate until some minutes after scram at the beginning of the TMI accident. The SRM stripchart response was at a low value at the beginning of the accident (with no high voltage on the detector), it raised quickly at nine minutes into the accident (when high voltage was restored) and then began to fall off at a normal reactor decay rate. 
When interpreting SRM signals during initial stages of the TMI-2 accident, it is important to consider competing effects associated with the presence of steam voids in the core. Several important effects identified in Reference 56 include: (1) voids displace boron, contributing to greater numbers of fissions in local regions; (2) voids decrease water density, reducing the moderating effect necessary for neutron-fuel interactions; and (3) voids enable more neutrons to leak from the core, escaping the fission process. Calculations reported in Reference 56 indicate that the leakage effect is the most important with respect to ex-core SRM detector count rates. It is also important to recognize that voiding different regions of the core will have a varying effect on ex-core detector readings. Voiding in the center regions of the core may be shielded from the detector by peripheral fuel assemblies and fluid in the downcomer annulus. Conversely, voiding the downcomer significantly affected the detector because neutrons were able to travel largely unimpeded to the detector. In later stages of the accident, evaluations indicated that the SRM response was associated with the heatup and relocation of core materials.

\subsubsection{Data}

Both SRM NI-1 and IRM NI-4 data were on the stripchart recorder, so data were digitized for inclusion in the TMI-2 database. ${ }^{67}$ In addition, data from the two SRMs were scanned and stored at hourly intervals on the plant computer. Figure 4-9 compares the NI-1 data stored on the computer, which was the only known source of data for NI-2, with data scanned from the stripchart for NI-1. The ordinate is the log of the counts per second. The amplitude as recorded on the plant computer appeared to be the most accurate, therefore, the amplitudes of the digitized data were adjusted to the computer values. Times for the digitized and computer printout data were adjusted to a zero time that corresponded to the time of turbine trip. Figure 4-10 compares plots of the IRM data from NI-4 and NI-3 during the first 1500 minutes after reactor trip. The ordinate is the log of the detector current in amperes. For most of the time duration plotted, the measured power levels are at the lower end of the IRM operating range.

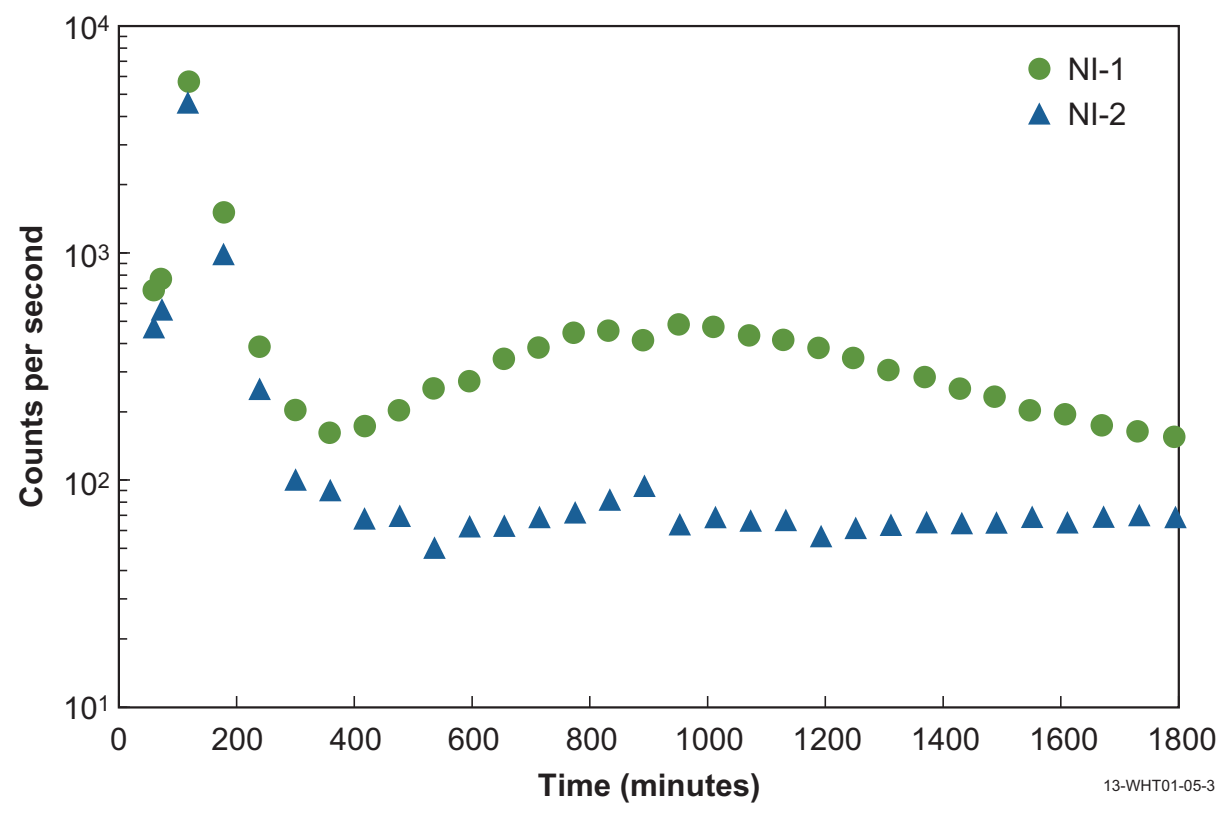

Figure 4-9. SRM data. 


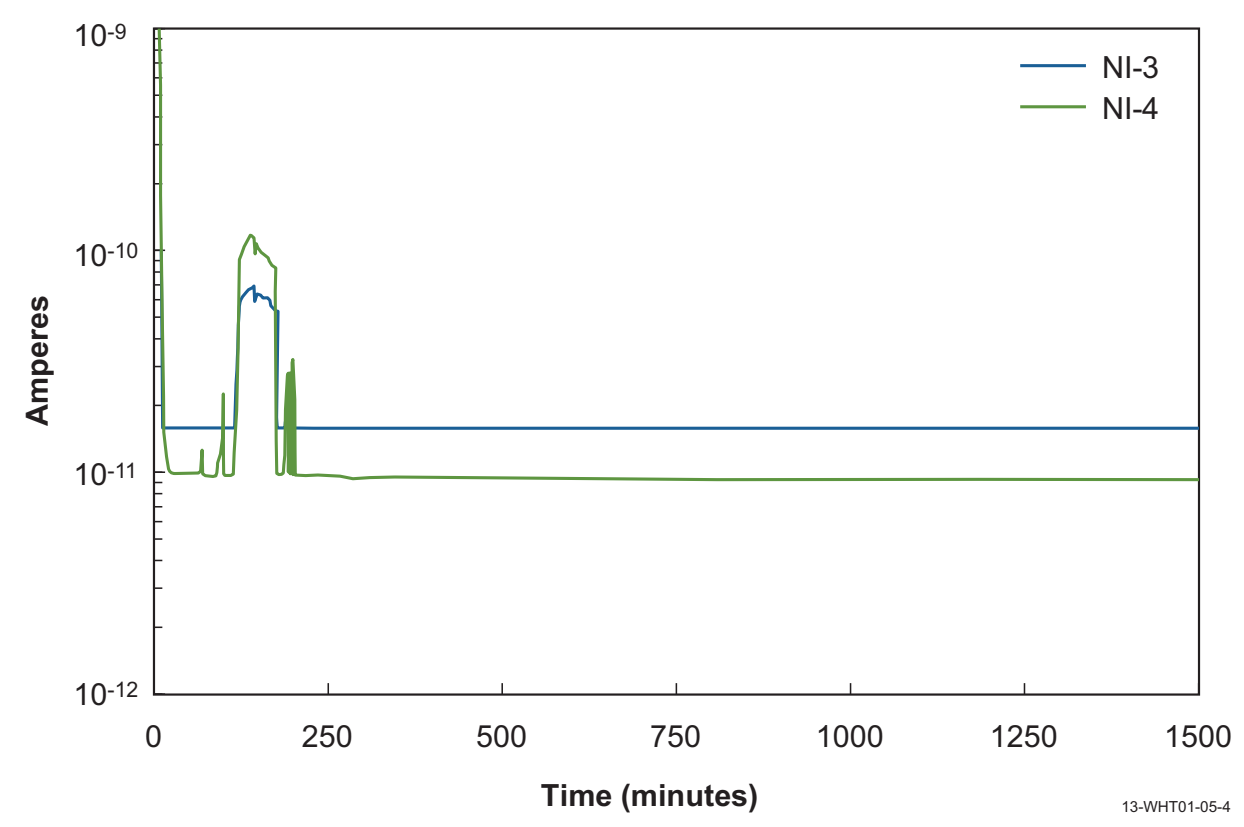

Figure 4-10. IRM data.

\subsubsection{Status}

Results ${ }^{67}$ from an analysis of the data indicate that the peak uncertainty in the SRM data was about 7\% when read from the computer and 9.3\% from the stripchart. Analysis of the IRM measurement channel data indicate that the uncertainties were large when these detectors were operating at the lower end of their operating range. Hence, Reference 67 recommends that IRM data be classified as "Trend" data (see Section 3.4) and only be used to infer insights about the general shape of the neutron flux curve and the timing of plant events.

Reference 54 reports results gained by performing a number of neutronics calculations for postulated conditions and comparing calculation results with the available data. One-dimensional ANISN ${ }^{68}$ neutronics calculations revealed that the increase in SRM response before the RCS coolant pumps stopped could be explained by homogeneous core voiding (e.g., the core is estimated to be $35 \%$ voided and peaked at $50 \%$ voiding when the pumps stopped at approximately 100 minutes after turbine trip). Figure 4-11 compares the measured SRM N 1-2 output on March 7, 1979 and expected response (in blue) and calculated accident response (in green).

Two-dimensional calculations ${ }^{69}$ evaluated the effects of phenomena, such as decreased core coolant levels, coolant mixing assumptions, and boron concentration. Results indicate that the onset of core uncovery occurred between 114 and 120 minutes after turbine trip (see Figure 4-12). Calculations suggest that the relocation of fuel containing fission products could lead to the observed abrupt upward shift in the SRM response at 227 minutes (3.8 hours), associated increases in primary system temperatures and pressures, and increased core-wide SPND activity. Analyses also indicated that the gradual rise in SRM response at six hours was consistent with the release of I-135 (See Figure 4-13). However, these earlier analyses assumed an intact core geometry. Reference 70 suggested that a partial absence of control material in the core region would cause neutron multiplication to increase and water level to lower, leading to an increase in SRM response. Sensitivity study results presented in Reference 70 indicate that nearly $80 \%$ 


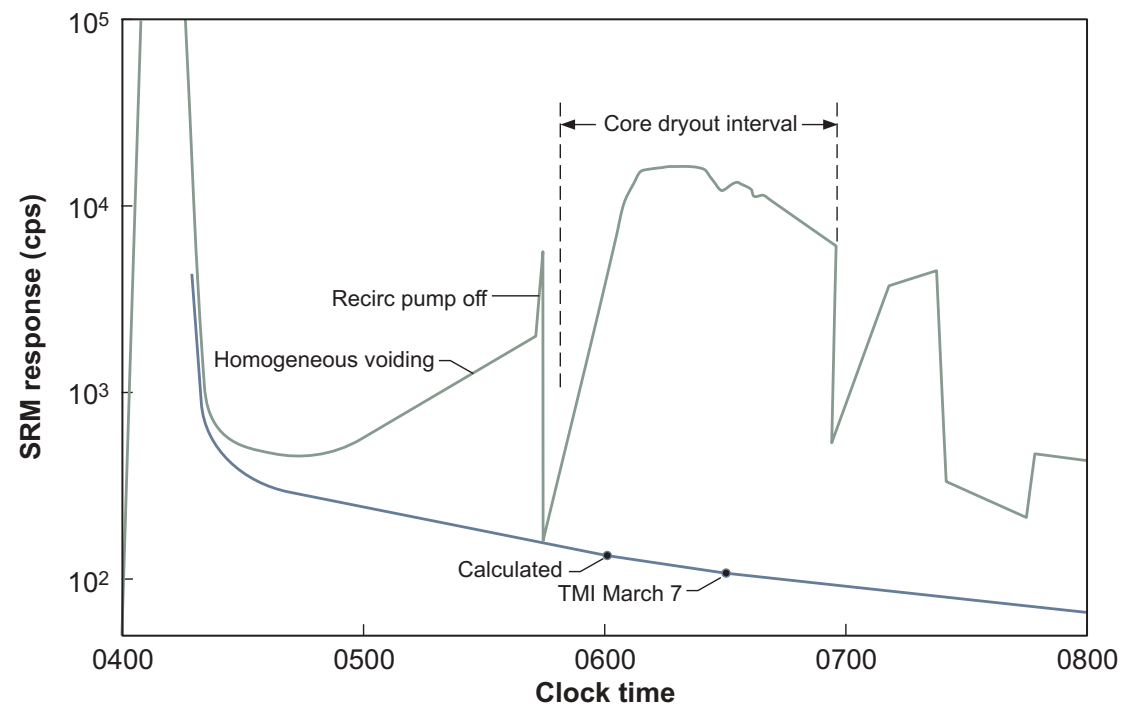

Figure 4-11. Observed response (in green), and "normal" following reactor shutdown that occurred at TMI-2 on March 7, 1979 and calculated (in blue). ${ }^{54}$

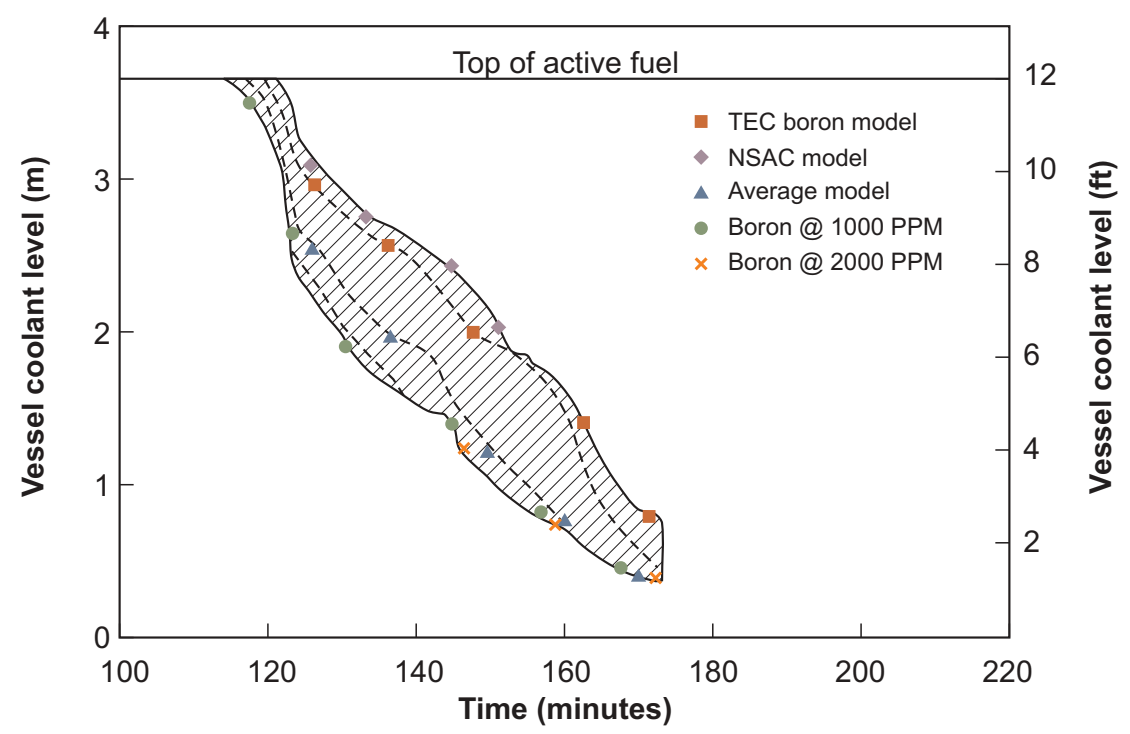

Figure 4-12. Core water level estimate sensitivity to boron concentration model assumptions. ${ }^{54}$

of the control rod material would need to relocate in order to predict SRM responses consistent with the observed data. Reference 70 evaluations also demonstrated that core material relocation assumptions and water level predictions are closely related.

Events attributed to changes in the SRM response are shown in the annotated plot in Figure 4-14. For the first 20 minutes (A), SRM behavior was consistent with a normal post-trip decay rate of about one-third decade per minute. Between 20 to 30 minutes (B), the SRM count should be decreasing through the 600 to $700 \mathrm{cps}$ range. However, the curve leveled out at around $5000 \mathrm{cps}$ due to voiding (steam bubbles) in the downcomer and core regions. This hypothesis was consistent with the fact that the pressure had reached saturation and there continued to be outflow through the open PORV. Void formation is also con- 


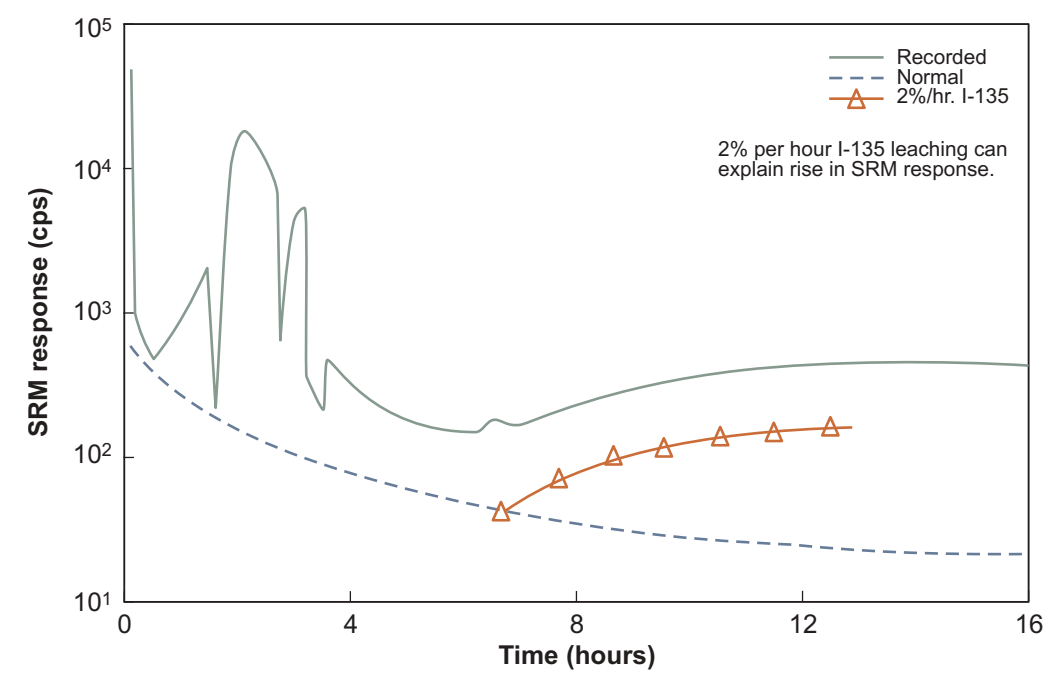

Figure 4-13. Recorded, "normal", and predicted with 2\%/hr I-135 leaching SRM response.

sistent with the observed drop in reactor coolant flow rate. Continued loss of coolant from the primary system (C) led to increased voiding and detector count rates. At approximately 73-74 minutes (D), the B reactor pumps were secured by the operators. At 100 minutes (E), the A pumps were secured. This caused a flow transient and voids separating to the upper regions of the RCS. The coolant filled lower regions of the RCS and caused an abrupt drop in the detector count rate (F). Continued release of fluid out of the PORV was not offset by available makeup flow, leading to an increase in count rate $(\mathrm{G})$. Competing effects (H) caused the count rate to increase at a slower rate until the count rate started to decrease (I). Startup of RCS 2B pump (J) filled the downcomer. At 200 minutes, high pressure injection flow initiated (L) filling the downcomer and causing the detector count rate to drop. Relocation of core materials (N) may have led to an increase in count rate.

In summary, the competing effects due to voiding and melt relocation make it difficult to interpret SRM response. Available information indicates that these ex-vessel detectors continued to function throughout the accident and could be used to not only measure flux levels but also provide qualitative information about the water level in the core and downcomer regions.

\subsection{Pressurizer Water Level}

During normal plant operation, the function of the pressurizer was to control the TMI-2 system pressure. This was accomplished by using heaters to increase the fluid temperature in the pressurizer (increasing system pressure) and by using the spray line to inject cold liquid into the pressurizer (reducing system temperature and pressure). The pressurizer was also equipped with a PORV to quickly relieve pressure under conditions such as a feedwater pump trip. This was the valve that stuck open in the TMI-2 accident. The level in the pressurizer was normally used as an indication of total RCS mass inventory, which is controlled through the use of the letdown and makeup systems. Unfortunately, once the primary system reached saturation conditions and steam voids existed in the reactor coolant system, the pressurizer level response was no longer coupled to the primary system in the normal manner understood by the operators. 


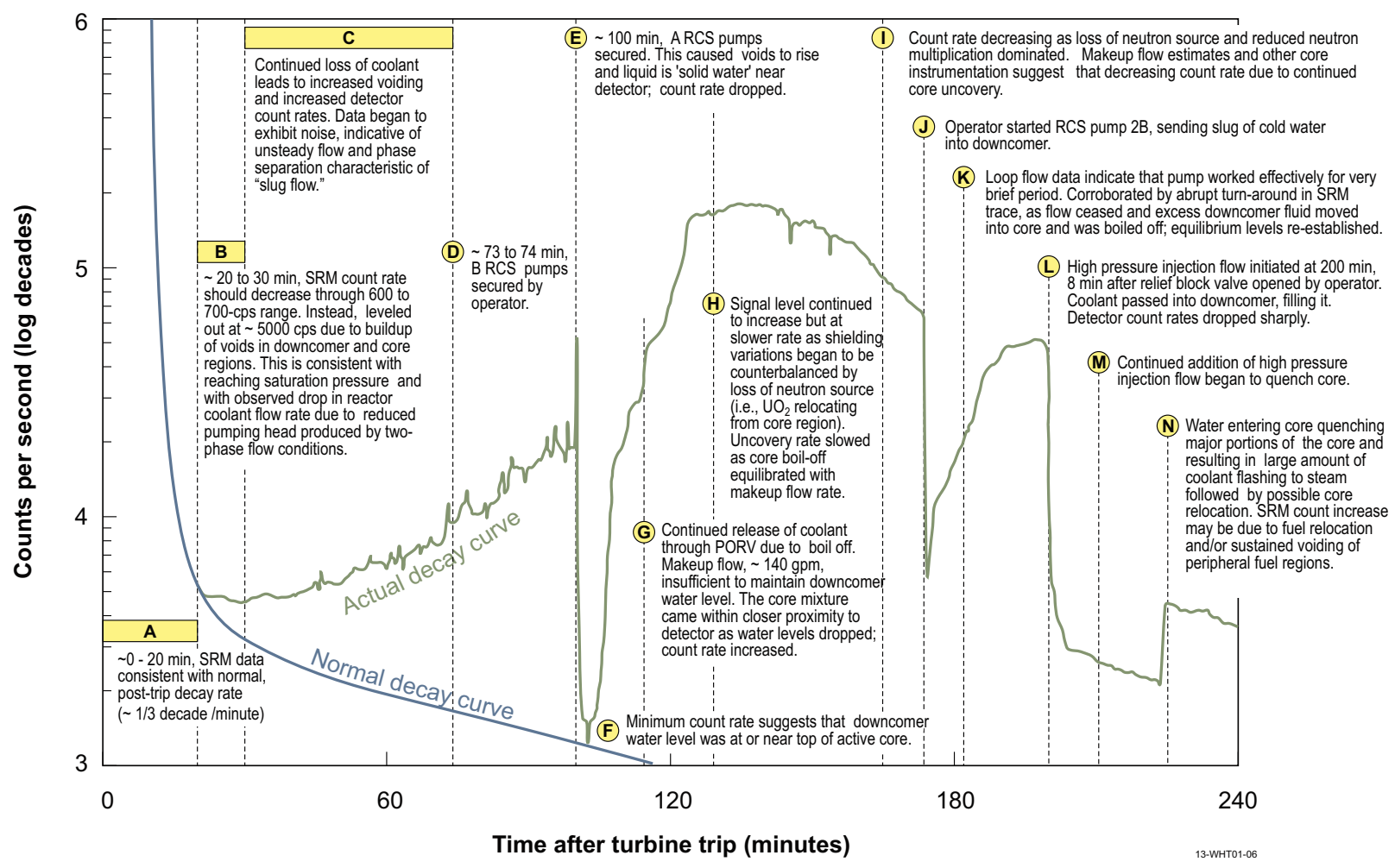

Figure 4-14. TMI-2 SRM response during the first 4 hours of the accident.

After the TMI-2 accident, there was considerable controversy about the reliability of the pressurizer level measurements during the accident. It was important to understand the accuracy of the pressurizer measurements because these measurements provided insights about the conditions in the RCS during the accident and insights about thermal hydraulic code input, such as the mass flow rate out of the PORV. Hence, each concern was carefully evaluated and resolved in References 71 and 72. As discussed in this section, available pressurizer levels data now appear consistent with current evaluations of RCS thermal-hydraulic conditions.

\subsubsection{System Description}

An isometric drawing showing the placement of the pressurizer in the TMI-2 RCS is shown in Figure 2-2, and a schematic of the pressurizer-level-measurement system is shown in Figure 4-15. The $25.4 \mathrm{~cm}$ schedule 140 pressurizer surge line enters the A-loop hot leg at an elevation of $98 \mathrm{~m}$. The surge line drops down from the hot-leg entrance to an elevation of $94.3 \mathrm{~m}$, travels approximately $10 \mathrm{~m}$ horizontally, then rises to the pressurizer entrance at an elevation of $95.1 \mathrm{~m}$ on the inside surface of the pressurizer.

The water level measurement was based upon the hydrostatic fluid head of the liquid column in the pressurizer. It was measured using the differential pressure between a liquid filled reference leg, external to the pressurizer, and the fluid in the pressurizer. The indicated coolant level corresponded to the collapsed water level rather than the level of the two-phase froth from flashing in the pressurizer. The un-insulated reference legs, which were external to the pressurizer, contained liquid at near containment temperature. As a result, condensate pots weren't installed because they weren't needed during normal operation. There were three independent water level measurements separated by 120 degrees around the pressurizer. The 
bottom tap for each was located at an elevation of $96.4 \mathrm{~m}$, and the top taps were at an elevation of $106.5 \mathrm{~m}$, for a total span of $1016 \mathrm{~cm}$. Between each of these sets of taps was a Bailey Instruments differential pressure transmitter, setup for a -10 to +10 volt output under an input head of 0 to $1016 \mathrm{~cm}$ of cold water at $20{ }^{\circ} \mathrm{C}$ ). These transmitters were mounted in instrument racks 424 (RC-1-LT1 and LT2) and 426 (RC-1-LT3), which were located outside of the secondary shield wall in the Reactor Building basement at an elevation to $86.9 \mathrm{~m}$. The transmitters were connected to the pressurizer taps using 1.2 -cm stainless steel tubing as sensing lines. The transmitters were zeroed when valved out of the system and vented to atmosphere, i.e., with no load applied to either side. As a result, when the transmitter was valved into the system with an empty pressurizer, the transmitter measured the 1016-cm hydrostatic head of the reference leg. When the pressurizer was full of cold water, the transmitter measures $0.0 \mathrm{~cm}$ differential pressure because the two hydrostatic heads were balanced.

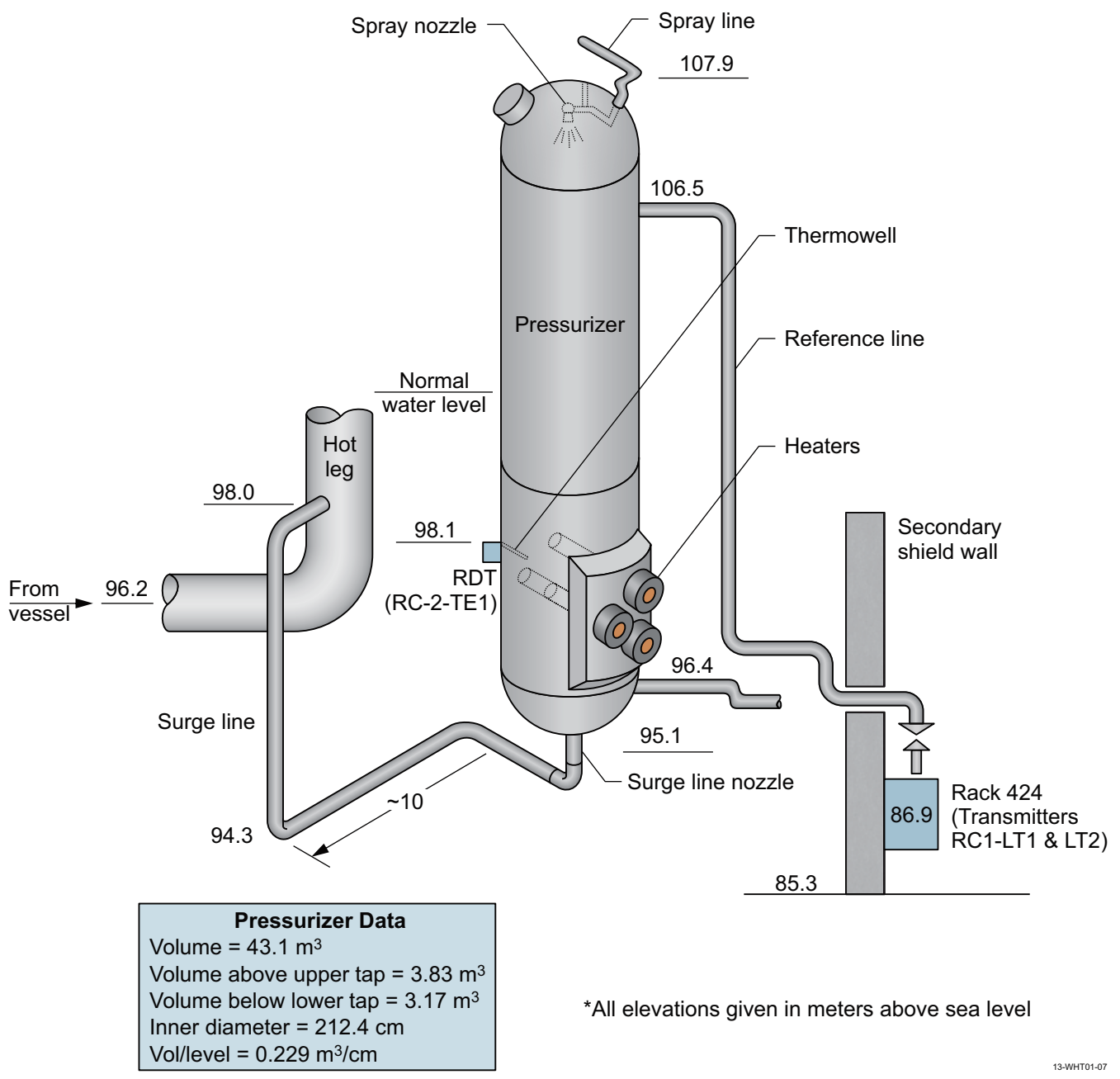

Figure 4-15. Pressurizer water level measurement system.

The output from one of the three water level transmitters and one of two pressurizer temperature sensors were used to calculate the temperature-compensated level in the pressurizer. The transmitter used for this calculation was selected from the Operators Control Panel, and the one used was not recorded. However, for normal operation, the RC-1-LT1 transmitter was used. The direct output from any of the transmitters was not recorded on a strip chart during the accident. A temperature compensation was performed to account for the difference in fluid densities between the reference leg and the pressurizer fluid. 


\subsubsection{Data}

Level in the pressurizer was normally maintained between 508 and $660 \mathrm{~cm}$. The level just prior to the feedwater pump trip at the initiation of the accident was $569 \mathrm{~cm}$. Figures 4-16, 4-17, and 4-18 compare the RCS pressure and pressurizer liquid level for the first 10, 100, and 300 minutes, respectively, of the accident. As documented in References 71 and 72, many of the observed changes in the pressurizer level can be correlated to phenomena in the RCS and can be supported by other information, such as other instrumentation data or documented operator actions. Selected examples are highlighted in this section.

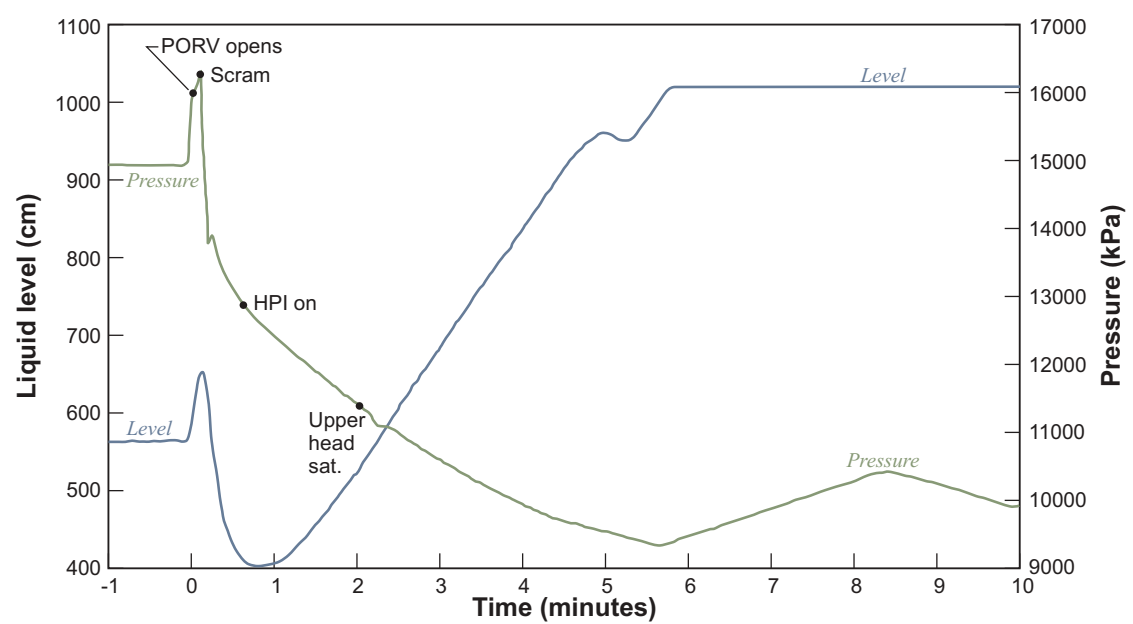

Figure 4-16. TMI-2 pressurizer liquid level and primary system pressure (0 to 10 minutes).

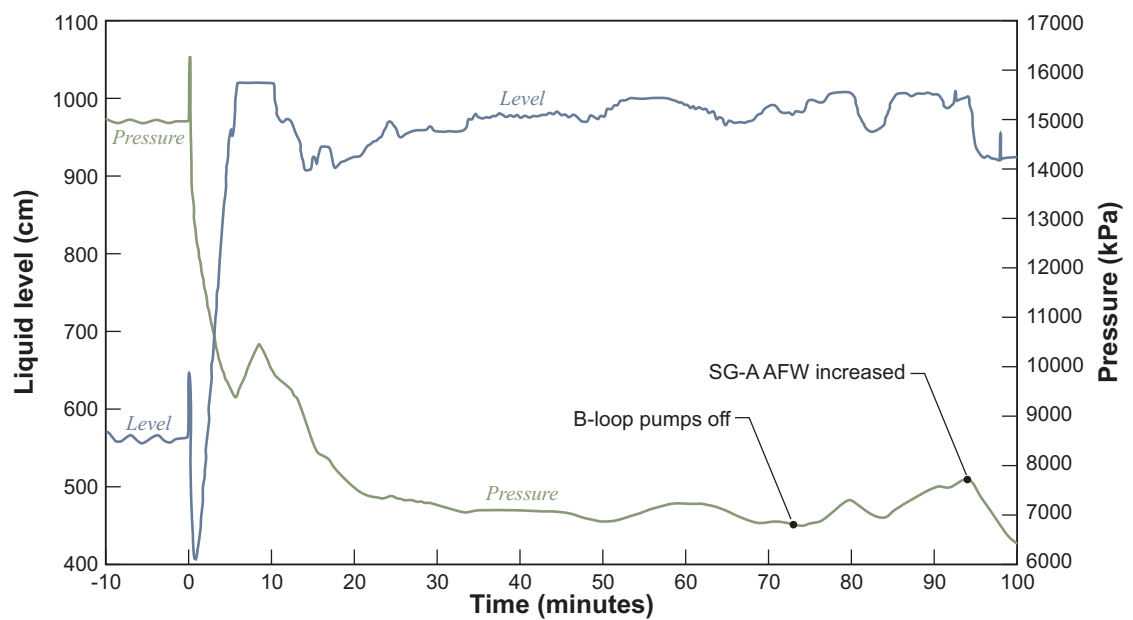

Figure 4-17. TMI-2 pressurizer liquid level and primary system pressure (0 to 100 minutes).

The pressurizer level, which was off-scale high $(1016 \mathrm{~cm})$ at 6 minutes, came back on scale by 11 minutes and remained on scale, though very high, through the rest of the time period shown in Figures 4-16 and 4-17. As the primary-to-secondary heat transfer degraded (in response to the termination of feedwater and the resulting decreasing secondary liquid level), more energy was released from the core than was removed from the RCS. The RCS coolant expanded, increasing RCS pressure. The pressurizer liquid level and RCS pressure continued to increase until the PORV opened at an RCS pressure of $15.7 \mathrm{MPa}$ (at $3 \mathrm{~s}$ ), and the reactor scrammed on a high-pressure trip at $16.3 \mathrm{MPa}$ (at $8 \mathrm{~s}$ ). After reactor scram, more energy 


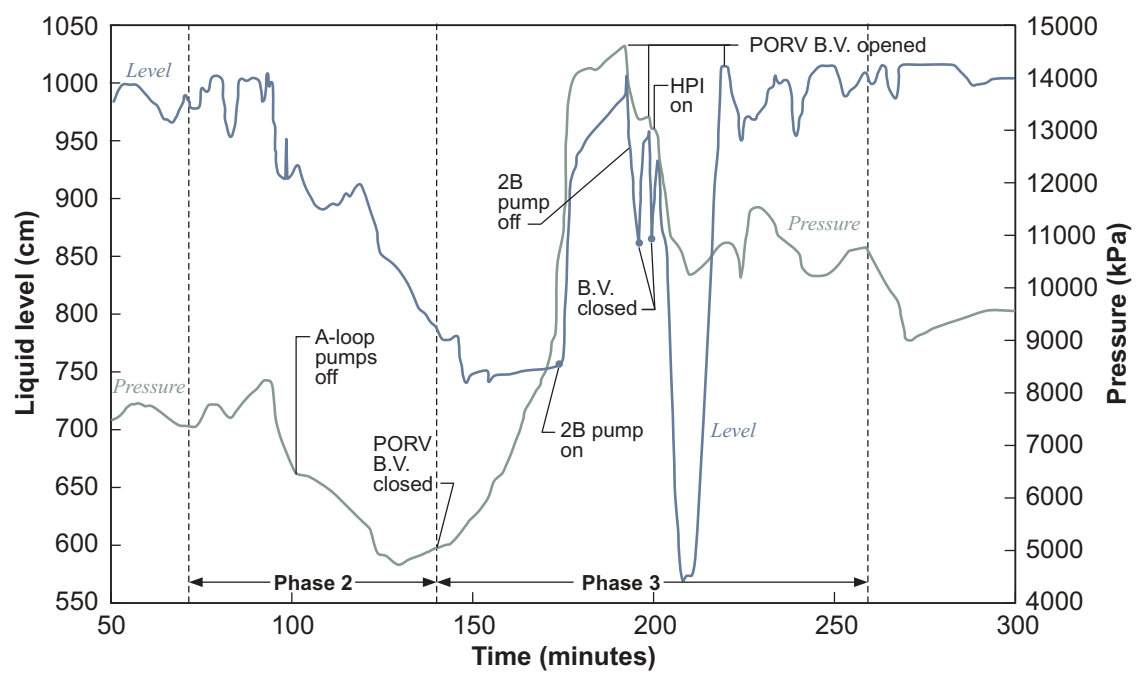

Figure 4-18. TMI-2 pressurizer liquid level and primary system pressure (50 to 300 minutes).

was removed from the RCS through the PORV and the steam generators than was being generated in the core, causing the RCS fluid to contract. This resulted in a rapid decrease in the RCS pressure and the pressurizer level, which should have caused the PORV to close on decreasing RCS pressure. However, as discussed in Section 2.2, the PORV failed to close. The operators failed to recognize that the PORV remained open, so they increased the makeup flow in an attempt to offset the pressurizer level decrease. The RCS pressure decrease continued, however, reaching the saturation pressure of the coolant in the upper plenum at approximately 2 minutes and saturation pressure for the rest of the RCS at 6 minutes. The reduction in primary heat source due to the reactor scram caused the temperature differential from hot to cold leg to decrease from an initial $20^{\circ} \mathrm{C}$ to near zero by 1.5 minutes. By that time, the secondary sides of the steam generators had dried out (see Section 4.7), and primary-to-secondary heat transfer ceased. Cessation of heat transfer from the RCS eventually caused the RCS pressure to increase. At approximately 5.7 minutes, the pressurizer filled and a much lower void fraction fluid started to flow out of the PORV. At 8 minutes, the operators opened the block valves, permitting auxiliary feedwater injection into the steam generator secondary sides. This restored primary-to-secondary heat transfer and started a gradual cooldown of the RCS.

After approximately the first 20 minutes, the RCS pressure remained nearly constant at $7 \mathrm{MPa}$ (see Figure 4-17). The operators, responding to the high pressurizer liquid level, decreased makeup flow and increased letdown flow. This resulted in an increasing RCS void fraction but did little to affect the pressurizer liquid level which was responding to the pressure differential caused by continued flow through the still-open PORV.

At approximately 73 minutes, the operators turned off the B-loop pumps because of low current and high vibration. During this phase, the pressurizer level decreased to a level of $790 \mathrm{~cm}$. The decreasing water level was a direct consequence of the continued RCS depressurization. At 90 minutes, the SRM output increased (see Section 4.5), indicating voiding in the core and/or downcomer, allowing more neutrons to escape the vessel. At 94 minutes, the operators increased auxiliary feedwater flow to the A-loop steam generator (SG), decreasing secondary side pressure, and increasing primary to secondary heat transfer. This led to a drop in RCS pressure and pressurizer water level (as saturate water flashed into steam). The pressurizer liquid level continued to decrease due to steam generation in the pressurizer by the heaters. 
A few minutes following shutdown of the A-loop pumps (at 100 minutes), output from the SRM increased indicating that the downcomer level was dropping below the top of the core. (The increase in the SRM output could also be interpreted as a result of the downcomer and core void fraction both increasing.) The A-loop hot-leg temperature started a rapid increase at about 118 minutes, indicating that core uncovery had started and that superheated steam was being generated in the core. At about 130 minutes, the RCS pressure began increasing, a further indication of increased vapor generation (both superheated steam and hydrogen). At 134 minutes, the output from the radiation monitors in the containment building began increasing, indicating that fission products were escaping the primary system through the PORV following failure of the fuel-rod cladding.

At 139 minutes, the operators closed the PORV block valve (see Figure 4-18). Between the time that core uncovery began (at about 125 minutes) until the PORV block valve was closed at 139 min, the pressurizer water level decreased at a rate of $4.6 \mathrm{~cm} / \mathrm{min}(1.8 \mathrm{in} . / \mathrm{min})$. Heater operation at a power of $1386 \mathrm{~kW}$ would account for a rate of $2.0 \mathrm{~cm} / \mathrm{min}(0.8 \mathrm{in} . / \mathrm{min})$. The remainder of the steam flow out the PORV would have been from steam generated in the core and entering the pressurizer through the surge line. Since part of the steam flowing out the PORV was generated in the pressurizer, the reduced steam velocities in the surge line probably allowed some liquid to drain out of the pressurizer.

At 174 min, the reactor coolant pump RC-P-2B was successfully restarted, and ran for 19 minutes. Within the first minute, the pressurizer heaters were de-energized and the pressurizer spray valve opened. Restart of the pump resulted in significant liquid flow from the $2 \mathrm{~B}$ cold leg being forced into the reactor vessel, reflooding undamaged portions of the core. Coincident with the pump restart was an approximate $28^{\circ} \mathrm{C}$ drop in the A-loop cold-leg temperature over the first few minutes of pump operation. This is perhaps an indication of reverse flow from the B-loop into the A-loop. An indication of additional liquid in the downcomer (and perhaps the core) was the abrupt drop in output from the SRM, as neutrons were absorbed by the liquid. As liquid penetrated the core, a large amount of steam and/or hydrogen was generated, resulting in a rise in the RCS pressure of 5.5 MPa-gauge in 2 minutes, with a further $1 \mathrm{MPa}$-gauge increase over the next 16 minutes. Coincident with this large pressure increase was a sharp rise in the pressurizer level from 762 to $914 \mathrm{~cm}$, with a further slow rise to $990 \mathrm{~cm}$.

At 200 minutes, the operators started the makeup pumps in the High Pressure Injection System (HPIS) mode at an injection rate of approximately $63 \mathrm{l} / \mathrm{s}$ for 15 minutes, which decreased the RCS pressure to about 10.3 MPa-gauge. Assuming that the pressurizer was still at saturation, this decrease in RCS pressure would result in the pressurizer liquid boiling, with the resulting steam formation displacing liquid in the pressurizer, causing a decrease in the liquid level. At 207 minutes, the pressurizer level decrease stopped; and at 210 minutes, the pressurizer level began increasing until it went off-scale high at 218 minutes. Coincident with this level increase was a repressurization of the RCS by about $0.6 \mathrm{MPa}$-gauge.

At 219 minutes, HPIS flow was reduced to about 6 1/s. At 220 minutes, the PORV block valve was opened. The pressurizer level returned on-scale, accompanied by a $0.7 \mathrm{MPa}$-gauge pressure drop. At 225 minutes, the A-loop cold-leg temperature jumped $70{ }^{\circ} \mathrm{C}$, suggesting the occurrence of reverse flow into the A-loop cold leg. This may have been caused by molten fuel falling into the liquid pool in the lower plenum, forcing the hot liquid in the downcomer back into the cold legs. At the same time, the RCS pressure rapidly increased by 1.4 MPa-gauge. This could have been due to steam generation from molten fuel.

At 262 minutes, makeup injection into the primary was increased. During this time, the PORV block valve was periodically opened and closed to decrease RCS pressure. The pressurizer level measurement was indicating a full, or nearly full, pressurizer. At 270 minutes, a pressurizer heater (group 10) tripped due 
to a ground fault. A ground fault is a condition in which the current flow in a circuit becomes unbalanced due to breakdown in the insulation, such as would occur if the heaters were shorting or the cabling was wet. As documented in Reference 73, cabling within the TMI-2 containment was subject to varying amounts of radiation, steam, humidity, reactor building spray, submergence, and a hydrogen burn event. Heater groups 4 and 5 tripped due to ground faults at 286 minutes, and heater group 3 tripped due to ground fault at 330 minutes. Reference 73 discounted arguments that such trips were due to an empty pressurizer (and hence that pressurizer water levels were erroneous) because the makeup system was injecting large amounts of water into the RCS and the pressurizer during the time of all but one of these trips and data indicating that the pressurizer line was subcooled.

Post accident measurements ${ }^{74}$ suggest several inoperable pressurizer circuits: one associated with a pressurizer heater element or its leads that had failed open and two associated with a pressurizer heater that had very low insulation resistance (e.g., less than $30 \mathrm{ohms}$ ). In addition, measurements indicated that a heater element circuit had high loop resistance consistent with a connection problem that could lead to it also being inoperable. However, the timing of any heater circuit degradation is not known.

\subsubsection{Status}

Several issues, such as dissolved hydrogen effects, reference leg boiloff or damage due to water hammer, and transmitter damage due to PORV exhaust temperatures, were identified that could have led to inaccurate measurements of the pressurizer water level during the TMI-2 accident. In References 71 and 72 , each of these postulated issues were evaluated in detail and discounted. In addition, any anomalies associated with ground fault trips of the pressurizer heaters were resolved. Additional confidence in the accuracy of the water level indicators was gained from the fact that all three transmitter readings were consistent on both occasions that they were checked by the operators (at 43 and 433 minutes after feedwater pump trip). In addition, the observed response was consistent with phenomena observed in the Semiscale integral system tests ${ }^{75}$ and from results from RELAP5 thermal hydraulic simulations. ${ }^{72}$

In summary, post-accident evaluations indicated that the liquid level values in the pressurizer were correct with an uncertainty of $\pm 43 \mathrm{~cm}$ ( \pm 17 inches). Most water level changes were explained by considering changes that occurred in the RCS. However, as noted above, reactor operators incorrectly interpreted these water levels as indicating that the RCS was nearly full of water, when in fact, the RCS was continually losing its water inventory.

\subsection{Steam Generator Secondary Water Level}

TMI-2 employed two B\&W once-through steam generators (OTSGs), which were vertical, straight tube and shell boilers in which the reactor coolant (the heat source) is on the tube side and the secondary coolant (the heat sink) is on the shell side. As shown in Figure 4-19, reactor coolant enters the OTSG at the upper plenum, flows down inside the tubes while transferring heat to the secondary shell-side fluid, and exits through the lower plenum. Feedwater, which can be supplied from the feed, condensate, and emergency feedwater systems, enters through the side of the steam generator, near the middle, travels down the downcomer, then up along the outside of the tubes, and exits the steam generator as superheated steam. Depending on steam pressure in the steam generator, combinations of the condensate, condensate booster, and main feedwater pumps, are used to maintain water level. 


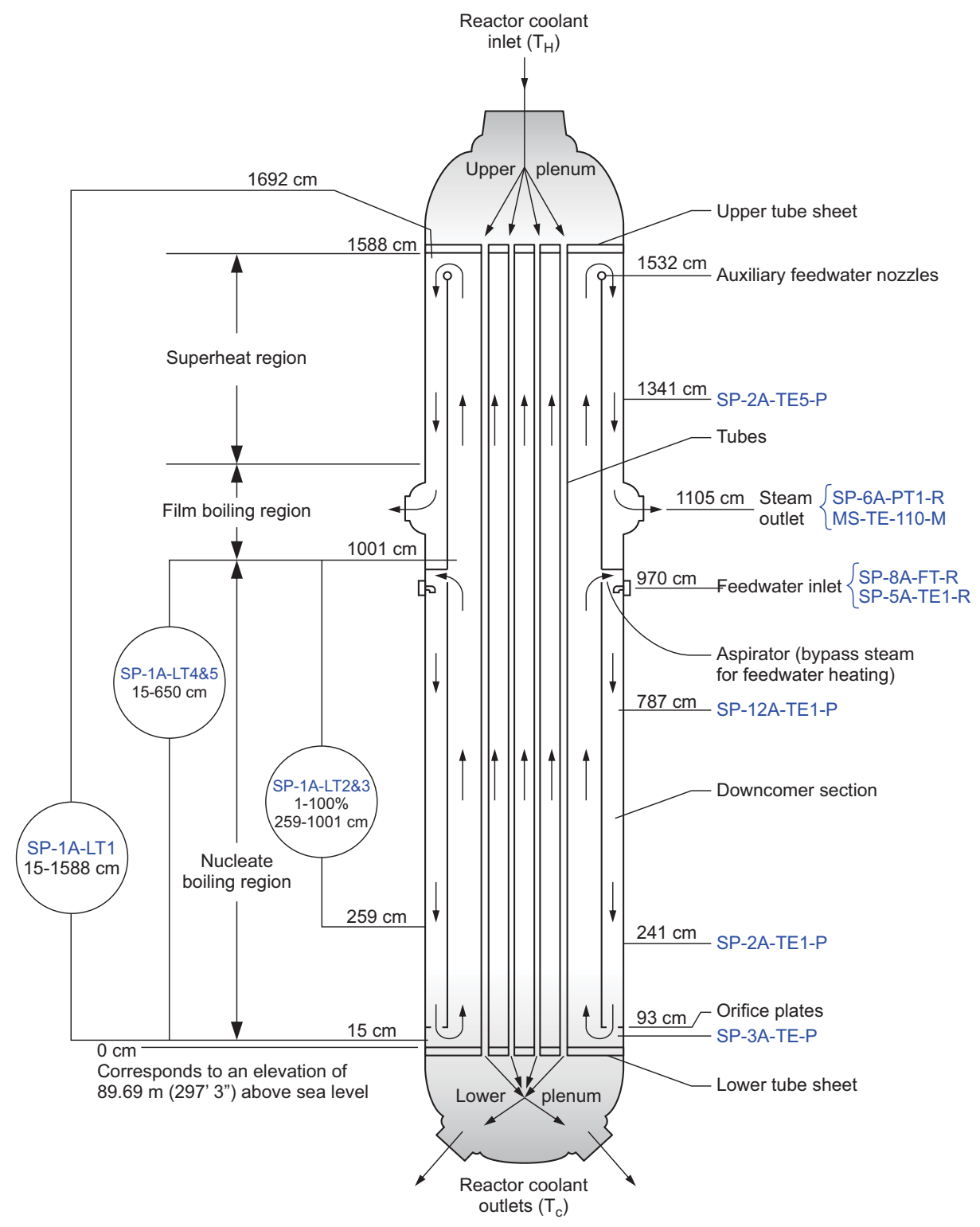

Figure 4-19. OTSG flow and water level indication.

During the accident, one of the major heat removal mechanisms from the primary was steaming from the OTSGs. Hence, accurate knowledge of the secondary side conditions is necessary for understanding the accident and for use as boundary conditions in accident simulations. Heat transfer to the secondary system was affected by the rate of feedwater introduction to the OTSG. This also controlled the area of the total tube bundle length that is exposed to liquid and low quality secondary coolant. Hence, OTSG water level is a significant parameter for evaluating conditions in the secondary.

\subsubsection{System Description}

As shown in Figure 4-19, there are three ranges of shell side water level indication in the OTSG. These ranges are: 
- Full Range (15-1539 cm) - Indication is obtained from one transmitter in each OTSG and is read in the control room with one indicator per generator.

- Start-Up Range (15-650 cm) - Indication comes from two transmitters per generator and is read in the control room with two dual indicators in units of equivalent liquid water level.

- Operating Range (0-100\%/3-744 cm) - Indication is obtained from two transmitters in each generator. Data are temperature compensated and read in the control room on two dual recorders. Sensors have a common upper tap with the start-up range sensors.

The start-up and operating ranges were used when taking the plant from a shutdown condition to full power. The full range was used primarily when the plant was being shutdown and for long term shutdown conditions.

All three measurements were based upon the hydrostatic pressure head due to the changing level in the secondary side. A Bailey differential pressure transmitter was used in each of the ranges for measurement of the difference between the hydrostatic head in a "reference leg," external to the steam generator, and the hydrostatic head of the level to be measured. However, each measurement used a different transmitter range. When comparing these two level signals, several factors must be considered as discussed in Section 4.7.2.

\subsubsection{Data}

During the TMI-2 accident, the secondary sides of the OTSGs boiled dry in the first $11 / 2$ minutes after the feedwater pump trip and the inadvertent closure of the auxiliary feedwater block values. Even though the auxiliary feedwater injection began 8 minutes into the accident, the steam generator levels did not begin increasing until about 26 minutes.

In order to obtain an accurate time history of the secondary liquid levels, all three measurements had to be converted to a common basis. However, Reference 76 omitted the full range transmitter from this process because it was observed that an installation issue had led to the full range transmitter giving erroneously low readings whenever the steam generator was steaming. Two problems must be addressed in combining readings from the startup and operating transmitters. First, the pressure drop across the orifice is unknown during the time of feedwater flow. However, once the feedwater pump tripped, the two levels should have equalized within a short time period, at least by the time that the secondary level increased to the bottom tap of the operating level at $259 \mathrm{~cm}$. The second problem with direct comparison of the levels is the need to consider temperature compensation of the operating level to compensate for changing liquid density as secondary pressures and temperatures change.

The best estimate composite water level obtained by converting the recorded operating level and start-up level for the A-loop and B-loop OTSG are shown in Figure 4-20 for the first 1000 minutes of the accident. Data chosen prior to the feedwater pump trip was from the start-up level transmitter. Then, the composite level was obtained by using the start-up level for levels less than $550 \mathrm{~cm}$ and the operating level for levels greater than $550 \mathrm{~cm}$. No adjustment was made in the A-loop level during the period when the operating level was saturated. 


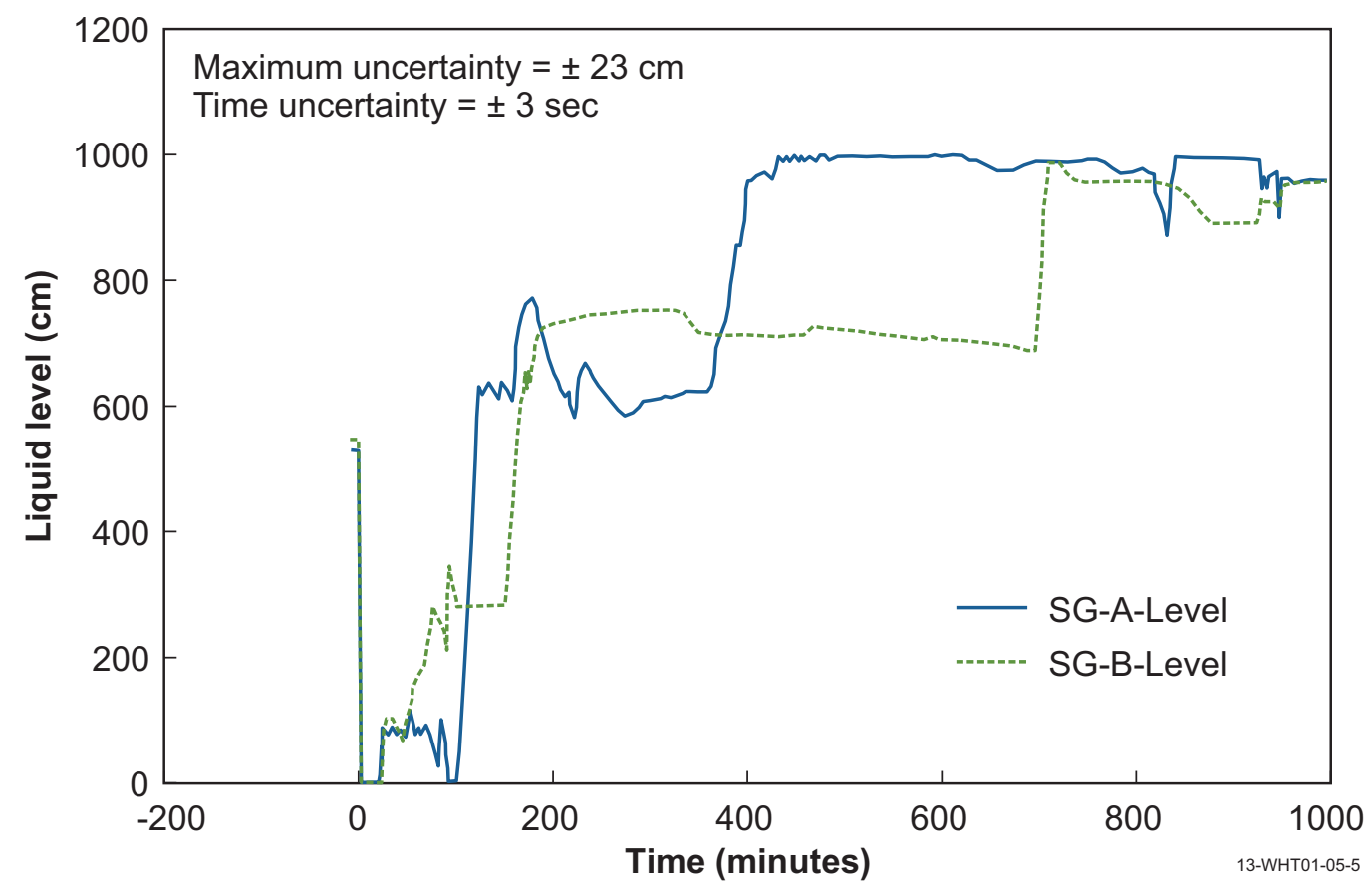

Figure 4-20. Water level in each TMI-2 steam generator.

\subsubsection{Status}

OTSG water levels recorded on the reactimeter were converted into a common measurement basis of the stratified level measured from the bottom tube sheet, and the converted measurements compared within their relative uncertainties following the feedwater pump trip. Evaluations concluded that the sensors were fully operational, and the measured data were assigned a category of "Qualified" by the DIRC. An uncertainty analysis of the measurements resulted in uncertainties of $\pm 23 \mathrm{~cm}$ for the converted operating level, $\pm 17 \mathrm{~cm}$ for the converted start-up level, and \pm 3 seconds for the timing. ${ }^{76}$

\subsection{Loose Parts Monitoring System}

During, and for several months after the TMI-2 accident, the reactor vessel and two steam generators were closely monitored for the existence of loose parts. To provide insights about the accuracy of such measurements, in-situ testing was performed on two Endevco Model 2652M4 Remote Charge Converters. More detailed examinations were then conducted after removing these instruments from the TMI-2 containment in November 1980.

\subsubsection{Description}

The Rockwell loose parts monitoring (LPM) System at TMI-2 used a total of eight channels to monitor the upper and lower tube sheets of the two steam generators. Signals from these channels were processed in a Rockwell electronics cabinet located in the cable spreading room. Alarms and a channel selectable audio output were located in the control room. Each channel consisted of an Endevco Model 2276 acceler- 
ometer mounted on the tube sheet and an Endevco Model 2652M4 charge converter mounted outside the O-ring. The accelerometers were exposed to high temperatures and radiation, while the charge converters were in much less severe environments. The normal radiation field around the charge converters was on the order of 1 to $10 \mathrm{mRad} / \mathrm{hr}$. The YM-AMP-7023 and YM-AMP-7025 charge converters, which were examined after the TMI-2 accident, were used to monitor opposite sides of steam generator B upper tube sheets. These were connected to the Rockwell cabinet by approximately 110 meters and 200 meters of coaxial cable, respectively.

\subsubsection{Data}

During the first month after the accident, the LPM channels were monitored closely. Data from these channels suggested that the components were functional, and data suggested that there were no loose components.

\subsubsection{Status}

In-situ testing revealed that YM-AMP-7023 and YM-AMP-2025 ${ }^{77}$ were severely degraded and that seven of the eight channels were inoperable. Evaluations suggested that most of the channels became inoperable within a day or two after the accident began. The cause for failure was radiation degradation of the MEM 511 MOS transistor used in the Q2 slot. Examinations indicated that the MOS transistors, in YM-AMP-7023 and YM-AMP-7025, had received total gamma doses of $1.8 \times 10^{5}$ and $5.4 \times 10^{5}$ rads, respectively. These levels correlated well with the $2.5 \times 10^{5}$ rads that the radiation detector HP-R-211 located near these transistors was estimated to have received. Examinations of two Endevco charge converters removed from the loose parts monitoring system inside containment found the devices to also be severely degraded by gamma radiation. In fact, these evaluations led to the determination that similar failures were occurring during normal operating conditions at another operating nuclear plant. This problem was subsequently corrected through a redesign by the manufacturer. ${ }^{78}$

Reference 79 concluded that the Endevco charge convertors were used in an application where it shouldn't have been deployed and recommended that guidance be provided by the US NRC to encourage the use of radiation resistant LPM systems. Current versions of U.S. Nuclear Regulatory Guide 1.133, which provides guidance relate to the use of loose parts monitoring systems, now encourages the use of radiation resistant LPM systems. $^{79}$

\subsection{Mass Flowrate}

During the first 100 minutes of the TMI-2 accident, the reactor coolant pumps continued to operate. At about 75 minutes into the accident, the two B loop pumps were shut off; and at just under 100 minutes, the A loop pumps were shut off. During the time that the RCS pumps weren't operating, the reactor coolant gradually changed from subcooled water to saturated water with a high void fraction. The measurement of primary coolant mass flowrate was made in each hot leg up to the time their respective pumps were shut off. Accurate mass flowrates are extremely important in TMI-2 accident simulations since accurate values allow codes to reduce uncertainties in predicting the time of phenomena, such as core uncovery. 


\subsubsection{System Description}

As discussed in References 80 and 82, the mass flowrate meter transducers measured velocity head and coolant temperature in each hot leg. These basic measurements were converted to mass flowrate by the meter electronics and the measurements were recorded on the "reactimeter."

Each of the primary hot leg coolant pipes had a mass flowmeter mounted at about the 105 meter elevation in a vertical section of pipe (see Figure 2-2). An RTD was mounted downstream of each flowmeter at an elevation of about the 108 meter elevation. The RTDs were designated RC-4A-TE1 and RC-4B-TE1 for loops A and B, respectively. The designation for the flowmeters was RC-14A-FT and RC-14B-FT for loops A and B, respectively. The flowmeter sensor is about 50 feet above the bottom of the heated core and about 5.5 meters below the top of the candy cane (see Figure 2-2).

The flowmeter consisted of a velocity head detector, a signal conditioning and amplifying section, and a coolant density computation section in which the temperature was measured using an RTD. The detector was essentially a pair of pitot tubes, one facing upstream and the other facing downstream with the legs connected to a differential pressure transducer. The four pairs of pitot tubes in each hot leg loop were connected in parallel and spaced $90^{\circ}$ apart azimuthally around the pipe. The differential pressure signal $(\triangle P)$ was put through a square root extractor and then multiplied by the square root of the coolant density $(\rho)$ and an appropriate constant $(k)$ to produce the mass flowrate measurement. All the hot leg temperatures and mass flowrate calculations were recorded on the reactimeter at three second intervals.

The RTD coolant temperature was used to determine the fluid density from a curve which represented the square root of steam table values around the normal reactor operating pressure $(P=14.8 \mathrm{MPa}$-gauge $)$ and temperature (between 271 and $327^{\circ} \mathrm{C}$ ). The loop coolant mass flowrate $(\dot{m})$ was continually computed according to the equation, $\dot{m}=\sqrt{\rho \Delta P}$.

\subsubsection{Data}

The mass flowrate and temperature in the primary coolant system were recorded on the reactimeter prior to and during the accident, which was set to sample each channel on a 3 second interval. As shown in Figure 4-21, the mass flowrate data are somewhat noisy.

\subsubsection{Status}

The flowmeter was designed to operate near the normal reactor full power conditions. During the accident, the flowmeter continued to indicate mass flowrate but was using an erroneous coolant density when the RCS depressurized and the coolant voided. Hence, the mass flowrate data from each hot leg had to be corrected for the error caused by calculating the liquid density using the flowmeter electronic circuits. Although it was known that the reduction in liquid density was due to the increased void fraction in the liquid, there was no way of knowing the time-dependent void fraction. A method was devised to estimate the maximum and minimum possible void fractions in the hot leg liquid. From these values, lower and upper densities were calculated. The recorded mass flowrate data were then corrected using the upper and lower density limits to yield a maximum and minimum probable mass flowrate. The mean value between the upper and lower limits was used as a substitute for the expected value. The actual expected value was thought to be between the mean value and the upper flowrate bound. Figure 4-22 shows the qualified mass flowrate data but with error bands. The error bands show calculated uncertainties, and qualified mean val- 


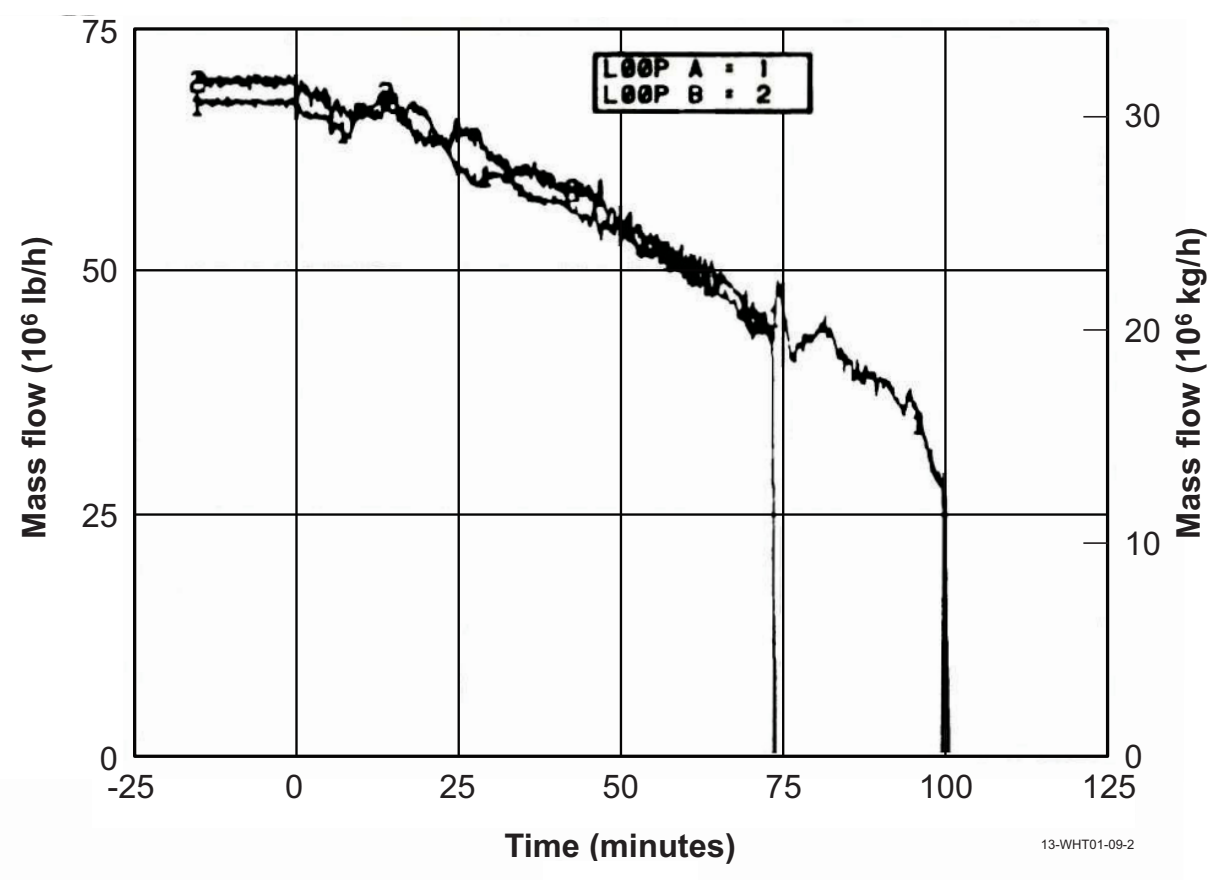

Figure 4-21. Recorded hot leg mass flow rate.
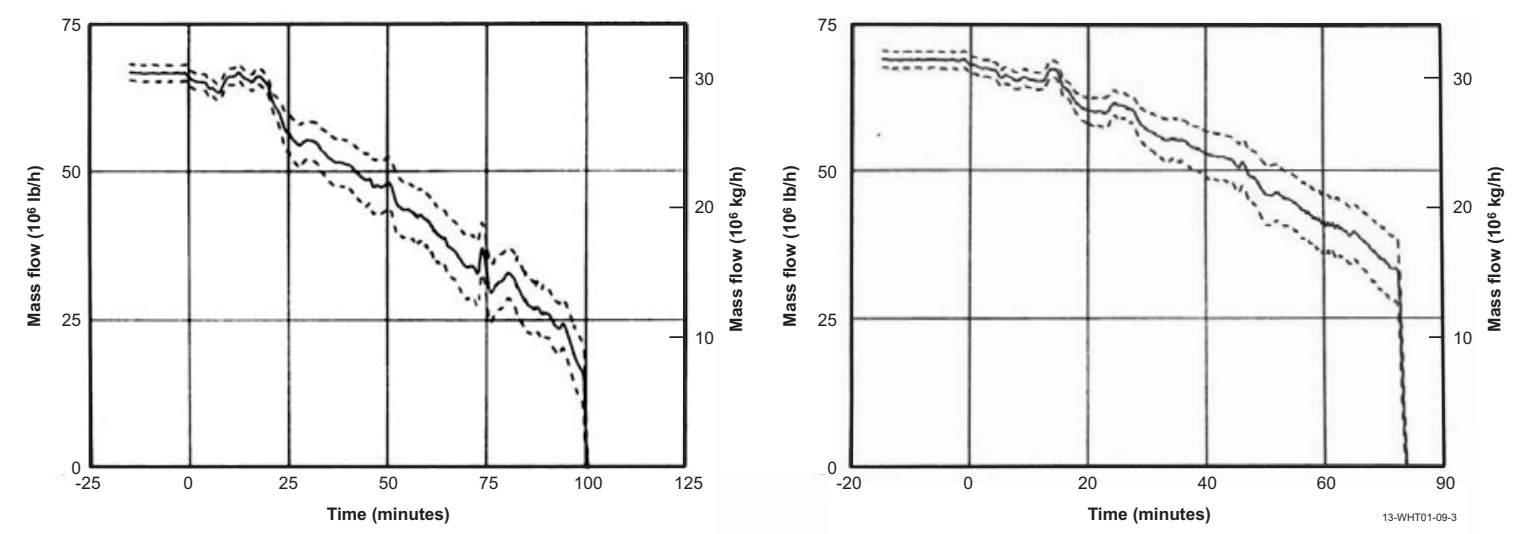

Figure 4-22. Qualified hot leg mass flow rates and uncertainties.

ues have been corrected for all known errors. As documented in Reference 80, the mass flowrate data were classified as "Qualified."

\subsection{Summary}

The effort required to qualify data from RCS sensors for TMI-2 post-accident evaluations included careful integration of instrumentation data, analysis relying on basic engineering principals, operator information, laboratory evaluations, comparisons with accident simulation results and large integral test data, 
and post-accident inspection. Results led to increased understanding of the accident and insights related to what instrumentation enhancements were needed to ensure that operators are better prepared to diagnose and mitigate any future events.

Initially, RCS sensors were interrogated in-pile and data were compared with data from other sensors to evaluate if responses were consistent (e.g., higher temperatures at times when flux levels implied lower water levels, etc.). In addition, a comprehensive review provides confidence about the timing of accident phenomena such as a major relocation of materials from the reactor core to the lower head. For example, the consistent increase from various sensors shown in Figure 4-23 suggests when relocation of core debris to the lower head occurred. The SRM count rate increased approximately $100 \%$ in less than 2 minutes (between 224 and 226 minutes) and then indicates a normal decay profile. Measured cold leg temperatures and RCS pressure shown in Figure 4-23 also increase rapidly at a time nearly coincident with the time when the abrupt increase in SRM response occurred.

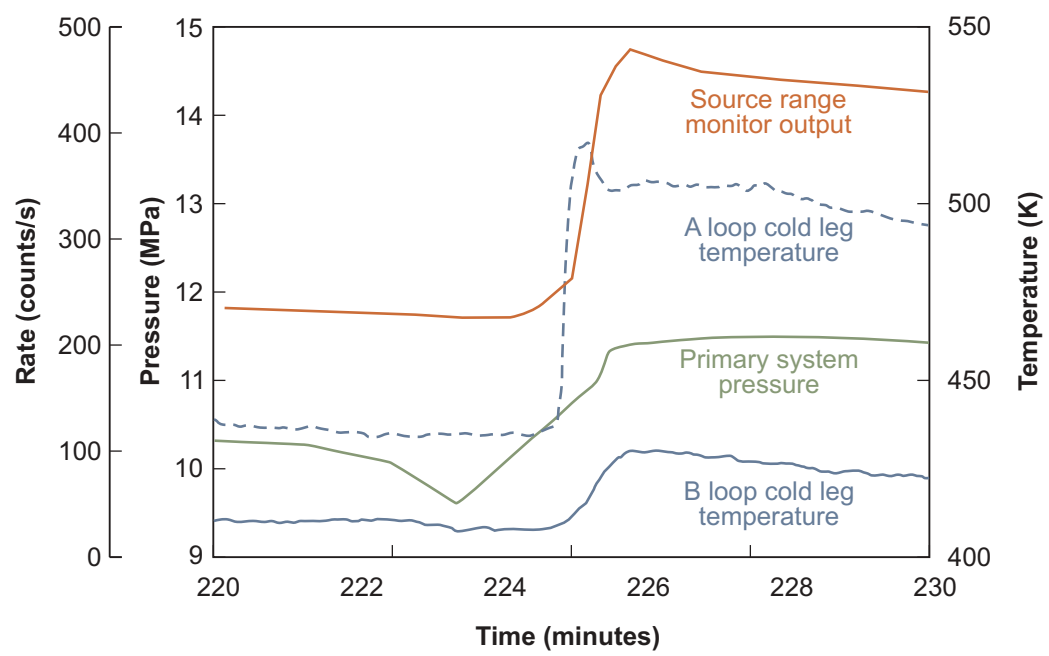

Figure 4-23. Overlay of SRM count rate, RCS pressure measurements, and cold leg temperatures.

To gain additional insights related to the response of selected sensors, such as SPNDs, RTDs, and thermocouples, laboratory evaluations were performed, exposing these sensors to conditions postulated to have occurred during the TMI-2 accident. In some cases, such as the SPNDs and differential pressure transducers, measured responses were compared with the response of sensors exposed to similar conditions in large scale facility experiments, such as tests conducted in the LOFT and Semiscale facilities. In other cases, such as the SRMs and IRMs, insights related to sensor response and accident progression were gained by performing neutronics calculations for postulated conditions and comparing calculation results with available data. As the TMI-2 recovery efforts progressed, selected sensors were removed from the RCS and evaluated.

Specific insights gained from the TMI-2 RCS sensor evaluations include:

- Data unavailability was often due to computational limits, such as storage memory, inadequate paper or ink, and 'preset' limits associated with anticipated operating ranges (rather than sensor operating limits). A wider range of limits and enhanced computational capabilities, with easy-to-read graphical displays, could easily alleviate such limitations. 
- Data unavailability often due to sensor range limitations focussed on assumed normal operating conditions. For example, sensors with ranges that encompassed unanticipated accident conditions (e.g., at saturated conditions with steam voids present in a PWR) could have provided operators much needed information.

- Failures in sensors located within the vessel were generally due to a combination of high temperatures and moisture ingress following sheath failure. In some cases, vibrations, moisture, and/or radiation exposure led to failures of sensors. Clearly, it is important to have sensors with operating envelopes that are extended to consider more likely accident conditions.

- Failures were often related to transmission component exposure, rather than sensor exposure. For example, cabling and connectors located outside the RCS were subjected to higher than anticipated temperatures, moisture levels, and radiation levels. It was speculated that most of the moisture intrusion problems would have occurred eventually in the plant without the accident. However, better positioning and enhanced components and/or shielding could alleviated such limitations.

- Inadequate status indicators, including the inability of the operators to detect that the PORV failed to close could be rectified by the use of additional indicators and sensors. In this case, indicators were only available to show that the solenoid coil was energized (nothing about the status of the valve position). As discussed in Section 2.5, the US NRC required that licensees make design changes so that positive indication of valve position was available in the control room. However, sensors could have been included to measure the drain tank water level, which would have provided the operators information that the drain tank relief valve was open. A thorough investigation of other such situations could help to alleviate similar occurrences in the future.

- Qualitative insights can be obtained by considering sensor response for alternate applications, e.g., ex-core source-range detector signals provide insights about real-time RCS water levels and in-core SPNDs provide insights about RCS temperature and water levels. However, such interpretations often require detailed analyses and assumptions related to the status of the RCS and core.

- Post-accident extraction and examinations are needed to confirm insights from other evaluations. For example, inspections of components from the loose parts monitor system found that they had degraded due to radiation exposure; whereas, data suggested that sensors were still operational.

- Careful evaluations of sensor data led to unexpected detection of instrumentation errors. For example, comparison of SG water level data led to the conclusion that the full range transmitter was incorrectly installed because readings were observed to be erroneously low when the SG was steaming.

In summary, a comprehensive set of instrumentation evaluations, that included careful integration of sensor data, analysis relying on basic engineering principals, operator information, laboratory evaluations, comparisons with accident simulation results and large integral test data, and post-accident inspection, was required for researchers to qualify RCS sensor data for TMI-2 accident simulations. Knowledge gained from these evaluations offer important lessons for the industry with respect to sensor survivability, the need for additional and/or enhanced sensors and indicators, and the identification of unanticipated failure modes for sensors when exposed to extreme accident conditions. A similar process should be followed at Daiichi Units 1, 2, and 3 to reap boiling water reactor (BWR)-specific benefits. 


\section{CONTAINMENT}

This section provides details about sensors within the containment and current views related to their survivability. Table 5-1 lists the sensors discussed in this section, highlights aspects about their design, and identifies the report section providing additional details related to each sensor.

Table 5-1. TMI-2 containment sensor review.

\begin{tabular}{|c|c|c|c|c|c|}
\hline Parameter & Sensor & $\begin{array}{l}\text { Report } \\
\text { Section }\end{array}$ & Function & Range & Post-Accident Status \\
\hline $\begin{array}{l}\text { Building } \\
\text { Pressure }\end{array}$ & Pressure transmitter & Section 5.1 & $\begin{array}{l}\text { Primary: } \\
\text { pressure; } \\
\text { Secondary: } \\
\text { timing of } \\
\text { hydrogen burn }\end{array}$ & $\begin{array}{l}\text { wide range: } 0 \text { to } 0.7 \\
\text { MPa-gauge; narrow } \\
\text { range: }-0.03 \text { to } 0.1 \\
\text { MPa-gauge }\end{array}$ & Operational \\
\hline $\begin{array}{l}\text { Building } \\
\text { Temperature }\end{array}$ & Platinum RTDs & Section 5.2 & $\begin{array}{l}\text { Primary: } \\
\text { Temperature }\end{array}$ & 0 to $1100{ }^{\circ} \mathrm{C}$ & $\begin{array}{l}\text { Operational, although possible } \\
\text { degradation due to moisture; Data } \\
\text { points too far apart to be useful during } \\
\text { hydrogen burn. }\end{array}$ \\
\hline \begin{tabular}{|c|} 
Core Flood Tank \\
Pressure \\
Monitor
\end{tabular} & Pressure transmitter & Section 5.3 & $\begin{array}{l}\text { Primary: Core } \\
\text { Flood Tank } \\
\text { Pressure }\end{array}$ & 0 to $5.5 \mathrm{MPa}$-gauge & Operational \\
\hline \begin{tabular}{|c|} 
Core Flood Tank \\
Water Level \\
Monitor
\end{tabular} & $\begin{array}{l}\text { Transmitter with LVDT and } \\
\text { bellows }\end{array}$ & Section 5.4 & $\begin{array}{l}\text { Primary: Water } \\
\text { Level }\end{array}$ & 0 to $14 \mathrm{ft} \mathrm{H}_{2} \mathrm{O}$ & $\begin{array}{l}\text { Three of the four units experienced seal } \\
\text { failures allowing severe corrosion }\end{array}$ \\
\hline $\begin{array}{c}\text { Building } \\
\text { Radiation Levels }\end{array}$ & $\begin{array}{l}\text { Area Radiation Monitors } \\
\text { Most: Geiger-Muller (G-M) } \\
\text { gamma detectors } \\
\text { Dome Monitor: Ion } \\
\text { chamber }\end{array}$ & Section 5.5 & $\begin{array}{l}\text { Primary: } \\
\text { radiation } \\
\text { monitor; } \\
\text { Secondary: } \\
\text { Timing of fuel } \\
\text { failure and } \\
\text { fission product } \\
\text { release }\end{array}$ & $\begin{array}{l}\text { Most: } 10^{-1} \text { to } 10^{4} \mathrm{mR} / \\
\mathrm{hr} \\
\text { Dome Monitor: } 10^{-1} \text { to } \\
10^{7} \mathrm{mR} / \mathrm{hr}\end{array}$ & $\begin{array}{l}\text { Failed due to high temperatures, } \\
\text { pressure wave associated with } \\
\text { hydrogen burn, high radiation levels, } \\
\text { and moisture. }\end{array}$ \\
\hline
\end{tabular}

As discussed in this section, many of the containment sensors and the associated cabling were exposed to conditions much harsher than their operating envelope. In particular, the progression of the accident resulted in higher temperatures, moisture levels, radiation levels, and pressure shocks than envisioned by plant designers.

During the first day of the accident, the environment inside the reactor building was one of intense radiation, steam, moderate temperature excursions, and a hydrogen burn resulting in a pressure spike that initiated a chemical suppression spray. Steam and radioactive reactor coolant were discharged into the building through the reactor coolant drain tank rupture disc. The steam rose from the basement through the open stairwell to the upper levels. The release of water and steam resulted in an average air temperature increase of about $17^{\circ} \mathrm{C}$ during the initial hours after the accident. Components directly in the steam path experienced higher temperatures.

A total of approximately 2.3 million liters of water accumulated in the basement and may have possibly reached a maximum level of approximately $8.3 \mathrm{ft}$ (291-ft elevation). Consequently, many instruments, electrical components, and cable trays were submerged. Because of the water in the basement and continuous operation of the air handling units, the relative humidity inside the reactor building remained at $100 \%$ for a period of two to three years. Post-accident evaluations ${ }^{81}$ of electrical components and devices indi- 
cated that a significant fraction had failed due to water submersion, moisture incursion, or corrosion associated with high humidity.

Generally, the dose history, excluding the basement, consisted of high dose rates for a short time followed by relatively small dose rates for a long time. The estimated total integrated radiation dose varies with location and elevation. Radiation levels at the 282-ft elevation (the reactor building basement) peaked at $1200 \mathrm{R} / \mathrm{h}$ near the air coolers. This corresponded to a maximum estimated integrated dose of $10^{8}$ rads. The integrated dose on the $305-\mathrm{ft}$ elevation was estimated at $10^{5} \mathrm{rads}$, and the integrated dose at the $372-\mathrm{ft}$ elevation was estimated at over $10^{6}$ rads.

The hydrogen burn occurred approximately ten hours after the start of the accident and resulted in a uniform increase in ambient temperature of approximately $27^{\circ} \mathrm{C}$. It is believed that the hydrogen burn started in the basement, with flames propagating to the upper regions of the reactor building. The pressure spike that resulted from the burn activated the reactor building pressure suppression spray for about five minutes.

\subsection{Building Pressure}

As discussed in Reference 83, the peak temperature associated with the hydrogen burn is difficult to quantify because it occurred over a very short time period. Hence, the reactor building temperature and pressure data were very important input for evaluations of the events that occurred during this phase of the accident. Several sources of data were available to estimate the reactor building pressure during the TMI-2 accident. ${ }^{83,84}$ There were two pressure transmitters associated with the strip chart recorder for which data were recorded continuously, and six reactor building pressure switches. In addition, pressure transmitters measured the reactor building pressure as a steam generator reference pressure, and these data were recorded on the reactimeter every 3 seconds.

\subsubsection{Sensor Location and Type}

The reactor building (containment) pressure was continuously recorded during the accident on two different strip chart recorders. ${ }^{49}$ Each recorder was a two-pen Taylor recorder, model $830 \mathrm{~J}$, with input from two different Foxboro pressure transmitters. One transmitter on each recorder had a wide range of 0 to 0.7 MPa-gauge, and the other transmitter had a narrow range of -0.03 to $0.1 \mathrm{MPa}$-gauge. The measurement, BS-PT-4388-N-S, was stored on recorder SC-056, from the narrow range transmitter, SN 3259652. This measurement was within its range (- -0.03 to $0.1 \mathrm{MPa}$-gauge) during the accident, with the exception of the pressure spike during the hydrogen burn. The only useful information from the wide range transmitter, BS-PT-4388-W-S (SN 3259653), is the magnitude of the pressure spike associated with the hydrogen burn. Therefore, this was the only value of the wide range transmitter data that was qualified. The narrow range pressure measurement on the other strip chart recorder (SC-055) BS-PR-1412-N-S was not recorded prior to the pressure spike due to failure of the pen to properly ink. Comparison between the two recorded narrow range measurements can be performed following the pressure spike. This was done to help in obtaining an estimate of the data uncertainty. The output from the wide range pressure transmitter BS-PT-1412-W-S was also routed to the plant computer. However, there was no indication that any data from this measurement were recorded during the accident. 


\subsubsection{Data}

Reactor building pressure was estimated by combining the narrow range data and the single data point for the pressure spike from the wide range channel. This combined measurement was designated as BS-PT-4388-S. The recommended composite reactor building pressure data are shown in Figure 5-1.

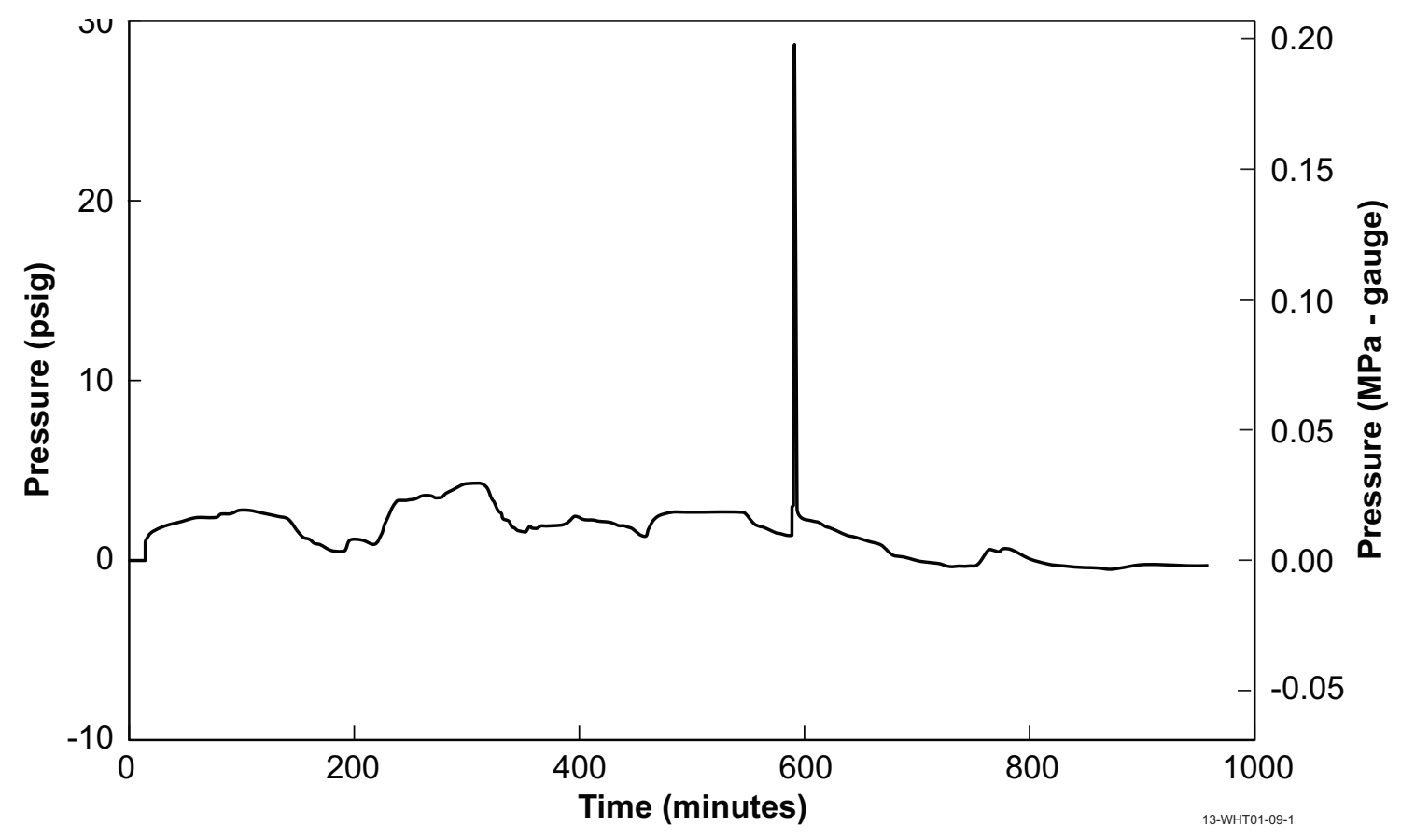

Figure 5-1. Containment building pressure.

\subsubsection{Status}

Data uncertainty estimates are $+2 \mathrm{kPa}$-gauge for the narrow range measurement and $+14.8 \mathrm{kPa}$-gauge for the wide range estimate. The magnitude of the pressure spike, which occurred at the hydrogen burn was 0.20 MPa-gauge from the wide range pressure measurement, BS-PT-4388-W-S. This compares well with other recorded pressure data, considering uncertainty associated with data digitization. The recommended composite reactor building pressure data were deemed "Qualified" in the TMI-2 Database.

\subsection{Building Temperature}

Because temperature measurements are key to understanding the TMI-2 accident and subsequent plant conditions, survivability and performance of the 16 RTDs in the reactor-building air handling system were investigated.

\subsubsection{Sensor Location and Type}

Containment air temperature measurement data at sixteen locations in the reactor building air handling system (see Table 5-2) were evaluated as part of the TMI-2 post-accident evaluation effort. ${ }^{85,86}$ The air 
handling system RTDs were Rosemount Series 78 sensors, having a single element with four lead wires. The RTDs conform to the International Platinum Temperature Scale No. IPTS-68 with an alpha coefficient of $0.00385 \mathrm{ohms} / \mathrm{ohm} /{ }^{\circ} \mathrm{C}$. The normal range of these RTDs was -100 to $660^{\circ} \mathrm{C}$ with an accuracy of $\pm 1{ }^{\circ} \mathrm{C}$ at $93{ }^{\circ} \mathrm{C}$. They nominally read $100 \mathrm{ohms}$ at $0^{\circ} \mathrm{C}$.

RTD data were recorded on a strip chart in the Unit-2 Control Room. The recorder was a Bristol 550 Dynamaster multipoint unit, which was a servo-operated null balance potentiometer and bridge instrument. The recorder, calibrated in degrees Fahrenheit, sequentially recorded 24 variables on a 12-in. strip chart and was ranged for 0 to $200^{\circ} \mathrm{F}$. The recorder printed one temperature point each $15 \mathrm{~s}$. With 24 points being printed for a complete cycle, it took 6 minutes to cycle and repeat an individual temperature point. RTD temperatures of special interest for understanding the TMI-2 accident included those located in the drain tank region (AH-TE-5012) and the letdown cooler region (AH-TE-5012).

Table 5-2. Location of reactor building RTDs. ${ }^{85}$

\begin{tabular}{|c|c|c|}
\hline RTD Identifier & Location & Elevation, $\mathrm{ft}$ \\
\hline AH-TE-5010 (ambient air) & Sump pump & 282 \\
\hline AH-TE-5011 (ambient air) & Letdown cooler & 282 \\
\hline AH-TE-5012 (ambient air) & $\mathrm{RC}$ drain tank & 282 \\
\hline AH-TE-5013 (ambient air) & Impinge barrier & 282 \\
\hline AH-TE-5014 (ambient air) & Near equipment hatch & 310 \\
\hline AH-TE-5015 (outlet temperature) & $\mathrm{A} / \mathrm{C}$ plenum outlet & 319 \\
\hline AH-TE-5016 (ambient air) & Primary shield concrete & 282 \\
\hline AH-TE-5017 (ambient air) & Primary shield concrete & 282 \\
\hline AH-TE-5018 (ambient air) & Primary shield concrete & 282 \\
\hline AH-TE-5019 (ambient air) & Primary shield concrete & 282 \\
\hline AH-TE-5020 (ambient air) & Top ceiling & 353 \\
\hline AH-TE-5021 (ambient air) & Top ceiling & 353 \\
\hline AH-TE-5022 (ambient air) & Southeast stairwell & 330 \\
\hline AH-TE-5023 (ambient air) & West stairwell & 330 \\
\hline AH-TE-5027 (outlet temperature) & $\mathrm{A} / \mathrm{C}$ plenum outlet & 305 \\
\hline AH-TE-5088(ambient air) & Southeast stairwell & 310 \\
\hline
\end{tabular}

\subsubsection{Data}

Figure 5-2 shows selected RTD data. Certain locations, such as the reactor coolant drain tank room (RTD 5012), experienced many temperature changes. Other locations showed no temperature change, such as the primary shield (RTDs 5016 through 5019). None of the 16 RTDs indicated a peak temperature greater than $90^{\circ} \mathrm{C}$. However, during the hydrogen burn, the top ceiling RTD 5020 behaved unexpectedly 
and recorded a negative trending trace, probably because of spray activity. Most other locations, including the other top ceiling RTD recorded a positive-trending trace during this time.

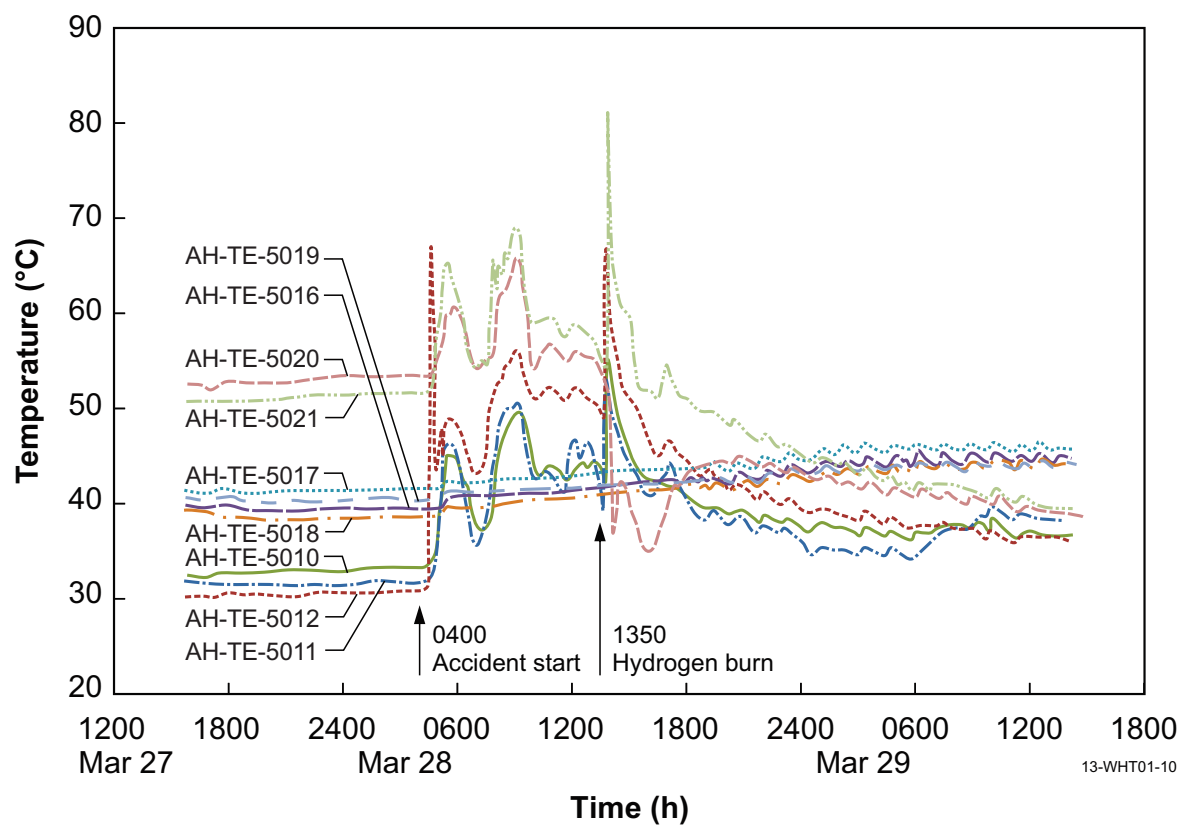

Figure 5-2. Reactor building temperatures at selected locations.

\subsubsection{Status}

RTD temperature measurements are based upon the fact that changes in the resistance of the sensing element are related to changes in its temperature. This resistance change, which is precise and repeatable when circuit characteristics remain unchanged, is usually measured by passing a known current through the sensing element and measuring the voltage drop across it.

Specifications on the Rosemount Incorporated Data Sheet for their Series 78 platinum RTD indicated accuracies of $1{ }^{\circ} \mathrm{C}$. However, in 1982, there was a resistance reading error equivalent to $6^{\circ} \mathrm{C}$ in the RTDs. This was believed to be due to corrosion and surface contamination that occurred after the accident. Data were printed every 6 minutes, but the estimated uncertainty of the precise time when data were printed was 90 seconds.

In-situ testing at TMI-2 indicated a problem with RTD temperature measurement. Specifically, RTD resistances were different when measured with the strip chart recorder system than when Fluke meters were used. A check of the instrument literature for all units showed that the strip chart recorder uses a constant current slightly greater than $1 \mathrm{~mA}$, whereas the Fluke meters used constant currents of 3 to $3.5 \mathrm{~mA}$. While such differences in current should not ordinarily cause differences in resistance and temperature readings, the accident environment at TMI-2 may have caused abnormal conditions for the RTDs. The RTDs, when installed at TMI-2 were not required to be sealed against high humidity or protected from other conditions that existed during and after the accident. Although the actual conditions of the RTDs and associated wire and circuit components are not known, it is possible that they experienced chemical con- 
tamination and corrosion at terminals and penetrations, thus leading to different readings when measurements were made with different currents.

Nevertheless, it was judged that the RTDs remained operational during the accident. However, because of their slow sampling rate, recorded peak temperatures from the RTDs were less than $93{ }^{\circ} \mathrm{C}$, which was much lower than the $650^{\circ} \mathrm{C}$ estimates obtained assuming peak pressures measured in the reactor building. ${ }^{84,83}$ Physical damage to organic materials substantiated that temperatures exceeded $232{ }^{\circ} \mathrm{C}$, which was also much higher than available data from the RTDs. Hence, data were evaluated as "Qualified" for all times except at temperature peaks. After the hydrogen burn, analysts increased the uncertainty estimates for RTD temperatures because of the high exposure temperatures.

\subsection{Core Flood Tank Pressure Monitor}

The program to evaluate the survivability of pressure transmitters in the TMI-2 Reactor Building selected several pressure transmitters from the Core Flood Tanks because they were easily accessible and because they could be removed without interfering with systems required for maintaining the plant in a safe configuration. Furthermore, these transducers were representative of other transducers found within the plant.

There were two 29,500 liter core flood tanks in the TMI-2 containment. Each tank contained borated water that is pressurized with nitrogen gas to $4.1 \pm 0.17 \mathrm{MPa}$-gauge. During a LOCA, water from the core flood tanks was released into the RCS when its pressure was less than 4.1 MPa-gauge.

\subsubsection{Sensor Location and Type}

Units designated CF-1-PT1 and CF-1-PT2 were the transmitters used to measure the pressure in Core Flood Tank A, and CF-1-PT3 and CF-1-PT4 were the transmitters used to measure the pressure in Core Flood Tank B.These E11GM-HASAD1 units, which were manufactured by the Foxboro Company, were contained within a stainless steel body. They had a calibration range spanning from 0 to $5.5 \mathrm{MPa}$-gauge and outputs ranging from 10 to $50 \mathrm{~mA}$.

Field measurements were performed on the CF-1-PT3 and CF-1-PT4 units. ${ }^{87}$ and 88 The field measurements included evaluations of the current pressure indications, passive measurements (signal recording, time domain output waveforms, frequency analysis) and active measurements (resistance, capacitance, impedance, and time domain reflectometry [TDR] tests obtained by removing instrument power and actively introducing a test signal). Evaluation results indicated that these two units were operational and had not experienced any degradation.

The CF-1-PT1 and CF-1-PT3 transmitters, which were located at the 324-ft elevation, well above the high water mark in the building, were examined in more detail. ${ }^{89,90,91}$ Visual examinations revealed a heavy coating of corrosion and some rust on the bolts holding the pressure port assembly together on CF-1-PTl. The interior of the transmitter, including the sensor/electronic module assembly, was free from corrosion and radioactive contamination. The circular junction box showed no signs of corrosion and was relatively free of radioactive contamination. The minor amount of contamination found in the junction box was probably a result of the removal process. It appears that the conduit installation associated with this 
transmitter did not permit water to enter the junction box, as was the case with other Foxboro units removed from TMI-2.

Visual inspections of CF-1-PT3 revealed minor corrosion and rust on its exterior. The interior of the transmitter, including the sensor/electronic module assembly was free from corrosion and radioactive contamination. The circular junction box showed no signs of corrosion; however, some mineral deposits were apparent, indicating that moisture had been in the junction box at some time. Radiation measurements indicated that the interior of the junction box was radioactively contaminated. Since the junction box seal appeared to be in good condition, it is likely that the water entered the junction box through the conduit. A seal located between the transmitter and the circular junction box prevented moisture from entering the transmitter itself.

\subsubsection{Data}

No failure or degradation of the transmitters were reported during or after the accident. As noted above, in-situ evaluations of their signals indicated that the CF-1-PT3 and CF-1-PT4 units were operational and had not experienced significant degradation.

\subsubsection{Status}

The Foxboro units were adequately sealed to prevent moisture damage to the internal mechanisms and the electronic module. The radiation environment appeared to have no effect on the long-term operation of the transmitters. Laboratory evaluation indicated that these units were still in calibration. The radiation environment from the accident did not appear to cause any permanent damage to the Foxboro transmitters.

\subsection{Core Flood Tank Water Level Monitor}

\subsubsection{Sensor Location and Type}

CF-2-LT1 and CF-2-LT2 were transmitters used to measure the water level in Core Flood Tank A, and CF-2-LT3 and CF-2-LT4 were transmitters used to measure the water level in Core Flood Tank B. These transmitters were located at the 324-ft elevation. These transmitters were manufacturer by the Bailey Meter Company (Model BY8231X-A), and they had a calibration range from 0 to $14 \mathrm{ft}_{2} \mathrm{O}$. The transmitters consisted of a linear variable differential transformers (LVDTs) with temperature compensation, and calibration adjustment for conversion of pressure difference to water level.

Field measurements were performed on the CF-2-LT2 and CF-2-LT4 units. ${ }^{92,93}$ The field measurements included evaluations of the current water level indications, passive measurements (signal recording, time domain output waveforms, frequency analysis) and active measurements (resistance, capacitance, impedance, and TDR tests obtained by removing instrument power and actively introducing a test signal). Evaluation results indicated that CF-2-LT4 unit was operational, but the CF-2-LT2 unit had experienced some degradation.

Visual examinations of the CF-1-LT1 and CF-1-LT2 transmitters ${ }^{93,78}$ revealed that there was a heavy layer of rust on assembly nuts and conduit fittings. The severe corrosion and degradation of internal com- 
ponents rendered the units inoperable. The units had a high level of internal radioactive contamination, indicating leakage into the units subsequent to the accident.

An initial visual examination of the CF-1-LT4 transmitter revealed a heavy layer of rust on the unit's assembly nuts, while the remainder of the exterior surfaces had only minor or no indications of rusting. The interior of the transmitter, including the housing and the electronics, was free of corrosion and rusting.

\subsubsection{Data}

As noted above, in situ tests performed on CF-2-LT2 during September 1980, indicated that the unit had probably failed. No in situ tests were performed on CF-2-LT1. Both of the Bailey transmitters were removed from service on December 12, 1980 because they did not respond to known level changes in Core Flood Tank A.

A transmitter calibration was performed on CF-2-LT4 in its as-received condition and compared with the last set of calibration data taken on this unit prior to the accident. Results indicate that the calibration had shifted by less than $3 \%$.

\subsubsection{Status}

Examinations revealed that three of the four Bailey units had failed. Examinations indicated that this degradation was due to extensive internal corrosion resulting from inadequate sealing. The major source of water into the housing was through the electrical conduits leading into the housing. One of the transmitters appeared to have a faulty seal around the cover plate which may have permitted some moisture to enter the transmitter housing. The water in the housing resulted in extensive corrosion and degradation of the electronic module. The CF-2-LT1, CF-2-LT2, and CF-2-LT3 units were inoperable. These results indicate the importance of a well-defined installation procedure that ensures adequate sealing of the housing and the following of approved conduit installation practices to prevent moisture leaks in the systems. ${ }^{78}$ Radiation effects on the Bailey transmitter could not be determined because of extensive water damage to the transmitter.

\subsection{Area Radiation Monitors}

Area radiation monitors were positioned at various locations within the TMI-2 reactor building to detect gross gamma radiation. ${ }^{56}$ These monitors provided critical radiation level information for detecting fission product release. Radiation level information from one of these monitors, the Dome Monitor, provided operators in the control room (see Figure 5-3) with radiation level information for assessing population exposure hazards in the event of a containment failure. The Dome Monitor reading, by itself, could be used to declare a General Emergency. Since the accident at TMI-2, the Dome Monitor was assigned a more important role in initial revisions to Regulatory Guide $1.97,{ }^{45}$ which addresses post accident monitoring equipment. It has been recognized that this monitor provided operators critical plant status information. 


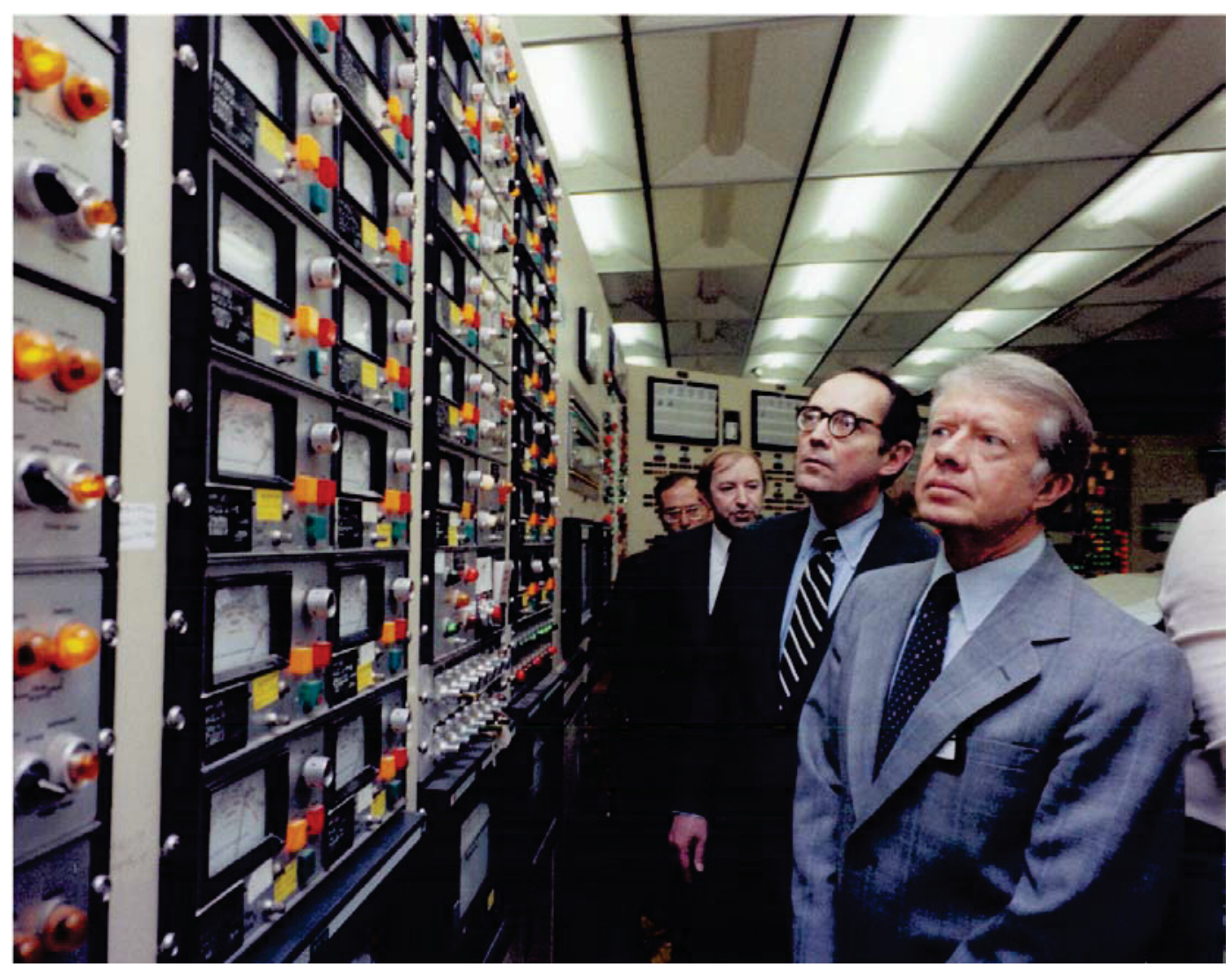

Figure 5-3. President Jimmy Carter observes radiation monitors in TMI-2 control room on April 1, 1979, accompanied by Pennsylvania Governor Richard Thornburgh and Harold Denton, NRC, (front to back). ${ }^{25}$

\subsubsection{Sensor Location and Type}

The positions of area radiation monitors in the reactor building are shown in Figure 5-4. ${ }^{56}$ Their spacing provided diverse locations for detecting high radiation levels.

Monitors HP-R-210, HP-R-211, HP-R-212, and HP-R-213 were Victoreen Model 857-2 designs containing Geiger-Muller (G-M) tube gamma detectors instruments covering ranges from $10^{-1}$ to $10^{4} \mathrm{mR} / \mathrm{hr}$, but these detectors were shielded by a 0.020 inch lead shield to flatten the response in the $100 \mathrm{keV}$ to 1.5 MeV range. Inkings on the stripchart from HP-R-212 and HP-R-213 were 'ambiguous', and there was some confusion whether data were from HP-R-212 or HP-R-213. However, it was later learned that the data were from HP-R-213 because the HP-R-212 monitor was not switched on until 92 days after the accident. Specifications for these monitors indicate upper limits of $60{ }^{\circ} \mathrm{C}, 0.21 \mathrm{MPa}$-gauge, and $100 \%$ relative humidity.

The dome monitor, HP-R-214, which was located on top of the elevator shaft enclosure roof at an elevation of 372 feet (see Figure 5-4), was the only instrument inside containment capable of measuring the high radiation levels that might be present during a LOCA. As such, plant technical specifications require that it be operative throughout a LOCA. 

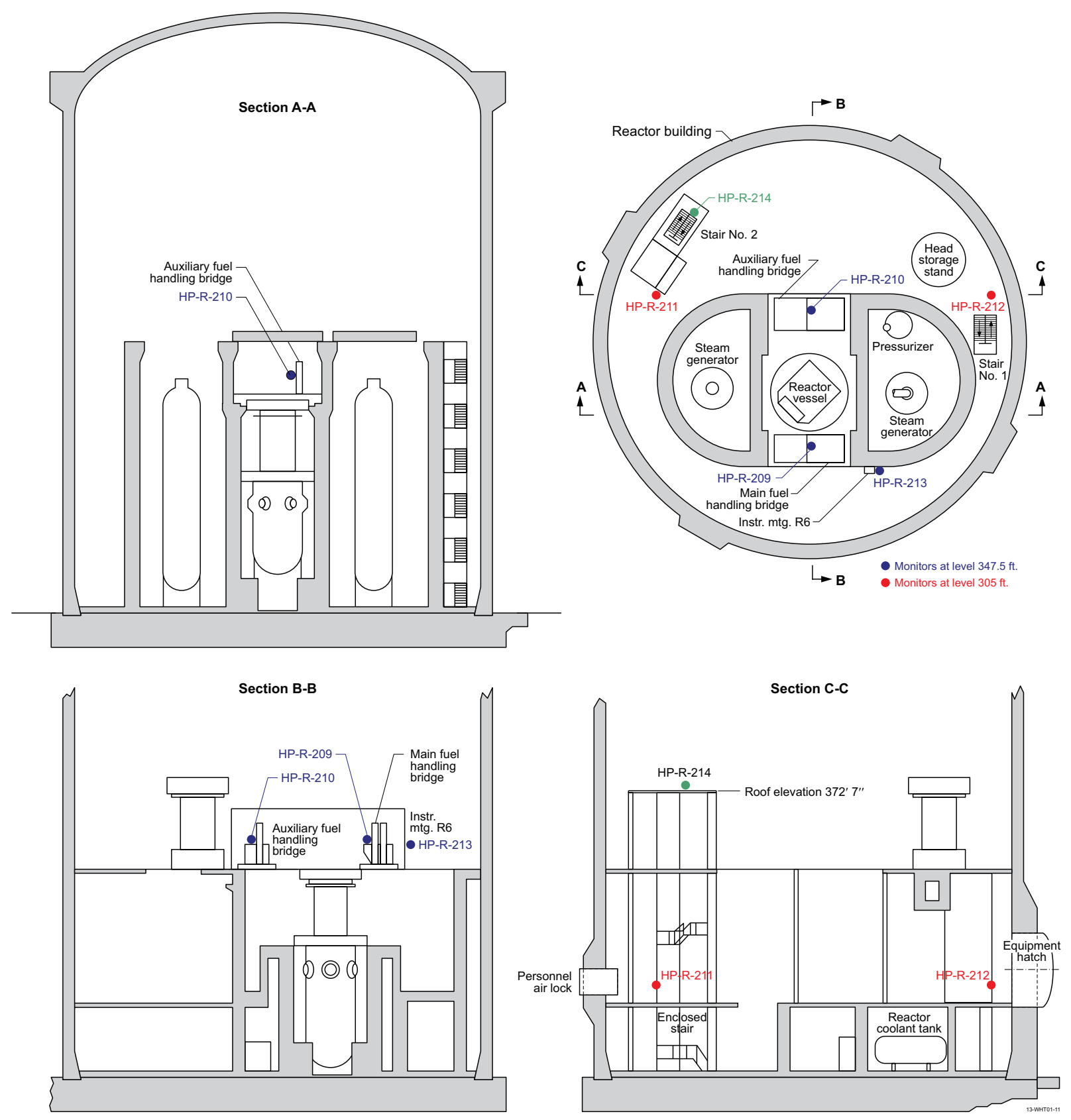

Figure 5-4. Containment radiation area monitor location.

The HP-R-214 monitor was an ionization chamber instrument that covered a range of $10^{-1} \mathrm{mR} / \mathrm{hr}$ to $10^{7} \mathrm{mR} / \mathrm{hr}$, when used in an unshielded configuration. However, the presence of a $4 \mathrm{~cm}$ lead shield and two holes $(1.27 \mathrm{~cm}$ and $0.318 \mathrm{~cm}$ in diameter) in this shield complicated data interpretation from this monitor. Specifications for this monitor indicate upper limits of $60^{\circ} \mathrm{C}, 0.10 \mathrm{MPa}$-gauge, and $95 \%$ humidity.

Field measurements were performed on the HP-R-212, HP-R-213, and HP-R-214 monitors. ${ }^{94-96}$ The field measurements included evaluations of the current radiation signal from each unit, passive measurements (e.g., time domain output waveforms, high frequency spectrum analysis) and active measurements (resistance, capacitance, impedance, and TDR tests). Evaluation results indicated that by the time that 

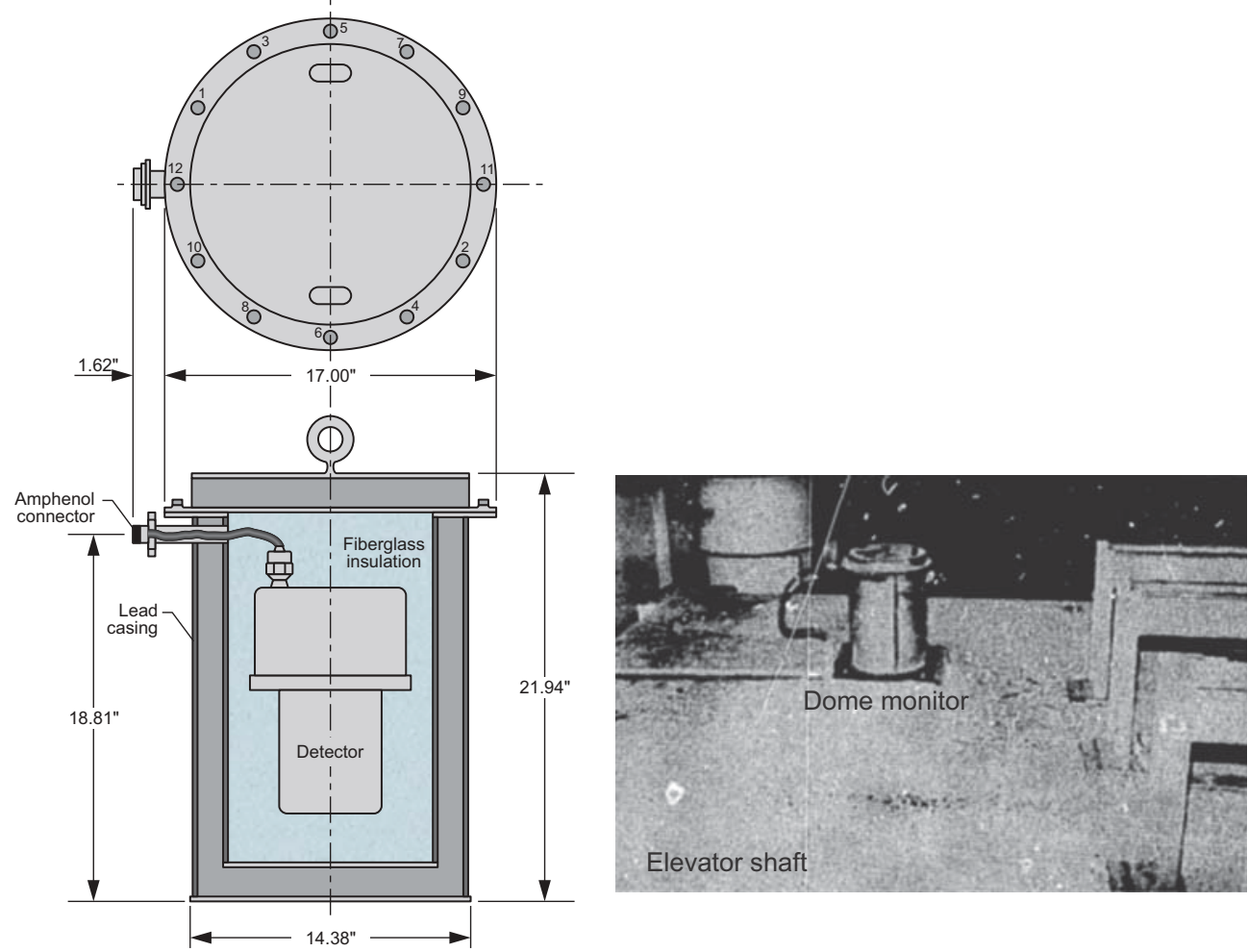

Figure 5-5. Photo and schematic of TMI-2 HP-R-214 dome monitor in stainless steel container.

these measurements were taken, all three monitors had failed although the cause of the failures were not discerned from these field measurements.

\subsubsection{Data}

There were no direct measurements of the environmental conditions experienced by these monitors, but it is speculated that the conditions exceeded instrumentation specifications, especially the temperatures near HP-R-210. Available information suggests that temperatures prior to 146 minutes were less then specifications. Therefore, Reference 56 concluded that it was reasonable to assume that at early times periods of interest, the monitors were supplying reasonably accurate information on the gamma radiation in the containment over the designed energy range of $100 \mathrm{keV}$ to $1.5 \mathrm{MeV}$.

Figure 5-6 compares data from HP-R-210, HP-R-213, and HP-R-214. Two curves, HP-R-214A and HP-R-214B, are given for the dome monitor. These two curves are due to uncertainties in the scale on the recorders. Curve A was prepared on the assumption that the span of HP-R-214 covered the full ten inches of recorder HP-U-1901 chart paper. A calibration performed after the accident suggested that the span of the instrument only covered eight inches, i.e., full range of $10^{7} \mathrm{mR} / \mathrm{hr}$ occurred at 3.9 decades on the HP-UR-1901 chart. Since such a shift in calibration could have occurred immediately after the accident, there is no way to determine which calibration applied at the time of the accident. Therefore, these curves may be considered as upper and lower bounds. Furthermore, it should be noted that there are additional uncertainties associated with HP-R-214 data because the dome monitor was positioned inside a lead-lined stainless steel shield. 
The accuracy of data from these monitors is also dependent on proper synchronization of chart time with real time. ${ }^{56,97}$ An operator made a note on the chart which he judged to be at 7:00 a.m. The radiation monitors response to several events during the time period from 4:00 a.m. to 7:30 a.m. are consistent with the operator annotations. Prior to 4:00 a.m. (see Figure 5-6), the monitors appear to be recording normal background levels that had persisted for several days before the accident. These background levels were attributed to activation products, such as ${ }^{16} \mathrm{~N}$ or direct shine effects. At $\sim 4: 00$ a.m., the readings on HP-R-213 and HP-R-214 dropped. The observed decreases appear consistent with the time when the reactor was tripped (thus, implying that the reactor operator's notation was 6 minutes in error, because it should have been 6:54 a.m. rather than 7:00 a.m.). Comparisons with the chart data and relief valve timing also supports this assessment, and Reference 56 concluded that the chart time could be synchronized with clock time to an accuracy of \pm 1 or 2 minutes. However, it is also noted that in the case of some detectors, such as the HP-R-210 and HP-R-214 monitors, the response is delayed by 2-5 minutes due to the flight time from the release points to the sensors.

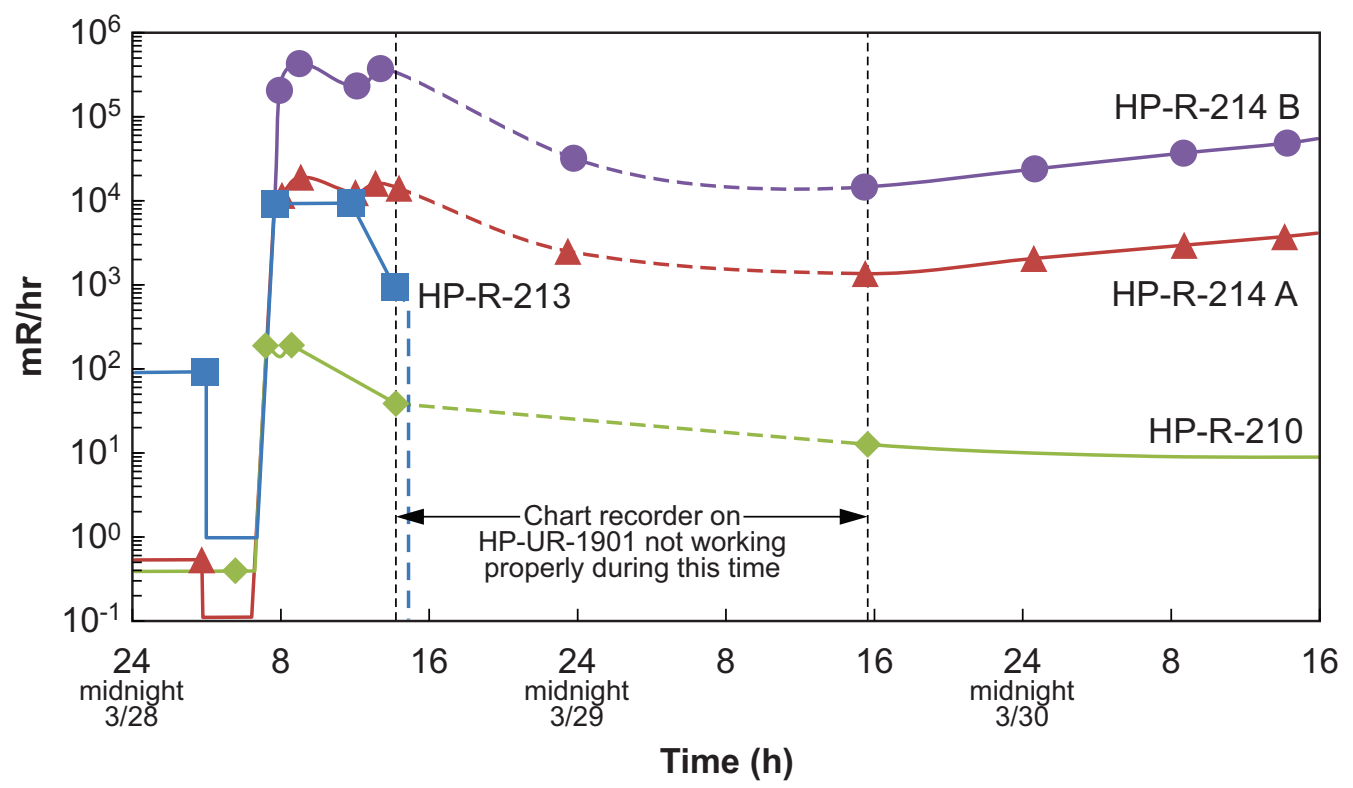

Figure 5-6. Containment radiation monitor response (Two curves are provided for HP-R-214 to reflect upper and lower bounds associated with uncertainties in recording scale).

Reference 56 reported efforts to evaluate if increases observed in chart data at around 6:25 a.m. could be correlated to fuel failures and release of noble gas species, such as ${ }^{133} \mathrm{Xe}$ which emits a $80 \mathrm{keV}$ gamma ray. Reference 56 notes that simplified calculations show that ${ }^{133} \mathrm{Xe}$ release from less than 10 fuel rods could significantly increase the response of monitors. The absence of any upscale behavior in any of the detectors prior to this time (and recognizing that there was a delay time of up to 5 minutes), Reference 56 concluded that there weren't any significant fuel failures prior to approximately 6:20 a.m. These failures were independent of actions to close the ERV block valve. It should also be noted that this was the approximate time that the block valve was closed. Although the upscale behavior of these monitors can be used to detect initial fuel failures, they cannot be used to provide insights about the magnitude or number of fuel failures. Uncertainties with respect to the effects of shielding, the effects of the environmental conditions 
on sensor performance, contributions of other species released during the accident, and the increase associated with direct shine from the reactor, are just some of the factors that preclude any such insights.

\subsubsection{Status}

The radiation levels measured by all the radiation monitors (e.g., the amplitude of the radiation monitor outputs) are classified as "Trend Data." As discussed in Section 3.4, this classification was assigned because of the unacceptably large uncertainty found in these measurement values. From a study of the recorded radiation levels it was concluded that (1) there were large uncertainties in the measurements after calibration, (2) there was no evidence that the detectors had been calibrated within years of the accident, (3) radiation effects on the electronic systems may have influenced readings after the accident.

The time-base of the data were classified as "Qualified," and uncertainties were assigned as ranging from 2 to 15 minutes. The uncertainties in the time-bases were estimated from the work done in establishing and correcting the time-base of each data set. No formal uncertainty analysis could be made on the radiation monitor data, either radiation levels or the time-base.

References 97 through 99 report results from examinations of the HP-R-211 area radiation detector, which was removed from the TMI-2 containment building on August 15, 1980. The detector, as noted above, was a gamma radiation monitor manufactured by Victoreen (Model 857-20) and employed a G-M tube. During the first day of the accident, the environment inside the containment was one of intense beta and gamma radiation, steam, moderate temperature excursions (up to $30^{\circ} \mathrm{C}$ ), a hydrogen burn and resultant pressure spike (up to $0.19 \mathrm{MPa}$-gauge), and $\mathrm{NaOH}$ /boron spray. The detector was judged to have failed at some time following the accident and indicated erroneous, low radiation levels after that point. Examinations indicated that the failure mode was a low impedance fault between the collector and emitter leads in a transistor in the detector output circuit. The transistor failed due to catastrophic, non-annealing, punch-through from collector to emitter caused by high voltage breakdown and energy deposition. Evidence suggested that this failure at least partially occurred when the reactor building sprays were initiated at 10 hours into the accident. Apparently, sprays and/or steam entered the connector assembly where the detector and cable mate, causing the 600 volt G-M tube power line to short, momentarily, to the signal output line. The authors suggested that these connections be redesigned in the future, and if possible that active electronics be located outside the containment. Further examinations of the cabling and transistors indicated that the long cabling lengths and radiation degradation of the transistors may lead to inaccurate radiation level measurements indicating lower radiation levels than are present in the containment. The authors recommended redesigning the circuit and using more radiation tolerant transistors to overcome these issues. Evaluations indicate that the electronics had received gamma radiation doses of $2.5 \times 10^{5}$ rads. However, decontamination efforts revealed that Cs-137 concentrations were as high as $0.973 \mu \mathrm{Ci} /$ $\mathrm{cm}^{2}$, which were higher than concentrations on the floors and walls.

Reference 100 reports results from examinations of the HP-R-213 detector, which was removed from the TMI-2 containment building on May 28, 1981. Data suggest that this detector failed at the time of the hydrogen burn. Most of the time, this detector was pegged at its maximum reading of $10^{4} \mathrm{mR} / \mathrm{hr}$. As noted above, this detector is also a Victoreen (model 857-2) design and employs a G-M tube to detect events. It was located in the in-core instrumental service area at the 347 foot level (see Figure 5-4). Data (see Figure 5-6) suggest that it was operational during the accident, but at its maximum upper limit, until the hydrogen burn occurred. Then, its output went to zero. Examinations indicate that the cause of the failure was a cracked G-M tube due to thermo-mechanical shock imparted to the entire detector assembly by the 
hydrogen burn. However, the numerous chips and scratches around the glass-to-metal seal suggest that the glass was in a weakened state prior to the hydrogen burn. Reference 100 notes that the glass thickness and printed circuit board mounting methods should have allowed a good quality tube to withstand substantially higher shocks and recommends that tighter quality controls be instituted to prevent such failures. Examinations suggest that the total gamma radiation dose accumulated by this detector was $9.9 \times 10^{5}$ rads.

Reference 101 reports results from examinations of the HP-R-212, which was removed from the TMI-2 containment building on November 13, 1981. As noted above, the HP-R-212 detector was not powered up until 92 days after the accident. Available data indicate that the detector only worked for five months, starting to fail in November 1979. This area radiation detector was located in the Equipment Hatch area at the 305-foot level. The detector was a gamma radiation monitor manufactured by Victoreen (Model 857-2) and employs a G-M tube to detect events. It is of the same design as radiation detectors HP-R-211 and HP-R-213. Examination of the detector showed the failure to be a G-M tube that had apparently used up the quench gas and was in continuous discharge. This detector design is not capable of driving 366 meters (1200 feet) of cable at a frequency of $40 \mathrm{KHz}$. Therefore, when the G-M tube went into continuous discharge, the output did not go to a reading of $10 \mathrm{R} / \mathrm{hr}$ as it should have, but read $20 \mathrm{mR} / \mathrm{hr}$. Reference 101 recommended several design changes for this detector and associated circuit for the rate meter. Examinations suggest that the total gamma radiation dose accumulated by this detector was $4.5 \times 10^{5}$ rads.

During the accident at TMI-2, operators used the Dome Monitor readings as required and declared a General Emergency based on an $8 \mathrm{R} / \mathrm{hr}$ high alarm. However, because of a low Containment Building pressure of only $7 \mathrm{kPa}$-gauge and concerns about the accuracy of the $40 \mathrm{R} / \mathrm{hr}$ calculation associated with this detector and its shielding, the supervisor ordered radiation surveys to be made around the plant boundary prior to recommending an evacuation. Radiation surveys revealed that no significant levels of radioactivity had been detected.

Reference 102 examinations of the Dome Monitor revealed that, while the declaration of a General Emergency was proper, the radiation levels measured were probably inaccurate at that time. Much later in the accident, they were certainly inaccurate. Reference 102 concluded that circuit failures occurred in the HP-R-214 monitor at various times during and following the first days of the accident. Failures in the detector electronics package and preamplifier circuits occurred within the first 3 hours of the accident due to moisture intrusion from the containment atmosphere. Radiation levels degraded transistors within the ion chambers in the Dome Monitor. As noted previously, the accuracy of the dome monitor was also decreased because of uncertainties associated with the recording scale and by the presence of a thick lead and stainless steel shield used to protect the detector and its electronics.

Reference 102 concluded that the accident at TMI-2 demonstrates the need for improving radiation measurements during a loss-of-coolant accident. The Dome Monitor failures indicate that similar systems should be reconsidered. Reference 102 provided several recommendations for design improvements, such as better seals that are periodically leak tested, use of radiation resistant components and placing electronics outside the containment so that the lead shield could be removed. Finally, accident analysis indicates that equipment used in containment should undergo more extensive environmental testing prior to installation. 


\subsection{Summary}

The effort to qualify data for TMI-2 post-accident evaluations of sensors within the reactor containment building included integration of available data, analysis relying on basic engineering principals, operator information, laboratory evaluations, comparisons with accident simulation results, and post-accident inspections of selected sensors. Results led to increased understanding of the accident that might not have been obtained otherwise. In addition, investigations provided significant insights related to what types of conditions (e.g., temperatures, pressures, dose levels, etc.) were experienced by sensors, what failures occurred, and what types of enhancements were needed to ensure that operators have better access in the future to the data required to diagnose and mitigate unanticipated events.

A significant result from the containment sensor investigations was the determination of the peak pressure associated with the hydrogen burn. Note that this peak pressure was only obtained by considering the results from diverse pressure sensors within the containment that covered a range of pressures. In addition, calculations assuming peak pressure values yield peak containment temperatures higher than available temperature data, which had a limited sampling rate. Such results emphasize the benefits of the comprehensive sensor performance and data qualification efforts undertaken after the TMI-2 accident and suggest that similar benefits could be obtained from evaluations of instrumentation and data from Daiichi Units 1 , 2 , and 3 .

Specific insights gained from the TMI-2 containment sensor evaluations include:

- Data unavailability was often due to computational limits, such as storage memory, inadequate paper or ink, insufficient sampling rates, and 'preset' limits associated with the anticipated operating range (rather than the sensor operating limits). A wider range of limits and enhanced computational capabilities, with easy-to-read graphical displays, could easily alleviate limitations, such as encountered with limited building RTD temperature and steam generator reference pressure transmitter sampling.

- No functional damage to the nuclear plant instrumentation or electrical components from thermal effects of the hydrogen burn could be identified. One G-M tube was determined to have failed at the time of the hydrogen burn, but its failure was deemed to be shock-related, possibly caused by the pressure wave associated with the hydrogen burn.

- Post-accident evaluations emphasized the need for more robust containment radiation measurement instrumentation. Identified Dome Monitor failures and data uncertainties led to several recommendations for design improvements, such as better seals that are periodically leak tested, the use of moisture and radiation resistant components and cabling, and relocating electronics outside the containment so that the lead shield could be removed.

- Evaluations emphasized the need to consider anticipated applications and more extensive inspection and maintenance programs for instrumentation and related systems. For example, data unavailability or high uncertainties could have been alleviated by the use of better installation and testing procedures with increased calibration checks. Such actions could have alleviated issues observed in dome monitor and RTD components.

- Surrogate testing of similar sensors and components that were more easily accessible and not required for plant safety monitoring, such as core drain tank water level and pressure measuring system components, allowed insights related to instrumentation degradation to be obtained without adversely impacting systems essential to maintaining the TMI-2 plant in a safe condition. 
In summary, a comprehensive set of instrumentation evaluations, that included careful integration of available data, analysis relying on basic engineering principals, operator information, laboratory evaluations, comparisons with accident simulation results, and post-accident inspection, was required for researchers to qualify containment sensor data for TMI-2 accident simulations. Knowledge gained from these evaluations offered important lessons for the industry with respect to sensor survivability, the need for additional and/or enhanced sensors and indicators, and the identification of unanticipated failure modes for sensors when exposed to extreme accident conditions. A similar process should be followed at Daiichi Units 1, 2, and 3 to reap BWR-specific benefits. 


\section{SUMMARY}

The accident at the TMI-2 reactor provided a unique opportunity to evaluate sensors exposed to severe accident environments. Conditions associated with the release of coolant and the hydrogen burn that occurred during the TMI-2 accident exposed instrumentation to harsh conditions, including direct radiation, radioactive contamination, and high humidity levels with elevated temperatures and pressures. As part of a program initiated in 2012 by the LWRS and NEET Programs within the DOE-NE, a review of TMI-2 references was completed to gain insights from prior TMI-2 sensor survivability and data qualification efforts. In addition, this effort was undertaken to provide insights related to sensor and data evaluations that could be implemented in upcoming Fukushima Daiichi recovery efforts.

Over 100 references related to instrumentation performance and post-accident evaluations of TMI-2 sensors and measurements were reviewed in this effort. Insights gained from this review are summarized within this section. As documented in this report, the post-accident evaluations of instrumentation components and data provided significant insights related to what types of conditions (e.g., temperatures, pressures, dose levels, etc.) were experienced by sensors, what failures occurred, and what types of enhancements were needed to ensure that operators have better access in the future to the data required to diagnose and mitigate unanticipated events. Sensors allowed approximately 3000 measurements to be made at TMI-2. However, the effort documented in this report focussed upon the set of sensors deemed most important by post-TMI-2 DIRC and instrumentation evaluation programs. In these earlier programs, efforts were focussed on data required by TMI-2 operators to assess the condition of the reactor and containment and the effect of mitigating actions taken by these operators. In addition, the prior effort focussed upon sensors providing data required for subsequent accident simulations. Table 6-1 lists the sensors evaluated in this report.

The effort required to qualify data from sensors for TMI-2 post-accident evaluations included careful integration of instrumentation data, analysis relying on basic engineering principals, operator information, laboratory evaluations, comparisons with accident simulation results and large integral test data, and post-accident inspection. Initially, sensors were interrogated in-situ; and data were compared with data from other sensors to evaluate if responses were consistent (e.g., higher temperatures at times when flux levels implied lower water levels, etc.). For example, comparisons of the response from various RCS sensors provided confidence about key accident phenomena. As discussed within this document, the simultaneous increase in SRM count rate, RCS pressure, and cold leg temperatures, provided analysts confidence about the timing of a major relocation of materials from the reactor core to the lower head. As another example, peak values for parameters such as containment building temperature would not have been obtained without considering the results from other sensors such as the containment building pressure transmitters. As noted within this document, calculations assuming peak pressure values yielded peak containment temperatures much higher than measured temperature data, which had a limited sampling rate. Such results emphasize the benefits of the comprehensive sensor performance and data qualification efforts undertaken after the TMI-2 accident.

To gain additional insights related to the response of selected sensors, laboratory evaluations were performed, exposing sensors to conditions postulated to have occurred during the TMI-2 accident. In some cases, measured responses were compared with the response of sensors exposed to similar conditions in large scale experiments, such as tests conducted in the LOFT and Semiscale facilities. In other cases, insights related to sensor response and accident progression were gained by performing neutronics calcula- 
Table 6-1. TMI-2 Sensors Reviewed in this Report.

\begin{tabular}{|c|c|c|c|}
\hline Parameter & Sensor & Function & Post-Accident Status \\
\hline \multicolumn{4}{|c|}{ RCS } \\
\hline $\begin{array}{l}\text { Core Exit } \\
\text { Temperature }\end{array}$ & Type K TC & $\begin{array}{l}\text { Primary: core exit temperature; } \\
\text { Secondary: Insights on liquid } \\
\text { level }\end{array}$ & $\begin{array}{l}\text { Failed due to high temperatures, steam, and } \\
\text { moisture ingress following sheath } \\
\text { degradation; Virtual junction formation } \\
\text { occurred in many of these thermocouples. }\end{array}$ \\
\hline $\begin{array}{l}\text { Cold Leg } \\
\text { Temperature }\end{array}$ & Platinum RTDs & Primary: Inlet temperature & $\begin{array}{l}\text { Operating; some cabling and connector } \\
\text { damage may have allowed moisture to } \\
\text { degrade insulation; extension cable shorting } \\
\text { may have occurred }\end{array}$ \\
\hline $\begin{array}{l}\text { Hot Leg } \\
\text { Temperature }\end{array}$ & Platinum RTDs & $\begin{array}{l}\text { Primary: Outlet temperature } \\
\text { Secondary: Insights on RCS } \\
\text { pressure }\end{array}$ & $\begin{array}{l}\text { Operating; some cabling and connector } \\
\text { damage may have allowed moisture to } \\
\text { degrade insulation; extension cable shorting } \\
\text { may have occurred }\end{array}$ \\
\hline $\begin{array}{l}\text { Reactor Coolant } \\
\text { Pressure }\end{array}$ & Pressure transmitters & Primary: RCS pressure & $\begin{array}{l}\text { Operational, but RCS pressure primarily } \\
\text { below } 11.7 \mathrm{MPa} \text {-gauge. }\end{array}$ \\
\hline $\begin{array}{l}\text { Flux - In-Core } \\
\text { Measurements }\end{array}$ & $\begin{array}{l}\text { Self-Powered Neutron } \\
\text { Detectors (SPNDs) on In-Core } \\
\text { Instrumentation Assemblies and } \\
\text { Moveable In-Core Detection } \\
\text { System }\end{array}$ & $\begin{array}{l}\text { Primary: Neutron flux } \\
\text { Secondary: Insights on } \\
\text { temperature and liquid level }\end{array}$ & $\begin{array}{l}\text { Most damaged due to high temperatures, } \\
\text { steam, and moisture ingress causing sheath } \\
\text { degradation. }\end{array}$ \\
\hline \multirow{3}{*}{$\begin{array}{l}\text { Flux - Ex-Core } \\
\text { Measurements }\end{array}$} & $\begin{array}{l}\text { Source Range Monitors } \\
\text { (SRMs) }\end{array}$ & \multirow{3}{*}{$\begin{array}{l}\text { Primary: Neutron flux } \\
\text { Secondary: Qualitative insights } \\
\text { on core liquid level }\end{array}$} & Operational \\
\hline & $\begin{array}{l}\text { Intermediate Range Monitors } \\
\text { (IRMs) }\end{array}$ & & $\begin{array}{l}\text { Operational, but large uncertainty. Power } \\
\text { levels at lower end of operating range. }\end{array}$ \\
\hline & Power Range Monitors (PRM) & & $\begin{array}{l}\text { Power levels at lower end of operating } \\
\text { range. }\end{array}$ \\
\hline $\begin{array}{c}\text { Pressurizer Liquid } \\
\text { Level }\end{array}$ & $\begin{array}{l}\text { Differential Pressure } \\
\text { Transmitter }\end{array}$ & Primary: Pressurizer liquid level. & Operational \\
\hline $\begin{array}{l}\text { Steam Generator } \\
\text { Water Level }\end{array}$ & $\begin{array}{l}\text { Differential Pressure } \\
\text { Transmitters }\end{array}$ & Primary: SG water level & $\begin{array}{l}\text { Operational, but full range transmitter } \\
\text { installed incorrectly. }\end{array}$ \\
\hline $\begin{array}{l}\text { Loose Parts } \\
\text { Monitoring }\end{array}$ & $\begin{array}{l}\text { Accelerometer and charge } \\
\text { converters }\end{array}$ & Primary: Presence of loose parts & $\begin{array}{l}\text { Charge converter degraded due to gamma } \\
\text { radiation }\end{array}$ \\
\hline $\begin{array}{l}\text { Hot Leg Mass } \\
\text { Flowrate }\end{array}$ & Mass flowmeter & Primary: Mass flowrate & $\begin{array}{l}\text { Operational; required corrections for } \\
\text { depressurization and voiding }\end{array}$ \\
\hline \multicolumn{4}{|c|}{ Containment } \\
\hline Building Pressure & Pressure transmitter & $\begin{array}{l}\text { Primary: Pressure; } \\
\text { Secondary: timing of hydrogen burn }\end{array}$ & Operational \\
\hline $\begin{array}{l}\text { Building } \\
\text { Temperature }\end{array}$ & Platinum RTDs & Primary: Temperature & $\begin{array}{l}\text { Operational, although possible degradation } \\
\text { due to moisture; Data points too far apart to } \\
\text { be useful during hydrogen burn. }\end{array}$ \\
\hline $\begin{array}{l}\text { Core Flood Tank } \\
\text { Pressure Monitor }\end{array}$ & $\begin{array}{l}\text { Pressure transmitter sealed in } \\
\text { stainless steel casing }\end{array}$ & $\begin{array}{l}\text { Primary: Core Flood Tank } \\
\text { Pressure }\end{array}$ & Operational \\
\hline $\begin{array}{l}\text { Core Flood Tank } \\
\text { Water Level } \\
\text { Monitor }\end{array}$ & $\begin{array}{l}\text { Transmitter with linear variable } \\
\text { differential transformer } \\
\text { (LVDT) and bellows }\end{array}$ & Primary: Water Level & $\begin{array}{l}\text { Three of the four units experienced seal } \\
\text { failures allowing severe corrosion }\end{array}$ \\
\hline $\begin{array}{l}\text { Building Radiation } \\
\text { Levels }\end{array}$ & $\begin{array}{l}\text { Area Radiation Monitors } \\
\text { Most: Geiger-Muller (G-M) } \\
\text { tube gamma detectors } \\
\text { Dome Monitor: Ion chamber }\end{array}$ & $\begin{array}{l}\text { Primary: radiation monitor; } \\
\text { Secondary: Timing of fuel failure } \\
\text { and fission product release }\end{array}$ & $\begin{array}{l}\text { Failed due to high temperatures, pressure } \\
\text { wave associated with hydrogen burn, high } \\
\text { radiation levels, and moisture. }\end{array}$ \\
\hline
\end{tabular}


tions for postulated conditions and comparing calculation results with available data. As the TMI- 2 recovery efforts progressed, selected sensors were removed from the RCS and containment for evaluation.

Evaluations of TMI-2 instrumentation demonstrated that both safety and non-safety-related sensors and components were affected by adverse environments and that many of these problems could have been avoided through applications engineering and more appropriate specifications, with only minor design changes being necessary. Specific insights gained from the TMI-2 sensor and data evaluations include:

- Data unavailability was often due to computational limits, such as storage memory, inadequate paper or ink, insufficient sampling rates, and 'preset' limits associated with anticipated operating ranges (rather than sensor operating limits). A wider range of limits and enhanced computational capabilities, with easy-to-read graphical displays, could easily alleviate limitations, such as encountered with limited building RTD temperature and steam generator reference pressure transmitter sampling.

- Data unavailability was often due to sensor range limitations that were focused on assumed normal operating conditions. For example, sensors with ranges that encompassed unanticipated accident conditions (e.g., at saturated conditions with steam voids present in a PWR) could have provided operators much needed information.

- Data unavailability was also attributed to inadequate status indicators. For example, the inability of the operators to detect that the PORV failed to close could have been rectified by the use of additional indicators and sensors. In this case, indicators were only available to show that the solenoid coil was energized (nothing about the status of the valve position). Since the TMI-2 accident, the US NRC required that licensees make design changes so that positive indication of valve position was available in the control room. However, sensors could also have been included to measure the drain tank water level, which would have provided the operators information that the drain tank relief valve was open. A thorough investigation of other such situations could help alleviate similar occurrences in the future.

- Failures in sensors located within the vessel were due to a combination of high temperatures and moisture ingress following sheath failure. In some cases, vibrations, moisture, and/or radiation exposure led to failures of sensors. Clearly, it is important to have sensors with operating envelopes that are extended to consider more likely accident conditions.

- Failures were often related to transmission component exposure, rather than sensor exposure. For example, cabling and connectors located outside the RCS were subjected to higher than anticipated temperatures, moisture levels, and radiation levels. It was speculated that most of the moisture intrusion problems would have occurred eventually in the plant without the accident. However, better positioning and enhanced components and/or shielding could alleviate such limitations.

- Qualitative insights can be obtained by considering sensor response for alternate applications, e.g., ex-core source-range detector signals provide insights about real-time RCS water levels, in-core SPNDs provide insights about RCS temperature and water levels. However, such interpretations often requires detailed analyses and assumptions related to the status of the RCS and core.

- No functional damage to the nuclear plant instrumentation or electrical components from thermal effects of the hydrogen burn could be identified. One Geiger-Mueller tube was determined to have failed at the time of the hydrogen burn, but its failure was deemed to be shock-related, possibly caused by the pressure wave associated with the hydrogen burn. 
- Evaluations emphasized the need to consider anticipated applications and more extensive inspection and maintenance programs for instrumentation and related systems. For example, data unavailability or high uncertainties could have been alleviated by the use of better installation and testing procedures with increased calibration checks. Such actions could have alleviated issues observed in dome monitor and RTD components.

- Post-accident evaluations emphasized the need for more accurate containment radiation measurements. Identified Dome Monitor failures and data uncertainties led to several recommendations for design improvements, such as better seals that are periodically leak tested, the use of moisture and radiation resistant components and cabling, and relocating electronics outside the containment so that lead shields could be removed.

- Post-accident extraction and examinations are needed to confirm insights from other evaluations. For example, inspections of components from the loose parts monitor system found that they had degraded due to radiation exposure; whereas, data suggested that sensors were still operational.

- Careful evaluations of sensor data led to unexpected detection of instrumentation errors. For example, comparison of SG water level data led to the conclusion that the full range transmitter was incorrectly installed because readings were observed to be erroneously low when the SG was steaming.

- Surrogate testing of similar sensors and components that were more easily accessible and not required for plant safety monitoring, such as core drain tank water level and pressure measuring system components, allowed insights related to instrumentation degradation to be obtained without adversely impacting systems essential to maintaining the TMI-2 plant in a safe condition.

Evaluations described in Sections 4 and 5 emphasized the need for 'applications analyses' to determine possible environments during which the devices must function (or not fail). These "environments" are not limited to just temperature, pressure, humidity (or steam), submersion (flooding), radiation, and vibration (both operational and seismic). They should also include the availability of power sources and the characteristics of supporting services such as instrument air, cooling water, lubrication (allowable contamination levels, moisture), calibration, and preventive maintenance. Such factors are often overlooked details of applications engineering that affect both equipment reliability and the interpretation of information received, as demonstrated at TMI-2.

TMI-2 instrument and electrical equipment degradation was often attributed to moisture ingress and corrosion. Water and vapor intrusion into the equipment housings caused erratic readings and ultimate failure. The TMI-2 post-accident environment was more moist than normal plant conditions, but the number of paths for moisture intrusion, the number of instrument failures, and the extent of corrosion found have generic implications for long-term equipment operability and maintenance practices at operating plants. These findings are reinforced by the fact that TMI-2 had just begun power operation. Seals had not undergone any significant aging, and there was limited human activity regarding disassembly of connectors or potential damage to conduit, connectors, or housing seals. In operating plants, routine maintenance activities will repeatedly disturb and challenge these seals.

It is also worth noting how the US regulatory response was informed by instrumentation evaluations. As part of their initial assessment after the accident, the US NRC required that licensees make design changes so that positive indication of valve position was available in the control room. In addition, prescriptive requirements for more robust instrumentation and computational and power sources to support this instrumentation were implemented. As more insights related to sensor performance became available, additional requirements related to anticipated accident environments were implemented. Although current 
requirements are less prescriptive, they still require that licensees be aware of what data are needed and the conditions that sensors must withstand. Nevertheless, current regulatory guidance for instrumentation does not include a comprehensive evaluation of the instrumentation required during severe accident conditions.

In summary, a comprehensive set of instrumentation evaluations, that included careful integration of available data, analysis relying on basic engineering principals, operator information, laboratory evaluations, comparisons with accident simulation results and large integral tests, and post-accident inspection, was required for researchers to qualify sensor data for TMI-2 accident simulations. Knowledge gained from these evaluations offered important lessons for the industry with respect to sensor survivability, the need for additional and/or enhanced sensors and indicators, and the identification of unanticipated failure modes for sensors when exposed to extreme accident conditions. A similar process should be followed at Daiichi Units 1, 2, and 3 to reap BWR-specific benefits. 


\section{REFERENCES}

1. R. HENRY, TMI-2: An Event in Accident Management for Light-Water-Moderated Reactors, American Nuclear Society, Chicago, IL, 2011.

2. J. REMPE, M. FARMER, M. CORRADINI, L. OTT, R. GAUNTT, and D. POWERS, "Revisiting Insights from Three Mile Island Unit 2 Post-Accident Examinations and Evaluations in View of the Fukushima Daiichi Accident," Nuclear Science and Engineering, 172, November 2012, pp 223-248.

3. B. B. SCHNITZLER and J. B. BRIGGS, "TMI-2 Isotope Inventory Calculations," EGG-PBS-6798, EG\&G Idaho, Inc., Idaho National Laboratory (1985).

4. E. L. TOLMAN, J.P. ADAMS, J. L. ANDERSON, P. KUAN, R. K. MCCARDELL, and J. M. BROUGHTON, "TMI-2 Accident Scenario Update," EGG-TMI-7489, Idaho National Laboratory (1986).

5. M. L. RUSSELL and R. K. MCCARDELL, "Three Mile Island Unit 2 Core Geometry," Nuclear Technology, 87, 865 (1989).

6. J.R. WOLF, J. L. REMPE, L.A. STICKLER, G. E KORTH, D. R. DIERCKS, L. A. NEIMARK, D. W. AKERS, B. K. SCHUETZ, T. L. SHEARER, S. A CHÁVEZ, G. L. THINNES, R. J. WITT. M. L. CORRADINI, and J. A. KOS, “TMI-2 Vessel Investigation Project Integration Report,” NUREG/ CR-6197, U.S. Nuclear Regulatory Commission (1994).

7. J. M. BROUGHTON, P. KUAN, D. A. PETTI, and E. L. TOLMAN, "A Scenario of the Three Mile Island Unit 2 Accident," Nuclear Technology, 87, 35 (1989).

8. F. E. HASKIN, ET AL., "Perspectives on Reactor Safety," NUREG/CR-6042, Rev. 2, SAND93-0971, March 2002.

9. J. G. KEMENY, ET AL., "Report of the President's Commission on the Accident at Three Mile Island," October 1979.

10. M. ROGOVIN and G. T. FRAMPTON, "Three Mile Island: A Report to the Commissioners and to the Public," NUREG/CR-1250, Vols. 1 and 2, January 1979.

11. R. L. MOORE, D. W. GOLDEN, and E.L. TOLMAN, "Three Mile Island Unit 2 Degraded Core Heatup and Cooldown Analysis," Nuclear Technology, 87, 990 (1989).

12. D. J. N. TAYLOR, "TMI SPND Interpretation," Proceedings of the First International Information Meeting on the TMI-2 Accident, Germantown, MD, October 1985.

13. P. HOFMANN, S. J. L. HAGEN, G. SCHANZ, and A. SKOKAN, "Reactor Core Materials Interactions at Very High Temperatures," Nuclear Technology, 87, 146 (1989).

14. C. S. OLSEN, R.R. HOBBINS, and B. A. COOK, "Application of Severe Fuel Damage Experiments to Evaluating Three Mile Island Unit 2 Core Materials Behavior," Nuclear Technology, 87, 884 (1989). 
15. A.D. KNIPE, S.A. PLOGER, and D.J. OSETEK, "PBF Severe Fuel Damage Scoping Test - Test Results Report,” NUREG/CR-4683, U.S. Nuclear Regulatory Commission (1986).

16. W. PASEDAG, "DOE's TMI-2 Accident Evaluation Program," Proceedings of an open forum sponsored by the OECD Nuclear Energy Agency and the U.S. Nuclear Regulatory Commission, Boston, MA, October 20-22, 1993.

17. A.M. RUBIN, "Overview and Organization of Three Mile Island Unit 2 Vessel Investigation Project," Proceedings of an open forum sponsored by the OECD Nuclear Energy Agency and the U.S. Nuclear Regulatory Commission, Boston, MA, October 20-22, 1993.

18. D. W. AKERS and B. K. SCHUETZ, "Physical and Radiochemical Examinations of Debris from the TMI-2 Lower Head," Nuclear Safety, 35, No. 2, 288 (1994).

19. N. COLE, T. FRIEDRICHS, and B. LIPFORD, "Specimens Removed from the Damaged TMI Reactor Vessel," Proceedings of an open forum sponsored by the OECD Nuclear Energy Agency and the U.S. Nuclear Regulatory Commission, Boston, MA, October 20-22, 1993.

20. D. R. DIERCKS and G. E. KORTH, "Results of Metallographic Examinations and Mechanical Tests of Pressure Vessel Samples from the TMI-2 Lower Head," Nuclear Safety, 35, No. 2, 301, (1994).

21. G. E. KORTH, "Peak Accident Temperatures of the TMI-2 Lower Pressure Vessel Head," Proceedings of an open forum sponsored by the OECD Nuclear Energy Agency and the U.S. Nuclear Regulatory Commission, Boston, MA, October 20-22, 1993.

22. D. R. DIERCKS and L. A. NEIMARK, "Mechanical Properties and Examination of Cracking in TMI-2 Pressure Vessel Lower Head Material," Proceedings of an open forum sponsored by the OECD Nuclear Energy Agency and the U.S. Nuclear Regulatory Commission, Boston, MA, October 20-22, 1993.

23. L. A. NEIMARK, "Insight into the TMI-2 Core Material Relocation Through Examination of Instrument Tube Nozzles," Nuclear Safety, 35, No. 2, 280, (1994).

24. E.L. TOLMAN, “TMI-2 Accident Evaluation Program,” EGG-TMI-7048, Idaho National Laboratory (1986).

25. US NRC, “Three Mile Island Accident of 1979 Knowledge Management Digest," NUREG/KM-001, December 2012.

26. U.S. NRC, “Nuclear Incident at Three Mile Island,” IE Bulletin No. 79-05, April 1, 1979.

27. U.S. NRC, "Nuclear Incident at Three Mile Island - Supplement," IE Bulletin No. 79-05A, April 5, 1979.

28. U.S. NRC, "Review of Operational Errors and System Misalignments Identified during the Three Mile Island Incident,” IE Bulletin No. 79-06, April 11, 1979.

29. U.S. NRC, "Review of Operational Errors and System Misalignments Identified during the Three Mile Island Incident," IE Bulletin No. 79-06A, Rev. 1 and 79-06B, April 14, 1979. 
30. U.S. NRC, "Events Relevant to Boiling Water Power Reactors Identified during Three Mile Island Incident" IE Bulletin No. 79-08, April 14, 1979.

31. U.S. NRC, "Nuclear Incident at Three Mile Island- Supplement," IE Bulletin No. 79-05B, April 21, 1979.

32. U.S. NRC, "Nuclear Incident at Three Mile Island,- Supplement" IE Bulletin No. 79-05C and 79-06C, July 26, 1979.

33. U.S. CONGRESS. SENATE, Committee on Environment and Public Works. Subcommittee on Nuclear Regulation, "Nuclear Accident and Recovery at Three Mile Island," Serial No 96-14, June 1980.

34. U.S. GAO, "Greater Commitment Needed to Solve Continuing Problems at Three Mile Island," GAO-EMD-81-106, August 26, 1981.

35. U.S. GAO, “Three Mile Island: The Most Studied Nuclear Accident In History,” September 1980.

36. ACRS, Letters from Max Carbon to US NRC on "TMI-2 Post -Accident Actions" (1979), "Additional ACRS comments on Hydrogen Control and Improvement of Containment Capability" (Sept. $8,1980)$, etc.

37. U.S. NRC, “TMI-2 Lessons Learned Task Force Status Report and Short-term Recommendations," NUREG-0578, July 1979.

38. U.S. NRC, “TMI-2 Lessons Learned Task Force Final Report,” NUREG-0585, October 1979.

39. U.S. NRC, "Investigation into the March 28, 1979 Three Mile Island Accident by the Office of Inspection and Enforcement," Investigative Report No. 50-320/79-10, NUREG-0600, July 1979.

40. U.S. NRC, "Report of Special Review Group, Office of Inspection and Enforcement on Lessons Learned From Three Mile Island,” NUREG-0616, October 1979.

41. U.S. NRC, "NRC Action Plan Developed as a Result of the TMI-2 Accident, NUREG-0660, Vols. 1 and 2, May 1980.

42. U.S. NRC, “Clarification of TMI Action Plan Requirements," NUREG-0737, November 1980.

43. U.S. NRC, "Clarification of TMI Action Plan Requirements," NUREG-0737, Requirements for Emergency Response Capability,: Supplement 1, January 1983.

44. U.S. NRC, "Resolution of Generic Safety Issues, Section 1. TMI Action Plan Items," NUREG-0933, http://www.nrc.gov/reading-rm/doc-collections/nuregs/staff/sr0933/, last accessed February 27, 2013.

45. U.S. NRC, "Instrumentation for Light-Water-Cooled Nuclear Power Plants to Assess Plant and Environs Conditions during and Following an Accident," Regulatory Guide 1.97, Revision 3, 1983.

46. U.S. NRC, "Criteria for Accident Monitoring Instrumentation for Nuclear Power Plants," Regulatory Guide 1.97, Revision 4, 2006. 
47. IEEE, "IEEE Standard Criteria for Accident Monitoring Instrumentation for Nuclear Power Generating Stations," Standard 497-2002, Reaffirmed June 12, 2008.

48. D. W. GOLDEN, K. AKAGANE, M. COLAGROASSI, P. DUMAZ, T. HAGA, K. HASHIMOTO, J. N. LILLINGTON, R. SAIRANEN. A. SHARON, R. O. WOOTON, T. VAN DER KAA, "Summary of the Three Mile Island Unit 2 Analysis Exercise," Nuclear Technology, 87, 326 (1989).

49. R. D. MCCORMICK, J.L. ANDERSON, and D.W. GOLDEN, "TMI-2 Data Summary Report," EGG-TMI-7843, September 1987.

50. R. RAINISCH, "Analysis of Gamma Scanning of In-Core Detector \#18 (L-11) in Lower Reactor Vessel Head,” TPO/TMI-175, GPU Nuclear Corporation, June 1985.

51. M. E. YANCEY, R. D. MEININGER, and L. A. HECKER, "TMI-2 In-Core Instrument Damage - An Update,” GEND-INF-031, Vol. II, EG\&G Idaho, Inc., Idaho National Laboratory (1984).

52. R. GOLD, J.H. ROBERTS, F.H. RUDDY, C.C. PRESTON, and W.N. MCELROY, "Solid State Track Recorder Neutron Dosimetry in the Three Mile Island Unit-2 Reactor Cavity," HEDL-7484, Westinghouse Hanford Company (1985).

53. V. R. FRICKE, “Core Debris Bed Probing,” TPB 84-8, Rev. 1, GPU Nuclear Corporation, Feb. 1985.

54. H.D. WARREN, L. BANDA, R. ANDERSON, L. OAKES,W. BENTLEY, A. BUHL, J. JONES, R. MONDAY, J. ROBINSON, and D. CAIN, "Interpretation of TMI-2 Instrument Data," NSAC-28, May 1982.

55. J. L. REMPE, D. L. KNUDSON, K. G. CONDIE, and S. C. WILKINS, "Thermocouples for High-Temperature In-Pile Testing," Nuclear Technology, 156, No. 3, December 2006, pp 320-331.

56. “Analysis of Three Mile Island - Unit 2 Accident," Electric Power Research Institute Report NSAC-80-1, Revised March 1980.

57. M.E. YANCEY and N. WILDE, "Preliminary Report of TMI-2 In-core Instrument Damage," GEND-INF-031, January 1983.

58. H.M. HASHEMIAN, Maintenance of Process Instrumentation in Nuclear Power Plants, Springer, Berlin, Germany, 2006.

59. R. M. CARROLL and R. L. SHEPARD, "Post-Accident Examination of Platinum Resistance Thermometers Installed in the TMI-2 Reactor," GEND-INF-064, September 1985.

60. H.D. WARREN, "SPND Thermal Currents in a Furnace," Appendix B, Interpretation of TMI-2 Instrument Data, NSAC-28, May 1982.

61. R. D. MEININGER, "Three Mile Island Technical Information and Examination Program Instrumentation and Electrical Summary Report," GEND 050, July 1985.

62. N. WILDE and J.L. MORRISON, "Response of the SPND Measurement System to Temperature during the Three Mile Island Unit 2 Accident," GEND-017, December 1981. 
63. M. N. BALDWIN and H. D. WARREN, "SPND Thermal Currents in a Furnace and Gamma Ray Field," Appendix C, Interpretation of TMI-2 Instruments and Data, NSAC-28, 1982.

64. H. D. WARREN and N. H. SHAH, "Neutron and Gamma-Ray Effects on Self-Powered In-Core Radiation Detectors," Nuclear Source and Engineering, Vol. 54, 1974, pp. 395-415.

65. H. ROCK and J. RANTANEN, "Temperature and Radiation Tests With Pt- and Rh Self Powered Neutron Detectors," Nuclear Instruments and Methods, Vol. 164, 1979, pp. 205-207.

66. C. P. CANNON, et al. "Mechanisms for Anomalous Signal Outputs from Self-Powered Neutron Detectors Dur1ng the TMI-2 Accident," Letter report to the U.S. Dept. of Energy, Middletown. PA. dated October 31, 1984.

67. R. D. MCCORMICK, "TMI-2 Source and Intermediate Range Neutron Flux Monitors Data Report," EGG-TMI-7174, March 1986.

68. "ANISN: Multiqroup One-Dimensional Discrete Ordinates Transport Code With Anisotropic Scattering," Radiation Shielding Information Center, CCC-254 (1979).

69. "DOT-IV: Two-Dimensional Discrete Ordinates Radiation Transport Code System," Radiation Shielding Information Center, CCC-320 (1979).

70. H.-Y. WU, A. J. BARATTA, M.-Y. HSIAO, and B. R. BANDINI, "Analysis of the TMI-2 Source Range Monitor during the TMI Accident,” EGG-TMI-7955, June 1987.

71. J. L. ANDERSON, "TMI-2 Pressurizer-Level Response," Proceedings of the First International Information Meeting on TMI-2, Compiled by Sid Langer and Willis R. Young, US Department of Energy Headquarters. Germantown, MD, October 1985.

72. J. L. ANDERSON, “Analysis of TMI-2 Pressurizer Level Indications,” EGG-TMI-7100, January 1986.

73. L. A. HECKER and H. J. HELBERT, "TMI-2 Cable/Connection Program: A Look at In-situ Test Data," GEND-INF-042, December 1983.

74. R. D. MEININGER, D. R. CHICK, C. P. CANNON, M. E. YANCEY, M. R. DINSEL, R. T. SOBERANO, “TMI-2 Cable/Connections Program FY-85 Status Report,” GEND-INF-068, September 1985 .

75. T. K. LARSON et al., Semiscale Simulations of the Three Mile Island Transient - A Summary Report, SEMI-TR-010, July 1979.

76. J. L. ANDERSON, "TMI-2 Once Through Steam Generator Secondary Level Analysis," EGG-TMI-7359, January 1987.

77. J.E. JONES, J. G. SMITH, and M. V. MATHIS, "Field Measurements and Interpretation of TMI-2 Instrumentation: YM-AMP-7023 and YM-AMP-7025,” GEND-INF-017, Vol. VII, January 1982.

78. C. W. MAYO, J. M. HUZDOVICH, A. R. ROBY, and L. D. TEST, "TMI-2 Instrumentation and Electrical Program Final Evaluation Report,” GEND-056, November 1986. 
79. M. B. MURPHY and R. E. HEINTZLEMAN, "Examination Results on TMI-2 LPM Charge Converters YM-AMP-7023 and YM-AMP-7025," GEND-020, November 1982.US NRC, Loose-part Detection Program for the Primary System Of Light-Water-cooled Reactors, Regulatory Guide 1.133, Revision 1, May 1981.

80. R. D. MCCORMICK, “TMI-2 Primary Coolant Mass Flowrate Data Report,” EGG-TMI-7485, December 1986.

81. F.T. SOBERANO, "Final Report on The In Situ Testing of Electrical Components and Devices at TMI-2," GEND-040, June 1984.

82. R. D. MCCORMICK, "Determination of Void Fraction from Source Range Monitor and Mass Flow Rate Data,” EGG-TMI-7324, September 1986.

83. J. K. JACOBY, R. A. NELSON, C. L. NALEZNY, and R. H. AVERIL, "Data Integrity Review of Three Mile Island Unit 2: Hydrogen Burn Data,” GEN-INF-023, Vol. 3, September 1983.

84. J. O. HENRIE and A. K. POSTMA, "Lessons Learned from Hydrogen Generation and Burning during the TMI-2 Event," GEND-061, May 1987.

85. J. W. MOCK, "Review of TMI-2 Resistance Temperature Detectors Accident Data and In-Situ Testing," GEND-INF-024, November 1982.

86. M.O. Fryer, "Analysis of Air-Temperature Measurements from the Three Mile Island Unit 2 Reactor Building," GEND-INF-030, April 1983.

87. J.E. JONES, J. G. SMITH, and M. V. MATHIS, "Field Measurements and Interpretation of TMI-2 Instrumentation: CF-1-PT4,” GEND-INF-017, Vol. I, November 1981.

88. J.E. JONES, J. G. SMITH, and M. V. MATHIS, "Field Measurements and Interpretation of TMI-2 Instrumentation: CF-1-PT3,” GEND-INF-017, Vol. II, November 1981.

89. R. C. STRAHM and M. E. YANCEY, "TMI-2 Pressure Transmitter Examination Program Year-End Report: Examination and Evaluation of Pressure Transmitters CF-1-PT3 and CF-2-LT3," GEND-INF-029, February, 1983.

90. M. E. YANCEY and R. C. STRAHM, "TMI-2 Pressure Transmitter Examination and Evaluation of CF-1-PT1, CF-2-LT1, and CF-2-LT2,” GEND-INF-029, Volume 2, April 1984.

91. M. E. YANCEY and R. C. STRAHM, "Examination and Evaluation of TMI-2 Transmitters CF-1-PT4 and CF-2-LT4," GEND-INF-029, Volume 3, January 1985.

92. J.E. JONES, J. G. SMITH, AND M. V. MATHIS, "Field Measurements and Interpretation of TMI-2 Instrumentation: CF-2 -LT4," GEND-INF-017, Vol. IV, January 1982.

93. J.E. JONES, J. G. SMITH, AND M. V. MATHIS, "Field Measurements and Interpretation of TMI-2 Instrumentation: CF-2 -LT2," GEND-INF-017, Vol. V, January 1982.

94. J.E. JONES, J. G. SMITH, AND M. V. MATHIS, "Field Measurements and Interpretation of TMI-2 Instrumentation: HP-R-212,” GEND-INF-017, Vol. VIII, January 1982. 
95. J.E. JONES, J. G. SMITH, AND M. V. MATHIS, "Field Measurements and Interpretation of TMI-2 Instrumentation: HP-R-213,” GEND-INF-017, Vol. IX, January 1982.

96. J.E. JONES, J. G. SMITH, AND M. V. MATHIS, "Field Measurements and Interpretation of TMI-2 Instrumentation: HP-R-214,” GEND-INF-017, Vol. X, April 1982.

97. R. D. MCCORMICK, “TMI-2 Radiation Monitor Data Report,” EGG-TMI-7376, September 1986.

98. M.B. MURPHY, G. M. MUELLER, and F. V. THOME, "Examination Results of the Three Mile Island Radiation Detector HP-R-211," GEND-014, October 1981.

99. J. W. MOCK, F. T. SOBERANO, and M. B. MURPHY, "Quick Look Report on HP-R-0211 Multivalued Behavior," July 1981.

100. J. M. MUELLER, "Examination Results of the Three Mile Island Radiation Detector HP-R-213," GEND-019, November 1982.

101. G. M. MUELLER, "Examination Results for the Three Mile Island Radiation Detector HP-R-212,' GEND-049, January 1984.

102. M.B. MURPHY, G. M. MUELLER, and W. C. JERNIGAN, "Analysis of the TMI-2 Dome Radiation Monitor," GEND-INF-063, August 1985.

103. F. T. SOBERANO, J. A. GANNON, and K. A. PARLEE, "Static In Situ Test of the Axial Power Shaping Rod and Shim Safety Control Rod Mechanisms," GEND-INF-026, August 1982.

104. “Axial Power Shaping Rod Test Meets with Success at TMI-2," TMI Unit 2 Technical Information and Examination Program Update, Volume 3, Number 1, November 1, 1982, published by EG\&G Idaho for the U.S. Department of Energy (B094-1182-2.5M).

105. R. W. GARNER, D. E. OWEN, and M.R. MARTIN, "An Assessment of the TMI-2 Axial Power-Shaping-Rod Dynamic Test Results,” GEND-INF-038, April 1983. 


\section{APPENDIX A. IN-CORE SYSTEMS}

The TMI-2 reactor relied on several in-core instrumentation systems, which contained multiple sensors. Some of these systems were moveable, allowing limited post-accident probing operations. This appendix describes these systems, system sensors are described in Section 4.

\section{A.1. In-core Instrumentation System}

The in-core instrumentation system at TMI-2 consisted of 364 SPNDs, 52 background detectors, and 52 thermocouples located in 52 instrument assemblies distributed throughout the core (see Figure A-1). Each assembly contained one Type $\mathrm{K}$ thermocouple, one gamma-compensating background detector, and seven rhodium SPNDs. A $0.25 \mathrm{~mm}$ thick Inconel instrument tube protected sensors within the assembly.The assemblies were positioned within the core via guide tubes, which exited the reactor vessel through the bottom head. Figure A-2 shows a block diagram of the in-core instrument assembly and its associated cabling. The SPNDS were equally spaced about $0.52 \mathrm{~m}$ apart along the active region of the core; thermocouple junctions were located approximately 19 to $20 \mathrm{~cm}$ above the core (see Figure A-3).

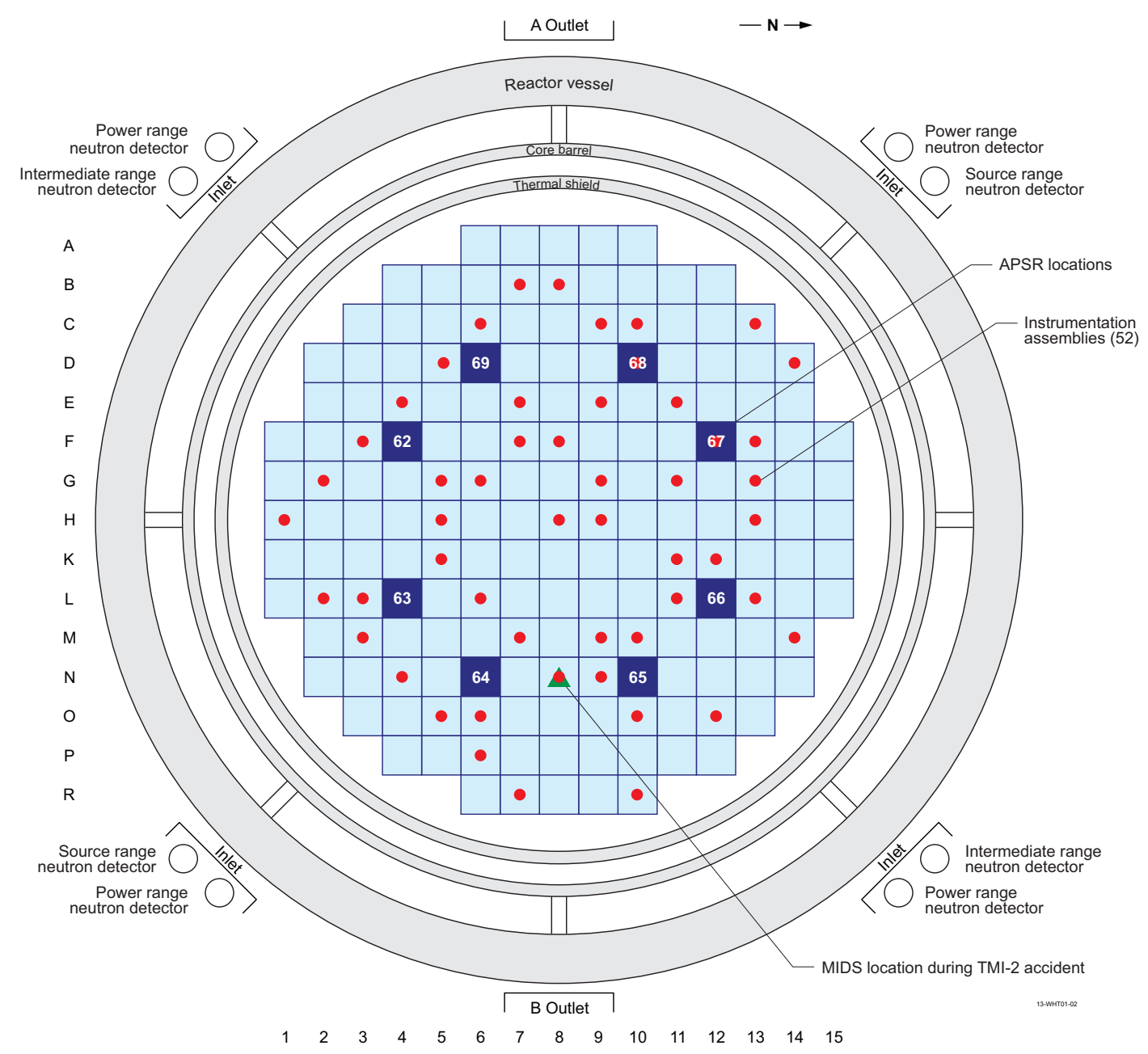

Figure A-1. Grid locations for TMI-2 core instrumentation. 


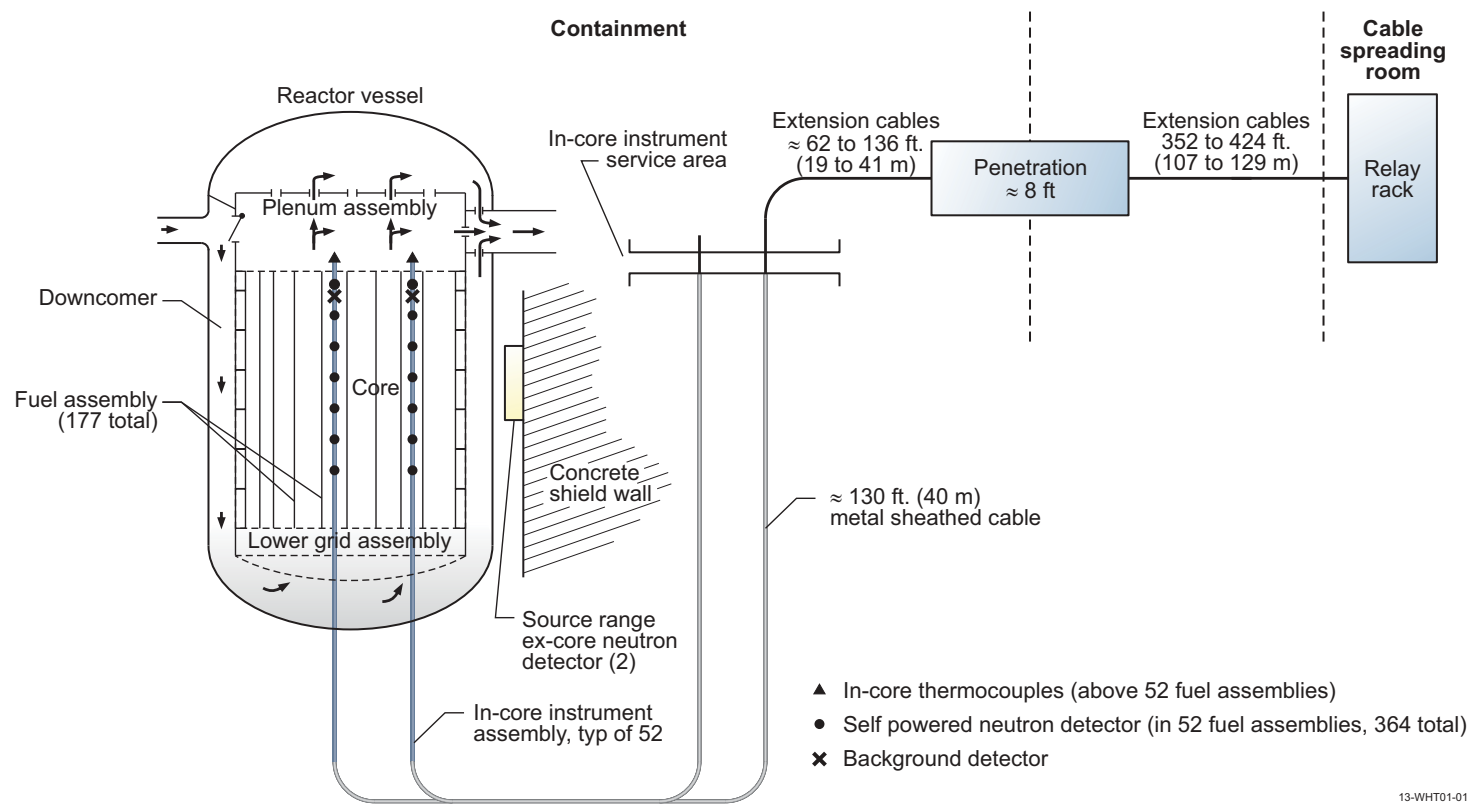

Figure A-2. Block diagram of in-core instrument assembly and associated cabling.

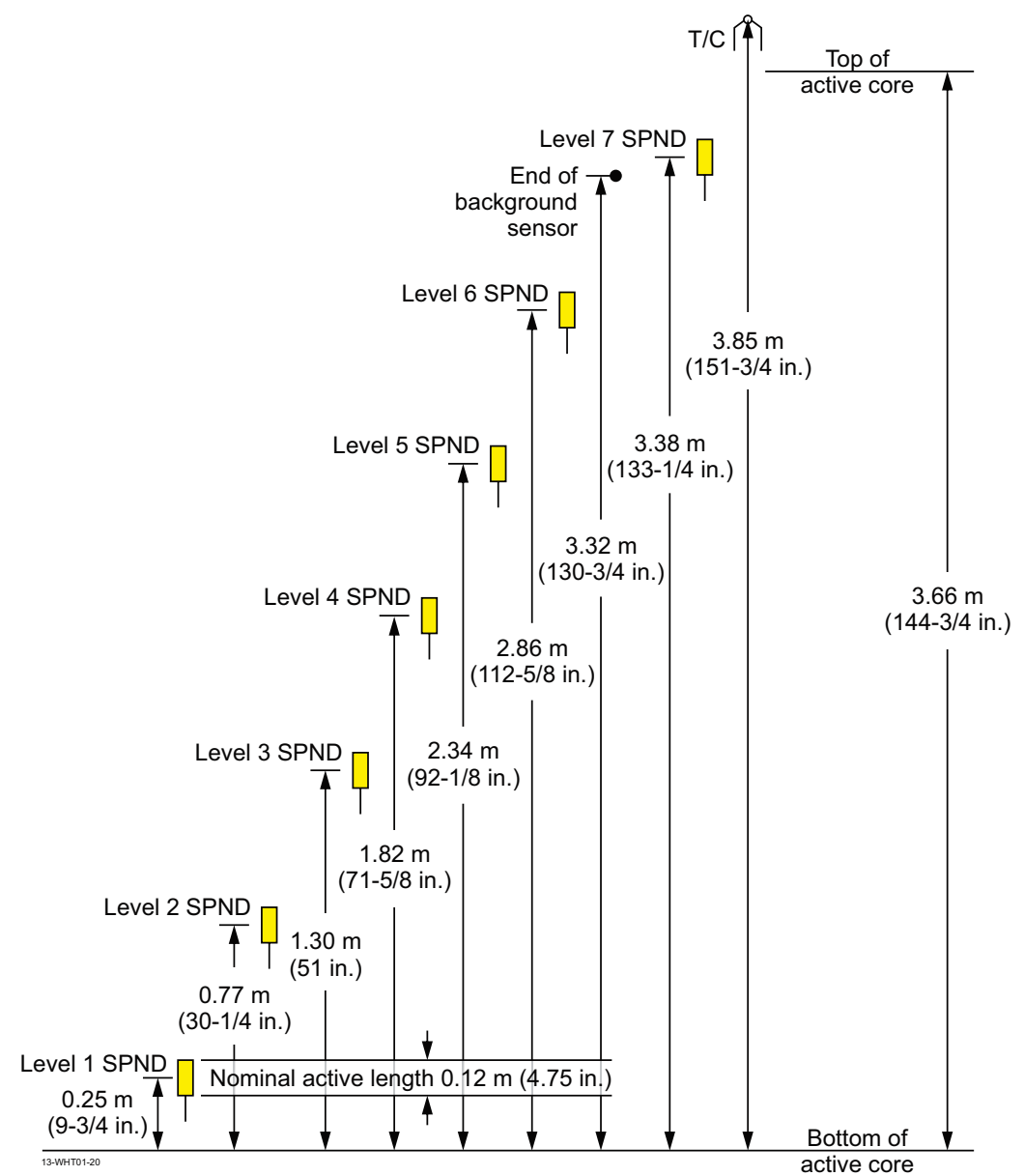

Figure A-3. Axial configuration of the TMI-2 in-core instruments. 
Figure A-4 provides more details related to the internals of the in-core instrumentation assembly. Each SPND consisted of: a rhodium emitter, $0.46 \mathrm{~mm}$ diameter by $0.12 \mathrm{~m}$ long; alumina insulation $(99.75 \%$ pure); a Zircaloy-2 center conductor lead wire, $0.28 \mathrm{~mm}$ in diameter by $39.0 \mathrm{~m}$ long; and an Inconel 600 oversheath $1.6 \mathrm{~mm}$ OD / $1.1 \mathrm{~mm}$ ID and $39.0 \mathrm{~m}$ long. The gamma-compensating sensor was identical to the SPNDs except that it did not have a neutron sensing rhodium emitter. The Type K chromel-alumel thermocouples had alumina insulation and an Inconel 600 outer sheath. The instrument assembly was routed up through the core from the bottom of the reactor vessel. As discussed below, this routing scheme was important in interpreting signals from system sensors.
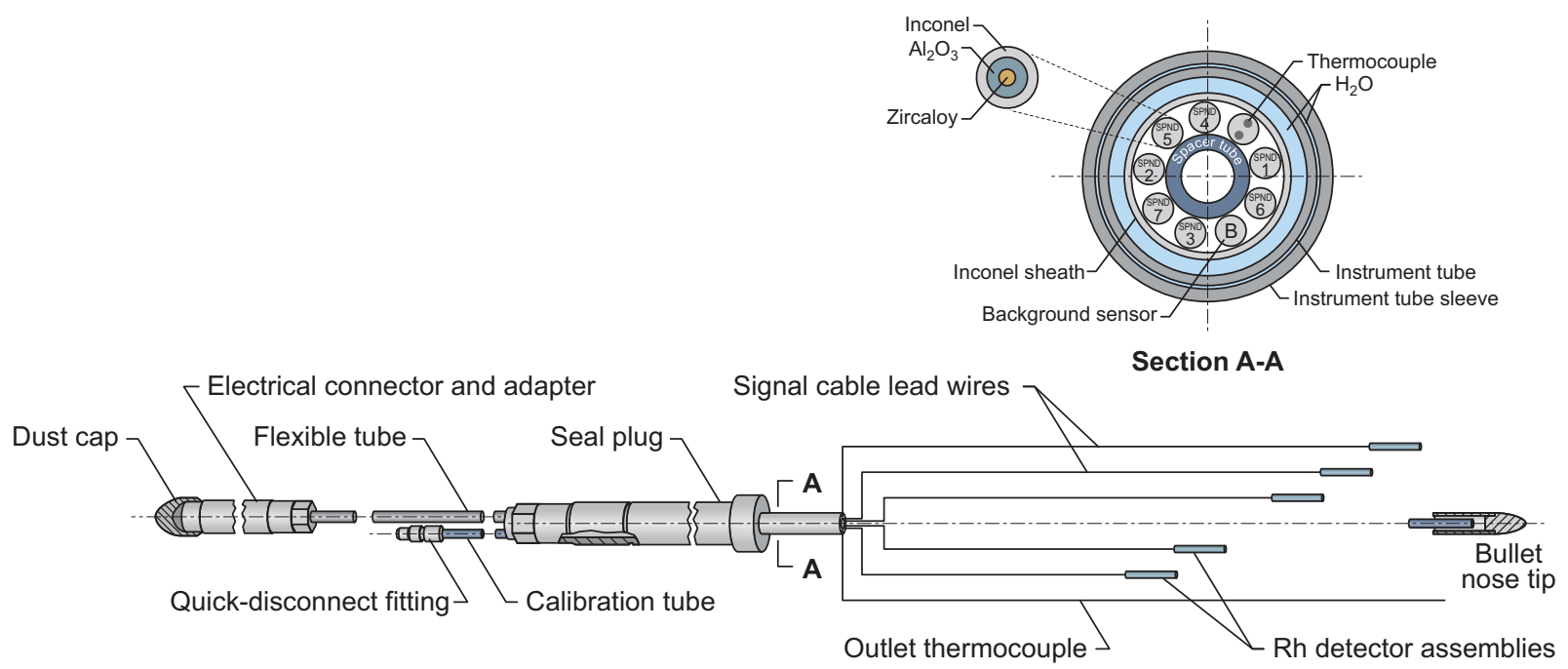

Figure A-4. Standard in-core detector assembly.

\section{A.2. Moveable In-core Detector System}

The TMI-2 reactor was also equipped with a movable in-core detector system (MIDS). Each MIDS instrument tube contained seven SPNDs, one reference gamma detector, and one core exit chromel/alumel thermocouple. The movable detector was housed in a $1.6 \mathrm{~mm}$ OD tube which could be inserted through the $2.4 \mathrm{~mm}$ OD hole in the center of the instrument tube. The MIDS layout is shown in Figure A-5. The drive unit consisted of a $0.5 \mathrm{~m}$ diameter drum driven by an electric motor through a rubber timing belt. The drum was grooved to accept the $1.6 \mathrm{~mm}$ detector housing. The drive was capable of inserting and withdrawing the detector in five minutes (e.g., 2-1/2 minutes for insertion and $21 / 2$ for withdrawal).

The MIDS was used to identify fuel densification and calibrate the in-core SPNDs. Hence, it was capable of insertion into any instrumented assembly in the core. However, to exploit this flexibility of location, the drive unit had to be repositioned. This process required entering the containment; hence, the MIDS location was limited to position N8 during the TMI-2 accident.

The normal parking position for the detector was approximately $3 \mathrm{~m}$ below the active section of the core. It could normally be inserted to a point a few centimeters above the active length of the core. During the early hours of the accident, an attempt was made to make a traverse of the core with the MIDS. The detector could not be moved from the parking location. A second attempt to move the detector was also unsuccessful. However, on the third attempt on April 11, the detector moved away from the parking posi- 


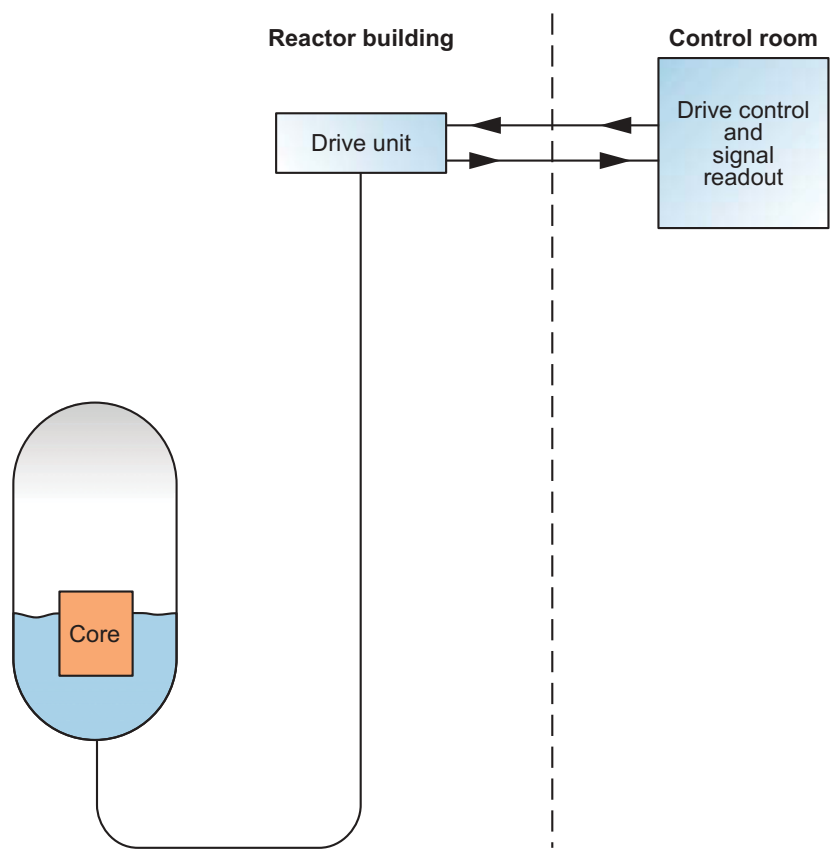

Figure A-5. Moveable in-core detection system.

tion toward the core. After the detector moved only a foot or two into the core, it encountered resistance. Finally, when the unit was inserted approximately three feet into the core, it became stuck and could no longer be either inserted or withdrawn. From these observations, one may conclude that debris had been driven through the tube and deposited around the detector, and that this debris was dislodged after several attempts to insert the detector. After finally getting the detector underway, it encountered an obstruction at the three-foot level. This suggests that the guide tube was damaged and had admitted debris, and that the damage was enough to distort the tube down to the three foot level.

\section{A.3. Axial Power Shaping Rods}

In addition to 61 control rod assemblies, the TMI-2 reactor contained eight axial power shaping rod assemblies (APSRs) that were used to adjust the axial power shape for efficient fuel utilization throughout the lifetime of the core. The APSRs were positioned symmetrically, forming a ring approximately midradius around the core (see Figure A-1). Each APSR assembly contained 16 stainless steel clad silverindium-cadmium shaping rods attached to a common spider, as shown in Figure A-6. Each APSR was inserted into a fuel assembly through guide tubes located within the assembly (see Figure A-7).

The APSRs did not perform a safety or control function, but were used only to flatten the axial power distribution within the core. Following the TMI-2 accident, the eight axial power shaping rods were in a partially withdrawn $(94 \mathrm{~cm})$ position $(25 \%$ of their full travel). At this position, $75 \%$ of their length remained inserted in the fuel assemblies. However, prior to head removal and core defueling, it was desirable that the APSRs be either fully inserted, or at least inserted to a hard-stop position, to provide vertical and torsional stability during the uncoupling of the drive leadscrews from the rod spider hubs. 


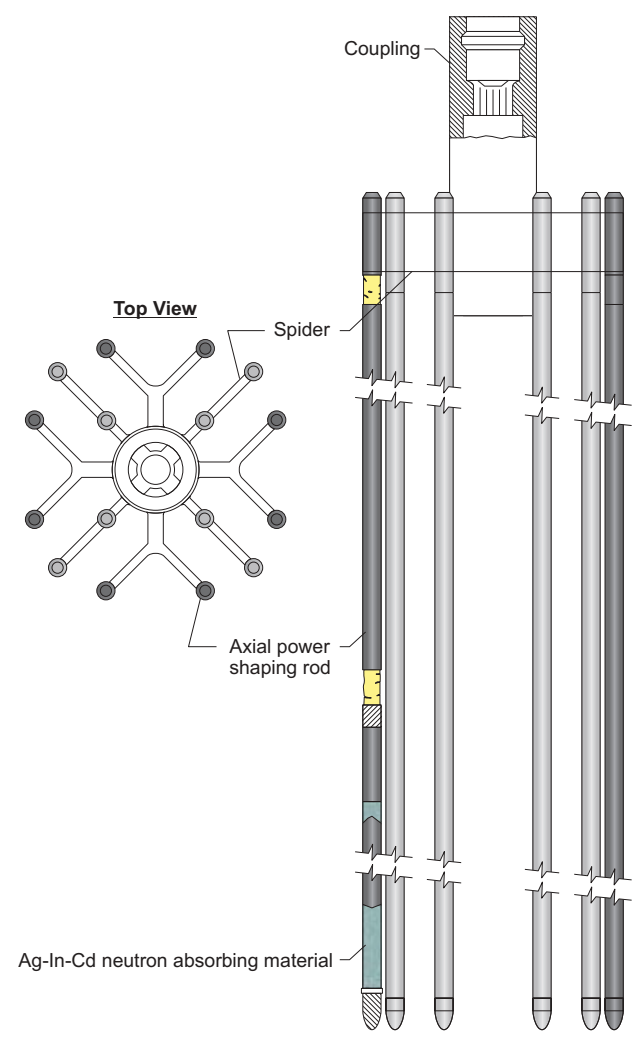

Figure A-6. TMI-2 axial power shaping rod assembly.

Although the eight APSRs contained no instrumentation, these assemblies were used as one method to evaluate the endstate of the TMI-2 core. In addition, accelerometers were mounted on the drive mechanisms of all the APSRs in an attempt to obtain acoustical signals that would provide some information about the physical condition of the APSRs and of the damaged TMI-2 reactor core.

As noted in Reference 104, the position indicators for the APRs survived the accident. However, as noted in References 104 and 105, initial attempts (June 23 to 25, 1982) to insert the APSRs encountered blockages in certain core positions. Although nearly half of the APSRs could be entirely (or almost entirely) inserted into the core [at locations 62(F-4), 65(N-10), 66(L-12), and 67(F-12)], APSRs encountered blockages that precluded much (or any) additional movement at other locations [e.g., 63(L-4), 64(N6), 68(D-10), and 69(D-6)]. Reference 105 noted that the locations where APSRs could be fully inserted correlated with locations where severe damage was observed in the initial "Quick Look" video inspections of the TMI-2 core. It was speculated that nearly complete insertion was possible because there was nearly total breakup of fuel assemblies and APSR assemblies at these locations. In addition, Reference 105 hypothesized that limited or no APSR movement at other locations was due to interference from core debris or distorted upper plenum support plates. Although qualitative insights were possible, no definitive information related to the physical condition of the TMI-2 core was obtained from the APSR evaluations. 


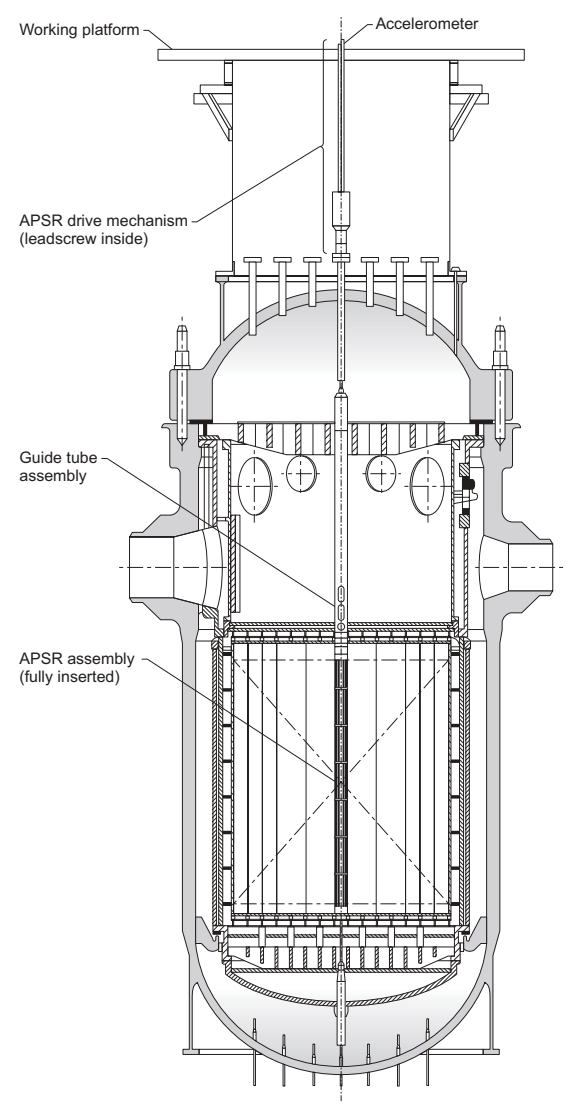

Figure A-7. Cross section of TMI-2 reactor vessel, showing typical axial power shaping rod assembly. 